\title{
Ciência aberta, questões abertas
}

Sarita Albagli Maria Lucia Maciel Alexandre Hannud Abdo

Organizadores 



\section{Ciência aberta, questões abertas}


Instituto Brasileiro de Informação em Ciência e Tecnologia (IBICT)

Diretora do Instituto Brasileiro de Informação em Ciência e Tecnologia Cecília Leite Oliveira

Coordenadora de Ensino e Pesquisa, Ciência e Tecnologia da Informação

Lena Vania Ribeiro Pinheiro

Coordenador de Editoração

Ramón Martins Sodoma da Fonseca

Universidade Federal do Estado do Rio de Janeiro (Unirio)

Reitor

Luiz Pedro San Gil Jutuca

Coordenação de Educação a Distância

Giane Moliari Amaral Serra

Ludmila dos Santos Guimarães 


\section{Ciência aberta, questões abertas}

Sarita Albagli

Maria Lucia Maciel Alexandre Hannud Abdo

Organizadores 
(C) (1) 2015

Este obra está licenciado com uma Licença Creative Commons Atribuição 4.0 Internacional. http://creativecommons.org/licenses/by/4.0/deed.pt_BR

Tradução

Maria Cristina Matos Nogueira

Sandra Cristina Possas

Copydesk and revisão de texto

Cândida Leite Georgopoulos

Isabel Vitória Pernambuco de Fraga Rodrigues

Normalização de texto

Ilce Gonçalves Milet Cavalcanti

Capa

Adriana Ballesté

Assistente de edição

Helena Antunes Faia

C569 Ciência aberta, questões abertas / Sarita Albagli, Maria Lucia Maciel e

Alexandre Hannud Abdo organizadores. - Brasília: IBICT; Rio de Janeiro: UNIRIO, 2015.

$312 \mathrm{p}$.

ISBN 978-85-7013-108-9

eISBN 978-85-7013-109-6

1. Ciência da informação. 2.Ciência política. 3. Cidadania. 4. Dados científicos.

I. Albagli, Sarita. II. Maciel, Maria Lucia. III. Abdo, Alexandre Hannud. IV. Título.

CDD 020

IBICT - Instituto Brasileiro de Informação em Ciência e Tecnologia SAS, Quadra 5, Bloco H, Lote 6, 70070 - Brasília/DF - Brasil
Unirio - Universidade Federal do Estado do Rio de Janeiro Avenida Pasteur, 296 - Urca 22290-240 - Rio de Janeiro/RJ - Brasil 


\section{Apresentação}

ESTE LIVRO REÚNE CONTRIBUIÇÕES de pesquisadores de diferentes áreas e países, incluindo o Brasil, com significativa atuação e reflexão no campo da ciência aberta e colaborativa.

O tema da ciência aberta ganha espaço não apenas nos ambientes institucionais de ciência, tecnologia e inovação, como também em outros contextos até então à parte dessas atividades, mobilizando outros grupos sociais como interlocutores das práticas científicas. As transformações nas relações entre ciência, tecnologia e sociedade daí decorrentes integram, por sua vez, novas dinâmicas de produção e circulação do conhecimento, da informação e da cultura, bem como o novo papel que essas dinâmicas desempenham nos processos contemporâneos de participação e mudança social.

Espera-se que esta publicação contribua para apresentar um panorama de temas e questões que hoje permeiam e delineiam a temática da ciência aberta, a partir de perspectivas e pontos de vista diversos; e, sobretudo, para instigar novas reflexões e provocar novas aberturas nas formas de produzir e circular conhecimento. Ela se dirige, assim, não apenas ao universo acadêmico, mas também a um espectro mais amplo de atores sociais que se preocupam com a democratização do conhecimento e da informação. 
O livro é resultado das discussões realizadas ao longo do Seminário Internacional "Ciência Aberta, Questões Abertas" ${ }^{1}$, realizado em 2014, no Rio de Janeiro, pelo Instituto Brasileiro de Informação em Ciência e Tecnologia (IBICT), a Open Knowledge Brasil (OKBr), a Universidade Federal do Estado do Rio de Janeiro (Unirio) e o Laboratório Interdisciplinar sobre Informação e Conhecimento (Liinc).

Agradecemos o apoio material e financeiro, que possibilitou esta realização, do Ibict, da Unirio, do Centro Brasileiro de Pesquisas Físicas (CBPF), da Rede Nacional de Pesquisas (RNP), do Conselho Nacional de Desenvolvimento Científico e Tecnológico (CNPq), da Coordenação de Apoio ao Aperfeiçoamento de Pessoal de Nível Superior (Capes) e da Fundação Carlos Chagas de Apoio à Pesquisa do Estado do Rio de Janeiro (Faperj).

Os organizadores

1 O programa, apresentações e links para os vídeos do Seminário Internacional estão disponíveis em http://www.cienciaaberta.net/encontro2014/ . 


\section{Sumário}

1 Ciência aberta em questão.................................................................... Sarita Albagli

2 Modos de ciencia: pública, abierta y común 27 Antonio Lafuente e Adolfo Estalella

3 Ciência aberta: revolução ou continuidade? 59 Alessandro Delfanti e Nico Pitrelli

4 caminho menos trilhado: otimizando para os impactos desconhecidos $e$ inesperados da pesquisa. Cameron Neylon

5 O que é ciência aberta e colaborativa, e que papéis ela poderia desempenhar no desenvolvimento?

Leslie Chan, Angela Okune e Nanjira Sambuli

6 Ciência cidadã: modos de participação e ativismo informacional

Henrique Z. M. Parra 
7 Hardware aberto para ciência aberta no sul global: diplomacia geek?

Denisa Kera

8 Ciência aberta: dos hipertextos aos hiperobjetos 169

Rafael Peretti Pezzi

9 Dados abertos e ciência aberta 201 Jorge Machado

10 Educação superior a distância, universidade aberta $e$ ciência cidadã: o desafio das diferenças. 229 Ludmila dos S. Guimarães

11 Por que open notebook science? Uma aproximação às ideias de Jean-Claude Bradley 253 Anne Clinio

12 Direções para uma academia contemporânea e aberta......287 Alexandre Hannud Abdo

Sobre os autores 


\section{Ciência aberta em questão}

Sarita Albagli

O MOVIMENTO PELA CIÊNCIA aberta deve ser pensado no contexto dos movimentos sociais que emergem em meio a mudanças nas condições de produção e circulação da informação, do conhecimento e da cultura, e que vêm desestabilizando arcabouços epistemológicos e institucionais vigentes. Trata-se de refletir sobre os desafios que essas mudanças trazem às dinâmicas científicas, seus valores e práticas, e sobre os novos olhares que se impõem para melhor compreender e lidar com tais desafios.

Ciência aberta é aqui entendida como processo, algo em construção, que mobiliza interesses e pontos de vista distintos (e, em alguns aspectos, antagônicos); e que também permite múltiplas (e por vezes conflituosas) interpretações.

Neste capítulo propõe-se pensar o movimento pela ciência aberta, a partir de duas grandes vertentes. Uma delas é a tensão hoje existente entre a socialização do conhecimento, da informação e da cultura, de um lado, e sua privatização, de outro (ALBAGLI; MACIEL, 2011). Considera-se que este constitui um dos principais pontos de conflitos e lutas que atravessam o que se chama sociedade em rede ou informacional (CASTELLS, 1999), capitalismo digital (SCHILLER, 2011) ou, ainda, capitalismo cognitivo (MOULIER BOUTANG, 2007). 
Parte-se do suposto de que essas diferentes formas de apropriação (social ou privada) são constitutivas dos antagonismos que caracterizam o atual regime de informação em ciência e tecnologia (C\&T) (ALBAGLI; MACIEL, 2012).

A outra vertente diz respeito à abrangência do próprio significado da ciência aberta. Hoje essa questão amplia, ou melhor, transcende o chamado campo científico (BOURDIEU, 2004), envolvendo maior porosidade e interlocução da ciência com outros segmentos sociais e outros tipos de saberes, no amplo espectro de possibilidades e espaços de produção do conhecimento. As abordagens da ciência aberta implicam superar a perspectiva de pensar a ciência a partir da sua produtividade intrínseca. Implicam o abalo de hierarquias, de fontes estabelecidas de autoridade e reputação, colocando foco nas relações entre ciência e poder, e, mais amplamente entre saber e poder.

Em quaisquer dos casos, trata-se, ab initio, de um debate e de um embate no plano das significações, que se investem de um caráter diretamente político, sendo um dos cernes na construção da democracia hoje.

O capítulo apresenta o quadro de conflitos e contradições em torno do conhecimento proprietário e aberto; situa e caracteriza o movimento pela ciência aberta nesse cenário; pontua os dilemas ético-políticos provocados por esse movimento; e, por fim, indica os desafios às institucionalidades para lidar com essas transformações.

\section{OS EMBATES DO CONHECIMENTO}

A obsessão pela propriedade intelectual, desde as duas últimas décadas do século XX, levou ao alargamento dos mecanismos de apropriação privada da produção intelectual e cultural, ampliando e aprofundando relações capitalistas de mercado para áreas que até então constituíam uma reserva social. O regime de proteção de 
direitos de propriedade intelectual (DPI) ancora-se em uma narrativa teórica e em um regime discursivo que procura legitimar os direitos de propriedade tout court. "Em certo sentido, a dinâmica de cercamento é a dinâmica expansionista do próprio capitalismo" (MAY, 2010, p. 13) ${ }^{1}$. Ao mesmo tempo em que deu nova proeminência à figura do autor individual, desconsiderando o fato de que todo novo conhecimento advém de conhecimento prévio e é portanto uma produção social, o endurecimento da proteção dos DPI beneficiou sobretudo agentes intermediários, verdadeiros rentistas do conhecimento, em detrimento dos próprios criadores.

Esse processo repercutiu diretamente nos formatos organizacionais e institucionais de produzir e circular ciência. A partir daí, aumentaram as pressões sobre os ambientes acadêmicos e universitários para o patenteamento e o retorno financeiro dos resultados das atividades de C\&T, mobilizando o estabelecimento de aparatos institucionais e legislação pertinentes a esses objetivos.

Nesse mesmo contexto, ampliou-se a dependência das publicações científicas em relação a editores privados, com a elevação exponencial dos preços das assinaturas de periódicos e, ainda, com a imposição de licenças restritivas de acesso e uso a materiais digitais, eliminando vários direitos até então resguardados, como o de fair use. Daí que as iniciativas mais expressivas nos estágios iniciais do movimento pela ciência aberta dirigiram-se centralmente para o acesso livre a publicações científicas.

Por outro lado, esse recrudescimento do regime de proteção de direitos de propriedade intelectual constituiu, em parte, uma reação às transgressões, que já então se praticavam na direção da livre reprodução e da circulação de informações e conhecimentos (MAY, 2000; MOULIER BoutANG, 2010). Disseminava-se amplamente a cultura livre digital, inspirada na cultura hacker e potencializada

1 In one sense the dynamics of enclosure is the expansionary dynamics of capitalism itself (MAY, 2010, p. 13). 
pelo desenvolvimento de sistemas eletrônicos e das plataformas digitais. Multiplicavam-se e difundiam-se relações e formas de produção não proprietárias, com maior autonomia dos participantes e em formatos não necessariamente estruturados e hierarquizados, traços que sempre foram mais marcantes na produção e na circulação da informação e do conhecimento do que na produção material (BENKLER, 2006; SODERBERG, 2008).

Essas novas práticas e espaços de interação e colaboração se desdobram em inovações nas dinâmicas produtivas, políticas e culturais, projetando noções com as de co-criação, e-science, produção peer-to-peer, produção wiki, crowdsourcing, co-inovação, ciência aberta, inovação aberta, entre outras. Logo, mais do que o compartilhamento da cultura, o que se afirma é a cultura do compartilhamento (CASTELLS, 2009).

Em paralelo, novos modelos de negócio se desenvolvem em torno da ideia de conhecimento aberto, no âmbito de um capitalismo cognitivo que se reproduz a partir da apropriação da informação e do conhecimento coletivamente produzidos. O capitalismo cognitivo (sobre)vive da exploração parasitária e rentista da produção coletiva, oferecendo condições para sua reprodução, como nas plataformas gratuitas de acesso às redes digitais, ao mesmo tempo que estraga essa própria dinâmica de valorização com o endurecimento dos mecanismos de proteção da propriedade intelectual (MOULIER BOUTANG, 2011; COcCO, 2012; ALBAGLI, 2012; DELFANTI, 2013).

Estabelece-se assim um embate entre distintas formas de apropriação. De um lado, a propriedade intelectual necessita impor-se por meio do comando e do controle, exigindo um aparato repressivo que procura compensar ou mitigar a fragilidade de uma legislação que se revela anacrônica e inaplicável nas atuais dinâmicas sociais e produtivas. De outro, a mercantilização do conhecimento e da informação requer a continuidade desse processo de polinização da produção em rede (MOULIER BOUTANG, 2011; ALBAGLI; MACIEL, 
2011), que, por sua vez, pressupõe liberdade para propiciar processos de contínua ressocialização do conhecimento.

Nesse sentido, os instrumentos de propriedade intelectual, em seu atual formato, já não cabem no novo paradigma. São mecanismos de escassez artificial de algo que não se esgota, ao contrário, fertiliza-se e reproduz-se na livre troca e nas interações, em um regime de acumulação baseado na produção de conhecimento por meio de conhecimento. A dualidade entre abundância/circulação ampliada/apropriação social versus escassez/concentração/apropriação privada da informação e do conhecimento pode assim estar desafiando os modos de regulação vigentes. Logo, na contracorrente dos novos cercamentos do que é produzido em comum, estabelece-se a crise de execução das relações de propriedade. Na era das redes (CASTELLS, 1996) e do acesso (RIFKIN, 2001), os próprios marcos jurídicos tradicionais de propriedade são postos em xeque (cocco, 2006).

\section{CIENNCIA ABERTA EM MOVIMENTO}

O movimento pela ciência aberta se insere nesse quadro de tensão entre, por um lado, novas formas de produção colaborativa, interativa e compartilhada da informação, do conhecimento, da cultura. E, por outro, mecanismos de captura e privatização desse conhecimento que é coletiva e socialmente produzido.

Esse movimento adquire hoje um alcance internacional, indicando que os modos atualmente dominantes de produção e de comunicação científica são inadequados, por estarem submetidos a mecanismos que criam obstáculos artificiais de várias ordens, especialmente legais e econômicos, à sua livre circulação e colaboração e, logo, a seu avanço e difusão ${ }^{2}$, quando não há praticamente barreiras técnicas à circulação imediata da informação.

2 A esse respeito, ver o capítulo de Cameron Neylon, neste livro. 
Advoga-se que a ciência aberta promove o aumento dos estoques de conhecimento público, propiciando não apenas a ampliação dos índices gerais de produtividade científica e de inovação, como também a das taxas de retornos sociais dos investimentos em ciência e tecnologia. Tem-se demonstrado que, historicamente, é no compartilhamento e na abertura à produção coletiva e não individual que melhor se desenvolvem a criatividade e a inovatividade. A complexidade dos desafios científicos e a urgência das questões sociais e ambientais que se apresentam às ciências impõem, por sua vez, facilitar a colaboração e o compartilhamento de dados, informações e descobertas.

Não há, no entanto, consenso e amplo entendimento quanto à extensão, ao significado e ao modus operandi do que venha a ser a ciência aberta, nem sobre suas implicações ${ }^{3}$. Alguns consideram ser esta uma retomada do verdadeiro espírito da ciência, tal qual preconizado por Robert Merton ${ }^{4}$, já na década de 1940. Outros argumentam que o atual movimento pela ciência aberta não expressa simplesmente um novo ciclo de revitalização do ethos mertoniano de uma ciência desinteressada, em contraposição ao endurecimento dos regimes de propriedade intelectual a partir da década de 1980. O movimento pela ciência aberta, em seu formato atual, reflete, na verdade, novos modos de pensar e de exercer a cientificidade, com repercussões diretas sobre os compromissos, normas e arcabouços institucionais que interferem diretamente na prática científica e nas suas relações com a sociedade. O desenvolvimento e a difusão das plataformas infocomunicacionais, da ética hacker e da cultura livre digital reverberam nas formas de produzir e circular conhecimento e informação em ciência (SORDERBERG, 2008; DELFANTI, 2013).

\footnotetext{
3 Ver o capítulo de Alessandro Delfanti e Nico Pitrelli neste livro.

4 Trata-se das normas propugnadas por Robert Merton para a atividade científica, em torno do acrônimo CUDOS (comunalismo, universalismo, desinteresse e ceticismo organizado).
} 
À medida que avança, o movimento pela ciência aberta modifica-se e incorpora novos elementos à sua agenda. Ciência aberta passa a constituir um termo guarda-chuva, que vai além do acesso livre a publicações científicas e inclui outras frentes, como dados científicos abertos ${ }^{5}$, ferramentas científicas abertas, hardware científico aberto ${ }^{6}$, cadernos científicos abertos ${ }^{7}$ e wikipesquisa, ciência cidadã, educação aberta (ALBAGLI; CLINIO; RAYCHTOCK, 2014).

Emblemático dessa diversidade que caracteriza hoje a ciência aberta é o amplo espectro de significados e pressupostos que envolvem a ideia e as iniciativas de ciência cidadã ${ }^{8}$. Esse espectro pode ser também compreendido em duas grandes vertentes. Uma delas reúne iniciativas que buscam mobilizar contribuições voluntárias, de vários tipos, em esforços de pesquisa, por parte de não cientistas, incluindo desde compartilhamento de recursos computacionais até coleta de informações de relevância científica, no que já se chama de crowdsourcing science. Nesta vertente -- que chamamos aqui de pragmática ou instrumental -- não há necessariamente abertura dos dados, ou influência dos voluntários no desenho e nos resultados da pesquisa.

Na outra vertente da ciência cidadã estão iniciativas orientadas para maior participação, intervenção e empoderamento de cidadãos não só nas formas de produção e uso, mas nos próprios rumos da pesquisa. É o caso do desenvolvimento de ferramentas abertas e descentralizadas em favor da democratização e apropriação cidadã da ciência e da tecnologia em favor da inovação social. Aqui se insere a participação de comunidades locais no controle e sensoriamento da qualidade do meio ambiente, bem como em questões e políticas públicas metropolitanas ressignificando a ideia de cidades

\footnotetext{
5 Ver o capítulo de Jorge Machado neste livro.

6 Ver os capítulos de Rafael Pezzi e de Denisa Kera neste livro.

7 Ver o capítulo de Anne Clinio neste livro.

8 Ver o capítulo de Henrique Parra neste livro.
} 
inteligentes na direção de cidades democráticas ${ }^{9}$, que implicam participação cidadã na cogestão do território e em novas formas de viver. Esta é a vertente que consideramos democrática.

Então, a noção de abertura está em disputa. Ou, ainda, é a própria noção de ciência que está em disputa.

A cultura do compartilhamento é também a cultura do remix. É nas artes que a cultura do remix ganha força, com os movimentos avant-garde de contracultura, a partir da década de 1960, que situam o artista e seu público no mesmo plano. A cultura do remix assume nova expressão com as plataformas de compartilhamento e a cultura digital. Na chamada netart, artistas e públicos se fundem e se confundem (CAMPANELLI, 2011).

Essa recolocação da relação entre autor e público contamina e se desdobra para a esfera da ciência. Na produção científica, fazemos remix o tempo todo. Fazemos recombinações de trabalhos já realizados, recombinações que podem ser mais ou menos criativas, mais ou menos radicais no avanço do conhecimento. O remix ocupa hoje uma linha cada vez mais tênue entre o que se considera apropriação legítima e o plágio.

Esfumaça-se a fronteira entre produzir e comunicar ciência, entre produtores e usuários de conhecimento, valorizando o processo (o fluxo, a dinâmica) antes que o produto (o estoque), no que Cocco (2012), inspirado em Paolo Virno e Walter Benjamin, chamou de "trabalho sem obra e obra sem autor". Produção e comunicação científicas passam a constituir processos indissociáveis, sendo a comunicação diretamente produtiva. No caso da publicação científica, a figura do peer review, a quem cabe operacionalizar o filtro de qualidade e de certificação da produção científica, pode vir a ceder terreno para a figura da curadoria, que remete ao estar junto, à atenção e ao cuidado, à coprodução.

\footnotetext{
9 Ver essa discussão em: http://www.eldiario.es/colaboratorio/Menu-participacion-democracia-plataformas-ciudadania_6_388171211.html. Acesso em 5 maio 2015.
} 
Assim, no desenvolvimento da ciência aberta, para além dos aspectos técnicos e tecnológicos (como o desenvolvimento de ferramentas livres, disponibilidade de plataformas computacionais abertas, e infraestrutura tecnológica para compartilhamento de dados), são as questões de ordem cultural, política e institucional (formais e informais) que mais interferem no caráter aberto ou proprietário dessas práticas. Mais importantes são os novos usos que implicam transformações nos métodos e estruturas lógicas da pesquisa e, logo, em seus resultados, em um processo de aprendizado e de inovações contínuos (ALBAGLI; APPEL; MACIEL, 2014).

\section{OS DESAFIOS ÉTICO-POLÍTICOS E A NOVA AGENDA DE DIREITOS}

Logo, a ciência aberta não se dirige tão somente às potencialidades e facilidades de geração e circulação de informação e conhecimentos - ou seja, a um produtivismo de nova ordem. Ciência aberta mobiliza múltiplos níveis e escopos de abertura, remetendo tanto a um sentido pragmático, de permitir maior dinamismo às atividades de ciência, tecnologia e inovação, quanto a um sentido democrático, de possibilitar maior diversidade de perspectivas no âmbito da própria ciência e, ainda, maior participação e intervenção da sociedade. São questões de ordem qualitativa, onde as dimensões ética e política estão estreitamente associadas (SCHNEIDER, 2013).

Do ponto de vista da ciência aberta, a dimensão ética se redesenha e se desdobra em diferentes níveis e âmbitos. Ela diz respeito ao compromisso ético de tornar o trabalho de pesquisa e seus resultados imediatamente disponíveis para utilização e remix de outros, enquanto boa parte das preocupações, nos códigos de integridade e ética da pesquisa adotados nas instituições científicas e de ensino, ainda se dirigem centralmente ao combate ao plágio

No âmbito das comunidades digitais de compartilhamento e produção colaborativa de conhecimento, revela-se uma eticidade 
intrínseca, princípios éticos nem sempre explicitados ou formalizados, que regem a dinâmica dessas comunidades. Nelas o foco é estabelecer barreiras de proteção contra free riders: você participa, você se apropria e você disponibiliza. Tais princípios fazem-se valer aí menos pelas sanções do que pela construção coletiva de regras de comportamento que, em última instância, remetem a questões de governança informacional.

Colocam-se também questões éticas às pesquisas com viés participativo, seja pela necessidade de obtenção de consentimento prévio informado das populações e grupos sociais envolvidos, seja de retorno dos resultados da pesquisa.

Cabem ainda questões que dizem respeito a finalidades da pesquisa, o que leva a indagar: Que ciência (aberta)? Em que direção? Para quem? Para que tipo de desenvolvimento? Que sociedade queremos $?^{10}$ Tais questões recaem não apenas no avanço do conhecimento científico em si, mas sinalizam sobretudo para suas repercussões e usos sociais ${ }^{11}$.

De partida, cabe assinalar que mais da metade da humanidade encontra-se excluída das grandes infraestruturas cognitivas, ou melhor, incluída de modo excludente. Logo, estão em jogo, e frequentemente em confronto, distintas perspectivas geopolíticas, geoeconômicas e geoculturais, que se cruzam com desiguais posições ocupadas pelos diferentes segmentos sociais.

Se os mercados de conhecimento e informação pressionam por um reforço dos códigos jurídicos que garantam o direito à propriedade intelectual, surgem mecanismos regulatórios visando reverter assimetrias resultantes da apropriação e distribuição privada dos conhecimentos científicos, sobretudo em áreas sensíveis e com

\footnotetext{
10 A esse respeito, ver Albagli e Maciel (2007).

11 A esse respeito, ver o capítulo de Leslie Chan, Angela Okune e Nanjira Sambuli neste livro.
} 
forte apelo social, como saúde, agricultura, alimentação e meio ambiente.

Ao criticar fortemente o atual regime de DPI, sobretudo na indústria farmacêutica, o Prêmio Nobel de Economia em 2001, Joseph Stiglitz, assevera: "Todo conhecimento é baseado em conhecimento prévio, e ao tornar conhecimento prévio menos disponível, a inovação é impedida"12 (STIGLITZ, 2015, p. 278). Para o autor, o fortalecimento desse regime tem trazido impactos negativos sobre o bem estar social e o aumento da desigualdade, tais como:

[....] preços mais altos para os consumidores, amortecimento do ritmo da inovação causado pela redução do acesso ao conhecimento, e, no caso de fármacos que salvam vidas, morte para todos que são incapazes de arcar com a inovação que poderia salvá-los. ${ }^{13}$ (STIGLITZ, 2015, p. 281)

Os pobres são certamente os mais afetados pelos sistemas de apropriação privada do conhecimento (e pelas patentes, em particular), na medida em que tais sistemas (ALBAGLI, 2012):

a) elevam artificialmente os preços de produtos, o que certamente afeta os mais carentes;

b) não difundem amplamente os benefícios dos avanços do conhecimento, sobretudo para os pobres;

c) enviesam os focos da pesquisa para áreas de interesse dos ricos, e não dos pobres;

d) impõem barreiras à pesquisa e, logo, à inovação, particularmente em áreas de interesse dos pobres.

12 "All knowledge is based on prior knowledge, and by making prior knowledge less available, innovation is impeded." (STIGLITZ, 2015, p. 278)

13 "[...] higher prices for consumers, the dampening effect on further innovation of reducing access to knowledge, and, in the case of life-saving drugs, death for all who are unable to afford the innovation that could have saved them." (STIGLITZ, 2015, p. 281) 
Os embates entre direitos de propriedade intelectual e conhecimento aberto deixam então de pertencer a uma arena estritamente científica ou técnica, de interesse limitado a especialistas, para mobilizar um amplo espectro de atores sociais, que veem suas vidas diretamente afetadas por essas questões. Os DPI tocam em áreas que vão da produção cultural à produção científico-tecnológica, passando pela saúde, o meio ambiente, a alimentação e agricultura, entre outras. Amplia-se a consciência de que os DPI têm efeitos que vão muito além dos econômicos:

[....] eles medeiam diretamente a experiência humana, o bem-estar e a liberdade [...] Porque a legislação de propriedade intelectual regula muito mais - do modo como podemos aprender, pensar e criar juntos até como e se temos acesso a medicamentos e alimentos de que precisamos para viver - , ela tornou-se um lugar central da luta política, não apenas localmente, mas globalmente. ${ }^{14}$ (KAPCZYNSKI, 2010, p. 23-24).

Então, por um lado, a ciência aberta coloca em pauta uma nova agenda de direitos que, para além dos direitos humanos e sociais, visa garantir a sustentabilidade e a sobrevivência da vida de modo amplo. Aqui a dimensão ética da ciência aberta nos remete ao conceito de justiça cognitiva (SANTOS, 1987), que, por usa vez, implica a possibilidade e a capacidade de formular outras perguntas e de considerar outras maneiras de viver em comum. Por outro lado, a necessidade de responder a demandas e agendas sociais de desenvolvimento pode impulsionar a maior abertura da ciência, em suas várias acepções.

\footnotetext{
14 "[...] [they] mediate human experience, well-being, and freedom. [...] Because intellectual property law regulates much more - from how we are able to learn, think and create together to how and whether we have access to the medicines and food that we need to live - i has become a central site of political struggle, not just locally, but globally." (KAPCZYNSKI, 2010, p. 23-24)
} 
Antonio Lafuente prefere falar em ciência do comum ${ }^{15}$. Em sua acepção, a ciência do comum é entendida menos como um bem comum (aquilo que, ao mesmo tempo, é de todos e não é de ninguém), que remete a um paradigma econômico proprietário, e mais como a ciência que está entre todos. Este seria o grande desafio ético da ciência aberta, que é o do diálogo com o outro, o estabelecimento de pontes e de mútuas fertilizações na diversidade de saberes. $\mathrm{O}$ comum também como ordinário, que não está representado, distinto, portanto, da ideia dos commons, que traz o simbolismo do sagrado - da terra, da água e do próprio conhecimento. Logo, um significado que remete mais ao imaginário antropológico do que ao econômico.

Para Schneider (2013, p. 69), essa dimensão ético-política:

[...] requer uma abertura aos saberes não científicos: para que a razão não se reduza à racionalidade técnica, há que estabelecer um diálogo com o pensamento não sistemático, com o mito, com a arte, com os valores, com o não racional, isto é, com tudo aquilo na vida que não é redutível ao cálculo instrumental. Não para igualar-se a esses saberes, mas para aprender com eles.

Situados nesse contexto de transformações, os desafios éticos colocados pela ciência aberta estão em evolução e sofrem flutuações. São desafios de várias ordens, requerendo respostas em diferentes níveis e dimensões.

\section{NOVAS INSTITUCIONALIDADES}

Uma das grandes questões do movimento pela ciência aberta é posta às institucionalidades. Os esforços de ciência aberta envolvem instâncias de ação e decisão diferenciadas, internas e externas

15 A esse respeito, ver o capítulo de Antonio Lafuente e Adolfo Estalella neste livro. 
à ciência, que vão desde o pesquisador individual e equipes de pesquisa até o nível macro das políticas públicas e das regulações internacionais, passando pelo nível meso das instituições científicas e agências de fomento ${ }^{16}$. Trata-se de distintos âmbitos, instâncias e mecanismos de regulação e governança - mais especificamente de governança informacional - envolvendo formas de gestão e resolução de conflitos e de poder, que mantêm suas especificidades. São instâncias frequentemente desconectadas entre si, mas que se influenciam direta ou indiretamente.

Por um lado, impõem-se novos formatos institucionais e arcabouços normativos e legais que incidem sobre as formas de produção, circulação, apropriação e uso do conhecimento científico. Requerem-se também novos modelos avaliativos que contribuam para superar as pressões do produtivismo acadêmico e para encontrar formas de acreditação que valorizem as novas dimensões éticas da pesquisa aberta e colaborativa, e que também contribuam para a criatividade e a inovatividade coletivas.

Por outro lado, estabelecem-se acordos tácitos, que não se restringem às institucionalidades formais. Eles podem ser compreendidos a partir de uma perspectiva pragmática dos regimes de informação, frutos das ações de informação ${ }^{17}$, que é o que também lhes confere dinamismo e abertura à mudança.

Trata-se tanto da abertura e da nova conformação de espaços e mecanismos institucionais existentes - da universidade às instituições de fomento à pesquisa - como da valorização de novos espaços de produção coletiva e aberta do conhecimento que se vem constituindo - como hackerspaces e outros espaços coletivos

\footnotetext{
16 A este respeito, ver o capítulo de Alexandre Hannud Abdo neste livro.

17 Na concepção de regime de informação aqui adotada, enfatizam-se dois aspectos centrais às abordagens de Berndt Frohman (1995) e Maria Nélida Gonzalez de Gomez (2002): o reconhecimento do papel das práticas informacionais (ações de informação) para além da dimensão institucional formal; e o reconhecimento do regime de informação como sendo um campo de disputa e conflito, do mesmo modo que de negociação e estabilização.
} 
cidadãos, nos ambientes urbanos e rurais. O propósito é propiciar novas formas de produção da ciência, bem como facilitar o diálogo cognitivo e a articulação entre diferentes tipos de conhecimento e de saberes. E, ainda, reconhecer e mobilizar a diversidade de atores sociais que são produtores de conhecimento e de experiências de aprendizado altamente relevantes, mas são desconsiderados pelos espaços institucionais tradicionais onde se produz e ensina ciência.

Inovações institucionais e sociais, que permitam proteger o que é coletiva e socialmente produzido, fazem parte de um esforço que começa a ganhar importância no sentido da construção de uma grande infraestrutura cognitiva do comum. Em que consistem formas novas e inovadoras de constituição e instituições da ciência aberta ou do comum está hoje em discussão. Como e em que direções esses caminhos serão traçados faz parte de um debate que deve ser aberto à ampla participação e à ampla gama de possibilidades de cenários alternativos futuros.

\section{REFERÊNCIAS}

ALBAGLI, Sarita. Informação, saber vivo e trabalho imaterial. In: ALBAGLI, Sarita (org.). Fronteiras da Ciência da Informação. Brasília: IBICT, 2013. Disponível em: http://livroaberto.ibict.br/handle/1/1020. Acesso em 20 ago 2014.

ALBAGLI, Sarita; APPEL, Andre L.; MACIEL, Maria Lucia. E-Science, ciência aberta e o regime de informação em ciência e tecnologia. Tendências da Pesquisa Brasileira em Ciência da Informação, Rio de Janeiro, v. 7, n. 1, 2014. Disponível em: http://inseer. ibict.br/ancib/index.php/tpbci/article/view/124/166. Acesso em 13 Março 2015.

ALBAGLI, Sarita; CLINIO, Anne; RAYCHTOCK, Sabryna. Ciência aberta: correntes interpretativas e tipos de ação. Liinc em Revista, Rio de Janeiro, v. 10, n. 2, nov. 2014. Disponível em: http://revista.ibict.br/liinc/index.php/liinc/article/ view/749/512. Acesso em 10 junho 2015.

ALBAGLI, Sarita; MACIEL, Maria Lucia. Informação, conhecimento e desenvolvimento. In: MACIEL, Maria Lucia; ALBAGLI, Sarita. Informação e desenvolvimento: 
conhecimento, inovação e apropriação social. Brasília: IBICT, 2007. p. 15-21. Disponível em: http://livroaberto.ibict.br/bitstream/1/793/1/informa\%C3\%A7\%C3\%A3o\%20e\%20desenvolvimento.pdf . Acesso em 30 Abril 2015. . Informação, poder e política: a partir do Sul, para além do Sul. In: MACIEL, Maria Lucia; ALBAGLI, Sarita (orgs.). Informação, conhecimento e poder: mudança tecnológica e inovação social. Rio de Janeiro: Garamond, 2011. p. 9-39.

Informação, conhecimento e democracia no Capitalismo Cognitivo. In: In: COCCO, Giuseppe; ALBAGLI, Sarita (orgs.). Revolução 2.0 e a crise do capitalismo global. Rio de Janeiro: Garamond, 2012.

BENKLER, Yochai. The wealth of networks. How social production transforms markets and freedom. New Haven and Londres: Yale University Press, 2006. Disponível em: http://cyber.law.harvard.edu/wealth_of_networks/Download_PDFs_of_the_ book. Acesso em 15 nov 2009.

BOURDIEU, Pierre. Usos sociais da ciência: por uma sociologia clínica do campo científico. São Paulo: UNESP, 2004.

CAMPANELLI, Vito. Remix Ethics. International Review of Information Ethics, v. 15, Sept. 2011. Disponível em: http://www.i-r-i-e.net/inhalt/015/015-Campanelli.pdf. Acesso em 13 Março 2015. p. 24-32.

CASTELLS, Manuel. A sociedade em rede. São Paulo: Paz e Terra, 1999. . Communication Power. Oxford: Oxford University Press, 2009.

COCCO, Giuseppe. O trabalho sem obra, a obra sem autor: a constituição do comum In: TARIN, Bruno; BELISÁRIO, Adriano. Copyfight. Rio de Janeiro: Beco do Azougue, 2012.

DELFANTI, Alessandro. Biohackers: the politics of Open Science. London: Pluto Press, 2013. p. 1-24

FROHMAN, Berndt. Taking policy beyond information science: applying the actor network theory for connectedness - information, systems, people, organisations. In: Information, Systems, People, Organisations, the $23^{\text {rd }}$ ANNUAL CONFERENCE OF THE CANADION ASSOCIATION FOR INFORMATION SCIENCE, Admonton, Alberta, 7-10 June 1995. Disponível em: http://instruct.uwo.ca/faculty/ Frohmann/actor.htm. Acesso em 20 maio 2015. 
GONZÁLEZ DE GÓMEZ, Maria Nelida. Novos cenários políticos para a informação. Ciência da Informação, jan. 2002, v. 31(1), p. 27-40.

KAPCZYNSKI, Amy. Access to Knowledge: a conceptual genealogy. In: KRIKORIAN, Gaelle; KAPCZYNSKI, Amy. Access to knowledge in the Age of intellectual property. New York: Zone Book, 2010. p. 17-56.

MAY, Christopher. The global political economy of intellectual property rights: the new enclosures. 2. ed. Nova York: Routledge, 2000.

MOULIER BOUTANG, Yann. Interview to Gaelle Krikorian. In: KRIKORIAN, Gaelle; KAPCZYNSKI, Amy. Access to knowledge in the Age of Intellectual Property. New York: Zone Book, 2010. p. 575-596.

RIFKIN, Jeremy. A era do acesso. São Paulo: Makron Books, 2001.

SANTOS, Boaventura de Sousa. Um discurso sobre as ciências. Porto: Edições Afrontamento, 1987.

SCHILLER, Dan. Capitalismo digital em crise. In: MACIEL, Maria Lucia; ALBAGLI, Sarita. Informação, conhecimento e poder: mudança tecnológica e inovação social. Rio de Janeiro: Garamond, 2011. p. 133-149.

SCHNEIDER, Marco. Ética, política e epistemologia: interfaces da informação. In: ALBAGLI, Sarita (org.). Fronteiras da Ciência da Informação. Brasília: IBICT, 2013. p. 58-77.

SODERBERG, Johan. Hacking Capitalism: the Free and Open Source Software Movement. New York and London: Routledge, 2008.

STIGLITZ, Joseph E. The great divide. UK: Allen Lane, 2015. 



\section{2}

\section{Modos de ciencia: pública, abierta y común}

Antonio Lafuente e Adolfo Estalella

Proclamar LA NATURALEZA PÚBLICA de la ciencia se ha convertido en un lugar tan común como discutido. El consenso a veces es abrumador: todo el mundo pide más ciencia y por todas partes se reclaman más fondos para la investigación, dando por hecho que la ciencia no sólo es económicamente necesaria sino moralmente irremplazable. El acuerdo, sin embargo, nunca fue absoluto y siempre hubo quien denunció un déficit democrático asociado a lo poco que se discute el tipo de ciencia que queremos o al hecho de que sigamos tratando como externalidades los daños que el despliegue de la tecnociencia produce sobre el entorno o la salud. Es verdad que, además de pública, la ciencia también es privada y que los entrecruzamientos entre la academia, el gobierno y las empresas son antiguos, intensos y, a veces, oscuros.

La ciencia no sólo es semi-pública, sino que tampoco puede vivir sin los públicos (NOwOTNY et al., 2005). Hay plétora de trabajos que insisten en la naturaleza social, urbana y colectiva de la ciencia. Lejos de lo que nos contaba la historiografía más rancia, la ciencia no es una empresa reservada para genios, ni algo que ocurre en el cerebro de unos pocos. Es obvio que el locus de la ciencia siempre fue la academia y el laboratorio, pero no es menos cierto que también 
ha ido ganando presencia en los cuarteles, consejos de administración, ferias comerciales y bolsas de valores. Pero nuestro listado de urgencia sería incompleto si no incorporara el garaje, el mercado y la calle. La ciencia siempre mantuvo una compleja, dinámica y vibrante relación con la gente, con los amateurs, con los artesanos, con los testigos, con los espectadores, con los activistas y con los consumidores. Y sí, es verdad que la ciudadanía, para bien y para mal, debe mucho a la ciencia, como también es correcta la tesis de que la ciencia debe mucho a la ciudadanía. Hay entonces mucha contribución anónima, invisible o tácita al conocimiento que nos cuesta reconocer y que nuestras historias se empeñan en desdeñar. No sólo es mayoritaria, como decía Gaston Bachelard (BACHELARD, 1986, p. 56), la figura modesta del travailleur de la preuve, sino que también se exageran la figura del líder académico, del jefe de grupo o del primer firmante. La consecuencia es que todo el mundo parece cómplice en producir una imagen esperpéntica y ciertamente interesada de la ciencia.

El autor, lo sabemos, nunca fue la pieza maestra del engranaje que mueve la maquinaria científica. Esta deriva reciente está asociada a los imperativos del new public management que, de un lado, reclama capacidades para regular la economía de la reputación y, de la otra, libertad para imponer los imaginarios que contribuyen a convertir el conocimiento en información codificada. Las consecuencias son devastadoras pues no sólo incentivan diversos procesos de privatización del saber, sino que también acentúan la producción de las nuevas asimetrías que exploran los environmental justice studies y que incrementan la gravedad de las prácticas identificadas como secretismo industrial, fraude académico, segregación social o monopolio económico.

Para desarrollar nuestro argumento hemos dividido el texto en tres partes. En la primera exploraremos el origen histórico de la condición de la ciencia como public good. En la segunda mostraremos los problemas que tiene hacer análogas las condiciones de 
commons science y de open science, lo que es tanto como decir que las exigencias de los movimientos open access u open data son necesarias pero no suficientes. La tercera sección argumentará que la condición de bien común no se adquiere cuando el bien es para todos, sino cuando es entre todos, lo que abre la condición de bien común hacia la exigencia de ser un tercer sector, junto a lo privado y lo público. La ciencia entendida como un commons no sería entonces una ciencia pública pero abierta o una ciencia extramural pero no mercantilizada. Tampoco sería una ciencia formal, como la de siempre, pero capaz de incluir a la ciudadanía en el diseño y evaluación de los proyectos y los resultados. No sería la ciencia de siempre pero ahora en versión democrática o postmoderna. La ciencia no es un commons por ser más funcional, abierta o militante, sino cuando es fruto de la implementación de prácticas cognitivas contrastadas, colectivas y recursivas. Los commons entonces serían otra forma históricamente diferenciada de producir conocimiento, comunidad y compromiso. Así, en la tercera parte, más que de la science as a commons, hablaremos de los commons as a science.

\section{LA CIENCIA COMÚN COMO BIEN PÚBLICO}

La idea de que la ciencia es un bien público es relativamente reciente. Philip Mirowski (2011) ha dedicado muchos esfuerzos a explicarlo. Y para entenderlo no hay más remedio que admitir que la presión a la que fueron sometidos los científicos por la Iglesia, los Imperios y los Estados tiene demasiados parecidos con la que actualmente tratan de imponer las corporaciones industriales. Sabemos que ya en el siglo XIX los laboratorios universitarios eran intensivamente peinados por industriales que buscaban entre sus probetas y bobinas algún descubrimiento sobre el que montar nuevos monopolios. Todo parece indicar que la naturaleza comunitarista de la ciencia ganó crédito porque de alguna forma había que legitimar como propietarios de los descubrimientos a las empresas 
que financiaban los laboratorios industriales. Así, si el hallazgo se tomaba por colectivo, nadie salvo el dueño del espacio donde se producía el conocimiento podía reclamar la patente.

La Segunda Guerra Mundial cambió drásticamente el panorama. Durante el segundo tercio del siglo XX el estado se atribuyó el derecho a dirigir la ciencia y también a crear las condiciones para que se aceleraran las innovaciones. La economía de guerra alumbró un complejo tecnomilitar donde el sector público invertía en ciencias básicas para garantizar la circulación libre de saberes entre los empresarios participantes en un juego cuyas reglas, fijadas por el ejército, estaban al servicio de la razón de estado. La condición de public goods implicó la estatalización y militarización de la llamada Big Science. A partir de los 1980's las cosas cambiaron a toda velocidad, pues la Bay-Dole Act (1980) y otras decisiones judiciales en USA crearon las condiciones para que se iniciara un proceso acelerado de privatización del saber. Los descubrimientos, y no sólo las invenciones, podían ser objeto de derechos de propiedad intelectual y, en consecuencia, podían ser tratados como activos que circulaban en bolsa y que atrajeran capital riesgo. Si en los 1960's el conocimiento fue tratado como un bien imperfecto que no podría sobrevivir en una situación de libre mercado sin el apoyo gubernamental, veinte años después ya se habían desarrollado los instrumentos jurídicos, políticos y financieros necesarios para que la ciencia coqueteara con la economía neoliberal. En este nuevo régimen de academic capitalism la frontera entre lo público y lo privado tiende a disolverse (SLAUGHTER; RHOADES, 2004; SLAUGHTER; LESLIE, 2001).

El tránsito, sin embargo, no se hizo sin resistencia. Lo que ya es obvio para todos sólo fue anticipado por algunos. Y sus argumentos siguen siendo de actualidad. Paul A. David (2008) nos ha explicado cómo desde los albores de la ciencia moderna los científicos empezaron a ser percibidos como gentes fuera de control debido a la sofisticada naturaleza de sus saberes. Y es que en la corte, dado que 
nadie podía actuar como contrapeso, se optó por abrir el conocimiento para que fueran los propios científicos quienes dictaminaran sobre la calidad del trabajo de sus colegas. Este sería el origen de los premios, las academias y las revistas periódicas. La autonomía de la ciencia implicó su organización como una empresa meritocrática, abierta y cosmopolita. Distinguir entre sabios y charlatanes requirió el concurso de nuevos espacios, distintos actores y diferentes mediaciones que, en su conjunto, nos obligan a tratar la llamada Revolución Científica no como una epistemic revolution, como la describieron autores como Alexander Koyrée o Thomas Khun, sino como una open science revolution. Michael Polanyi también quiso apuntase al club de quienes negaban que el conocimiento podía ser tratado como información para luego, tras desanclarlo de sus lugares de producción, convertirlo en un recurso monetarizable. La commodification de la ciencia era imposible porque sólo se podía patentar el conocimiento que no fuera tácito. Norman Wiener, por su parte, defendió que la innovación era un fenómeno emergente que, como en cualquier otro sistema complejo, estaba asociado a la multiplicidad y heterogeneidad de las interacciones entre los distintos actores, mientras que las patentes operarían como cuellos de botella que impedirían la fluidez de la información. Las tres posiciones mencionadas argumentan que la ciencia sólo prospera cuando se mantiene como una empresa colectiva cuyos frutos no son reductibles a información codificable y cuya organización desborda los intentos de confinarla en un entorno protegido (JONES, 2006). La historia de las ideas, la antropología de las organizaciones y la economía de la innovación coincidían en la necesidad de reclamar del estado un papel activo en la preservación de la ciencia como public goods (MIROWSKI; SENT, 2008; SENT, 1999). Y esta es la tradición que asume y hereda Michel Callon en su provocadora forma de concebir la ciencia.

El razonamiento de Callon (1994) comienza exigiendo de sus lectores la aceptación de que el conocimiento siempre fue una 
empresa muy mundana y nunca aislada de los intereses circundantes. Decir otra cosa equivalía a ignorar el mucho trabajo ya realizado en el ámbito de los estudios de la ciencia. Reclamar para la ciencia la condición de commons implicaba aceptar la tesis errónea de que las ideas son fácilmente transportables entre distintos emplazamientos, ya sean disciplinares, culturales o geográficos. Y es verdad que durante décadas, quizás siglos, hemos contado la historia de la ciencia como si se tratara de la expansión planetaria de una mancha de aceite o de la transmisión de una epidemia. No hay nada natural en la trasmisión del saber. Se equivocaron quienes asimilaban la difusión de la ciencia a la propagación de ideas. Lo que los STS nos han enseñado es que verificar cualquier ley natural o comprobar la pertinencia de un concepto científico reclama plétora de máquinas, técnicos o reactivos, además de tiempo y recursos para producir, seleccionar, contrastar, discutir, estandarizar y comunicar los resultados. Decir que las leyes de Newton se cumplen en Cuzco significa que somos capaces de replicar en los Andes toda la parafernalia que permite verificarlas. $Y$, en definitiva, lo que estamos diciendo es que las ideas existen embebidas en las cosas y que hay muy poco de inmaterial en la transmisión del saber. Por eso cada vez es más necesario distinguir entre saber con palabras y aprender con las manos. Querer que la ciencia sea un commons es un proyecto utópico y obliga a plantearnos si de verdad podemos asumir unos costes de trasmisión que serían inabarcables (ARVANITIS, 1996).

La actor-network theory llevaba años cuestionando que la noción de comunidad científica sea el elemento básico y motor de la dinámica de la ciencia. Si la ciencia es una empresa que funciona en red entonces podemos exigir que adopte la forma más conveniente al propósito de garantizar la diversidad y proliferación de actores, preguntas y procesos. Una ciencia sana tendría que promover la Freedom of Association para que siempre estén operativas formas diferentes de organización; también pide Callon una Freedom of Extension para que la red impida el cerramiento o imposición de 
alguna forma de ortodoxia o canon, $y$, ya por fin, invita a todos los actores involucrados a una Lucha contra la Irreversibilidad cuya función sería impedir que los monopolios creen estándares que bloqueen la innovación. Es decir que la noción de public goods está explícitamente asociada a la de diversidad y no a la de libre acceso. Lo importante entonces no sería repartir por igual los bienes, sino crear las condiciones para que no se interrumpan los procesos de producción y diversificación del saber. El bien que queremos proteger no es el conocimiento, sino la pluralidad de formas de socialización que favorece. No necesitamos al estado para proteger el conocimiento mismo, sino las redes por las que circula. No se trata de proteger las ideas que se publican o merecen recibir un Nobel, como las infraestructuras que las sostienen y que, con frecuencia, son tan opacas como contrarias al procomún.

\section{LA CIENCIA COMÚN COMO CIENCIA ABIERTA}

Imaginar la ciencia como un bien común exige dejar de pensarla como una cosa que se puede apartar del mercado (HESS; OSTROM, 2007; CORSÍN-JIMÉNEZ, 2013b). También tenemos que desvincular dicha reclamación de las nociones de libre acceso. Elinor Ostron lo argumentó con contundencia memorable: nada puede ser más contrario al bien común que el open access. De hecho, la confusión entre ambos conceptos es lo que condujo a Garrett Hardin (HARDING, 1968) a proclamar la tragedia de los commons y a exigir como estrategia de supevivencia la patrimonialización, púbica o privada, para los bienes que de verdad importaran. Los commons, repitió Ostron (1990), no son una cosa, sino una forma de gestión que fracasa cuando la comunidad que los sostiene y es sostenida por ellos no se dota de reglas eficaces para, entre otras amenazas, protegerse de los free riders.

Durante la última década hemos asistido al nacimiento de varios movimientos que han reclamado para la ciencia la condición de 
empresa abierta. Aunque no todos sus defensores usan los mismos argumentos ni ponen el énfasis en los mismos conceptos, parece razonable mencionar dos tipos principales de motivos. Por una parte, están quienes cuestionan la práctica generalizada de la externalización del proceso de comunicación. Todos comparten la crítica de que el actual sistema es tan despilfarrador como paradójico, pues implica hacer enormes gastos para producir papers que luego debemos comprar a quienes previamente se los hemos regalado a precio cero (MOULIA et al., 2013). Y lo dicho para los artículos empeora bochornosamente cuando pensamos en los datos, pues los científicos se han acostumbrado a un régimen de competición tan apremiante que han hecho de la no cooperación el santo y seña de su ecosistema profesional. Si los datos son el fundamento del trabajo académico, no sorprende que en semejante régimen del saber los laboratorios traten los resultados como un bien escaso que debe ser protegido del pirateo. El problema académico es grave, pero es mucho más inquietante cuando pensamos en los ensayos clínicos o en los dictámenes expertos que condicionan los procesos de technology assesment y, en general, gran parte de las decisiones políticas que afectan a nuestra vida en común.

El segundo motivo para reclamar el acceso libre a la información científica tiene que ver con el desiderátum de las políticas bien informadas, la fe en la libre elección y el robustecimiento de la democracia. Los debates sobre las opciones energéticas, el consumo de transgénicos, la calidad del aire, el etiquetado de alimentos o el tratamiento de los enfermos crónicos, por no mencionar el papel que nuestra sociedad debe asignar a la homeopatía o las muchas formas de medicina alternativa, abren procesos que deben ser abiertamente discutidos. Tampoco es asunto menor que los costes exagerados de la información científica o de los medicamentos excluyan de su uso a las instituciones, pacientes o países pobres, lo que convierte a la ciencia en otro de los factores que ensanchan las asimetrías de nuestro mundo. 
Despilfarro, carrerismo y opacidad son críticas merecidas que justifican la deriva a favor del open access. La calidad de la democracia y la justica global no son objetivos menores y quizás tampoco aplazables. Pero es verdad que hay algo que huele mal en todo este debate. Las políticas de open science corrigen alguna de las carencias más sangrantes del sistema actual, pero no es menos cierto que la distribución abierta, online y gratuita tiene un coste cuyos principales beneficiarios son las grandes corporaciones o, en otras palabras, quienes tengan capacidad para capitalizar la información. Más aún, no es obvio que la accesibilidad corrija de manera decisiva el papel de la ciencia en nuestro mundo. Que esté disponible la información no quiere decir que podamos usarla y hacer algo con ella, pues seguirá siendo un material demasiado vinculado a las tecnologías y los valores con los que fue producida. Tenía razón Ulrich Beck (BECK, 1992, p.166) cuando afiló el lápiz para escribir que los hechos no son más que la respuesta posible a una pregunta que podría haberse hecho de otra manera. $\mathrm{O}$, de forma más directa, de poco nos servirían unos instrumentos que, una vez accesibles, sólo podrían funcionar al servicio de las mismas cuestiones, los mismos protocolos y las mismas formas de validar el conocimiento. Tenemos que preguntarnos si las cosas podrían ser de otra manera. ¿Hacer más funcional la ciencia es todo a lo que podemos aspirar?

Quienes han estudiado la open science nos han invitado a considerar fenómenos como SETI o todos los proyectos de crowdsourcing asociados con la plataforma pionera BOINC. La computación voluntaria se ha manifestado como un potente mecanismo para abordar problemas que demandan enormes capacidades de cálculo. La computación distribuida, privada, pública o ciudadana, tiene ya muchos éxitos de los que vanagloriarse: GalaxyZoo o Innocentive han atraído numerosos estudios que quieren explicarnos cómo el mundo del Big Data o de la innovación abierta conforman nuevos híbridos con los que tendremos que aprender a convivir. Wikipedia y Fold.it, dos proyectos muy distintos, muestran sin paliativos la 
potencia emergente que pueden desplegar las multitudes conectadas (FRANZONI; SAUERMANN, 2014). Estamos hablando de dispositivos colosales que interconectan a millones de humanos; nos estamos refiriendo también a nuevas formas de producir y validar conocimiento (NIELSEN, 2011). Pero no es solo que el crowdsourcing, aliado al crowdcrafting y el crowdfounding, permiten alimentar el viejo sueño siempre postergado capaz de reemplazar el ilustrado technology for the people por el más empoderador technology by the people (HAND, 2010). Hay ejemplos que autorizan a imaginar una ciudadanía capaz de producir hechos que antagonicen con los datos oficiales, ya sea que hablemos de crisis medioambientales o alimentarias, ya sea que nos refiramos a producción de nuevas cartografías, distintas patrones o instituciones diferentes. Si así fuera estaríamos en los albores de nuevos regímenes del conocimiento que se vertebrarían alrededor de otras formas de codificar, archivar, comunicar y validar el conocimiento. El espacio del laboratorio, otrora reservado para los expertos, comienza a ser un espacio muy disputado. Los expertos tienen motivos para sentirse inquietos. Todo indica que su hegemonía consolidada podría estar en peligro. No es la primera vez que algunas movilizaciones de descontentos han provocado un ensanchamiento del espacio del saber, incluyendo nuevos actores y diferentes preguntas. Quienes aceptan estos planteamientos, tratan la influencia del criollismo, el higienismo, el feminismo, la diversidad funcional o el medioambientalismo como procesos de modernización epistémica (HESS, 2007; LAFUENTE, 2012). Isabelle Stengers (2005) habla ya de cosmopolíticas para recordarnos que la contundencia con la que los legos siempre fueron expulsados del espacio público debe ser reemplazada por un gesto más respetuoso con el pluralismo epistémico. Hay que firmar la paz: necesitamos un acuerdo duradero que no insista en la división del mundo entre los que saben y los que no saben, un armisticio que salve al mundo de la arrogancia de los selectos. Decir que necesitamos la ciencia para garantizar un futuro próspero no 
es suficiente, pues no son pocas las veces que se ha reclamado más ciencia para acabar gaseando tropas, bombardeando ciudades o, en general, legitimando una política de exclusión que, en definitiva, garantiza nuevas guerras para la ciencia (STENGERS, 2006).

La ciencia ciudadana ha venido mostrando su capacidad para lograr presencia en el espacio público (IRWIN, 1995; COLLINS; EVANS, 2002). El síndrome de la enfermedad de la Guerra del Golfo (BROWN et al., 2011), las luchas de los afectados por el AIDS (EPSTEIN, 2007), el plante que representa la Asociación Francesa de Miopatías (CALLON; RABEHARISOA, 2003; RABEHARISOA; CALLON, 1999), los cuestionamientos introducidos por las feministas del cáncer de mama (MCCORMICK et al., 2011) o la visibilidad lograda por los pacientes electrosensibles (CHATEAURAYNAUD; DEBAZ, 2010), tienen muchas cosas en común. Aquí queremos destacar una innovación que, como nos enseñó John Dewey (DEWEY, 1927; BROWN, 2009), es crucial para nuestra democracia: haber dejado de ser invisibles y conquistado capacidad de interlocución con las administraciones públicas. Lo importante es la forma en la que lo lograron, pues de la protesta pasaron a la propuesta, demostrando su habilidad para producir, mezclar y comunicar información basada en datos, conceptos y objetos científicos validados. La precariedad de sus medios o el acoso político al que fueron sometidos no impidió el avance de sus propuestas. Se han ganado, como explica Jacques Rancière, el derecho a ciudad. Nos han enseñado otras formas de civilidad más inclusivas y contrastadas. Han demostrado -es decir, probado con argumentos y ocupado con el cuerpo-, su derecho a tomar la palabra en el espacio público (RANCIÈRE, 2007).

Si tuviéramos que hacer un balance de urgencia de lo que significa la ciencia ciudadana, tendríamos que reconocer que es más ciencia, aunque hecha extramuros de la academia. En efecto, la ciencia ciudadana es ciencia independiente, conocimiento desarrollado por comunidades virtuosas que, radicales en su retórica política, son más conservadores de lo que imaginamos en la práctica científica. 
Por ejemplo, comparten con Robert Merton los valores que caracterizaban comunidades científicas imaginarias: comunitarismo, universalismo, desinterés, objetividad, escepticismo. Así que la ciencia ciudadana sería el último refugio que queda para la ciencia mertoniana, mientras que la llamada Mode 2 science sería lo que siempre tuvimos, una hibris variable que ensambla los intereses académicos, con los empresariales y gubernamentales (NOWOTNY; SCOTT; GIBBONS, 2001; NOWOTNY et al., 2003; STRATHERN, 2003). Son muy distintas, pero ambas comparten un mismo proyecto epistémico, aún cuando muchas veces la ciencia ciudadana adoptó perfiles contra-hegemónicos. Y al igual que la energía eólica compite con la nuclear o la fósil, lo cierto es que todas pueden convivir ordenadamente.

\section{COMMONS AS A SCIENCE}

La ciencia ciudadana no es algo monolítico y habría que usar el plural para evocarla. Todas las ciencias ciudadanas comparten un gesto resistencialista. Algunas además han mostrado que hay formas alternativas de relacionarse con el entorno político, económico, científico y ambiental. Llegados a este punto es obligado mencionar la cultura hacker. Y, cierto, debemos mucho a Pekka Himannen (HIMANEN, 2001) y a su noción de ética hacker, como expresión de un inconformismo tecnológico que niega que las cosas sólo pueden ser aquello para lo que fueron diseñadas. Pero el gesto hacker más radical, como nos enseñó McKenzie Wark (2004), no sólo implica un cuestionamiento de las funcionalidades sino un enfrentamiento con las propiedades. Hackear el mundo no es sólo inventar nuevas posibilidades de habitarlo y transformarlo, sino devolver al común lo mucho que ha sido abusivamente patrimonializado por los estados y los mercados. Los primeros hackers, allá por los 1960's y en adelante, inventaron la cuadratura del círculo: para ser autor no había que ser propietario, pues sólo se podía alcanzar la condición de creador de algo en el momento mismo de donarlo. 
Nadie ha sido más radical en estos planteamientos que el movimiento hacker. Nadie ha logrado mejor que ellos traducir en prácticas y protocolos sostenibles la apuesta por una cultura abierta, experimental, inalienable, horizontal y distribuida. Los textos que se han escrito para explorar cada una de estas palabras forman ya una montaña. No la subiremos en estas páginas, pero tampoco la perderemos de vista. Escribir código no es lo único que hacen los partidarios del Software Libre, un ecosistema que sólo funciona por el ensamblaje armonioso de programadores, documentalistas, testeadores y traductores. Se requieren muchos cuidados y no todos sucumben a la deriva del especialista. El éxito del SL está vinculado a que funciona o, en otros términos, a que los programas corren, son funcionales, hacen sus tareas de forma eficiente. Pero con ser notable el cumplimiento de esta expectativa, lo que lo convierte en un fenómeno cultural, político y tecnológico excepcional son las formas de organización del conocimiento a que ha dado lugar. ¿Cómo explicarlo en pocas líneas?

Nos quedaremos con dos de sus características: el fork (COLEMAN; GOLUB, 2008) y la recursividad (KELTY, 2008). Se produce un fork cuando una parte de la comunidad involucrada en el desarrollo de un proyecto decide optar por otra alternativa y separarse del criterio dominante. Cuando eso ocurre, los discrepantes tienen derecho a llevarse todo el código que hasta ese momento compartían. El SL entonces siempre está abierto a todas sus posibilidades, siempre resulta ser un diseño en beta, un prototipo encarnado en una comunidad no identitaria, un proyecto que siempre es "more than many and less than one" (CORSÍN JIMÉNEZ, 2013). Son recursivos los proyectos que aprenden de sus errores, algo que hacen los niños por sistema y que, a veces, también logramos imitar los adultos. Pero aquí nos interesa la noción de recursividad cuando se aplica a sistemas y no a personas o proyectos simples. Y en tales circunstancias decimos que hay recursividad cuando no sólo se preserva la funcionalidad del dispositivo, sino su integridad moral 
o, en otras palabras, cuando son los protocolos y el código los encargados de preservar los valores que sostienen el proyecto, es decir la comunidad.

Lo que hace vibrantes las comunidades de software libre no es el propósito de producir para todos, sino el de construir entre todos. El commons por el que trabajan no está garantizado por el libre acceso, sino por la voluntad de no excluir ninguna forma de colaboración que mejore el resultado. Y no nos referimos sólo a personas, sino también a culturas. El resultado, obviamente, no es un producto, sino una forma de entender nuestras relaciones con la tecnología y con los otros humanos, basada en el principio de que el lenguaje en el que se comunican las máquinas debe ser abierto y que las comunidades deben serlo entre pares que disuelvan los bordes artificiales e imaginarios que nuestra sociedad crea entre nacionales y extranjeros, expertos y amateurs, comunicar y compartir, o entre libre y gratis. Ya lo hemos dicho, estamos hablando de comunidades cosmopolitas, informales y basadas en la economía del don (LEACH, NAFUS; KRIEGER, 2009). Tampoco es la gratuidad la divisa que hace singulares estas producciones. Compartir el código ha obligado a ingeniar modelos de negocio alternativos que no arruinen a quienes optan por el SL.

\section{HACER CIUDAD}

La cultura hacker, sin embargo, no está hoy restringida a los geeks, ni es un asunto para informáticos frikies. Hoy hablamos de hackear los museos, la academia o la ciudad (COHEN; SCHEINFELDT, 2013). Disponemos de centenares de proyectos que se atreven a mirar las artes como si fueran empresas que debiéramos refundar sobre fundamentos no tan mercantiles, luchando para sacar la música, la pintura o la arquitectura del anzuelo de las industrias culturales, el turismo o la especulación inmobiliaria. La propia ciudad, nuestras plazas y solares abandonados, pueden ser habitados de 
otra manera. No todo debe ser sacrificado a la velocidad, la seguridad y el lucro. Todas nuestras necesidades no son satisfechas por el transporte, la policía y el comercio. Nuestras calles pueden ser un lugar de encuentro entre vecinos que no se juntan para consumir o protestar. La calle está siendo ensanchada como el espacio por antonomasia de una forma de sociabilidad que nunca habíamos tenido y que sin embargo parece que la estábamos perdiendo.

Mucha gente tiene miedo de deambular, consumir comida callejera, acudir a fiestas espontáneas, rozar cuerpos no familiares o, peor aún, de tener tiempo libre (DELGADO, 2011). En definitiva, ya no vivimos con nuestros vecinos, sólo los soportamos y nuestras ciudades sólo son contenedores de humanos huidizos. Proliferan las ciudades en cuyas plazas y solares se agrupan ciudadanos que, hartos de tanta sumisión a los ideales del consumismo individualista, están recuperando el gusto por compartir bailes, alimentos, ferias, bazares, mercadillos y otras formas de fiesta e interacción populares. Estuvieron a punto de convencernos de que hacíamos bien olvidando estas formas de sociabilidad anticuadas. Ahora, sin embargo, las vemos como un patrimonio que encarna parte de lo mejor de nosotros, es decir, de todo lo que compartimos y hacemos juntos.

Muchos arquitectos, artistas y científicos sociales lo saben y no dejan de escribir sobre el asunto. Pero no avanzamos mucho. La ciudad debiera ser okupada, tenemos que disputársela a las corporaciones del ocio, de la seguridad y de la vivienda (HARVEY, 2012). Y este es el origen de toda una serie de nuevos urbanismos emergentes que operan un cambio singular en una ciudad que transita desde la figura del escenario para las protestas a la de objeto mismo de propuestas (VV. AA., 2009; VASUDEVAN, 2014). El nuevo urbanismo está surgiendo en los solares abandonados, los huertos urbanos, las rutas en bici, los paseos nómadas, las asambleas de barrio, las fiestas vecinales, la memoria viva, los mercados de proximidad y, en fin, en las mil y una manera de asociarse que implican estas formas 
de experimentar la urbe colectivamente, apostando por los vínculos frágiles, esporádicos, tentativos, intermitentes y, sin embargo, reconocibles, concretos, situados y funcionales.

Nos quedaríamos cortos, sin embargo, si redujéramos la noción de propuesta a un plan de acción que cabe en un documento que selecciona, articula, temporaliza y presupuesta un paquete de líneas concretas de acción. Todo eso, obviamente debe suceder, pero lo que importa es cómo se logra identificar la narrativa y la comunidad que lo sostiene. Lo que importa son las prácticas experimentadas hasta lograr que un colectivo heterogéneo logre producir el mencionado documento (RILES, 2001). Lo que importa es su capacidad para sortear malentendidos y desencuentros antes de reconocerse como coproductores de una forma singular de representar su manera compartida de visualizar problemas. Lo que importa, en definitiva, son los aprendizajes que tuvieron que realizar para llegar juntos a algún sitio. Lo importante es que aprendieron a construir entre todos. Por eso, estos colectivos de urbanismo emergente se configuran como verdaderos laboratorios ciudadanos donde se experimenta con nuestra capacidad para aprender a vivir juntos mientras damos forma y producimos propuestas viables, para abordar los problemas de nuestro entorno. Se hacen propuestas y, sobre todo, se re-configura la experiencia de lo urbano. Hay pues un desplazamiento en la manera de habitar la ciudad y hacer política: el que va desde el discurso a la intervención, el que nos lleva desde la palabra fugaz a la problematización de las infraestructuras (CORSíN JIMÉNEZ, 2014). El movimiento Occupy global es quizás un ejemplo paradigmático de esa otra manera de practicar lo urbano. Las acampadas que fueron desplegadas en geografías tan dispares como New York, Madrid, Grecia o Hong Kong fueron un gesto de re-urbanización de la ciudad que ponía en juego el propio cuerpo, alumbraba una manera distinta de relacionarnos e imaginar la ciudad, mientras dotaba con nuevos materiales la acción política (CORSín JiMÉNEZ; ESTALELLA, 2014). Algo especialmente evidente 
cuando se pone en relación con el ciclo iniciado hace más de una década por el movimiento altermundista. Si las protestas del altermundismo pretendían asaltar la ciudad ajena, Occupy ha tratado de ocupar literalmente la ciudad propia (MAEcKelberG, 2012). Pero Occupy es únicamente el indicador de un movimiento de alcance global que se extiende atrás en el tiempo y se expande en una geografía global mediante iniciativas que reclaman el derecho a una ciudad distinta.

Henry Lefebvre (1969) nos regaló hace varias décadas, en plena efervescencia urbana del mayo del 68, la figura del derecho a la ciudad. Una expresión difusa recuperada recientemente por muchas iniciativas que intentan hacer una ciudad distinta; en efecto, el derecho a ciudad, quizás por su ambigüedad inicial, se ha convertido en un símbolo emblemático de las nuevas movilizaciones urbanas. Nos referimos a iniciativas que no se limitan a reclamar el derecho a esto o aquello otro sino que hacen otras cosas. No se trata de reclamar simplemente las calles, sino de hacer plazas. El espacio urbano intervenido materialmente nos dota a quienes lo habitamos de nuevas capacidades y una sensibilidad renovada mientras equipa el derecho a la ciudad con nuevas infraestructuras (MARRES; LEZAUN, 2012). Los huertos urbanos que salpican los solares abandonados, los muebles que habilitan espacios vecinales y las iniciativa que ocupan vacíos urbanos son instancias donde el derecho a la ciudad ya no es un ejercicio de reclamación sino un trabajo de composición de una ciudad distinta donde se diluye la escisión entre lo urbano y lo rural, convirtiendo la calle en una extensión hospitalaria del hogar y llenando de vecindad lo que antes sólo era una herida, un vacío, urbano.

En todos esos proyectos la gente está aprendiendo a experimentar su ciudad de otra manera, y aunque las personas acreditadas son bien recibidas nunca ejercen como expertos. Ningún saber es desdeñado en estos experimentos colectivos que siempre desbordan la experticia formal y la tradicional. Se trata de proyectos en 
donde todos experimentan, todos investigan, todos interpretan, todos contrastan, todos consensuan, todos aprenden y (entre) todos crean conocimiento nuevo (ESTALELLA; CORSÍn JIMÉNEZ, 2014). Cada vez es más abundante la literatura que explora otras formas de experimentar que no están asociadas a la idea de contrastar hipótesis. Son muchas las culturas experimentales históricamente desplegadas, y no todas se desarrollaron asociadas a la idea de demostración. Probar, junto con nombrar, colectar, describir y cambiar el mundo, son gestos que conforman distintos estilos de experimentación (KLEIN, 2003). Lo que hemos aprendido de los estudios de la ciencia es que la tarea de conocer algo tiene menos que ver con la tarea de ensamblar proposiciones que con construir relaciones con el entorno: no es un esfuerzo de musculatura mental sino una práctica relacional (ROUSE, 2002). Ningún ejemplo es más claro que estas intervenciones en la ciudad de naturaleza tentativa, precaria, vulnerable y esperanzadora o, dicho de otra manera, experimental. A nadie le espantan las soluciones salvo cuando son simplistas y excluyentes, por eso se dedica más tiempo a escuchar que a planear, a hacer que a pensar y a decir que a escribir. Construir una buena pregunta requiere anteponer la lógica de los cuidados a la de la prueba y las epistemes plurales a las funcionales. Una buena pregunta asamblea actores potencialmente muy heterogéneos y configura un espacio abierto a la identificación de los asuntos por aclarar, la discusión de las ideas pret-à-porter, el contraste de las experiencias personales, la crítica de los patrones interpretativos circulantes, el examen del valor que asignar a los datos o el análisis de otros abordajes alternativos. En su conjunto, las personas, los instrumentos, los modelos y las prácticas conforman un sistema experimental que, como ocurre en la mejor ciencia académica y nos explicó Rheinberger (1997), se pone en marcha sin la seguridad del resultado y entre convicciones más borrosas y fluidas de lo que tienden a contar demasiados manuales de metodología y la mayoría de los relatos sobre la ciencia. Hay mucho riesgo en querer 
experimentar otras maneras de habitar la urbe y en querer convertir nuestras vulnerabilidades en una oportunidad para reconocer la emergencia de nuevas texturas de lo urbano o, como dirían Despret y Galetic (2007), para dejarse afectar por esa vibración inaudita, ese palpitar no codificado (LATOUR, 2004a; SÁNCHEZ-CRIADO, 2005). Así, la ciudad (en) común que estamos evocando no nace de la experticia de los urbanistas o los políticos, sino que es traída a la existencia para dar respuesta a otras formas de querer habitarla.

Latour (2004b, 2010) dice que estamos delante de nuevas formas de componer el mundo que no debemos confundir con las típicamente modernas basadas en hechos contrastados o en opiniones consensuadas. La política y la ciencia deben admitir que su reparto de atribuciones sobre el mundo no es suficiente: no todo son asuntos de derecho o de hecho. No todo puede ser gestionado mediante leyes, acuerdos, estándares e innovaciones. Hay mucho que admirar en todas esas entidades que la ciencia ha traído al mundo y de las qua ya no queremos ni sabemos prescindir: el mundo se ha llenado de neuronas, ozono y neutrinos, por no hablar de los hadrones, los transgénicos, los bits y los cromañones. Es inútil pintar el cuadro completo, pero sería injusto no hablar del mercado del carbón atmosférico, la crisis de las abejas, los disruptores endocrinos y de la profanación de la intimidad. Tampoco los políticos han renunciado a sembrar nuestra vida con multitud de objetos prodigiosos: los derechos, las infraestructuras, los estándares, las etiquetas, los impuestos, las banderas y las vacaciones sólo son una parte ínfima de su legado. La política no es asunto para tomárselo a la ligera: nuestra deuda con los electos es inmensa. Pero seríamos insensibles a lo que (nos) pasa sin evocar la prevaricación, la desigualdad, el secreto, la guerra, el saqueo y otras producciones mostrencas. Todos esos entes han ensanchado nuestro mundo, nuestro firmamento, nuestro cuerpo, nuestra urbe, nuestra lengua y nuestra intimidad.

Hacer una urbe entre todos, componer una ciudad común, reclama algo más que códigos y congresos. Lo repetimos: ni queremos, 
ni sabemos, ni jugamos a destruir el mundo de la política y de la ciencia. Pero es verdad que el mundo de los electos y de los selectos ya no nos representa por completo. Tenemos, podemos y sabemos componer un mundo común. Para componerlo hay que traer a la existencia entes que todavía no lo habitan como, por ejemplo, un nuevo derecho a la ciudad, un nuevo habitante urbano, una nueva sensibilidad, un nuevo órgano..., una colección de entes que ayuden a crecer lo común, es decir lo creado entre todos. Componer una ciudad no implica producir nuevos consensos o disensos; tampoco reclama nuevos mapeos de la realidad que expandan nuestra capacidad para conocer o desdeñar el entorno. El mundo común no está reclamando más expertos, ni más alcaldes, ni tampoco más agnósticos, paranoicos o descreídos. El mundo común es un mundo (en) común, hecho entre todos, con palabras, prácticas, protocolos e infraestructuras que, como ya se dijo, tienen que ser abiertas, emergentes y recursivas. Lo más difícil de aceptar es que todavía no sabemos, como tampoco conocieron a sus criaturas Newton ni Montesquieu, cuáles son los entes que compondrán el mundo común.

\section{HACER CUERPO}

La urbe parece un objeto abordable por actores no acreditados. Pero ¿y el cuerpo? ¿Tendremos que reinventar también un cuerpo (en) común, un cuerpo entre todos? La respuesta en sí (LAFUENTE; IBÁÑEZ-MARTÍN [s.d.]). La expansión acelerada de los padecimientos crónicos, unido al creciente número de personas con graves trastornos mentales, alimentarios, adictivos o de conducta, junto a la existencia de muchos colectivos de afectados por alergias o intolerancias, convierten los males sin expectativa de cura en un fenómeno nuevo e inquietante. Nos han educado en la convicción de que todos los males tenían una solución técnica y científica y, por tanto, política. No estábamos preparados para enfrentarnos a lo 
obvio y admitir que todos los cuerpos no son iguales y que cada uno reacciona de forma diferente ante las mismas terapias o circunstancias. Y así, las soluciones generales siempre producen minorías de afectados. Pero es que, además, no todo el mundo soporta igual la mala calidad de nuestro aire o el contacto con sustancias químicas cuyos efectos sobre la salud ignoramos. Parecería que de repente hemos sido atacados por una epidemia de fragilidad. Mucha gente, no sabemos si son los más lúcidos o los más desahuciados, han perdido la confianza en que los saberes institucionalizados puedan ofrecerles algún consuelo. Y hay respuestas para todo, desde los que se han echado en brazos de cualquier discurso tan alternativo como confuso, hasta los que se han puesto a conversar entre ellos para explorar lo que (nos) pasa.

El primer ejemplo inexcusable es Alcohólicos Anónimos (KURTZ, 1982). Un caso bien conocido porque el cine lo ha mostrado innumerables veces. Su relevancia cognitiva y política se cuenta rápido pues nos estamos refiriendo a una iniciativa promovida por los propios afectados que se despliega al margen de las instituciones públicas, ya sean académicas o asistenciales, ya sean sanitarias o policiales. En las reuniones de AA se asume que no hay cura individual y que es la potencia del grupo (a veces identificada, sobre todo en los orígenes, con la presencia de una fuerza divina o trascendente) la que permite el rescate desde el infierno que habitan quienes sucumbieron a la adicción y a todas las mentiras para aparentar que tenían la situación bajo control. Admitir la fragilidad propia se convierte en la clave que conduce a cada uno de los asistentes a sentirse reconocido y entendido en los relatos ajenos. El mal, en consecuencia, deja de ser la consecuencia de un fracaso individual para ir configurándose como expresión de una cultura que hipertrofia lo individual frente a lo relacional. Un adicto sería alguien que se ha tomado demasiado en serio la ficción de que tiene un yo perfectamente confinado en el espacio y en el tiempo, lo que es tanto como decir que encaja con precisión en su cuerpo y en su 
memoria. Un adicto sería alguien incapaz de admitir la naturaleza sistémica de eso que llamamos personalidad. Lo que estarían haciendo los asistentes de AA en sus reuniones, basándose en la experiencia vivida y mediante la palabra hablada, sería reencontrarse consigo mismos alrededor de un yo que es más distribuido, abierto y emergente. Nadie lleva un héroe en su interior salvo los candidatos a desplomarse, y los alcohólicos son la herida por la que sangra un mundo demasiado proclive a la competición y al gesto heroico. Lo novedoso está en que lo experiencial adquiere no sólo un valor cognitivo, sino también terapéutico; es decir que los concernidos afirman que las reuniones de AA les cambiaron la vida o, en otros términos, certifican que mejoró su calidad de vida. La curación por la palabra es un asunto antiguo y disputado, lo que aquí nos interesa es el reconocimiento que hoy logró el llamado recovery movement, un movimiento formado por muchos colectivos de adictos y de enfermos mentales que reconocen en AA una indudable fuente de inspiración (FARRIS; KUTZ, 1990; WHITE, 2005). Son miles los grupos de AA por todo el mundo, pero no siempre los concernidos viven cerca o tienen facilidad para desplazarse hasta un lugar de encuentro.

Reunir cuerpos dispersos siempre fue difícil y costoso. Pero internet lo permite a costa (casi) cero (SARASOHN-KAHN, 2008; FERGUSON, 2007). Tenemos muchos ejemplos de comunidades que han utilizado internet para reunirse y charlar sobre lo que (les) pasa. Hablamos de colectivos decepcionados por la respuesta que han recibido de las instituciones académicas y públicas. Nos referimos a grupos de afectados que no han encontrado en las terapias formales el bienestar que esperaban. Son muchos los colectivos de afectados que han decidido adoptar un gesto crítico respecto a las prácticas médicas y a sus instituciones canónicas (RODRÍGUEZ-GIRALT, 2010; BROWN, 2004). Y tenemos dos casos sobre los que detenernos para explorar el alcance de estos movimientos contra hegemónicos. El primero son los electrosensibles (CHATEAURAYNAUD; 
DEBAZ, 2010), una enfermedad que padecen con distinto grado de gravedad entre el $3 \%$ y el $5 \%$ de los europeos. Las electrosensibles son pacientes que tuvieron que luchar por un diagnóstico, pues sin ser reconocidas como enfermas podían ser despedidas en sus trabajos o ser tratadas en sus entornos familiares como personas sin coraje y sin voluntad. En la práctica sabemos que un porcentaje de las afectadas podían sufrir el síndrome de fatiga extrema y quedaban muy mermadas para el desempeño de una vida normal. Sin energía y sin diagnóstico su vida se convertía en un calvario lleno de incomprensión y malentendidos, pues con frecuencia lo que se les decía desde las consultas médicas era que padecían una especie de shock postraumático originado en su incapacidad para adaptarse a los cambios tecnológicos de nuestro tiempo. No eran las ondas las que la estaban matando, sino su resistencia para adaptarse al mundo moderno. Así las cosas, decidieron reunirse y comenzar a discutir lo que les pasaba con la intención de elaborar un documento que pudiera representarlas, es decir que diera forma al mal que padecían. Y lograron convencer a las autoridades en los países escandinavos. Tanto, que la electrosensibilidad fue aceptada como una nueva enfermedad que devolvía a sus pacientes la condición de plena ciudadanía y los privilegios que todavía tienen los enfermos en las llamadas sociedades del bienestar.

El segundo caso que queríamos tratar está formado por un colectivo gigantesco en red que agrupa a enfermos mentales hartos de tomar ansiolíticos y antidepresivos. No sólo discuten que la solución a los problemas que experimentan sean las pastillas, sino que apuestan por dar el mayor valor cognitivo a su propia experiencia personal. Han decidido usar el chat para tratar de entenderse mutuamente, y tratar de averiguar si hay algo en lo que sienten que responda a algún patrón compartido. Lo que ocurre cuando se ponen a charlar los enfermos mentales de las Brain Talk Communities (HOCH; FERGUSON, 2005), como sucedía con las electrosensibles, es que no hay ni palabras para nombrar sus males. Como el 
diagnóstico o el tratamiento que se les da no les satisface se ven en la obligación de identificar rasgos que puedan ser reconocidos como síntomas, lo que les obliga a fabricar un lenguaje compartido y contrastado. Compartido porque la comunicación no se interrumpe y contrastado porque necesitan estar seguras de que los remedios caseros, locales o estrambóticos que circulan por el chat son eficaces y no simples placebos. No sólo contrastan pócimas, sino también ideas, unas veces escuchadas en las consultas de sus médicos respectivos, y otras leídas en algún repositorio académico de libre acceso. Lo que estamos diciendo es que los concernidos, basándose tanto en la experiencia propia (la propiacepción de la que hablara Merleau-Ponty) como en la experticia a la que tuvieran acceso (leyendo papers o escuchando a médicos), han sido capaces de organizar una especie de ensayo clínico gigantesco en tiempo real donde los afectados han tomado las riendas de su propio cuerpo. Nadie estaría más interesado en encontrar buenas respuestas que quienes se juegan su propia vida mientras las buscan. Saben que sólo pueden aspirar a una mejora en la calidad de vida: al menos para ellos, el paradigma de la curación quedó atrás.

El experimento se confirma cuando concuerdan que están mejor, aunque esta mejoría sea un compromiso sostenido entre todos y no una solución individual, al igual que con los drogodependientes. Si los participantes logran ser tomados en serio por las instituciones científicas formales (los electrosensibles o los afectados por el síndrome de la guerra del golfo, por ejemplo, lucharon para merecer un diagnóstico) o experimentan una mejoría (como los enfermos mentales), no hay más remedio que admitir que estamos hablando de un conocimiento hecho entre todos. La comunidad que lo sustenta es reconocible en la medida en que el conocimiento que produce es validado por ser funcional. En fin, la comunidad de afectados existe en/por esa actividad cognitiva. Se trata de una comunidad de aprendizaje que ha sido capaz de vertebrar un colectivo de naturaleza intergeneracional y culturalmente heterogéneo, lo 
que significa que han actuado como brockers sociales. Pero su papel como vectores de innovación social no eclipsa su importancia como productores de conocimiento y como creadores de otras formas de sociabilidad.

Recapitulemos la naturaleza de su actividad en red: experimental, abierta, relacional, distribuida, horizontal, colaborativa, inalienable y recursiva. Lo que están haciendo los conversadores es inventarse un cuerpo relacional basado en lo experiencial; es decir, en todo eso que un científico tiende a calificar de colateral, irrelevante o inútil. Es la misma experiencia que antes describimos para el urbanismo. Desde los solares abandonados y mediante prácticas sociales ignoradas por ser características de pobres, incultos o marginales estamos reinventando la ciudad. De la misma forma estamos creando un cuerpo común a partir de lo que sobra, de lo desdeñado por irrelevante (LAFUENTE; IBÁÑEZ-MARTíN [s.d.]). No es que los científicos desdeñen todo lo que no saben, sino que sus protocolos y practicas les impiden considerar lo experiencial como un material desde donde construir conocimiento contrastado.

\section{CIENCIA COMÚN}

Ya tenemos todo lo que necesitamos para concluir. Llamamos ciencia común a una forma de producir conocimiento que debe poder hacerse entre todos. La condición entre todos es distinta del para todos que caracteriza a los bienes públicos. La ciencia común no es ni mejor ni peor que la pública o privada, sino diferente. Está hecha a partir de otras prácticas y desde otros materiales, como también es diferente la forma por la que el conocimiento es validado.

Si debe poder hacerse entre todos es necesario que no requiera de saberes previos acreditados. Nadie exige títulos, ni experiencia previa. Los rituales de ingreso no discriminan entre los que saben y los que no saben, o entre los capaces y los incapaces. No hay 
exámenes, ni competición. Nadie busca a los mejores ni a los más preparados. La ciencia común entonces no es pensable a partir de los imaginarios del experto. Puede haberlos, lo normal es que siempre haya en los colectivos aludidos gentes con alguna titulación o con más lecturas o, por qué no, con más dedicación. No todos los participantes saben lo mismo, ni lo saben de la misma manera. Es justo lo contrario. Cada uno ha llegado al colectivo por sus propios medios sin que hubiera ningún proceso de filtrado para que los integrantes fueran algo más homogéneos. Para que sea entre todos, para que nadie sobre y para que nadie pueda dominar la situación, el conocimiento debe construirse a partir de un material tan abundante como ordinario: la experiencia. Algo que todos tenemos. Más aún, algo en lo que todos somos expertos, pues todos conocemos matices, incluso no verbalizados, acerca de lo que nos pasa y sobre lo que podemos discutir con flexibilidad y criterio propio. Todos sabemos mucho acerca de lo que nos pasa y todos podemos participar en un proceso cuyo destino es saber que es lo que tenemos en común o, en otros términos, encontrar las palabras con las que describir las experiencias que compartimos. Los casos que hemos descrito, tanto en el ámbito de cuerpo como en el de la urbe, muestran que la ciencia común es parte de la respuesta que las comunidades de afectados han encontrado para hacer visible su particular manera de habitar el mundo, es decir su otra manera de sentirlo, de narrarlo y de compartirlo.

La búsqueda de la que hablamos es experimental por compartida, contrastada y pública. El proceso siempre está abierto a la llegada de nuevos interlocutores y otros puntos de vista. El proceso, siendo abierto, no es infinito, pues acaba cuando los participantes, como ocurría en AA, empiezan a sentirse mejor, cuando son innegables los signos de mejoría en la calidad de vida. La verdad del experimento está contenida en la bondad de sus consecuencias para los participantes. Es la comunidad de concernidos la que certifica la credibilidad de los procedimientos. La comunidad no sólo 
se constituye mientras experimenta y sus integrantes aprenden a vivir juntos resolviendo los problemas que les afectan, sino que se hace ejemplar y sostenible, lo que es tanto como decir que es replicable y hospitalaria.

La ciencia común que se ha configurado alrededor de la recuperación de la experiencia de algo que estuvimos a punto de olvidar, la vivencia de un cuerpo y de una ciudad común, no es una alternativa a la ciencia académica. Ambas se necesita mutuamente, aunque alguna veces las veremos disputarse el espacio público y también a los públicos.

\section{REFERENCIAS}

ARVANITIS, Rigas . La science pour le développement est-elle une science publique?. In: WAAST, R. (Ed.). Les sciences au sud. Etat des lieux. Paris: Editions de l'ORSTOM, 1996. p. 175-185.

BACHELARD, Gaston. Le rationalisme appliqué. Paris : PUF, 1986.

BECK, Ulrich. Risk society: towards a new modernity. London: Sage, 1992.

BROWN, Mark B. Science in democracy. expertise, institutions, and representation. New York: The MIT Press, 2009.

BROWN, Phil; ZAVESTOSKI, S.; MCCORMICK, S.; MAYER, B.; MORELLO-FROSCH, R.; GASIOR ALTMAN, R. Embodied health movements: new approaches to social movements in health. Sociology of Health and Illness, v.26, n.1, p. 50-80, 2004.

BROWN, Phil; ZAVESTOSKI, Stephen; CORDNER, Alissa; MCCORMICK, Sabrina; MANDELBAUM, Joshua; LUEBKE, Theo; MEADOW, Linder. A narrowing gulf of difference?: disputes and discoveries. In the study of gulf war-related illnesses. In: BROWN, P.; MORELLO-FROSCH, R.; ZAVESTOSKI, S. (Ed.). Contested illnesses: citizens, science, and health social movements. Berkeley: University of California Press, 2011. p. 79-107.

CALLON, Michel. Is science a public good? Fifth Mullins Lecture, Virginia Polytechnic Institute, 23 March 1993. Science, Technology \& Human Values, v.19, n.4, p. 395-424, 1994. 
CALLON, Michel; RABEHSRISOA,Valolona . Research 'in the wild' and the shaping of new social identities. Technology \& Society, v.25, p.93-204, 2003.

CHATEAURAYNAUD, F. ; DEBAZ, J. Le partage de l'hypersensible : le surgissement des électro-hypersensibles dans l'espace public. Sciences Sociales et Santé, v.28, n.3, p. 5-33, 2010.

COHEN, Daniel J.; SCHEINFELDT, Tom ( Ed.). Hacking the academy: new approaches to scholarship and teaching from digital humanities. Ann Arbor: University of Michigan Press, 2013.

COLEMAN, Gabriella; GOLUB, Alex. Hacker practice. Moral genres and the cultural articulation of liberalism. Anthropological Theory, v.8, n.3, p. 255-277, 2008.

COLLINS, Harry; EVANS, R. Evans. The third wave of science studies: studies of expertise and experience. Social Studies of Science, v.32, n.2, p. 235-296, 2002.

CORSÍN JIMÉNEZ, Alberto. An anthropological trompe l'oeil for a common world. Oxford; New York: Berghahn, 2013 b.

CORSÍN JIMÉNEZ, Alberto. The prototype: more than many and less than one. Journal of Cultural Economy, v.7, n.4, p.381-398, 2013.

CORSÍN JIMENEZ, Alberto. The right to infrastructure: a prototype for open source urbanism. Environment and Planning D: Society and Space Advance Online, v.32, p. 342-362, 2014.

CORSÍN JIMENEZ, Alberto; ESTALELLA, Adolfo. Assembling neighbors: the city as hardware, method and a 'very messy kind of archive'. Common Knowledge, v.20, n.1, p. 150-171, 2014.

DAVID, Paul A. The historical origins of 'Open Science'. An essay on patronage, reputation and common agency contracting in the scientific revolution. Capitalism and Society,v.3, n.2, 2008.

DELGADO, Manuel. El espacio público como ideología. Madrid: Catarata, 2011.

DESPRET, Viciene; GALETIC, S. Faire de James un "lecteur anachronique" de Von Uexküll: esquisse d'un perpectivisme radical. In : DEBAISE, D. (Ed.). Vie et expérimentation: Peirce, James, Dewey. Paris: Vrin, 2011. p. 45-76.

DEWEY, John . The public and its problems. In: ROGERS, Melvin L. (Ed.). An essay in political inquiry. Penn: Penn State University Press, 2012. 
EPSTEIN, Steven. The construction of lay expertise: AIDS activism and the forging of credibility in the reform of clinical trials. Science, Technology, \& Human Values, v. 29, p. 408-437, 1995.

ESTALELLA, Adolfo; CORSÍN JIMÉNEZ, Alberto. Atmósferas de la escucha: órgano de un urbanismo experimental en Madrid. In: MATERIA A DEBATE, 4. Madrid: Club de Debates Urbanos, 2014. p. 253-263.

FARRIS, Linda; KURTZ, E. The self-help movement. Social Work With Groups, v. 13, p.101-115, 1990.

FERGUSON, Tom. E-patients: how they can help us heal health care. San Francisco [s.n.] 2007. Disponível em: http://e-patients.net/e-Patients_White_Paper.pdf. Acesso en: 5 mar. 2015.

FRANZONI, Chiara; SAUERMANN, Henry. Crowd science: the organization of scientific research in open collaborative projects. Research Policy, v.43, p. 1-20, 2014. HAND, Eric. Citizen science: people power. Nature, v.466, p. 685-687, 2010.

HARDING, Garret. The tragedy of the commons. Science, v.162, p. $1243-1248$, 1968.

HARVEY, David. Rebel cities. From the right to the city to the urban revolution. London; New York: Verso, 2012.

HESS, Charlotte; OSTROM, Elinor (Ed.). Understanding knowledge as a commons. From theory to practice. Cambridge: The MIT Press, 2007.

HESS, David J. Alternative pathways in science and industry. Activism, innovation, and the environment in a era of globalization. Cambridge: The MIT Press, 2007.

HIMANEN, Peka. The hacker ethic and the spirit of the information age. New York: Random House, 2001.

HOCH, D.; FERGUSON, T. What I've leaerned from e-patients. Plos Med, v.2 , n.8, p. e206, 2005.

IRWIN, A. Citizen science: a study of people, expertise and sustainable development. London: Routledge, 1995.

JONES, Adrian. Intellectual property and the nature of science. Cultural Studies, v.20, p. 145-64, 2006. 
KELTY, Christopher. Two bits. The cultural significance of free software. Durham: Duke University Press, 2008.

KLEIN, Ursula. Styles of experimentation. In: GALAVOTTI, M. C. (Ed.). Observation and experiment in the natural and social sciences. Dordrecht: Kluwer, 2003. p. 159-185. KURTZ, E. Why A.A. works: the intellectual significance of Alcoholics Anonymous. Journal of Studies on Alcohol, v.43, p. 38-80, 1982.

LAFUENTE, Antonio. Modernización epistémica y sociedad expandida. In: DIAZ, Rubén (Ed.). Educación expandida. Sevilla: Zemos98, 2012. p. 131-150.

LAFUENTE, Antonio; IBÁÑEZ-MARTÍN, Rebeca. Cuerpo común, y cuerpos colaterales. En prensa, manuscrito.

LATOUR, Bruno. An attempt at a "Compositionist Manifesto". New Literary History, v.41, p. 471-490, 2010.

LATOUR, Bruno. How to talk about the body? The normative dimension of science studies. Body and Society, v.10, p. 205-229, 2004a.

LATOUR, Bruno. Whose cosmos, which cosmopolitics? Comments on the peace terms of ulrich beck. Common Knowledge, v.10, n.3, p. 450-462, 2004 b.

LEACH, James; NAFUS, Dawn; KRIEGER, Bernhard. Freedom imagined: morality and aesthetics in open source software design. Ethnos, v.74, n.1, p.51-71, 2009. LEFEBVRE, H. El derecho a la ciudad. Barcelona: Península, 1969.

MCCORMICK, Sabrina; BROWN, Phil; ZAVESTOSKI, Stephen; CORDNER. Alissa. The personal is scientific, the scientific is political: the public paradigm of the environmental breast cancer movement. In: BROWN, P.; MORELLO-FROSCH, R.; ZAVESTOSKI, S. (Ed.). Contested Illnesses: citizens, science, and health social movements. Berkeley: University of California, 2011. p. 147-168.

MAECKELBERGH, M. Horizontal democracy now: from alterglobalization to occupation. Interface: a Journal for and about Social Movements, v.4, n.1, p. 207-234, 2012. MARRES, N.; LEZAUN, J. Materials and devices of the public: an introduction. Economy and Society, v.40, n.4, p. 489-509, 2011.

MIGNOLO, Walter D. The many faces of cosmo-polis: border thinking and critical cosmopolitanism. Public Culture, v.12, n.3, p. 721-748, 2000. 
MIROWSKI, Philip. Science-mart. Privatizing american science. Cambridge: MA:Harvard University Press, 2011.

MIROWSKI, Philip; SENT, Esther-Mirjam. The commercialization of science and the response of STS. In: HACKETT, Edward J.; AMSTERDAMSKA, Olga; LYNCH, Michael; WACJMAN, Judy (Eds.). The Handbook of science and technology studies. Cambridge, MA: MIT Press, 2008. p.635-89.

MOULIA, Bruno et alli. Main basse sur la science publique : le «coût de génie» de l'édition scientifique privée. Paris: INRA, 2013. Disponível em : http://www.inra. cgt.fr/actions/revendications/Main_basse_sur_la_Science.pdf. Acesso em : 5 mar.2015.

NIELSEN, Michael. Reinventing discovery: the new era of networked science. Princeton: Princeton University Press, 2011.

NOWOTNY, Helga; PESTRE, Dominique; SCHIMIDT-ABMANN, Eberhard; SCHULZE-FIELITZ, Helmuth; TRUTE, Hans-Heinrich (Ed.). The public nature of sveince under assault. Politics, markets, science and law. Berlin: Springer, 2005.

NOWOTNY, Helga et al. Mode 2 Revisited. Minerva, v.41, p. 175-94, 2003.

NOWOTNY, Helga; SCOTT, Peter; GIBBONS, Michael. Re-thinking science: knowledge and the public in an age of uncertainty. Oxford: Polity, 2001.

OSTROM, Elinor. Governing the Commons: the evolution of institutions for collective action. Cambridge: Cambridge University Press, 1990.

RABEHARISOA, Vololona; CALLON, Michel. La gestion de la recherche par les malades: le cas d l? In: SÉMINAIRE RESSOURCES TECHNOLOGIQUES, 1999. Paris: Association Française ciontre les Myopathies, 1999.

RANCIÉRE, Jacques. En los bordes de lo político. Buenos Aires: La cebra, 2007.

RHEINBERGER, Hans-Jörg. Toward a history of epistemic things: synthesizing proteins in the test tube. Stanford, CA: Stanford Univ. Press, 1977.

RILES, Annelise. The network inside out. Ann Arbor, MI: University of Michigan Press, 2001.

RODRÍGUEZ-GIRALT, Israel. El activismo encarnado. Barcelona Metrópolis. Revista de Información y Pensamiento Urbanos, v.79, p.11-15, 2010. 
ROUSE, Joseph. How scientific practices matter: reclaiming philosophical naturalism. Chicago: University of Chicago Press, 2002.

SÁNCHEZ-CRIADO, Tomás. El cultivo de las emociones en diferentes tradiciones: antropología de la ciencia. William James y Etnopsicología en la obra de Vinciane Despret. [S.1.] Asociación Ibero Americana en Red, AIBR, jul./ago. 2005.

SARASOHN-KAHN, Jane. The wisdom of patients: health care meets online social media. Oakland: California HealthCare Foundation, 2008.

SENT, Esther-Mirjam. Economics of science: Survey and suggestions. Journal of Economic Methodology, v. 6, p.95-124, 1999.

SLAUGHTER, Sheila; LESLIE, Larry L. Expanding and elaborating the concept of academic capitalism. Organization , v.8, n.2, p. 154-161, 2001.

SLAUGHTER, Sheila; RHOADES, Gary L. Academic capitalism: politics, policies, \& the entrepreneurial university. Markets, state, and higher education. Baltimore: The Johns Hopkins University Press, 2004.

STENGERS, Isabelle. The cosmopolitical proposal. In: LATOUR, Bruno; WEIBEL, Peter (Ed.). Making things public: atmospheres of democracy. Cambridge, MA: MIT Press, 2005. p. 994-1004.

STENGERS, Isabelle. La Vierge et le neutrino. Les scientifiques dans la tourmente. Paris: Les empêcheurs de penseur en rond, 2006.

STRATHERN, Marilyn. Redescribing society. Minerva, v.41, n.3, p. 263-276, 2003. VV. AA. Post-it city: ciudades ocasionales, Barcelona: Turner, 2009.

VASUDEVAN, A. The makeshift city: Towards a global geography of squatting. Prog Hum Geogr, 2014.

WARK, Mckenzie . A hacker manifesto. Cambridge: Harvard University Press, 2004. WHITE, William L. Recovery: its history and renaissance as an organizing construct concerning alcohol and other drug problems. Alcoholism Treatment Quarterly, v.23, n.1, p. 3-15, 2005. 


\section{3 \\ Ciência aberta: revolução ou continuidade?}

Alessandro Delfanti e Nico Pitrelli

A DESCOBERTA CIENTÍfICA PODERÁ se tornar tão rápida e imediata como um tweet? Para Michael Nielsen, especialista em computação quântica e defensor da ciência aberta, estamos no meio de uma transição para uma nova era científica, uma era comparável à da revolução científica do século XVII e à da transição para a Idade Moderna. De acordo com seu livro Reinventing Discovery (2012), graças à Internet temos uma chance de transformar radicalmente o modo como o conhecimento é produzido. O cientista estadunidense destaca duas direções tomadas pelo impacto das redes sobre a ciência: a aceleração na velocidade da descoberta científica e uma mudança profunda nas relações entre ciência e sociedade. Este aumento da eficiência epistêmica e social é baseado no impacto da abertura no empreendimento científico.

Ciência aberta é um conceito muito amplo, que engloba diversas práticas e ferramentas ligadas à utilização das tecnologias digitais colaborativas e ferramentas de propriedade intelectual alternativas. Algumas definições inclusivas propõem que a ciência aberta abraça práticas tão diferentes como o acesso aberto à literatura científica ou formas digitalmente mediadas de colaboração aberta, bem como o uso de licenças copyleft para promover a reutilização 
dos resultados de pesquisas científicas e protocolos. Por exemplo: Foster, um projeto recentemente financiado pela Comissão Europeia para a criação de mecanismos sustentáveis para os pesquisadores da União Europeia adotarem práticas de ciência aberta, assim define ciência aberta: "A condução da ciência de um modo que outros possam colaborar e contribuir, em que os dados de pesquisa, as notas de laboratório e outros processos científicos estejam livremente disponíveis, com termos que permitam reuso, redistribuição e reprodução da pesquisa"1.

A árvore taxonômica deste conceito se ramifica em várias direções (ver também FECHER; FRISKE, 2014). O site lista pelo menos cinco classes diferentes de questões ou de temas relacionados à ciência aberta: acesso aberto, dados abertos, pesquisa aberta reprodutível, avaliação científica aberta, e políticas de ciência aberta. Cada um desses temas pode ser subdividido em muitos outros subtópicos, que representam todo o espectro das dificuldades enfrentadas em um regime de ciência aberta. Sem considerar gestão de dados de pesquisa e, finalmente, ética e questões legais.

Essa complexidade pode explicar, em parte, por que, apesar do tom enfático dos apologistas da Internet, alguns cientistas parecem estar relutantes quanto à adoção das oportunidades que as redes oferecem. Vinte anos após o nascimento da World Wide Web no CERN, em Genebra, a pesquisa científica está abraçando a mudança a um ritmo mais lento do que outros campos de produção cultural. Por exemplo, a física pode parecer uma das disciplinas que tiraram mais proveito das oportunidades oferecidas pelas tecnologias digitais e de conexão: desde o nascimento da Internet moderna, físicos têm introduzido arquivos de pré-publicações em que qualquer

\footnotetext{
1 "the conduction of science in a way that others can collaborate and contribute, where research data, lab notes and other research processes are freely available, with terms that allow reuse, redistribution and reproduction of the research" .Disponível em: https://www. fosteropenscience.eu/foster-taxonomy/open-science-definition. Acesso em: 19 jan. 2015.
} 
pesquisador pode depositar e disponibilizar gratuitamente as primeiras versões dos artigos científicos antes de submetê-los a uma publicação acadêmica. No entanto, em iniciativas recentes no campo da física demandam enormes esforços técnicos e financeiros, assim como reiteram fortes promessas de inovação, a reprodução de práticas tradicionais parece prevalecer. Em janeiro de 2014, físicos lançaram o consórcio SCOAP32 (Sponsoring Consortium for Open Access Publishing in Particle Physics, Consórcio Patrocinador para Acesso Aberto a Publicações em Física de Partículas), uma iniciativa sem precedentes para um modelo de publicação de acesso aberto na física de partículas. O consórcio inclui algumas das instituições científicas mais importantes do campo, com o CERN em primeiro lugar. Essas instituições reúnem recursos financeiros que normalmente seriam alocados para assinaturas de revistas - e, preferencialmente, de revistas de livre acesso. O consórcio SCOAP3 então distribui esses recursos em um modelo "pagamento por artigo", garantindo, assim, o financiamento para o custo de publicação das revistas mais importantes em física de partículas. Graças ao SCOAP3, qualquer pessoa com um computador ligado à Internet é capaz de acessar os artigos publicados na área, disponibilizados livremente on-line pelos editores.

Obviamente, pode ser difícil o modelo SCOAP3 exportar para outras disciplinas: a física de partículas é um campo relativamente pequeno e coeso, com um número limitado de periódicos e uma forte cultura de compartilhamento. Além disso, enquanto esta mudança para um modelo de acesso aberto pode ser a primeira iniciativa envolvendo todo um campo científico, a principal alteração introduzida está no nível da relação financeira entre editoras e universidades, e não nas modalidades de produção do conhecimento científico. O objetivo final do SCOAP3 é, de fato, o artigo científico, uma forma de troca de conhecimentos que remonta ao século XVII.

2 Disponível em: http://scoap3.org/. Acesso em: 19 jan. 2015. 
Neste caso, o fenômeno central é a remediação, ou seja, a transposição de um meio antigo (o artigo científico publicado por uma revista acadêmica) para uma nova tecnologia (o artigo científico publicado on-line, por revistas científicas baseadas na web) (BOLTER; GRUSIN, 2000). Isso é tudo menos um processo revolucionário. Mas as tecnologias digitais oferecem um espectro muito mais amplo de possibilidades: escrita e design colaborativo (Wikipedia e Linux), sistemas de classificação distribuídos (Amazon e Yelp), análise automática de tendências com base em megadados (Twitter). Enquanto algumas ferramentas e tecnologias semelhantes estão sendo adotadas por outras disciplinas científicas, especialmente a biologia, a mudança parece ser mais lenta do que as rupturas causadas pelas tecnologias digitais em outras indústrias culturais. Por que o campo que inventou a web parece tão lento em adotar as oportunidades que cria? Por que não está mais conduzindo a evolução da Internet?

Alguns ativistas da ciência aberta parecem intrigados com o ritmo lento de mudança, uma vez que dão como certo que "a ciência quer ser aberta." Mas, considerando todas essas variáveis e problemas, é difícil apoiar uma posição que retrata a ciência como teleologicamente dirigida a uma maior abertura. Em nossa opinião, as transformações relacionadas com o surgimento das mídias digitais precisam ser colocadas em uma perspectiva histórica. A ciência aberta não é necessária, mas, sim, uma entre muitas evoluções possíveis dependentes de vários fatores que incluem (e vão além da) evolução e a adoção tecnológica, e até mesmo mudança cultural. Compreensivelmente, a maioria das abordagens da ciência aberta tende a realçar a dimensão de novidade e mudança. Sem negar a importância cultural e a produtividade desses pontos de vista, gostaríamos de salientar que outras perspectivas devem ser consideradas. Aqui esboçamos três questões que, acreditamos, devem ser reconhecidas como problemas centrais por qualquer agenda de pesquisa que analisa a ciência aberta e o impacto das tecnologias digitais 
na produção e circulação do conhecimento científico: a resiliência dos formatos de comunicação ao longo do tempo - neste caso, o artigo científico; o aumento da importância de a ciência manter suas fronteiras sociais; e, finalmente, o posicionamento social mais amplo da pesquisa científica e suas práticas de comunicação.

Em primeiro lugar, devemos considerar que, independentemente das descrições hegemônicas da comunicação científica digital como "revolucionária", a mudança nos meios de comunicação (e, portanto, em sistemas de publicação) muitas vezes mantém um equilíbrio entre continuidade e descontinuidade (BORGMAN, 2007). O conceito de remediação dá conta da evolução das novas tecnologias de mídia, enquanto explica a persistência de formatos de comunicação. Deve esta lição ser aplicada ao artigo científico? Isto é o que a história da comunicação acadêmica parece revelar. Esta ideia é apresentada por estudiosos que analisaram em detalhe o surgimento e a evolução do artigo científico, enfatizando as mudanças no estilo, na organização e na estrutura argumentativa deste tipo de comunicação ao longo do tempo. Mais interessante para o escopo deste trabalho, autores como Gross et al. (2002) especulam sobre a atualidade do artigo científico na era digital, mostrando também que há razões históricas e epistemológicas para explicar sua influência duradoura. Neste cenário, o problema da criação de novas formas de recompensa para práticas como o compartilhamento de dados ou a postagem em blogs pode ser de importância secundária. A centralidade do artigo revisado por pares como produto final da pesquisa científica pode responder à necessidade de comunicar a informação científica complexa de acordo com modalidades de leitura e de aprendizagem estabelecidas. Por exemplo, o principal efeito da digitalização de livros não foi a fragmentação ou a decomposição da leitura, mas, sim, a transposição digital das formas de leitura linear e em profundidade para ambientes que fazem livros fáceis de se portar, socializar ou modificar. Não surpreende, então, que velhas práticas pareçam se inserir em novas 
tecnologias e moldá-las de forma contínua. Por exemplo, os físicos afirmam que o repositório pré-impressão online arXiv, que, desde o seu surgimento no início da década de 1990, tornou-se o principal meio para a circulação de conteúdo acadêmico em uma série de disciplinas, como física e matemática, imita a prática tradicional de envio de pré-publicações de artigos para os colegas em outras universidades. Cópias físicas das pré-publicações eram postadas em quadros de avisos dos departamentos para que professores e alunos pudessem lê-las e, esperava-se, enviar comentários escritos ou críticas. Christopher Kelty argumenta de forma semelhante sobre a biologia sintética de código aberto, ao traçar a árvore genealógica de suas práticas de compartilhamento até os boletins de organismos-modelo (KELTY, 2012).

Em segundo lugar, gostaríamos de destacar a importância das fronteiras do empreendimento científico. Ao longo dos três séculos a partir do nascimento da primeira revista científica, a ciência tem frequentemente confrontado a necessidade de construir e defender a fronteira entre dentro e fora, entre cientistas e não cientistas, entre conhecimento científico e não científico (GIERYN, 1999). Hoje, assistimos a uma renegociação sem precedentes dos limites da autoridade cognitiva da ciência, ou seja, sua capacidade de apresentar-se como depositária do conhecimento; daí a resistência à mudança. De acordo com um crescente corpo acadêmico, o conhecimento científico e os "especialistas" que o representam já não comandam a autoridade inquestionável e a confiança do público, que já lhes foi concedida (MAASEN; WEINGART, 2006). A ciência aberta em rede tem o potencial de promover uma transformação semelhante à que se seguiu à invenção da imprensa. No entanto, este é um processo tortuoso que pode levar décadas até que um novo equilíbrio seja encontrado. No século XVII, a imprensa revelou novas características do conhecimento e tem facilitado transformações sociais e políticas no mundo da pesquisa desde então. O mesmo está acontecendo com a ciência aberta: como o telescópio de Galileu, ela nos mostra 
que o que sabíamos sobre o conhecimento e sua dinâmica pode estar errado. Como observado anteriormente, a ciência da era Gutenberg baseou-se em um produto final, muitas vezes em forma de artigo revisado por colegas e publicado em uma revista acadêmica. Imaginar o processo criativo como uma iniciativa aberta e coletiva pode ser um dos principais obstáculos por trás do ritmo lento da "revolução" da ciência aberta. Os meios digitais e redes, por exemplo, mostram que o conhecimento científico está em uma versão beta perene, nunca concluída e sempre aberta a modificações, e sua produção é composta por um número de diferentes objetos que se caracterizam por uma situação incerta com relação a publicações, tais como conjuntos de dados, computadores, software, etc. Este é o oposto do artigo científico tradicional, que tem um ou mais autores reconhecidos, é estável, e pode ser depositado nas bibliotecas (ou arquivos), onde será discutido e contestado, mas não modificado, incrementado ou melhorado, reforçando, assim, os limites sociais da pesquisa científica.

Finalmente, há razões mais profundas para as dificuldades encontradas pela ciência aberta contemporânea. A dimensão pública da ciência, que surgiu no século XVII, atende às expectativas dos filósofos naturalistas de sucesso econômico e à acumulação de reputação de forma muito melhor do que os modelos "fechados" de circulação da informação. O preço a se pagar é o menor controle sobre o conhecimento produzido. Mas este efeito colateral é aceito porque, em troca, os cientistas naturalistas ganham um novo papel social (e os benefícios correspondentes), adentrando o meio dos ricos e poderosos patronos das cortes europeias (DAVID, 2001). A ironia aparente de tornar amplamente disponíveis os resultados de um trabalho sem qualquer compensação econômica direta pode ser explicado pela crescente sofisticação da matemática e da filosofia naturalista nos séculos XVI e XVII. Os patronos, ansiosos por se valorizar pela proximidade com os melhores estudiosos, não possuíam o conhecimento necessário para compreender e para avaliar sua 
qualidade e, portanto, baseavam suas escolhas em um julgamento coletivo expresso pela comunidade de especialistas. Assim, filósofos naturalistas precisaram adotar novas práticas de intercâmbio, circulação e validação de conhecimentos. Para ser confiável e verificável, o conhecimento deve ser transparente e visível. Isso aconteceu por meio da troca de correspondências, publicação de revistas, comentários e críticas, que foram baseados no sistema de impressão, naquela época em plena ascensão. A inovação tecnológica foi a condição necessária para a passagem de um mundo de conhecimento misterioso e secreto sobre a natureza para um novo modelo público e coletivo de produção científica. No entanto, hoje, como no século XVII, a mudança tecnológica não é a única força por trás de uma transformação geral das práticas de comunicação científica. Em levantamento sobre os obstáculos para a adoção de práticas de ciência aberta, Scheliga e Friesike (2014) destacam o fato de a abertura poder ser vista como um dilema social em que "o que é o melhor interesse coletivo da comunidade científica não é necessariamente o melhor interesse do cientista individual." Enquanto os pesquisadores parecem concordar sobre as repercussões positivas de um processo científico mais aberto, eles também apontam para a necessidade de superar os obstáculos, tanto individuais quanto sistêmicos. Entre os obstáculos individuais, os autores identificam o medo de "parasitismo" e a relutância em revelar partes do processo de pesquisa, tais como resultados negativos. Obstáculos sistêmicos parecem ser apontados como restrições e limitações institucionais, como, por exemplo, a falta de critérios de avaliação adequados para incluir práticas de ciência aberta ou a necessidade de melhor padronização de novas formas de publicação. Em suma, os obstáculos parecem estar relacionados a uma difícil integração da ciência aberta no contrato social da pesquisa científica, mais do que à resistência cultural de estudiosos individuais.

Gostaríamos de encerrar este capítulo analisando, especialmente, a importância crucial dos limites que mantêm a autoridade 
científica e a dos incentivos sociais e econômicos que a determinam. Propomos que a investigação sobre o sistema de comunicação científica e, em particular, sobre a ciência aberta digitalmente mediada incorpore mais explicitamente as preocupações relacionadas ao poder sobre o conhecimento científico e às transformações de contratos sociais da ciência já estabelecidos. A partir desta perspectiva, o surgimento de práticas que renovam o sistema de comunicação científica pode ser visto como uma tentativa de confirmar os limites da ciência, enquanto intervém para superar os problemas relacionados à gestão da comunicação científica - ou seja, o problema de quem a controla e lucra com ela. Por exemplo, os arquivos on-line de pré-publicação ou as iniciativas de acesso aberto, tais como novas revistas ou novos regimes de financiamento para revistas acadêmicas, aparecem como maneiras de construir formas de legitimação pública, que são resgatadas do poder econômico das editoras comerciais. Estas considerações estão relacionadas a avaliações mais abrangentes que apoiam a ideia de uma coevolução dos sistemas de ciência, sociedade e comunicação. O cientificismo tende a representar a sociedade como atrasada em relação à ciência, e os não especialistas como um possível obstáculo à inovação científica e tecnológica. De acordo com este ponto de vista, ciência e sociedade vivem em diferentes domínios e não entendem uma à outra. Pontos de vista similares espelham o ideal das comunidades científicas herméticas e coesas, caracterizadas por uma forte homogeneidade cultural e ética. Este modelo provavelmente nunca refletiu a realidade da prática científica, e seria ainda mais difícil aplicá-lo às profundas mudanças que levaram alguns estudiosos a descrever um "novo contrato" entre ciência e sociedade. Esta nova solução, surgida após o fim da Guerra Fria, é caracterizada por uma configuração social que "afeta a ciência moderna, na sua organização, divisão de trabalho e práticas do dia-a-dia, e também em núcleos epistemológicos" (GIBBONS, 1999). Neste contexto, a inovação científica de hoje se torna uma atividade não determinística, em 
que a relação entre os sistemas e práticas de produção de conhecimento de comunicação é tudo, menos linear.

No entanto, qualquer grande descontinuidade na organização social da investigação científica anda de mãos dadas com uma mudança intelectual e cultural que expressa o desejo de compartilhar conhecimento, muitas vezes independentemente de incentivos econômicos. Para produzir as transformações radicais prefiguradas pela ciência aberta, tanto a mudança cultural quanto a institucional - no século XVII assim como hoje - precisam ser alimentadas e estabilizadas. Meios digitais interativos são a pré-condição para uma transformação da natureza do conhecimento, como a imprensa o foi no século XVII, desde que a ciência seja capaz de definir incentivos materiais e de reputação que possam tornar significativa a sua utilização maciça. Muitas vezes apologistas da ciência aberta atual concentram-se no desejo de uma produção científica mais coletiva e produtiva, negligenciando lógicas econômicas institucionais (TYFIELD, 2013). A história da Revolução Científica nos ensina que os dois caminhos devem convergir, para que a mudança surja. Por exemplo, os novos sistemas de avaliação e de comunicação permitirão que a ciência conserve as formas atuais de legitimação social? Problemas antigos podem surgir em novas formas: como no passado, a ciência aberta mostra uma nova faceta do conhecimento científico. No entanto, o seu surgimento pode ser um processo longo e doloroso.

\section{REFERÊNCIAS}

BOLTER, J. D.; GRUSIN, R. Remediation: understanding new media. Cambridge: MIT Press, 2000.

BORGMAN, C. Scholarship in the digital age. Cambridge: MIT press, 2007.

DAVID, P. From keeping 'nature's secrets' to the institutionalization of 'open science'. Oxford: University Economic and Social History Series 023, Economics Group, University of Oxford, 2001. 
FECHER, B.; FRIESIKE, S. Open science: one term, five schools of thought. In: BARTLING, S.; FRIESIKE, S. Opening science. New York: Springer, 2014. p.17-47. GIBBONS, M. Science's new social contract with society. Nature, n. 402, C81-C84, 1999.

GIERYN, T. Cultural boundaries of science: Credibility on the line. Chicago: University of Chicago Press, 1999.

GROSS, A.; HARMON, J.; REIDY, M. Communicating science: the scientific article from the 17th century to the present. Oxford: Oxford University Press, 2002.

KELTY, C This is not an article: Model organism newsletters and the question of 'open science’. BioSocieties v.7, n.2, p. 140-168, 2012.

MAASEN, S.; WEINGART, P. (Ed.). Democratization of expertise?: exploring novel forms of scientific advice in political decision-making. New York: Springer, 2006.

NIELSEN, M. Reinventing discovery: the new era of networked science. Princeton: Princeton University Press, 2012.

SCHELIGA, K.; FRIESIKE, S. Putting open science into practice: A social dilemma?. First Monday, v.19, n.9, 2014.

TYFIELD, D. Transition to science 2.0: 'Remoralizing' the economy of science. Spontaneous Generations: A Journal for the History and Philosophy of Science, v.7, n.1, p. 29-48, 2013. 



\section{4}

\section{caminho menos trilhado: otimizando para os impactos desconhecidos e inesperados da pesquisa}

Cameron Neylon

Two roads diverged in a wood, and I-

I took the one less traveled by, And that has made all the difference.

Robert Frost - em The Road Not Taken

O OBJETIVO DA ACADEMIA

Para o que é a pesquisa? A que objetivo servem a academia, a universidade, ou o instituto de pesquisa? Essas são questões que evitamos, em parte porque é difícil chegar a um consenso, mas também porque elas requerem um nível de autoexame que é desconfortável. Sondar nossas próprias motivações, bem como as daqueles que nos financiam, pode ser perturbador.

Pode haver ampla concordância na sociedade de que a pesquisa é, de modo geral, algo positivo, mas existe muito pouca concordância sobre o que ela é. Governos orientados para o mercado veem um valor econômico na inovação. Ativistas buscam especialistas acadêmicos para questionar o foco do governo no mercado. Pacientes e suas famílias têm esperança em novos tratamentos, ambientalistas buscam estudos que demonstrem os danos que podem ser causados 
pelas fábricas que produzem esses tratamentos. Tecnólogos podem apontar o valor da ciência em nos ajudar a entender e a domar o mundo natural. Humanistas apontam o valor das humanidades em ajudar-nos a compreendermos a nós mesmos, de modo a evidenciar a necessidade de domar o mundo lá fora.

Um acordo sobre que resultados a pesquisa deveria gerar pode ser difícil. Há aí questões profundas sobre valores. No entanto, deveríamos ser capazes de chegar a um acordo sobre a academia ter responsabilidade com relação àqueles que pagam pela pesquisa. Trata-se da responsabilidade de desempenhar-se bem, segundo aqueles valores. Desempenhar-se bem pode significar eficiência ou eficácia; nem isso é claro. Mas desempenhar-se bem é uma responsabilidade que deveríamos assumir e discutir.

\section{TESTANDO O DESEMPENHO DAS INSTITUIÇÕES}

Criamos instituições para desenvolver pesquisas. Em um mundo perfeito, criaríamos essas instituições com base em valores compartilhados claramente articulados. Usaríamos esses valores para articular uma definição efetiva e útil da missão da instituição que balizaria a avaliação do seu desempenho.

Definições de missão podem ser tentativas pouco claras, mas as melhores são ferramentas úteis para a tomada de decisões estratégicas. Elaborar uma boa definição de missão é um desafio substancial. Particularmente difícil, se não impossível, é articular definições que estimulem avaliações objetivas de desempenho, ainda expressando o conjunto completo de valores compartilhados. Objetivos facilmente mensuráveis e instrumentais sustentam uma avaliação instrumental, que promove o comportamento instrumental - o desempenho conforme a medida, e não conforme a missão.

$\mathrm{Na}$ prática, medimos o que podemos medir, e isso se torna a missão de facto. Em vez de nos perguntarmos se temos um bom 
desempenho na produção de novos conhecimentos e se os estamos transferindo eficazmente para as pessoas que podem usá-los, perguntamo-nos quantos artigos foram publicados e em que revistas acadêmicas. Os problemas do instrumentalismo e da metrificação ingênua na avaliação da pesquisa são bem conhecidos. Não vamos gastar muito tempo com eles, mas devemos ter em mente essas críticas.

\section{ESTRATÉGIAS INSTRUMENTAIS E LIDERANÇA INSTITUCIONAL}

O problema com a métrica não é a métrica em si. Esses proxies, ou indicadores, medem o que medem. O problema surge quando decisões estratégicas são tomadas com base nessas medidas, e não em avaliações de desempenho informadas por uma missão bem definida. O problema não é que o número de artigos, ou o índice $\mathrm{H}$, ou a receita de financiamentos não podem responder a uma pergunta; o problema é que eles não podem dar respostas completas às perguntas que deveriam ser feitas: quão produtivo é um pesquisador, qual a sua influência na comunidade, de que forma contribui para a instituição.

Essas perguntas, e outras que derivariam de uma definição de missão bem elaborada, não têm uma resposta direta. Não vão ser respondidas por um único indicador, nem por uma simples "cesta de medidas". Indicadores e métricas podem apenas ser dados que apóiem a tomada de decisões estratégicas. Com frequência, na busca por uma objetividade ilusória, empregamos medidas quantitativas como forma de evitar a responsabilidade da tomada de decisões.

A principal contribuição de um líder institucional efetivo deve ser a tomada de decisões estratégicas bem embasadas. Apoiar-se em tabelas e métricas, estabelecer patamares ou metas de desempenho são sinais de falta de confiança em sua habilidade de tomar decisões. Os melhores líderes institucionais usarão métricas e 
outros indicadores como dados para auxiliá-los a tomar decisões. Eles não usarão medidas quantitativas para tomar decisões. Eles terão um conjunto variado de dados à mão e a compreensão de como integrá-los para avaliar uma ampla gama de atividades de pesquisa.

\section{PORTFÓlIOS VARIADOS E O CUMPRIMENTO DA MISSÃO}

O impacto futuro da pesquisa é imprevisível, e o investimento envolve risco. A resposta racional para esta situação é diversificar o portfólio. Em cada nível de detalhamento - pesquisador, grupo, departamento, instituição - faz sentido possuir um espectro de diferentes atividades que, em conjunto, otimizem a oportunidade de produzir valor.

O verdadeiro custo do instrumentalismo descrito acima tem sido a homogeneização. As instituições estão todas tentando subir na mesma tabela de classificação, baseada em critérios estreitos. Apenas um pequeno número de instituições de alto prestígio tem autoconfiança para traçar seu próprio caminho. A ironia é que instituições em todo o mundo buscam subir nas classificações para serem iguais a Harvard ou Stanford ou Cambridge, ao passo que estas instituições fazem o que fazem em porque, geralmente, ignoram essas mesmas tabelas.

Ao final, a finalidade da pesquisa científica é uma pergunta que instituições, comunidades, nações e públicos globais devem responder para si mesmos. No entanto, quando as instituições fazem essa pergunta, elas deveriam focar mais naquilo que as torna únicas e não no que as torna uma pálida imitação de Princeton ou Oxford. A diversidade de missão e de foco no nível institucional pode ajudar a cumprir a missão em nível nacional e global, com a criação de um portfólio de perfis institucionais.

A diversidade no nível institucional também abrirá espaço para um espectro mais amplo de pesquisadores, gerando resultados e impactos mais diversificados. Criam-se assim, é claro, desafios aos 
líderes institucionais e à liderança institucional efetiva. Em última instância, o desafio da avaliação é o de desenvolver um conjunto de indicadores suficientemente diverso para apoiar o acompanhamento e gerenciamento de um portfólio tão variado. Talvez mais desafiador ainda seja saber como combinar esses indicadores para embasar uma tomada de decisão efetiva.

\section{IMPACTOS E INDICADORES}

Mesmo reconhecendo que a concordância sobre os valores e a missão do empreendimento de pesquisa é um desafio, será útil, de toda maneira, considerar os diferentes tipos de resultados que podemos almejar e até onde podem ser mensurados. "Impacto" pode parecer um palavrão em alguns círculos acadêmicos, mas é um termo técnico útil.

Há uma variedade de definições utilizadas, mas no atual contexto usarei um significado que busca expandir aquele usado pelo Conselho de Pesquisa Australiano (Australian Research Council) ${ }^{1}$, do Conselho de Pesquisas do Reino Unido (Research Councils $\mathrm{UK})^{2}$, incluindo o escopo traçado pelo projeto da LSE (London School of Economics) de Impacto das Ciências Sociais (LSE Impact of Social Sciences Project) ${ }^{3}$ : a mudança no mundo que resulta da difusão dos resultados da pesquisa. Podemos falar de diferentes formas de impacto, inclusive impactos econômicos, como a criação de empregos, mas certamente sem parar aí. Podemos também considerar impactos nos campos de políticas, legislação, educação, cultura, meio ambiente e saúde. Incluo explicitamente

\footnotetext{
1 Disponível em: http://www.arc.gov.au/research-impact-principles-and-framework\#Definition . Acesso em: 21 jun. 2015

2 Disponível em: http://www.esrc.ac.uk/funding-and-guidance/impact-toolkit/what-how-and-why/what-is-research-impact.aspx . Acesso em: 21 jun. 2015

3 Disponível em: http://blogs.lse.ac.uk/impactofsocialsciences/introduction/ . Acesso em: 21 jun. 2015
} 
impactos em atividades de pesquisa, bem como "impactos mais amplos".

De novo, a priorização de diferentes tipos de impacto é uma questão a ser discutida pela comunidade, mas podemos admitir que esses impactos dependem de os resultados de pesquisa serem disseminados para aqueles lugares onde podem ser aplicados. Os resultados podem ser conceitos, habilidades, novas tecnologias ou abordagens, ou podem ser pessoas. Haverá diversidade de resultados, de impactos e de trajetórias que os unam.

Figura 1 - Diversas formas de impacto da pesquisa

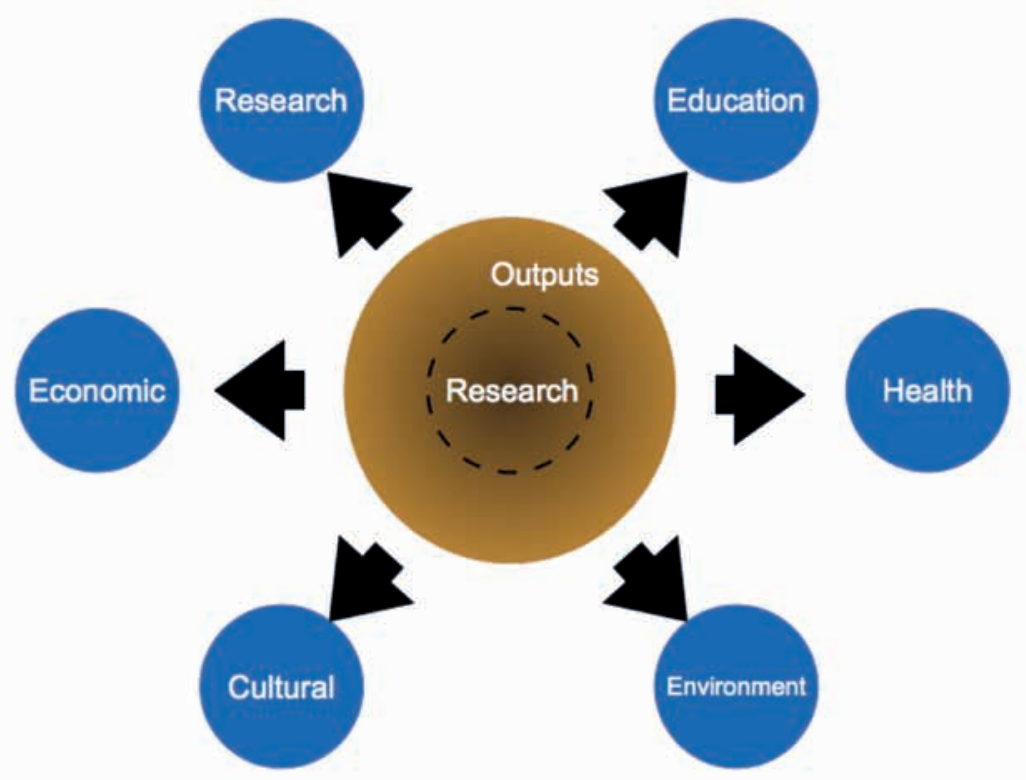

Essas diversas categorias de efeito têm pouco em comum, estando ligadas apenas pelo processo de pesquisa que leva a elas. A pesquisa é transmitida através dos resultados (apesar de esta distinção estar se tornando mais porosa, como indicado pelas linhas pontilhadas) e, através de algum processo, transforma-se em efeitos e em impactos. 


\section{PROXIES, INDICADORES E SEUS SIGNIFICADOS}

O que queremos, em última instância, é maximizar os impactos; mas, na prática, eles quase nunca podem ser medidos diretamente. Os resultados, por contraste, tendem a ser mais fáceis de acompanhar e de medir. Nosso foco tradicional em artigos de pesquisa e nas referências a eles é motivado, pelo menos em parte, pela facilidade de acompanhamento e de quantificação.

Se focarmos no impacto da pesquisa como um exemplo, nosso objetivo será medir a mudança em pesquisas futuras que resultam de um dado projeto, de um dado resultado/produto, ou do trabalho de um pesquisador. O que temos medido tradicionalmente é a produtividade em publicações e citações. Com toda a diversidade potencial de impactos e resultados possíveis, nossa percepção ficou restrita quase que totalmente a esses dois conjuntos de proxies. Não se trata apenas de a mensuração e o instrumentalismo serem problemáticos em si mesmos, mas de nosso campo de visão ficar terrivelmente limitado.

O movimento da pesquisa online e a maior disponibilidade de informação em geral sobre o empreendimento da pesquisa forneceram novos proxies, que têm o potencial de oferecer uma visão mais rica (NEYLON; WU, 2009; PRIEM et al. 2010). Somos capazes de acompanhar discussões e utilizar a pesquisa em um espectro muito maior de lugares, da mídia social à tradicional, através de serviços de favoritos e de fontes secundárias, tais como a Wikipedia e documentos de legislação. 
Figura 2 - O conjunto crescente de indicadores e proxies que podem ser úteis à mensuração das trajetórias do impacto da pesquisa em pesquisas futuras. No passado, tínhamos apenas as publicações e citações para trabalhar.

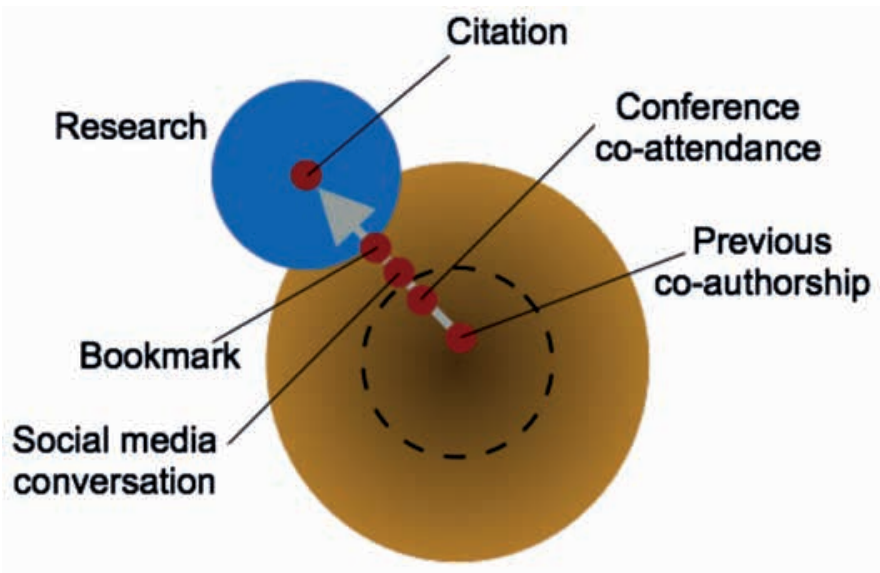

Esta variedade mais rica de dados tem o potencial de oferecer uma visão muito mais diversificada do fluxo de conhecimentos e de embasar uma diversidade mais ampla de atividades. Ao mesmo tempo, há sempre questões sendo levantadas com relação ao significado dessas mensurações. Um tuíte pode nos dizer tanto quanto uma citação? As inclusões nos favoritos do Mendeley significam que alguém de fato leu o artigo? A cobertura da mídia tradicional necessariamente significa que a pesquisa é boa, útil ou importante?

\section{CONTANDO PROXIES OU CONTANDO HISTÓRIAS}

Uma objeção levantada com frequência em relação a qualquer medida quantitativa, inclusive as citações, é que a contagem é ilusória. Esta objeção aparece na forma de uma afirmação do tipo "as citações também podem ser negativas" ou "a popularidade não é indicativa de impacto". Essas críticas adquirem mais peso quando 
observamos proxies tais como downloads ou menções nas mídias sociais, com relação aos quais os números podem ser grandes e a popularidade (parece que) desempenha um papel importante.

Uma forma mais produtiva de usar esses proxies pode ser usá-los para descobrir e contar histórias. No caso das mídias sociais em particular, os números costumam ser traiçoeiros, dados os efeitos do reforço. É importante investigar quem está falando a respeito da produção de determinada pesquisa e o que estão dizendo (bem como para quem o dizem).

Por exemplo, uma história que gosto de contar diz respeito ao Twitter. Estava investigando trabalhos publicados pela Universidade da Cidade do Cabo no PLOS, usando dados do serviço de PLOS Article Level Metrics, bem como do serviço altmetric.com, que fornece informação sobre a geolocalização de tuítes. Havia muito poucos tuítes sobre esse conjunto de trabalhos originados na África do Sul. No entanto, um dos trabalhos (JEWKES et al. 2011) destacou-se por ter menções de origem sul-africana.

Esse trabalho versava sobre a relação entre a situação do HIV e a violência doméstica. Em particular, as referências eram feitas a centros de atendimento à mulher, clínicas de saúde sexual e centros de apoio para minorias sexuais. Além disso, pude identificar as referências específicas e a pessoa que estava disseminando essa pesquisa para lugares onde ela poderia ser aplicada diretamente. A contagem de tuítes não foi muito útil nesse caso, mas a identificação de quem estava por trás deles contava uma história poderosa.

No entanto, há um sentido em que tanto as objeções à métrica quantitativa quanto a habilidade de contar histórias expõem a falácia básica do modo como pensamos a respeito de métricas velhas e novas. Em todo esse texto, tomei o cuidado de me referir a medidas como proxies ou "indicadores". Com frequência, as objeções, tanto com relação a "significados" como em relação à quantificação, surgem devido a um pressuposto de que o que importa é a métrica em si. Claro está que isso nunca é verdade; o que conta não são as 
citações, mas a influência que elas representam; não são as menções nas mídias sociais, mas a maneira como essas menções nos informam sobre as comunidades que usam a pesquisa; não são os downloads, e sim o que eles indicam sobre o uso da pesquisa.

Todas essas medidas são apenas proxies ou representantes das coisas que realmente importam; mas, em muitos casos, não são nem mesmo isso: são indicadores do fluxo de conhecimento. É mais útil, talvez, pensar que são luzes que acendem quando o conhecimento passa por um determinado ponto em seu trajeto. As mesmas luzes podem resultar de diferentes trajetos, e o conhecimento pode fluir através de diferentes caminhos com o mesmo destino.

Figura 3 - Uma imagem figurativa dos caminhos de transferência do conhecimento (setas) e os sinais que surgem (pontos vermelhos)

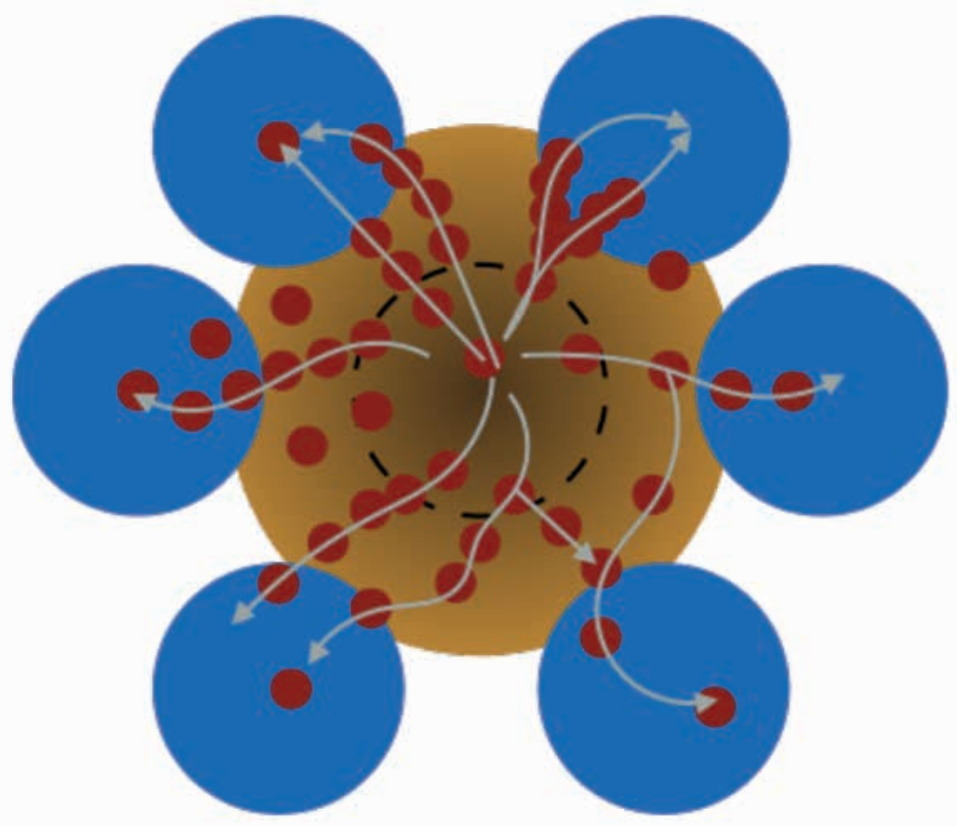


As palavras observáveis são apenas os pontos vermelhos; a maioria de nossos sistemas de avaliação das pesquisas se baseia em apenas dois desses pontos: citação e publicação.

Podemos pensar sobre o trajeto do impacto como um conjunto de fluxos, no qual o fluxo propriamente dito é invisível. Tudo o que temos são indicadores que assinalam partes desse fluxo. Fica claro que é apenas combinando múltiplas medidas que podemos identificar um trajeto específico. A pobreza de nossas medidas tradicionais também fica evidente: uma ou duas luzes piscando em um único (suposto) trajeto nos informa(m) pouco ou nada de útil. Por fim, a questão "o que significa essa métrica?" desaparece. A métrica não significa nada isoladamente, é um indicador, é meros dados que, combinados com outros, podem nos ajudar a compreender os trajetos pelos quais um dado conhecimento é disseminado.

Podemos também integrar a visão narrativa com a visão quantitativa. As histórias são instâncias de fluxo de conhecimento por diversos trajetos. A análise quantitativa de indicadores pode nos ajudar a entender os fluxos totais e seus trajetos, bem como a identificar instâncias específicas desse fluxo. A história relatada anteriormente é apenas um exemplo rudimentar desse tipo de análise, mas abordagens mais sofisticadas são certamente possíveis.

\section{O CAMINHO MENOS TRILHADO, O CAMINHO DESCONHECIDO}

Este modelo de trajeto é potencialmente muito poderoso. Primeiro, ele nos ajuda a evitar a falácia de que uma métrica contabilizável é o que importa. Em seguida, nos oferece um caminho para abordagens analíticas mais sofisticadas que não assumem algum conhecimento prévio do que são os trajetos. Isto traz o potencial da analítica de "grandes dados" ao problema de identificação e mapeamento dos trajetos. 
Este é superficialmente semelhante a muitos outros modelos de como a pesquisa gera impacto. A maioria dos modelos descreve ou busca trazer à tona algum tipo de trajeto ou trajetos. O Becker Model of Impact para as ciências biomédicas foca em formas específicas de impacto e identifica indicadores que se encontram no caminho de cada um deles (BERNARD BECKER MEDICAL LIBRARY, s/d). O modelo Payback e a ferramenta BRIDE, desenvolvida a partir dele (SCOBLE et al., 2010), têm um modelo conceitual semelhante. Muitos desses modelos apoiam-se na teoria de difusão da inovação, que é em si um modelo linear (WALTER et al., 2013).

Mesmo naquelas abordagens em que participantes e atores sociais estão engajados na definição de impactos desejados, como na abordagem "Análise Participativa de Trajetos de Impacto" (Participatory Impact Pathways Analysis) (STEPs CENTER, s/d), o foco é definir os trajetos que existem ou que são desejáveis, para monitoramento futuro. No conjunto, os modelos e metodologias existentes assumem que há trajetos conhecidos (ou passíveis de serem descobertos), lineares de modo geral, pelos quais o conhecimento ou insight fluem para gerar impactos.

Isso leva a modelos de avaliação em que diversos indicadores estão ligados a impactos específicos e, portanto, a trajetos específicos. Eles desenvolvem abordagens matriciais em que, ao medir a presença de indicadores específicos - às vezes por abordagens quantitativas, às vezes qualitativas - alguns impactos específicos (ou seu potencial futuro) tornam-se evidentes. Por sua vez, as mesmas matrizes podem ser usadas para otimizar a disseminação e assim maximizar aqueles impactos desejados.

\section{UM MODELO dE “CAMINHOS OCULTOS” DE FLUXOS DE CONHECIMENTO A IMPACTOS DA PESQUISA}

Contrastando com esses modelos lineares e explícitos, o modelo desenvolvido na seção anterior pressupõe que os trajetos são 
desconhecidos e, provavelmente, altamente ramificados. Há um foco implícito em indicadores mais granulares e, até certo ponto, mais quantificáveis, por oposição a indicadores ou evidência qualitativos e narrativos. Por fim, há um requisito implícito de que os indicadores sejam ligados a eventos, ou seja, que possam ser marcados no tempo.

Formalmente, esse modelo de trajetos ocultos é descrito como um conjunto de canais (indicadores) mensuráveis nos quais é possível medir sinais. Esses sinais indicam processos (fluxos de conhecimento ao longo de trajetos definidos). Os sinais podem ser concebidos como foguetes ou luzes piscantes, que indicam quando uma transferência particular de conhecimento está ocorrendo ao longo do trajeto. Qualquer indicador pode estar atrelado a um, a muitos ou a nenhum dos trajetos. Os trajetos em si não podem ser observados, apenas inferidos.

Figura 4 - Padrões de sinais a partir de processos subjacentes diferentes

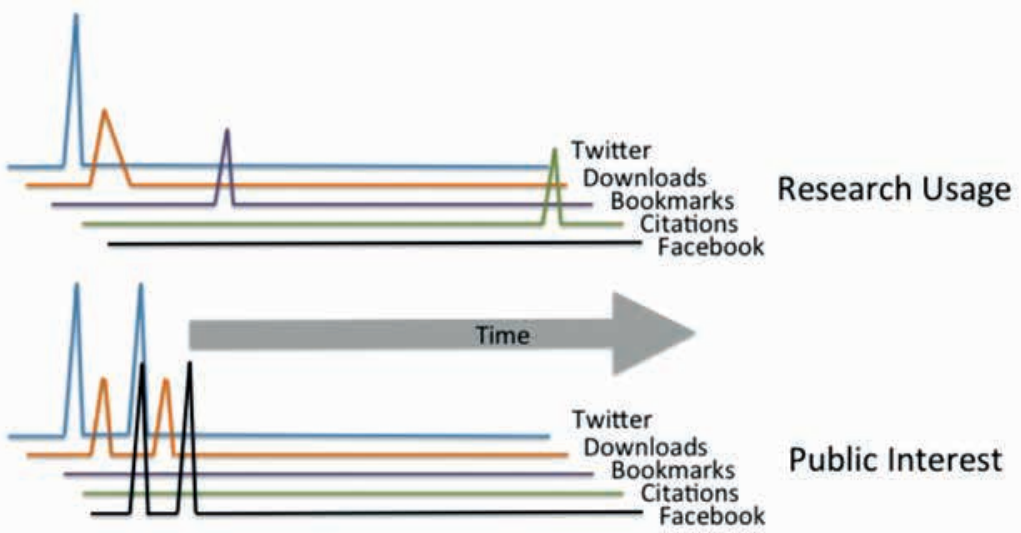

Ambos os processos levam a sinais do Twitter e canais de downloads, mas o uso para pesquisa também mostra atividade posterior em Favoritos e citação. $\mathrm{O}$ interesse público mostra 
maior correlação com o Facebook, bem como uma correlação mais estreita com o domínio do tempo. Os padrões de sinais são hipotéticos, baseados em observação não quantitativa de conjuntos específicos de dados.

A maneira de inferir um trajeto é identificar padrões de sinais que ocorrem em conjuntos de indicadores (canais de sinais). Por exemplo: um trajeto hipotético de "transferência de conhecimento acadêmico" pode incluir um tuíte (pelo qual um acadêmico descobre um trabalho), um download ou leitura, uma inclusão em Favoritos seguida de citação na literatura formal. O impacto em um grupo de pacientes pode começar do mesmo lugar (tuíte, download) e se ramificar numa conversa no Facebook, seguida de postagens no mural de um serviço focado em pacientes.

É claro que todos esses processos ocorrem ao mesmo tempo, gerando padrões de sinais complexos que precisam ser desembaraçados. De modo geral, isso implica o uso de métodos de probabilidade máxima para modelar distribuições de probabilidade de conjuntos de processos possíveis que expliquem os padrões de sinais observados. Essencialmente, o objetivo é abarcar os conjuntos de dados mais amplos disponíveis, de forma a caracterizar o problema como sendo de processamento de sinais de domínio do tempo. Há métodos analíticos poderosos da engenharia e de outras disciplinas, desenhados para lidar exatamente com esse tipo de problemas: tentar desembaraçar processos subjacentes múltiplos que geram sinais complexos em canais múltiplos.

\section{MaPEANdo tRajeTOS DESCONHECIDOS}

A vantagem dessa abordagem conceitual é que ela gera o potencial não apenas de se identificar fluxos de conhecimento pelos caminhos que acreditamos conhecer, mas também de permitir que surjam novos caminhos. Em vez de assumir a existência de trajetos 
específicos ou de buscar trazê-los à tona através de conversas com grupos de interesse, a abordagem possibilita partir do pressuposto de que há fluxos de conhecimento dos quais ninguém tem consciência e tentar descobri-los.

Não há certeza de que isso seja possível na prática. Tais abordagens requerem grandes quantidades de dados com informação de tempo de alta qualidade. Apesar da quantidade de dados que possuímos estar certamente aumentando, não está claro se ela é suficiente para fazer surgir novos trajetos. Mesmo que tenhamos os dados, a qualidade de informação de tempo é geralmente insatisfatória. Para os tuítes, podemos utilizar uma marca de tempo, mas dados de download de artigos apresentam resolução de tempo muito variável, e são coletados de forma diferente por organizações diferentes. Ao tentarmos esse tipo de análise, precisamos identificar as falhas em nossos dados.

Um efeito colateral da análise que busca identificar os processos subjacentes em andamento é que há também o potencial de detectar sinais que surgem de processos não relacionados aos impactos desejados. Tais sinais podem incluir erros ou problemas na coleta ou processamento de dados, ou podem refletir tentativas de manipular a métrica. Já sabemos, por exemplo, que sinais potentes em um determinado canal (tal como downloads), que não estão correlacionados com sinais de outros canais (tais como inclusões em Favoritos ou tuítes), indicam manipulação.

Esta abordagem apresenta três pontos fracos. O primeiro, discutido acima, é a dependência da escala e da qualidade dos dados. $\mathrm{Na}$ prática, talvez só possamos distinguir as correlações de sinais mais fortes, e assim não conseguirmos identificar os caminhos desconhecidos que desejaríamos. O segundo é que, claramente, os caminhos propriamente ditos estão mudando a cada momento. Isto complica a análise e, apesar de não impossibilitá-la, aumenta ainda mais a exigência de escala e de qualidade de dados para se obterem novos insights. Em um mundo ideal, o melhor seria ter um conjunto de 
dados em um ambiente estável. A ironia, claro, é que estamos interessados na análise precisamente porque o ambiente não é estável.

A última fraqueza é a mais importante. Essas abordagens não conseguem identificar os trajetos reais. Podemos apenas inferir que um caminho que podemos descrever qualitativamente corresponde a um modelo probabilístico de correlações de sinais. De forma geral, essa análise não pode fornecer evidência direta do impacto propriamente dito. Os sinais indicam processos subjacentes, não mudanças na palavra. Para usar essas análises de forma a entendermos ou otimizarmos o impacto, precisamos inseri-la numa prática social, o que nos remete à necessidade de articular valores.

\section{GERENCIAMENTO E ARQUITETURA RESPONSÁVEIS DO EMPREENDIMENTO DE PESQUISA}

O foco desse modelo de transferência de conhecimento por trajetos ocultos está na exploração de uma capacidade analítica técnica para melhor entender e otimizar os trajetos que levem a impactos de pesquisa. É fundamentalmente tecnológico. No entanto, comecei com algo que é fundamentalmente uma questão social de responsabilidade e valores. Como juntar essas duas coisas?

Para mim, a ligação se faz pela liderança, pelo gerenciamento e o desenho institucional. Na prática, a discussão sobre quais são os valores compartilhados para o empreendimento de pesquisa é contínua. Esses valores vão evoluir e mudar na medida em que as necessidades das comunidades mudarem e que nossa capacidade de lidar com elas mudar também. Tenho como pressuposto que uma forma de abordar tanto essa questão da mudança e da incerteza como a da imprevisibilidade de resultados das pesquisas é abraçar a diversidade em vários níveis. A diversidade de objetivos, de habilidades, de produção, e de agendas de pesquisa tem o potencial de proteger tanto as capacidades, como a agilidade de resposta às 
necessidades cambiantes, além de fornecer controles que podem ser ajustados para otimizar os impactos.

A característica definidora da pesquisa é a imprevisibilidade. Se soubéssemos a resposta, não precisaríamos pesquisar. É praticamente impossível escolher vencedores. Isso torna imperativo o planejamento de nossas instituições no nível dos sistemas. As decisões sobre projetos individuais, nomeações ou formas de disseminação serão sempre apostas informadas. Mas podemos ajustar os processos pelos quais tomamos essas decisões para otimizar o resultado médio. É perfeitamente possível desenhar um circuito elétrico sem saber que trajeto um elétron individual vai percorrer.

Um desafio central para o desenho desses sistemas é o de otimizar a possibilidade de resultados e impactos inesperados, trajetos inesperados para o impacto. É uma crença dos pesquisadores de que os insights mais importantes resultam de acasos felizes. No entanto, focamos quase que exclusivamente em formas conhecidas de comunicação para públicos específicos e conhecidos, definidos por revistas específicas. Na verdade, nem ao menos sabemos quanto impacto uma pesquisa causa nos lugares esperados versus os inesperados. Tentamos medir o impacto esperado (ou, mais estritamente, o progresso em sua direção) através de um conjunto de proxies terrivelmente estreitos - embora em expansão - que são completamente inadequados para a tarefa; mas eu defendo que temos a responsabilidade de também tentar maximizar o inesperado.

O modelo dos caminhos ocultos que descrevi aqui busca lidar com a ausência de dados que deveria preocupar um líder institucional responsável. Mas, ao tratar dessa questão, o modelo também retira toda tranquilidade que possa derivar da mensuração do progresso pelas classificações ingênuas e simplistas que atualmente caracterizam a tomada de decisões institucional.

Estas classificações simples são confortavelmente normativas: as mais altas são "boas"; as mais baixas são "ruins". Todos concordam, mesmo aqueles que se opõem radicalmente às classificações 
em si. No modelo focado em caminhos a impactos diversos, não há "alto" ou "baixo", não há posições normativas sobre quais impactos são melhores ou mais importantes. Essas não são nem mesmo decisões que os líderes possam tomar, já que envolvem comunidades inteiras.

A responsabilidade dos líderes torna-se, portanto, maior e, em muitos sentidos, a liberdade de ação diminui. Um líder é um curador das discussões que articulam esses valores, o guardião e o zelador de uma definição de missão útil, e um engenheiro que deve constantemente tentar ajustar milhares de contextos para otimizar-lhes a importância.

Este talvez não seja o conjunto de habilidades que caracteriza a atual geração de líderes institucionais, mas é um conjunto estreitamente alinhado com gestores bem sucedidos de comunidades online. Talvez seja necessário o surgimento de uma nova geração mas, por sua vez, as instituições do futuro serão aquelas bem sucedidas em um mundo da comunicação online. Este pode ser, de fato, o caminho menos trilhado, mas, com sorte, ele pode fazer toda a diferença para o futuro de um empreendimento de pesquisa bem sucedido, integrado à comunidade e responsável.

\section{REFERÊNCIAS}

AUSTRALIAN RESEARCH COUNCIL. Research impact principles and framework. [online]. Disponível em: http://www.arc.gov.au/research-impact-principles-and-framework\#Definition. Acesso em: 20 jun. 2015

BERNARD BECKER MEDICAL LIBRARY. Assessing the impact of research - How to use the model. [online]. Disponível em: https://becker.wustl.edu/impact-assessment/how-to-use. Acesso em: 20 jun. 2015

ECONOMIC AND SOCIAL RESEARCH COUNCIL (UK). What is research impact. [online]. Disponível em: http://www.esrc.ac.uk/funding-and-guidance/impact-toolkit/what-how-and-why/what-is-research-impact.aspx. Acesso em: 20 jun. 2015 
FROST, Robert. The road not taken. In: FROST, Robert. Mountain interval. selected poems. [S.l.: s.n.] 1920. Disponível em: http://www.poets.org/poetsorg/ poem/road-not-taken. Acesso em: 21 jun. 2015.

JEWKES, R.; SIKWEYIYA, Y.; MORRELL, R.; DUNKLE, K. The relationship between intimate partner violence, Rape and HIV amongst South African Men: a cross-sectional study. PLoS One, v.6, n.9, p. e24256, 2011. doi:10.1371/journal. pone.0024256.

LONDON SCHOOL OF ECONOMICS. The impact blog - introduction. [online]. Disponível em: http://blogs.lse.ac.uk/impactofsocialsciences/introduction/. Acesso em: 20 jun. 2015

NEYLON, C.; WU, S. Article-level metrics and the evolution of scientific impact. PLoSBiol, v.7, n.11, p. e1000242, 2009. doi:10.1371/journal.pbio.1000242.

PRIEM, J.; TARABORELLI, D.; GROTH, P.; NEYLON, C. Altmetrics: a manifesto. [online]. [S.1.][s.n.] 2010. Disponível em: http://altmetrics.org/manifesto/.Acesso em: 20 jun. 2015

SCOBLE, R.; DICKSON, K.; FISHER, J.; HANNEY, S. Research impact evaluation, a wider context: findings from a research impact pilot. [online]. [S.1.][s.n.] 2010. Disponível em: http://bura.brunel.ac.uk/handle/2438/4149. Acesso em: 20 jun. 2015

STEPS CENTRE. Participartory Impact Pathways Analysis (PIPA). [online]. Disponível em: http://steps-centre.org/methods/pathways-methods/vignettes/pipa/. Acesso em: 20 jun. 2015

WALTER, I.; NUTLEY, S.; DAVIES, H. Research impact: a cross sector review - literature review. [online]. [S.1.][s.n.] 2003. Disponível em: www.ruru.ac.uk/pdf/LSDA\%20literature\%20review\%20final.pdf. Acesso em: 20 jun. 2015 



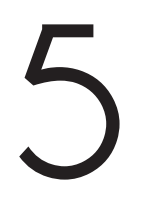

\title{
O que é ciência aberta e colaborativa, e que papéis ela poderia desempenhar no desenvolvimento?
}

\author{
Leslie Chan, Angela Okune e Nanjira Sambuli
}

INTRODUÇÃO

Este capítulo apresenta os contextos e a base lógica para a criação da Rede de Ciência Aberta e Colaborativa sobre Desenvolvimento (OCSDNet - Open and Collaborative Science in Development Network), um projeto de pesquisa e prática de três anos co-financiada pelo Centro de Pesquisa em Desenvolvimento Internacional (IDRC - International Development Research Centre) no Canadá e pelo Departamento de Desenvolvimento Internacional (Department of International Development), no Reino Unido.

Lançada em julho de 2014, a rede é coordenada juntamente pelo iHub - Nairobi's Innovation Hub, com base em Nairobi, Quênia, e pelo Centro de Estudos Críticos em Desenvolvimento (Centre for Critical Development Studies) da Universidade de Toronto Scarborough no Canadá. Ela é apoiada por uma equipe internacional de especialistas, conhecidos praticantes da ciência aberta e pesquisadores de políticas. O capítulo também descreve o enquadramento organizacional da OCSDNet, bem como a maneira como ela pretende mobilizar e apoiar pesquisadores e praticantes do Sul Global por meio de um processo de estágios múltiplos de construção de rede. 
Estas ações visam apoiar o objetivo mais abrangente do projeto, que é investigar se, e sob quais condições, um conjunto de práticas de ciência aberta poderia levar a novas práticas e formas de pensar o desenvolvimento e seus resultados.

Também delineamos as estratégias adotadas pela equipe da OCSDNet para atingir os objetivos mais específicos do projeto, que são: a formulação de uma série de perguntas de pesquisa sobre a natureza e os pressupostos da ciência aberta; e o apoio a uma comunidade de praticantes da ciência aberta no Sul Global, cujas pesquisas e práticas aprofundarão nossa compreensão dos princípios e impactos da pesquisa aberta e da co-criação de conhecimento.

É comum na literatura caracterizar-se a ciência aberta como processos que envolvem o compartilhamento de planos de pesquisa, dados e publicações, ciência cidadã participativa, formas crowdsourced de coleta de dados (RIN/NESTA, 2010; THE ROYAL SOCIETY, 2011; FRANZONI; SAUERMANN, 2014), e novas formas de colaboração científica internacional, tornadas possíveis por tecnologias em rede e produção peer-to-peer (NIELSEN, 2011; KOCAREV; IN, 2010; BARTLING; FRIESIKE, 2013). Um exemplo comum é o Projeto Genoma Humano, no qual o compartilhamento aberto e rápido de dados com sequências de genes e proteínas pela Internet facilitou enormemente sua realização em tempo recorde, com impactos múltiplos em cascata (WADMAN, 2013). Da mesma forma, crowdsourcing foi usado para monitorar o desflorestamento no Brasil e na Indonésia ${ }^{1}$, a violência política no

1 Disponível em: http://www.crowdsourcing.org/editorial/crowdsourcing-to-help-brazilian-ngo-monitor-deforestation /16207 Acesso em 19 jun. 2015. E disponível em: http://bigideas.berkeley.edu/wp-content/uploads/2014/11/Curtailing_Deforestation_in_Indonesia-Improving_Forest_Mapping_and_Monitoring_using_Drones_Technology-.pdf Acesso em 19 jun. 2015. 
Quênia, desastres naturais no Haiti e no Paquistão e a violência de gênero no Egito $^{2}$.

No entanto, ainda não se entende com clareza como esses mecanismos desafiam e enriquecem sistemas tradicionais de pesquisa; nem como novas colaborações e instituições tornadas possíveis pelas redes poderiam levar a mudanças mais justas e inclusivas na produção e no compartilhamento de conhecimentos no Sul Global. A intenção da OCSDNet é examinar de maneira crítica alguns pressupostos comuns a respeito da ciência aberta e seu pretenso impacto no desenvolvimento, e começar a juntar indícios dos efeitos, tanto positivos quanto não intencionais, das práticas de construção de conhecimento possibilitadas pelas redes. No longo prazo, o projeto pretende gerar um enquadramento conceitual mais rico sobre as interações complexas da ciência aberta em diversos contextos institucionais. Também pretende estimular diálogos sobre o pensamento e a formulação de políticas em apoio a práticas emergentes, documentadas por projetos de pesquisa dentro da rede.

\section{HISTÓRICO E FUNDAMENTAÇÃO}

\section{CONVERGENCIA DE ABERTURA}

A característica fundamental da ciência é que os resultados da pesquisa científica devem ser tornados públicos para permitir construções futuras do conhecimento. De fato, o progresso da ciência depende do acesso a compreensões e contribuições anteriores de cientistas ao reservatório comum do conhecimento. $\mathrm{Na}$ era $\mathrm{Gu}-$ tenberg, a divulgação da ciência era feita principalmente através da publicação de artigos sobre pesquisas em revistas acadêmicas. No entanto, à medida que o empreendimento de publicações científicas

2 Disponível em: Harass Map http://harassmap.org/en/ Acesso em: 19 jun. 2015 
passou a ser dominado por interesses comerciais devido ao alto lucro que poderia ser obtido, os frutos da ciência tornaram-se cada vez menos públicos, passando a ser desfrutados apenas por aqueles indivíduos e organizações suficientemente privilegiados para poder arcar com o crescente custo de acesso (CHAN; COSTA, 2005; CHAN et al., 2011).

A Internet introduziu mudanças profundas na natureza pública e aberta da comunicação científica. Assim, a Iniciativa de Acesso Aberto de Budapeste (Budapest Open Access Initiative, 2002) inicia-se com a afirmação: "Uma tradição antiga e uma nova tecnologia convergiram para possibilitar um bem comum sem precedentes"3. A tradição antiga refere-se à boa vontade de acadêmicos e cientistas em compartilhar gratuitamente os frutos de suas pesquisas para favorecer a investigação e o conhecimento, visando o bem público. A nova tecnologia é, naturalmente, a Web, com sua arquitetura peer-to-peer e base de tecnologia aberta. Durante a última década, ferramentas e redes abertas permitiram o florescimento dos movimentos de abertura em diversos domínios: iniciativas, em todo o mundo, de acesso aberto e de recursos educacionais abertos, de dados abertos e de governos abertos, de inovações abertas e de desenvolvimento aberto ${ }^{4}$.

Fazendo uso de princípios de código aberto e produção entre pares, essas iniciativas abertas também compartilham uma trajetória histórica, a de terem começado como movimentos de base em contextos localizados, mas expandindo-se mundialmente com grupos de interesse e participantes cada vez mais diversos, e, ainda, sendo cada vez mais apoiadas e, de fato, defendidas por

3 "An old tradition and a new technology have converged to make possible an unprecedented public good." Disponível em: http://www.budapestopenaccessinitiative.org/read Acesso em 19 jun. 2015

4 Ver, por exemplo, os diversos capítulos no livro vivo Open Science editado por Bartling e Friesike (2014); diversos capítulos sobre abertura no livro Open Development editado por Smith e Reilly (2014); um longo ensaio sobre inovação aberta por Foray (2013). 
financiadores e formuladores de políticas, tanto em nível local como no internacional ${ }^{5}$.

No caso do acesso aberto, o apoio de financiadores e formuladores de políticas nacionais e multilaterais se baseia na evidência emergente de que a abertura de resultados da pesquisa financiada aumenta muito o retorno do investimento em pesquisa, não apenas em termos econômicos (HOUGHTON et al., 2009; HOUGHTON; sWAN, 2013), mas também na criação de novas formas de impacto social e político (JOSEPH, 2013). Estas podem incluir novas oportunidades de empreendedorismo, de participação de cidadãos em processos políticos e de novas formas de colaboração inclusiva, todas constituindo benefícios potenciais para além dos objetivos originais do financiamento.

De maneira semelhante, em alguns países de renda baixa e média (LMICs - low- and middle-income countries), a rápida adoção e profunda penetração de tecnologias móveis estão possibilitando o acesso a serviços bancários e de saúde, a recursos de aprendizagem e a plataformas importantes de compartilhamento de informação. Essas oportunidades têm o potencial de empoderar cidadãos que anteriormente não desfrutavam de tais formas de acesso e participação (FUCHS; ELDER, 2013).

\footnotetext{
5 Para uma história sucinta do crescimento e da convergência de diversos movimentos de base para abertura de bens comuns (commons), ver Bollier (2008). Nos níveis regional e nacional, políticas sobre ciência aberta estão sendo, na atualidade, ativamente formuladas pela Comissão Europeia como parte de uma Agenda Digital para a Europa. Disponível em> <http://ec.europa.eu/commission_2010-2014/kroes/en/blog/open-science>, Acesso em 19 jun. 2015 a Fundação Nacional de Ciência (National Science Foundation) nos Estados Unidos tem uma longa história de apoio ao compartilhamento de dados de pesquisas financiadas com recursos públicos. Disponível em: <http://www.nsf.gov/bfa/dias/policy/ dmp.jsp>. Acesso em: 19 jun. 2015
} 


\section{DESENVOLVIMENTO ABERTO}

Em todas essas iniciativas abertas, há um consenso crescente de que regimes tradicionais de propriedade intelectual (PI) de restrição e proteção máximas não apenas sufocam a inovação, mas também restringem e limitam a participação daqueles com meios e poder político limitados (DE BEER et al., 2014). Diversos acadêmicos (e.g. BOYLE, 2009; DRAHOS; BRAITHWAITE, 2002; SHAVER, 2015; KIRCHSCHLAEGER, 2013) sugerem que o direito à ciência e à cultura requer uma visão da inovação e difusão do conhecimento, como bens públicos, em vez da prática corrente de proteção à propriedade intelectual, reconfigurando assim a agenda de acesso ao conhecimento como uma exigência de atendimento a direitos fundamentais (DONDERS, 2011).

Excluir indivíduos da oportunidade de aproveitar os frutos e benefícios da investigação científica também é percebido como uma questão de justiça social, na medida em que viola os direitos fundamentais do indivíduo, proclamados na Declaração Universal de Direitos Humanos de $1948^{6}$ e no Acordo Internacional de Direitos Econômicos, Sociais e Culturais adotado pela Assembleia Geral da ONU7 em 1966 (Nações Unidas, 1966). O entendimento do acesso ao conhecimento científico e à participação na ciência como um direito humano contraria a tendência de ver a ciência e o desenvolvimento principalmente através de uma lente macroeconômica, oferecendo uma alternativa importante ao paradigma de desenvolvimento das últimas décadas centrado na economia, com foco exclusivo no crescimento econômico (ESCOBAR, 1995; STIGLITZ et al., 2010; STIGLITZ, 2012).

6 Disponível em: http://www.un.org/en/documents/udhr/ . Acesso em: 1 Setembro 1, 2014

7 Disponível em: http://www.ohchr.org/EN/Professionallnterest/Pages/CESCR.aspx . Acesso em: 1 Setembro 1, 2014 
O descontentamento crescente com o paradigma tradicional de desenvolvimento, acoplado à observação emergente de que o acesso a tecnologias abertas e à participação equitativa na produção de conhecimento pode melhorar a qualidade de vida e o bem-estar de pessoas em regiões marginalizadas, deu origem a uma nova escola de pensamento conhecida como desenvolvimento aberto (Open Development) (SMITH et al., 2011; SMITH; REILLY, 2014).

O desenvolvimento aberto é uma proposição ampla, de acordo com a qual modelos abertos e a produção em sistema cooperativo - possibilitados por tecnologias de rede disponíveis em toda parte, por estruturas de incentivo não baseadas no mercado e regimes de licenciamento alternativos (tais como as licenças do Creative Commons) - podem resultar em maior participação, acesso e colaboração de diferentes setores sociais e econômicos.

Essas interações, por sua vez, podem gerar novos benefícios sociais em áreas tão diversas como educação, saúde, ciência e inovação, governo e participação de cidadãos e empresas médias e pequenas.

Um entendimento fundamental do desenvolvimento aberto é que, embora as novas tecnologias não sejam os únicos agentes da mudança social, elas estão profundamente incorporadas em nosso tecido social, econômico e político. Precisamos, portanto, compreender a abertura no contexto de um quadro sociotécnico e de estrutura de poder complexos (BUSKENS, 2014). Essa compreensão da necessidade de entender a dinâmica de poder da estrutura institucional e de como os indivíduos são frequentemente limitados por práticas existentes é central à definição do modelo conceitual que orienta o desenvolvimento da OCSDNet.

\section{DEFININDO CIÊNCIA ABERTA}

Nas diversas iniciativas abertas, vemos também as fronteiras do que pode ser aberto sendo cada vez mais expandidas. Essa tendência é mais aparente na área emergente da ciência aberta. 
De acordo com Michael Nielsen, autor de Reinventing Discovery (NIELSEN, 2011), "A ciência aberta é a ideia de que conhecimentos científicos de todos os tipos deveriam ser compartilhados abertamente tão logo quanto possível no processo de descoberta"8. A Rede Britânica de Informação sobre Pesquisa (British Research Information Network) definiu a ciência aberta como

[....] a ciência desenvolvida e comunicada de forma a permitir a outras pessoas contribuírem, colaborarem e acrescentarem aos esforços de pesquisa, com todos os tipos de dados, resultados e protocolos tornados disponíveis gratuitamente em diferentes estágios do processo (RIN/NESTA, 2010) ${ }^{9}$

No processo de pesquisa tradicional, as publicações apenas se tornavam disponíveis para o público como produto final, e não necessariamente de maneira aberta. Por outro lado, na ciência aberta, não apenas artigos de pesquisa são abertamente acessíveis: esse acesso se estende a outros objetos de pesquisa, tais como dados, códigos de software, protocolos e fluxos de trabalho, de tal maneira que as pessoas têm liberdade de usar, reusar e distribuir sem restrições legais, sociais ou tecnológicas. Em alguns casos, a ciência aberta também ocasiona a abertura de todo o processo de pesquisa, da definição da agenda, da geração e análise de dados à disseminação e uso, com a ajuda de diversas plataformas e ferramentas sociais emergentes (O'HARA; HALL, 2013).

\footnotetext{
8 "Open science is the idea that scientific knowledge of all kinds should be openly shared as early as is practical in the discovery process".

9 "science carried out and communicated in a manner which allows others to contribute, collaborate and add to the research effort, with all kinds of data, results and protocols made freely available at different stages of the research process". Disponivel em: http://www.rin. ac.uk/our-work/data-management-and-curation/open-science-case-studies. Acesso em: 19 jun. 2015
} 
A ciência aberta utiliza a prevalência da Internet e das ferramentas digitais associadas para possibilitar maior colaboração local e global na pesquisa. Tal colaboração não precisa se limitar a comunidades tradicionais de pesquisa; pode também incluir a participação de cientistas cidadãos, tanto em parceria com instituições tradicionais como com lugares onde a pesquisa não é tradição, com frequência usando software, hardware e outras tecnologias abertas (WOELFLE et al., 2011; BARTLING; FRIESIKE, 2014).

Fecher e Friesike (2013) realizaram um levantamento do cenário atual da ciência aberta e tentaram criar uma tipologia das diversas atividades abarcadas por esse conceito abrangente. Não é surpresa terem eles encontrado uma diversidade de atividades envolvendo diferentes atores (que, com frequência, se sobrepunham), diversas ações e estratégias, mas - o que é mais importante - essas atividades eram direcionadas por diferentes motivações, incentivos, pressupostos e objetivos finais (Tabela 1).

Tabela 1 - Uma tabela simplificada mostrando as diferentes atividades (envolvendo motivações e atores diferentes) que foram agrupadas dentro do conceito de Ciência Aberta.

\begin{tabular}{|c|c|c|c|c|c|}
\hline & $\begin{array}{l}\text { Conhecimento } \\
\text { como bem } \\
\text { público }\end{array}$ & Pragmática & $\begin{array}{c}\text { Infraestrutura } \\
\text { eletrônica }\end{array}$ & $\begin{array}{l}\text { Engajamento } \\
\text { público }\end{array}$ & $\begin{array}{c}\text { Sistema de } \\
\text { valores }\end{array}$ \\
\hline 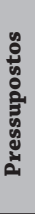 & $\begin{array}{l}\text { O acesso ao } \\
\text { conhecimento } \\
\text { é altamente } \\
\text { desigual. }\end{array}$ & $\begin{array}{l}\text { Colaboração } \\
\text { aberta é mais } \\
\text { eficiente para } \\
\text { a criação de } \\
\text { conhecimento e } \\
\text { descobertas. }\end{array}$ & $\begin{array}{l}\text { Infraestrutura } \\
\text { e ferramentas } \\
\text { da rede são } \\
\text { essenciais à } \\
\text { colaboração } \\
\text { aberta. }\end{array}$ & $\begin{array}{c}\text { A ciência é um } \\
\text { empreendimento } \\
\text { público e deveria } \\
\text { ser accessível ao } \\
\text { público. }\end{array}$ & $\begin{array}{c}\text { Existe a } \\
\text { necessidade de } \\
\text { se criar uma } \\
\text { nova métrica e } \\
\text { incentivos. }\end{array}$ \\
\hline घूँ & $\begin{array}{l}\text { Tornar o conhe- } \\
\text { cimento acadê- } \\
\text { mico livremente } \\
\text { disponível para } \\
\text { todos. }\end{array}$ & $\begin{array}{c}\text { Abrir o } \\
\text { processo de } \\
\text { descoberta do } \\
\text { conhecimento } \\
\text { tão cedo quanto } \\
\text { possível. }\end{array}$ & $\begin{array}{l}\text { Criar platafor- } \\
\text { mas, ferramen- } \\
\text { tas e serviços } \\
\text { abertos para } \\
\text { cientistas. }\end{array}$ & $\begin{array}{l}\text { Engajar cidadãos } \\
\text { no desenho e } \\
\text { condução da } \\
\text { pesquisa. }\end{array}$ & $\begin{array}{c}\text { Desenvolver } \\
\text { medidas } \\
\text { alternativas e } \\
\text { um sistema de } \\
\text { avaliação mais } \\
\text { inclusivo. }\end{array}$ \\
\hline
\end{tabular}




\begin{tabular}{|c|c|c|c|c|c|}
\hline & $\begin{array}{c}\text { Conhecimento } \\
\text { como bem } \\
\text { público }\end{array}$ & Pragmática & $\begin{array}{c}\text { Infraestrutura } \\
\text { eletrônica }\end{array}$ & $\begin{array}{l}\text { Engajamento } \\
\text { público }\end{array}$ & $\begin{array}{c}\text { Sistema de } \\
\text { valores }\end{array}$ \\
\hline 递 & $\begin{array}{l}\text { Cientistas, } \\
\text { elaboradores } \\
\text { de políticas, } \\
\text { financiadores, } \\
\text { cidadãos. }\end{array}$ & $\begin{array}{l}\text { Cientistas e de- } \\
\text { senvolvedores } \\
\text { de ferramentas. }\end{array}$ & $\begin{array}{l}\text { Cientistas, } \\
\text { designers e } \\
\text { provedores de } \\
\text { plataformas. }\end{array}$ & $\begin{array}{l}\text { Cidadãos, cientis- } \\
\text { tas, organizações } \\
\text { não-governamen- } \\
\text { tais. }\end{array}$ & $\begin{array}{l}\text { Cientistas, } \\
\text { financiadores, } \\
\text { legisladores }\end{array}$ \\
\hline 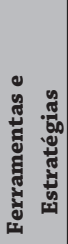 & $\begin{array}{l}\text { Acesso aberto, } \\
\text { licença aberta, } \\
\text { dados abertos, } \\
\text { código aberto. }\end{array}$ & $\begin{array}{l}\text { Dados abertos, } \\
\text { código aberto, } \\
\text { crowdsourcing, } \\
\text { acesso aberto, } \\
\text { licença aberta. }\end{array}$ & $\begin{array}{c}\text { Definição } \\
\text { de padrões } \\
\text { e protocolos } \\
\text { interoperáveis } \\
\text { para troca de } \\
\text { conhecimento. }\end{array}$ & $\begin{array}{l}\text { Plataformas de } \\
\text { mídias sociais } \\
\text { (Facebook, Twit- } \\
\text { ter, blogs, etc.), } \\
\text { crowdsourcing. }\end{array}$ & $\begin{array}{l}\text { Altmetria, } \\
\text { revisão por } \\
\text { pares aberta, } \\
\text { índices de } \\
\text { abertura. }\end{array}$ \\
\hline
\end{tabular}

Fonte: Adaptada a partir de FECHER; FRIESIKE, 2013.

Quando tentamos entender a ciência aberta, é importante ir além dos mecanismos de acesso e reuso, tais como a afirmação de que a ciência aberta é um "conhecimento científico que as pessoas têm a liberdade de usar, reusar e distribuir sem restrições legais, tecnológicas ou sociais" ${ }^{10}$. Se tomarmos como pressuposto inicial que a ciência aberta envolve a colaboração e a participação de diversos atores em uma variedade ampla de contextos institucionais, com motivações, valores e intenções as mais variadas, então precisamos ver a ciência aberta como um processo condicional, não como uma condição binária, operando dentro de um sistema sociotécnico altamente complexo que abrange o local e o global (HALFORD et al., 2012).

Assim, compreender os princípios e a dinâmica da colaboração e participação é central para as atividades da rede OCSDNet, na medida em que a abertura diz respeito a mais do que apenas o acesso (CHAN; GRAY, 2013). Assim, adotamos ciência aberta e colaborativa

10 "[....] scientific knowledge that people are free to use, re-use and distribute without legal, technological or social restrictions". Disponível em: http://science.okfn.org/ Acesso em: 19 jun. 2015 
(OCS na sigla em inglês) como um termo operacional para a rede de pesquisa, para nos lembrar da natureza central da colaboração e participação em rede (SHRUM et al., 2007).

\section{CiênCIA aberta e desenvolvimento}

A OCSDNet foi criada em momento oportuno, dada a consciência crescente, por um lado, do papel essencial da ciência, tecnologia e inovação (CT\&I) nas atividades de desenvolvimento (WAGNER, 2009); e, por outro, o interesse crescente no papel da abertura da ciência como conjunto de princípios transformadores, tanto para a reflexão como para as práticas de desenvolvimento (CRIBB; HARTOMO, 2010).

No livro The New Invisible College: Science for Development, Caroline Wagner afirma que:

Como muitas partes do sistema de conhecimento, a organização da pesquisa científica está mudando de maneira fundamental. Redes auto-organizadas, abrangendo o globo, são a característica mais notável da ciência hoje em dia. Essas redes constituem a faculdade invisível de pesquisadores: cientistas que colaboram não porque lhes disseram para fazê-lo, mas porque eles querem fazê-lo; não porque trabalham no mesmo laboratório ou mesmo no mesmo campo, mas porque compartilham insights, dados ou habilidades. As redes podem assumir o papel de instituições em alguns lugares do mundo que não possuem uma longa história de construção de infraestrutura científica. (WAGNER, 2009, p. 2) ${ }^{11}$

\footnotetext{
11 "Like many parts of the knowledge system, the organization of scientific research is changing in fundamental ways. Self-organizing networks that span the globe are the most notable feature of science today. These networks constitute an invisible college of researchers: scientists who collaborate not because they are told to but because they want to, not because they work in the same laboratory or even in the same field but because they have complementary insight, data, or skills. Networks can take on the role of institutions in some parts of the world that do not have a long history of building scientific infrastructure." (WAGNER, 2009, p. 2).
} 
Ao mapear a emergência de redes globais de ciência e rastrear as dinâmicas impulsionando seu crescimento, Wagner argumenta que a transição da grande ciência para as redes globais cria oportunidades sem precedentes para países em desenvolvimento aproveitarem a ciência e o potencial de inovação. Em vez de desperdiçarem recursos para copiar instituições e políticas científicas da era pré-digital, formuladores de políticas de países em desenvolvimento deveriam alavancar as redes, criando incentivos para que cientistas foquem nas pesquisas que respondem a suas preocupações e para que encontrem maneiras de ligar o conhecimento à solução de problemas locais (WOLKOVICH et al., 2012).

Esta abordagem é bastante apropriada porque muitos dos grandes desafios que a humanidade enfrenta hoje em dia, tais como a mudança climática, a degradação do meio ambiente, a emergência de doenças infecciosas, o acesso inadequado à água potável e a insegurança alimentar são, por natureza, globais, mas desproporcionalmente mais danosas às economias emergentes. Lidar com esses desafios requer não apenas soluções locais apropriadas, mas também o desenvolvimento rápido e sustentável de novas ferramentas e abordagens que se inspiram nos comuns globais de ciência e conhecimentos.

A queda dramática nos custos da computação e, em todo o mundo, o crescente acesso de pesquisadores à Internet, bem como a redes digitais associadas, embasam a promessa de que alguns desses desafios do desenvolvimento possam ser resolvidos por meio do compartilhamento aberto de dados, métodos, infraestrutura e outras abordagens abertas da descoberta do conhecimento e solução de problemas (SMith et al., 2011; SMITH; REILly, 2014). A prática emergente da Descoberta de Medicamentos de Fonte Aberta (Open Source Drug Discovery) para doenças negligenciadas (MASUM; HARRIS, 2011; WOELFLE, 2011; ROBERTSON et al., 2014); a incorporação da ciência cidadã a uma ampla variedade de pesquisas relacionadas ao monitoramento ambiental e a mudanças climáticas (VITOs et al., 
2013; SUZUKI, 2014; SEE et al., 2014), bem como o uso crescente de redes sociais para a colaboração científica entre cientistas do Sul Global (e.g. GUERRERO-MEDINA et al., 2013) são apenas a ponta do iceberg.

Além de chamar a atenção para esses problemas em nível global, que requerem intervenções no longo prazo, a ciência aberta e colaborativa também promete aumentar a visibilidade e o impacto da pesquisa em nível local, facilitar a participação de pesquisadores em colaborações locais e internacionais, estimular o engajamento do público com a ciência por meio de atividades tais como ciência cidadã, e promover a cultura do compartilhamento do conhecimento, bem como uma nova reflexão sobre inovação social. Estes são considerados resultados de curto prazo, que trazem benefícios diretos para o desenvolvimento e que poderiam contribuir para o fortalecimento da capacidade local de pesquisa, pela educação e pela participação.

No longo prazo, esses resultados têm o potencial de levar a uma participação mais equitativa de pesquisadores do Sul Global que, com frequência, são marginalizados no processo competitivo de pesquisa tradicional, impulsionado pelas agendas do Norte. (YNALVEZN; SHRUM, 2011; DUQUE et al., 2012).

Essa situação tem ainda o potencial de nos levar a formas de conhecimento mais expandidas e inclusivas, e está de acordo com nosso pressuposto de que a colaboração envolve uma contribuição equitativa - tanto na formulação como na busca de soluções para os problemas relevantes - e não apenas o cumprimento de normas estabelecidas por aqueles que ocupam o poder ou estão encarregados dos recursos (HAVERKORT et al., 2012).

A respeito disso, a abertura não é apenas uma questão de obter acesso ao conhecimento, mas também do direito à participação no processo de produção desse conhecimento, impulsionado por assuntos de relevância local em vez de fazê-lo por agendas de pesquisa estabelecidas em outros lugares ou impostas de cima para baixo. 
No entanto, enquanto a ciência aberta é louvada por muitos como um objetivo a ser atingido, a prática está longe de ser universal no Norte Global (GRUBB; EASTERBROOK, 2011; PIWOWAR, 2011; WHYTE; PRYOR, 2011) e a consciência de seus benefícios e práticas são menos proeminentes ainda no Sul Global. De fato, muitos pesquisadores em organizações bem estabelecidas resistem ativamente às mudanças perturbadoras que ocorrem como resultado de práticas abertas, na medida em que essas mudanças simultaneamente põem em questão noções antigas de autoridade científica, confiança, qualidade, reconhecimento, bem como de incentivos (MASUM; TOVEY, 2011; PRIEM et al., 2012; BERNAL, 2013).

E embora muitos dos pretensos benefícios para o desenvolvimento da ciência aberta e colaborativa (alguns dos quais delineamos anteriormente) sejam muito atraentes, há, no momento, pouca evidência empírica sustentando ou negando essas afirmações.

De fato, como argumentamos anteriormente, o conceito de ciência aberta e colaborativa é abrangente, abarca uma diversidade de atividades, atores, pressupostos, motivações e contextos institucionais; e o resultado dessas interações complexas é, com frequência, incerto. Tais resultados podem ser também de natureza negativa, e exacerbar ainda mais problemas de participação desigual, disparidade de gêneros e maior exclusão de pesquisadores que não tenham a capacidade de se beneficiar das ferramentas e dos recursos da rede (POWELl et al., 2012)

Questões também já foram levantadas com relação ao conflito potencial entre as abordagens abertas da ciência e interesses de privacidade e de segurança pessoal e social dos cidadãos (CHANDRAMOHAN et al., 2008; CHURCH et al., 2009; PISANI; ABOUZAHR, 2010).

Em resumo, temos uma compreensão muito limitada dos contextos sociais, políticos e institucionais, bem como do quadro de valores e incentivos dentro dos quais ocorrem as abordagens abertas da ciência (DELFANTI, 2013). Da mesma maneira, não 
compreendemos bem os mecanismos (causais e outros) que ligam as práticas da ciência aberta a resultados potenciais de desenvolvimento. O programa de pesquisa e a rede da OCSDNet foram desenhados para abordar essas falhas em nossa compreensão através de processo de coleta de dados e de construção de teoria em múltiplos estágios.

\section{METAS E OBJETIVOS ESPECÍFICOS DA OCSDNET}

Para abordar a meta ampla e bastante ambiciosa da OCSDNet descrita acima, há necessidade de um conjunto mais específico de objetivos e estratégias para orientar a geração de observações, coleta de dados e construção de teoria. Ao mesmo tempo, precisamos construir uma Teoria da Mudança (Theory of Change - ToC) para orientar o desenho e a implementação de problemas de pesquisa. A ToC tem por objetivo explicitar os pressupostos da situação problema, os mecanismos de mudança em potencial, os contextos institucionais e os atores da ciência aberta e colaborativa OCS, os resultados de curto e longo prazo e os processos necessários para que ocorram as mudanças desejadas.

Para estes fins, os principais objetivos da OCSDNet incluem:

1) apoiar (tanto financeira como intelectualmente) novos subprojetos e atividades que gerem evidências sobre se, e em que condições, as abordagens abertas da ciência possibilitam pesquisas que contribuam para os objetivos de desenvolvimento do Sul Global;

2) construir uma comunidade de praticantes da ciência aberta e de líderes em diferentes contextos, alimentando uma rede de pesquisa interativa e oferecendo uma plataforma facilitadora e os recursos necessários;

3) identificar as barreiras estruturais, técnicas, culturais e de políticas que impeçam indivíduos e organizações de participarem da ciência aberta e colaborativa, bem como 
determinar como lidar melhor com essas barreiras. Este objetivo será atingido através de uma síntese dos resultados de pesquisa gerados pelos diversos subprojetos;

4) contribuir para a construção de uma nova e vibrante área de estudo (ciência aberta e colaborativa para o desenvolvimento), produzindo diretrizes e sínteses do conhecimento para subsidiar políticas e práticas.

Os itens 1 e 2 constituem objetivos de curto prazo e requerem input financeiro e coordenação substanciais. Na medida em que 3 e 4 são objetivos de médio e longo prazo, o iHub, o espaço de inovação de Nairóbi para a comunidade tecnológica, assumiu o papel de coordenação da rede, administrando o apoio financeiro oferecido pelo IDRC (International Development Research Centre) e pelo DFID (Department for International Development). para os subprojetos da rede, e disponibilizando, para os pesquisadores, recursos e apoio à rede. O Centro de Estudos de Desenvolvimento Crítico (Centre for Critical Development Studies) da Universidade de Toronto assumiu o papel de coordenação da pesquisa, responsável por sintetizar os resultados dos subprojetos e por gerar um modelo conceitual para orientar debates e pesquisas futuras na área de ciência aberta e desenvolvimento.

\section{A ABORDACEM DE PESQUISA DA OCSDNET}

\section{Financiamento e apoio a subprojetos}

Para a primeira etapa do projeto da rede, a OCSDNet lançou uma chamada internacional para trabalhos conceituais sobre potenciais projetos de pesquisa. A chamada focou estudos de caso que empregam processos abertos inovadores de geração de conhecimento e de ações direcionadas a uma gama de desafios do desenvolvimento em diversos contextos do Sul Global. Os trabalhos conceituais deveriam 
tratar de um ou mais dos quatro temas principais, centrais aos objetivos de pesquisa da rede. Esses temas foram identificados a partir de duas oficinas de escopo financiadas pelo IDRC e realizadas antes do lançamento do projeto da OCSDNet. Os temas são:

1) Motivações (incentivos e ideologias)

2) Infraestrutura \& tecnologias.

3) Comunidades de prática em ciência aberta e colaborativa.

4) Impactos potenciais (positivos e negativos) da ciência aberta e colaborativa.

Descrições detalhadas de cada tema, questões de pesquisa a eles associadas e como esses temas se enquadram no modelo conceitual proposto estão disponíveis em http://ocsdnet.org/thematic-areas/.

Além disso, buscava-se um mix de projetos que incluíssem a pesquisa científica em diferentes domínios voltados para a produção de novos conhecimentos, bem como pesquisas críticas sobre iniciativas correntes, focadas nos comportamentos, contextos, desafios e oportunidades tornados possíveis pela ciência aberta e colaborativa.

A chamada resultou em 91 propostas de trabalhos conceituais de todo o Sul Global, entre os quais 14 foram convidados para a oficina de desenvolvimento de uma proposta completa que teve lugar em Nairóbi, em meados de outubro de 2014. O processo de seleção foi realizado por assessores e pela equipe de coordenadores da OCSDNet, bem como por avaliadores externos. Os critérios de seleção foram divulgados para os candidatos através da chamada, e eles receberam materiais informativos bastante completos para ajudá-los na preparação do trabalho conceitual ${ }^{12}$.

12 Para detalhes da chamada e materiais de background, ver: http://ocsdnet.org/application-2/. Acesso em 11 jun. 2015. 


\section{CONSTRUÇÃO DE TEORIA E DE COMUNIDADE}

A oficina foi o primeiro passo do processo de construção de uma comunidade, oferecendo um foro para os candidatos se conhecerem e conhecerem os assessores e a equipe da OCSDNet.

$\mathrm{Na}$ oficina, os candidatos receberam dos assessores e coordenadores OCSDNet, bem como de seus colegas, feedback detalhado sobre suas propostas. A oficina ofereceu uma oportunidade de interação face a face e um espaço importante para os candidatos refinarem suas propostas e para se assegurarem de que as mesmas se tornassem propostas passíveis de financiamento, com um orçamento detalhado de acordo com os requisitos dos financiadores. Também ofereceu oportunidades para compartilhar problemas de pesquisa em comum, metodologias, protocolos de monitoramento e avaliação, e - mais importante - para se definir como os diversos projetos poderiam contribuir para o objetivo comum: como a ciência aberta e colaborativa pode abordar diferentes desafios do desenvolvimento.

A oficina foi um passo claro para atingir os objetivos 1, 2 e 4, na medida em que os participantes representavam um amplo espectro de disciplinas, domínios e atividades, do hardware aberto em diversos países do sudeste da Ásia à adaptação a mudanças climáticas de povos nativos na África do Sul, com os elementos em comum do uso de abordagens abertas e colaboração para examinar oportunidades e desafios do desenvolvimento.

Os participantes da oficina representavam 11 países do Sul Global, com 3 propostas de projetos da África Subsaariana, 1 do Oriente Médio, 1 do Caribe, 5 da América Latina e 4 do sul, leste e centro da Ásia. Os participantes também representavam uma diversidade de disciplinas: de cientistas ambientais a sociólogos da ciência, de especialistas em estudos sobre políticas a praticantes da ciência cidadã em hardware aberto. Possuíam, portanto, experiência, conhecimentos e concepções de desenvolvimento bastante diversos, bem 
como percepções diferentes da ciência aberta e colaborativa, fazendo do evento uma oportunidade importante para compartilhar desafios em comum e para debater diferenças em suas abordagens, prioridades e formas de conhecer.

A diversidade dos participantes sublinhou a importância da ciência aberta e colaborativa como um empreendimento multi e interdisciplinar, com a necessidade de atrair e integrar ideias, métodos de pesquisa e modelos analíticos de disciplinas que tradicionalmente não atravessam fronteiras. Isso é particularmente importante para pesquisadores e praticantes do Sul Global, que podem trazer perspectivas valiosas, mas com frequência negligenciadas, de diversos contextos institucionais.

Foi importante que um dos principais consensos a emergir da oficina tenha sido a necessidade de considerar a ciência aberta e colaborativa sob a perspectiva da justiça cognitiva, a noção de que a ciência aberta e colaborativa deveria buscar empoderar atores locais, incluindo pesquisadores e cidadãos, levando em consideração a pluralidade dos sistemas de conhecimento; e dar prioridade a desafios de desenvolvimento de relevância local (SANTOS, 1987; VISVANATHAN, 2005; REILLY, 2014; BARRETO, 2014). O pressuposto é que, ao apoiar a capacitação por meio da participação em pesquisas, as comunidades locais são empoderadas com maior autonomia e habilidade de criar meios de vida melhores e mais sustentáveis. "Os pesquisadores precisam trabalhar com a sociedade e os níveis de base porque são as pessoas que estão sofrendo e sabem quais são os problemas", observou a assessora da OCSDNet, Hebe Vessuri ${ }^{13}$. Isto se tornou um tema transversal importante para diversos dos subprojetos propostos. Contamos com a emergência de outros temas transversais à medida que os diversos projetos se desenvolvem e os participantes aprendem uns com os outros.

13 Disponível em: http://www.scidev.net/Global/networks/news/network-open-access-research-development-impact.html. Acesso em 19 jun. 2015 


\section{ATIVIDADES ATUAIS E FUTURAS}

Após mais diálogos on-line com os assessores, com outros candidatos e com avaliadores externos, os candidatos apresentaram suas propostas finais no fim de dezembro de 2014. Todos os projetos foram subsequentemente aprovados para financiamento no início de janeiro de 2015 e todos estão disponíveis no site da OCSDNet ${ }^{14}$ (). Os candidatos e organizações hospedeiras também passaram pelo devido processo diligente exigido pelos financiadores. A previsão era de que todos os projetos começassem em fevereiro de 2015, e tivessem duração de 24 meses.

Através desses projetos, a rede espera estar mais bem preparada para começar a trabalhar na direção do objetivo 3 ("Identificar as barreiras estruturais, técnicas, culturais e de políticas à participação de indivíduos e organizações na ciência aberta e colaborativa e determinar como essas barreiras podem ser abordadas") e na direção da construção de uma Teoria da Mudança.

Além do desenvolvimento de subprojetos da OCSDNet, a equipe da rede criou e lançou um site para a organização ${ }^{15}$. Esse site inclui um blog, bem como fóruns sobre tópicos específicos, oferecendo espaço para participantes da rede e partes interessadas em: (1) compartilhar e acessar recursos; (2) participar de debates sobre questões relativas à abertura e ao desenvolvimento; e (3) informar-se sobre as atividades da rede.

A criação do site é um passo fundamental na direção do objetivo 2 ("Construir uma Comunidade de Praticantes da Ciência Aberta e Líderes em diferentes contextos, alimentando uma rede de pesquisa interativa"). Nos próximos meses, a equipe da OCSDNet continuará a incentivar a participação ampla no site, preparando conteúdos relevantes para o blog, estimulando debates em diversos fóruns, oferecendo recursos para ferramentas de networking e abordagens

\footnotetext{
14 Disponível em http://ocsdnet.org/projects/ Acesso em: 28 jun. 2015.

15 Disponível em: http://www.ocsdnet.org. Acesso em: 19 jun. 2015
} 
de pesquisa, bem como aumentando a visibilidade das atividades da OCSDNet nas mídias sociais. Os recebedores de financiamentos da OCSDNet também serão anfitriões, e participarão de uma variedade de seminários e oficinas relacionados à ciência aberta e colaborativa, e ao desenvolvimento. Essas atividades serão reportadas e compartilhadas no site para ampliar o debate e a participação.

Cada projeto financiado também deverá fornecer à rede atualizações regulares, e os coordenadores as compartilharão amplamente. Estes relatórios também formarão a base do trabalho contínuo de síntese que constitui a fase de construção de teoria do projeto. Ao mesmo tempo, a equipe da OCSDNet participará de exercícios regulares de monitoramento e avaliação com os subprojetos, e também como com a rede como um todo. Os resultados dessas avaliações também serão amplamente disponibilizados às comunidades interessadas.

\section{CONSIDERAÇÕES FINAIS}

Dados os interesses florescentes e convergentes na abertura e na ciência aberta em todo o mundo, não é surpreendente observar uma multiplicação de projetos voltados para a investigação da natureza e do impacto potencial da abertura sobre as práticas e o discurso científicos. A OCSDNet faz parte dessa tendência em crescimento, apesar de o foco da rede no Sul Global e no discurso sobre desenvolvimento se diferenciar das demais iniciativas baseadas no Norte. À medida que o projeto da rede se desenvolve, começamos também a mapear os diferentes atores, agências e diálogos sobre políticas em todo o mundo, e a identificar áreas de interesses e abordagens em comum.

Também estamos cientes da necessidade de sermos cautelosos em mostrar grandes entusiasmos com a ciência aberta e suas reivindicações utilitárias de eficiência, retorno sobre o investimento e crescimento econômico (MANSELL; TREMBLAY, 2013). Enquanto 
permanecemos cautelosamente otimistas com o potencial da ciência aberta e colaborativa de reformatar as práticas e o discurso do desenvolvimento, gostaríamos de levantar as questões críticas sobre quais benefícios reais a ciência aberta e colaborativa poderia trazer ao Sul Global, onde persistem assimetrias nas estruturas de poder e profundas desigualdades em acesso aos recursos.

Obviamente, muitas questões permanecem abertas e demandam investigação e coleta de dados. Ao mesmo tempo, como Hebe Vessuri (2015, p. 298) observou, havia uma forte necessidade de se criar "um modelo comparativo que promovesse interconexões orgânicas entre múltiplas vozes e alimentasse uma variedade de abordagens". A criação de diálogos enriquecedores entre diferentes formas de conhecer em um complexo ambiente em rede é, de fato, um dos principais desafios da OCSDNet e nós o recebemos com entusiasmo.

\section{REFERÊNCIAS}

BARRETO, José-Manuel. Epistemologies of the south and human rights: Santos and the quest for global and cognitive justice. Indiana Journal of Global Legal Studies, v. 21, n. 2, Summer 2014. Disponível em: http://ssrn.com/abstract=2535488. Acesso em: 22 jun. 2015

BARTLING, S.; FRIESIKE, S. (Ed.). Opening science. Cham: Springer International Publishing, 2014. Disponível em: http://link.springer.com/10.1007/978-3-31900026-8. Acesso em: 22 jun. 2015.

BERNAL, I. Open access and the changing landscape of research impact indicators: new roles for repositories. Publications, v.1, n.2, p.56-77, 2013. doi:10.3390/ publications 1020056

BOLLIER, D. Viral spiral: how the commoners built a digital republic of their own. New York: New Press, 2008.

BOYLE, J. The public domain: enclosing the commons of the mind. Yale: Yale University Press, 2009. 
BUSKENS, I. Open development is a freedom song: revealing intent and freeing power. In: SMITH, M. L.; REILLY, K. M. (Ed.). Open development: networked innovations in international development. Cambridge, MA: MIT Press, 2014.

CHAN, L.; COSTA, S. Participation in the global knowledge commons: challenges and opportunities for research dissemination in developing countries. New Library World, v.106, n.3/4, p.141-163, 2005.

CHAN, L.; GRAY, E. Centering the knowledge peripheries through open access: implications for future research and discourse on ICT for development. In Matthew L. Smith e Katherine M. A. Reilly (Eds.). Cambridge open development: networked innovations in international development. MA: MIT Press, 2014.

CHAN, L.; KIRSOP, B.; ARUNACHALAM, S. Towards open and equitable access to research and knowledge for development. PLoS Med, v.8, n.3, p.e 1001016, 2011. doi:10.1371/journal.pmed.1001016.

CHANDRAMOHAN, Daniel; SHIBUYA Kenji; SETEL, Philip; CAIRNCROSS, Sandy; LOPEZ, Alan D.; MURRAY, Christopher J.L.; ŻABA, Basia; SNOW, Robert W.; BINKA, Fred. Should data from demographic surveillance systems be made more widely available to researchers?. PLoS Medicine, v. 5, n. 2, p.e 57, 2008.

CHURCH, G.; HEENEY, C.; HAWKINS, N.; VRIES, J. de; BODDINGTON, P.; KAYE, J.; WEIR, B. Public access to genome-wide data: five views on balancing research with privacy and protection. PLoS Genetics, v.5, n.10, p.e 1000665, 2009.

CRIBB, J.; HARTOMO, T. S. Open science: sharing knowledge in the global century. Collingwood, Vic.: CSIRO Publishing, 2010.

DE BEER, J.; ARMSTRONG, C.; OGUAMANAM, C.; SCHONWETTER, T. Innovation \& intellectual property: collaborative dynamics in Africa. Cape Town: UCT Press, 2014.

DELFANTI, A. Biohackers. The politics of open science. London: Pluto Press, 2013.

DONDERS, Y. The right to enjoy the benefits of scientific progress: in search of state obligations in relation to health. Medicine, Health Care, and Philosophy, v.14, n.4, p.371-381, 2011. doi:10.1007/s11019-011-9327-y

DRAHOS, P.; BRAITHWAITE, J. Information feudalism: who owns the knowledge economy?. London: Earthscan, 2002. 
DUQUE, R. B.; MILLER, B. P.; BARRIGA, O.; SHRUM, W.; HENRIQUEZ, G. Is internet use associated with reporting fewer problems in collaboration? Evidence from the scientific community in Chile. Science Communication, v.34, n.5, p. 642678, 2012. doi:10.1177/1075547011432364.

ESCOBAR, A. Encountering development: the making and unmaking of the third world. Princeton, NJ: Princeton University Press, 1995.

FECHER, B.; FRIESIKE, S. Open science: one term, five schools of thought. n. 218, 2013. Disponível em: http://www.researchgate.net/profile/Benedikt_Fecher/ publication/236607487_Open_Science_One_Term_Five_Schools_of_Thought/ links/0deec5183a5b4bc99f000000.pdf Acesso em: 22 jun. 2015

FORAY, D. Patent-free innovation: a review of economic works including the analysis of a recent work in the field of experimental economics. Revue Économique, v.64, n.1, p. 9, 2013. doi:10.3917/reco.641.0009.

FRANZONI, C.; SAUERMANN, H. Crowd science: the organization of scientific research in open collaborative projects. Research Policy, v.43, n.1, p. 1-20, 2014. doi:10.1016/j.respol.2013.07.005.

FUCHS, Richard; ELDER, Laurent. Conclusions: A decade of innovations that matters. In: ELDER, L.; EMDON, H.; FUCHS, R.; PETRAZZINI, B. (Eds.). Connecting ICTs to Development: The IDRC experience. Canada: International Development Research Centre, 2013. p.267-278.

GRUBB, A. M.; EASTERBROOK, S. M. On the lack of consensus over the meaning of openness: an empirical study. PLoS One, v.6, n.8, 2011. doi:10.1371/journal. pone.0023420.

GUERRERO-MEDINA, G.; FELIÚ-MÓJER, M.; GONZÁLEZ-ESPADA, W.; DÍAZ-MUÑOZ, G.; LÓPEZ, M.; DÍAZ-MUÑOZ, S. L.; COLÓN-RAMOS, D. A. Supporting diversity in science through social networking. PLoS Biol, v.11, n.12, e1001740, 2013. doi:10.1371/journal.pbio.1001740.

HALFORD, S.; POPE, C.; WEAL, M. (2012). Digital futures? sociological challenges and opportunities in the emergent semantic web. Sociology, 2012. doi:10.1177/0038038512453798. 
HAVERKORT, B.; BURGOA, F. D.; SHANKAR, D.; MILLER, D. Towards co-creation of sciences: building on the plurality of worldview, values and methods in different knowledge communities. New Delhi, India: Nimby Book, 2012.

HESS, C.; OSTROM, E. A framework for analysing the microbiological commons. International Social Science Journal, v.58, n.188, p. 335-349, 2006.

HESS, C.; OSTROM, E. A framework for analyzing the knowledge commons. In: UNDERSTANDING knowledge as a commons. From theory to practice. Cambridge: MIT Press, 2005.

HOUGHTON, J.W.; RASMUSSEN, B.; SHEEHAN, P.J.; OPPENHEIM, C.; MORRIS, A.; CREASER, C.; GREENWOOD, H.; SUMMERS, M.; GOURLAY, A. Economic implications of alternative scholarly publishing models: exploring the costs and benefits, report to the Joint Information Systems Committee (JISC). \& Loughborough: Victoria University \& Loughborough University, 2009.

HOUGHTON, J.; SWAN, A. Planting the green seeds for a golden harvest: comments and clarifications on "Going for Gold". D-lib magazine, v. 19, n. 1/2, Jan-Feb., 2013. Disponível em: http://www.dlib.org/dlib/january13/houghton/01houghton.html Acesso em: 22 jun. 2015

JOSEPH, H. The Open Access Movement Grows Up: taking stock of a revolution. PLoS Biol, v.11, n.10, 2013. e1001686. doi:10.1371/journal.pbio.1001686.

KIRCHSCHLAEGER, P. G. Human rights as ethical basis for science. Journal of Law, Information \& Science, v.22, n.2, 2013. doi:10.5778/JLIS.2013.22.Kirchschlaeger.1. KOCAREV, L.; IN, V. Network science: a new paradigm shift. Ieee Network, v.24, n.6, p. 6-9, 2010. Disponível em: http://ieeexplore.ieee.org/lpdocs/epic03/wrapper.htm?arnumber=5634436. Acesso em: 22 jun. 2015

MCGINNIS, M.D. An introduction to IAD and the language of the Ostrom Workshop: a simple guide to a complex framework. Policy Study Journal, v.39, n.1, p. 169-183, 2011.

MANSELL, R.; TREMBLAY, G. Renewing the knowledge societies vision: towards knowledge societies for peace and sustainable development. Report. Report prepared for the WSIS+10 Review for the Communication and Information Sector, 
UNESCO and for presentation in the "Knowledge Societies, Stakeholder Accountability for Sustainable Development" Panel at the UNESCO WSIS+10 Conference. Unesco: Paris, 2013. Disponível em: https://en.unesco.org/post2015/sites/ post2015/files/UNESCO-Knowledge-Society-Report-Draft--11-February-2013. pdf. Acesso em: 22 jun. 2015

MASUM, H.; HARRIS, R Open source for neglected diseases: magic bullet or mirage? Washington DC: Results for Development Institute, 2011. Disponível em: http:// healthresearchpolicy.org/sites/healthresearchpolicy.org/files/assessments/files/ Open\%20source\%20high\%20res.pdf Acesso em: 22 jun. 2015

MASUM, H.; TOVEY, M. (Ed.). The reputation society: how online opinions are reshaping the offline world. Cambridge, Mass: MIT Press, 2011.

NIELSEN, M. A. Reinventing discovery: the new era of networked science. Princeton, N.J.: Princeton University Press, 2011

O'HARA, K.; HALL, W. Web science. In: DUTTON, W. (Ed.). The Oxford handbook of internet studies. Oxford: Oxford University Press, 2013. P.48-68. Disponível em: http://eprints.soton.ac.uk/273097/. Acesso em: 22 jun. 2015

OSTROM, E. Governing the commons: the evolution of institutions for collective action. Cambridge: Cambridge University Press, 1990.

OSTROM, E. The rudiments of a revised theory of the origins, survival, and performance of institutions for collective action. Workshop in political Theory and Policy Analysis. Bloomington: Indiana University, 1985. Disponível em: http://dlc.dlib.indiana.edu/dlc/bitstream/handle/10535/8225/Elinor_ The\%20Rudiments\%20of\%20a\%20Revised\%20Theory\%20of\%20the\%200rigins, \%20Survival,\%20and\%20Performance.pdf?sequence=1 . Acesso em: 28 jun. 2015.

OSTROM, E. Understanding institutional diversity. Princeton: Princeton University Press, 2009.

PISANI, E.; ABOU ZAHR, C. Sharing health data: good intentions are not enough. Bulletin of the World Health Organization, v.88, n.6, p. 462-466, 2010.

PIWOWAR, H. A. Who shares? who doesn't? Factors associated with openly archiving raw research data. PloS One, v. 6, n. 7, e18657, 2011. doi:10.1371/journal. pone.0018657. 
POWELL, M.; DAVIES, T.; TAYLOR, K. C.. ICT for or against development? An introduction to the Ongoing Case of Web 3.0. IKM Working Paper, n. 16, March 2012. Disponível em: http://wiki.ikmemergent.net/files/1204-IKM-Working_Paper_ 16-WEB3-Mar_2012-2. Acesso em: 28 jun. 2015.

PRIEM, J.; PIWOWAR, H. A.; HEMMINGER, B. M. Altmetrics in the wild: using social media to explore scholarly impact. ArXiv, p.1203.4745, 2012. Disponível em: http://arxiv.org/abs/1203.4745. Acesso em: 22 jun. 2015

REILLY, K. M. Open Data, knowledge management, and development: new challenges to cognitive justice. Open Development: Networked Innovations in International Development, v. 297, 2014.

RIN/NESTA. Open to all? Case studies of openness in research. 2010. Disponível em: http://www.rin.ac.uk/our-work/data-management-and-curation/open-science-case-studies. Acesso em: 22 jun. 2015

ROBERTSON, M. N.; YLIOJA, P. M.; WILLIAMSON, A. E.; WOELFLE, M.; ROBINS, M.; BADIOLA, K. A.; TODD, M. H. Open source drug discovery - A limited tutorial. Parasitology, v.141, Special Issue 1, p. 148-157, 2014. doi:10.1017/ S0031182013001121.

SANTOS, B. S. A discourse on the sciences. In: SANTOS, B. S. (Ed.). Cognitive justice in a global world: prudent knowledge for a decent life. Toronto: Lexington Books, 1987/2007.

SEE, L.; COMBER, A.; SALK, C.; FRITZ, S.; VAN DER VELDE, M.; PERGER, C.; OBERSTEINER, M. Comparing the quality of crowdsourced data contributed by expert and non-experts. PLoS ONE, v.8, n.7, p. e69958, 2013. doi:10.1371/journal.pone.0069958.

SHAVER, Lea. The right to science: ensuring that everyone benefits from scientific and technological progress. Indiana: Indiana University Robert H. McKinney School of Law Research, 2015. Paper No. 2015-5. Disponível em: http://ssrn.com/abstract=2564222 or http://dx.doi.org/10.2139/ssrn.2564222 Acesso em: 22 jun. 2015 SHRUM, W.; GENUTH, J.; CHOMPALOV, I. Structures of scientific collaboration. Cambridge, MA: MIT Press, 2007.

SMITH, M. L.; ELDER, L.; EMDON, H. Open development: a new theory for ICT4D. Editors. Information Technologies and International Development, v. 7, n.1, 
p. 1-76, 2011. Special issue. Disponível em: http://itidjournal.org/itid/issue/ view/40. Acesso em: 22 jun. 2015

SMITH, M. L.; REILLY, K. M. A. Open development: networked innovations in international development. Cambridge, MA: MIT Press, 2014.

STIGLITZ, J. E. The price of inequality. New York; London: W.W. Norton \& Company, 2012.

STIGLITZ, J. E.; SEN, A.; FITOUSSI, J.-P. Mismeasuring our lives: why GDP doesn't add up: the report. New York: New Press : Distributed by Perseus Distribution, 2010.

SUZUKI, D. Citizen scientists can fill info gaps about Fukushima effects. . 2014, Jan. 28. Disponível em: http://rabble.ca/blogs/bloggers/david-suzuki/2014/01/citizen-scientists-can-fill-info-gaps-about-fukushima-effects. Acesso em: 22 jun. 2015

THE ROYAL SOCIETY. Knowledge, networks and nations: global scientific collaboration in the 21st century. London: The Royal Society, 2011. Disponível em: https://royalsociety.org/ /media/Royal_Society_Content/policy/publications/2011/4294976134.pdf Acesso em: 22 jun. 2015

VESSURI, H. Global social science discourse: a southern perspective on the world. Current Sociology, 2014. Doi:0011392114556595.

VISVANATHAN, S. Knowledge, justice and democracy. In: LEACH, M.; SCOONES, I.; WYNNE, B. Science and citizens: globalization and the challenge of engagement. New York: Zed Books, 2005. p.83-94.

VITOS, M.; LEWIS, J.; STEVENS, M.; HAKLAY, M. Making local knowledge matter: supporting non-literate people to monitor poaching in Congo. In: ACM SYMPOSIUM ON COMPUTING FOR DEVELOPMENT, 13., 2013. Proceedings. Bangalore: ACM, 2013. Disponível em: http://dev3.acmdev.org/papers/dev-final45.pdf . Acesso em 28 jun. 2015.

WADMAN, M. Economic return from Human Genome Project grows. Nature, 2013. doi:10.1038/nature.2013.13187.

WAGNER, C. S. The new invisible college: science for development. Washington D.C.: Brookings Institution Press, 2009. 
WHYTE, A.; PRYOR, G. Open science in practice: researcher perspectives and participation. The International Journal of Digital Curation, v.6, n.1, p. 199-213, 2011. WOELFLE, M.; OLLIARO, P.; TODD, M. H. Open science is a research accelerator. Nature Chemistry, v.3, n.10, p.745-748, 2011. doi:10.1038/nchem.1149.

WOLKOVICH, E. M.; REGETZ, J.; O'CONNOR, M. I. Advances in global change research require open science by individual researchers. Global Change Biology, v.18, n.7, p. 2102-2110, 2012.

YNALVEZ, M. A.; SHRUM, W. M. Professional networks, scientific collaboration, and publication productivity in resource-constrained research institutions in a developing country. Research Policy, v.40, n.2, p. 204-216, 2011. doi:10.1016/j. respol.2010.10.004. 



\section{6}

\section{Ciência cidadã: modos de participação e ativismo informacional}

Henrique Z. M. Parra

\section{TECNOLOGIAS DE CONHECIMENTO E CONTROLE}

O salto da chamada sociedade da informação para o mundo da inteligência foi tão rápido que temos dificuldade em apreender as profundas transformações e continuidades em jogo. SmartPhone, SmartCity, SmartGrid, SmartHome, SmartTV, SmartCitizen... tecnologias diversas que prometem a gestão eficiente da vida em um mundo sem fricção (para usar um termo caro aos entusiastas da acelerada sucessão tecnológica). O mundo smart, antes presente apenas no discurso corporativo e publicitário, vai sutilmente adentrando novas esferas da vida cotidiana com a disseminação de novos artefatos técnicos. Em todos eles, temos como elemento comum a informatização digital dos processos tecnicamente mediados, combinada à produção contínua de um novo fluxo de informações geradas pelo efeito de coordenação cibernética.

A expansão do codificável, promovida pela informatização e pela convergência digital sobre inúmeras atividades humanas tecnicamente mediadas, cria novas tensões entre dinâmicas que convivem lado a lado: o surgimento de novas formas de produção de conhecimento, graças ao amplo acesso a informações, produzido 
através das interações em redes cibernéticas, simultaneamente à modulação de nossas vidas, à formação da sociedade de controle e à expansão do capitalismo informacional.

Nosso crescente uso de tecnologias digitais de comunicação gera uma infinidade de dados, rastros e indícios sobre nossa existência mediada por esses dispositivos. Consciente ou inconscientemente, transformamos cada ação, cada interação, cada pensamento expresso na rede, em uma nova informação registrável e quantificável. Isso é possível porque a interatividade/o feedback entre entidades comunicantes é um imperativo do desenho sociotécnico da rede, uma característica fundamental para o funcionamento das tecnologias cibernéticas. Ela está na base dos processos colaborativos em redes digitais, nas formas ampliadas da produção científica, nas diversas expressões da ciberpolítica e do ativismo digital, mas também é uma das condições que permitem a expansão da produção e da extração de valor sobre nossas interações na rede ao mesmo tempo em que modificam as formas de exercício do poder nas sociedades contemporâneas.

Simultaneamente ao surgimento de novos conhecimentos e atores cognitivos, observa-se a difusão de outras formas de criação e resistência política, ao lado de iniciativas de participação cidadã ou gestão pública baseadas em mecanismos de interação entre cidadãos e governos (cidadania 2.0; ciberdemocracia, experiências de participação on-line e consulta cidadã). De maneira transversal, palavras como participação, colaboração, transparência, acesso à informação, passam a integrar o vocabulário de ativistas, cientistas, gestores governamentais e de organizações não-governamentais. Mas o que significa participação ou transparência quando o acesso à informação, as mutações nas fronteiras público-privado ou entre o trabalho e o não-trabalho tornam-se fluidas e tecnicamente reguladas?

Amy Kapczynski (2010), ao retomar a tese foucaultiana segundo a qual a produção de novos saberes participa do surgimento de 
formas renovadas de governo (governamentalidade e biopolítica), interroga se estaríamos vivendo um momento análogo diante das formas de conhecer inauguradas pela expansão das tecnologias digitais. Indicialidade, rastreabilidade, simulação computacional, produção distribuída (crowdsourcing), mineração de dados, fenômenos de emergência, análise de padrões, entre outras, são alguns dos elementos que passam a compor um novo repertório metodológico e epistemológico. Alguns autores referem-se a elas como ciências do silício, ciberciências, entre outras denominações (PARRA, 2014a). Mas quais são as características e os problemas colocados por essas formas de conhecer inauguradas pelas tecnologias digitais?

Analisamos questões semelhantes em outros trabalhos ${ }^{1}$. Neste capítulo, dirigimos nossa atenção para alguns casos empíricos brasileiros, destacando as formas de participação e colaboração entre cientistas e não-cientistas implicadas nesses modos de conhecer, bem como os desafios decorrentes da mediação digital no processo investigativo. Mais especificamente, no capítulo discute-se como algumas experiências de ciência cidadã são desafiadas a colocar a prática científica na fronteira do ativismo político e informacional. Indiretamente, pretendemos indagar as possibilidades e os limites para a produção de conhecimento no campo das ciências humanas através das tecnologias digitais: como delinear a tênue fronteira entre as humanidades digitais, a engenharia social, o capitalismo cognitivo e a formação da sociedade de controle?

\section{CIÊNCIA CIDADÃ E MODOS DE PARTICIPAÇÃO}

Observamos, na última década, uma diversificação nas formas de colaboração entre cientistas, cidadãos e pesquisadores

\footnotetext{
1 Em trabalhos anteriores discutimos as relações entre a expansão das tecnologias digitais de comunicação, as formas de exercício do poder emergentes e as novas configurações do capitalismo contemporâneo (PARRA, 2009; 2014a).
} 
não-acadêmicos, reinventando a dimensão pública da ciência e transformando tanto as relações entre amadores e profissionais como as próprias dinâmicas de produção, validação, difusão e apropriação dos conhecimentos produzidos. Excelente levantamento dessas experiências são os trabalhos de Antonio Lafuente (2010; 2011; 2013) analisando a pluralidade de modos de conhecimento que estão atualmente se constituindo. Observa-se a multiplicação dos atores cognitivos-políticos que entraram em cena (comunidades afetadas, pacientes, movimentos sociais etc.); dos locais e instituições de produção e difusão de novos saberes (associações, universidades livres, coletivos on-line); de novas comunidades e práticas epistêmicas. Um universo de conhecimentos que às vezes ignora sua própria diversidade, às vezes convive de maneira pacífica e, em outros casos, conflita de forma violenta. Acreditamos que não se trata apenas de uma mudança quantitativa na produção de informações e conhecimentos, mas que estamos vivendo a emergência de novas formas de conhecer cujas características (epistemes, metodologias e cosmologias) estão sob disputa.

Muitas dessas experiências de colaboração entre cientistas profissionais e cidadãos interessados (que em alguns casos são reconhecidos como pesquisadores amadores) têm sido reunidas sob o nome de ciência cidadã. Em 2013, o Green Paper on Citizen Science - relatório de pesquisa que apresenta um conjunto de avaliações e sugestões para futura elaboração de políticas públicas - foi produzido pelo Socientize Consortium ${ }^{2}$ para a Comissão Europeia da Unidade de Ciência Digital, iniciativa no âmbito da "Europa 2020: Estratégia para um crescimento inteligente, sustentável e inclusivo"3.

2 O portal eletrônico do Consórcio está disponível em http://www.socientize.eu/?q=eu Acesso em 11 jun. 2015.

3 Site da iniciativa Europa 2020 com versão em português disponível em http://ec.europa. eu/europe 2020/europe-2020-in-a-nutshell/index_pt.htm Acesso em 11 jun. 2015. 
O documento realiza uma interessante compilação de experiências de ciência cidadã na Europa, aponta suas condições de desenvolvimento e os desafios que estão colocados para seu fomento em direção às políticas de inovação científica e tecnológica, objetivos definidos no Europa 2020 como parte de uma estratégia política mais ampla para o desenvolvimento econômico e social. Conforme o próprio relatório descreve, não há ainda uma definição consolidada para a noção de ciência cidadã:

Podem-se encontrar diferentes definições para Ciência Cidadã. Algumas assumem aspectos mais tradicionais, entendendo Ciência Cidadã como uma abordagem que envolve voluntários do público em geral nas investigações científicas durante o processo de coleta e análise de dados. Outras definições são mais amplas, como sendo o público participante nas investigações científicas incluindo atividades como a realização das perguntas, elaboração de hipóteses e interpretação dos resultados. As discussões atuais em torno da definição de ciência cidadã não estão apenas focadas no escopo das atividades, mas também interrogam o que pode ser entendido por "voluntário" e como as equipes de ciência cidadã podem ser compostas. O que ainda não podemos encontrar é uma definição amplamente aceita de ciência cidadã. (SOCIENTIZE CONSORTIU, 2013, p. 22) ${ }^{4}$.

Ainda assim, o mesmo documento indica um conjunto de elementos que nos ajudam a circunscrever essas experiências:

\footnotetext{
4 "Different definitions can be found for Citizen Science, where some take up more traditional aspects, understanding Citizen Science as an approach, which involves volunteers from the general public in scientific investigations during data collection and analysis. Others define it more broadly, as the public participating in scientific research, which includes also scientific activities like the asking of questions, formulation of hypotheses, interpretation of results. Current discussions around the definition of citizen science not only focus on the scope of activities but also what to understand under "volunteers" and how to composite citizen science teams. What we cannot find is one generally accepted definition of citizen science yet". (SOCIENTIZE Consortium, 2013, p. 22).
} 
Ciência cidadã refere-se ao engajamento do público em geral nas atividades de pesquisa científica quando os cidadãos contribuem ativamente para a ciência, seja com seu esforço intelectual, com seu conhecimento local ou com suas ferramentas e recursos. Os participantes fornecem dados experimentais e instalações para pesquisadores, elaboram novas questões e criam conjuntamente uma nova cultura científica. Enquanto agregam valor, os voluntários adquirem de forma instigante novos aprendizados e habilidades e um conhecimento mais profundo do trabalho científico. Como resultado deste cenário de abertura, transdisciplinar e conectado em redes, as interações entre ciência, política e sociedade são aprimoradas em direção a uma democratização da pesquisa baseada em processos de decisão informados por evidências. (SOCIENTIZE CONSORTIUM, 2013, p. 6) $)^{5}$.

Para avançar no detalhamento das diferentes expressões da ciência cidadã utilizarei uma tipologia elaborada por Alexander Hallavais (2013). Em seu trabalho, assim como no consórcio Socientize, a produção de conhecimento científico é analisada no entrecruzamento dos seguintes fenômenos: a expansão das tecnologias de comunicação digital, da colaboração distribuída (crowdsourcing) e do uso de grandes bancos de dados (big data). É vista, portanto, sob a ótica de novas oportunidades para a colaboração entre cientistas, cidadãos e instituições científicas, mas também para ampliação das possibilidades de produção, coleta, compartilhamento e análise dos dados. Insere-se, portanto, na perspectiva de aplicação do

5 "Citizen Science refers to the general public engagement in scientific research activities when citizens actively contribute to science either with their intellectual effort or surrounding knowledge or with their tools and resources. Participants provide experimental data and facilities for researchers, raise new questions and co-create a new scientific culture. While adding value, volunteers acquire new learning and skills, and deeper understanding of the scientific work in an appealing way. As a result of this open, networked and trans-disciplinary scenario, science-society-policy interactions are improved leading to a more democratic research based on evidence-informed decision making" (SOCIENTIZE Consortium, 2013, p. 6). 
conhecimento científico em um modelo de desenvolvimento cujas premissas não serão aqui analisadas.

Hallavais comenta que muitas dessas experiências partilham de um entendimento público da ciência, percebido nas seguintes direções: (1) envolvem a alfabetização e a difusão científica; (2) são práticas que criam formas de participação pública na realização de pesquisas ou que buscam legitimação através da consulta pública sobre decisões científicas; (3) manifestam-se em torno de pesquisas não realizadas (undone science), nas reivindicações de temas ou problemas que não são investigados e que deveriam ser abordados pela ciência institucionalizada.

A partir dessas três abordagens, Hallevais (2013) propõe quatro modelos para tipificar a ciência cidadã. Ainda que o enquadramento formal seja insuficiente para abarcar a complexidade dos casos, ele contribui para a compreensão dos principais vetores presentes na organização do campo. Paralelamente ao quadro proposto pelo autor, desenvolverei argumentos complementares e, sempre que possível, fornecerei exemplos brasileiros relacionados, principalmente, ao campo das ciências humanas, socioambientais e da comunicação ${ }^{6}$.

Na primeira situação - Modelo A — inserem-se as experiências de colaboração entre os próprios cientistas e suas instituições. A informatização e a convergência digital criaram novas possibilidades

6 A escolha deste recorte justifica-se pelas seguintes razões: são áreas do conhecimento com que tenho maior familiaridade e pelas quais me interesso; são casos menos conhecidos, dado que nas ciências exatas e biológicas há maior visibilidade dessas iniciativas. Para um escopo mais amplo desta temática no Brasil veja o mapeamento colaborativo (em processo) sobre ciência aberta - https://pt.wikiversity.org/wiki/ Pesquisa:Ci\%C3\%AAncia_ aberta_no_Brasil. Acesso em 11 jun. 2015. 
de pesquisa e de compartilhamento de dados ${ }^{7}$. Tanto nas ciências humanas que agora enveredam pelas humanidades digitais, como nas demais ciências, surgem novas formas de compartilhamento de recursos, metodologias e conhecimentos produzidos que passam a exigir a criação de novos protocolos em diversas etapas da atividade científica.

Neste caso, é importante destacar que uma das condições para que tal modelo se realize é o grau de abertura praticado pelo cientista. Há diferentes entendimentos sobre o conceito de ciência aberta. O grupo de trabalho brasileiro Ciência Aberta ${ }^{8}$ utiliza em seu site uma definição abrangente proposta por Michael Nielsen: “[....] a ideia de que o conhecimento científico, de todos os tipos, deve ser compartilhado abertamente tão cedo quanto praticável no processo de descoberta". A partir de informações disponíveis no site deste mesmo grupo podemos adicionar outras características que também estariam presentes na ciência aberta, tais como: o "[....] desenvolvimento de padrões, software, hardware, insumos, metodologias e instrumentos de pesquisa como recurso comum"; ou o “[....] desenvolvimento do processo científico em registro público imediato e permanente, com colaboração aberta a todos" ${ }^{\text {. Na prá- }}$ tica concreta, todavia, tais definições produzirão um leque diverso de experiências em que as próprias noções de abertura, comum, transparência, público adquirem sentidos distintos.

\footnotetext{
7 Alguns exemplos que podemos citar: Grupo de Pesquisa em Humanidades Digitais https://humanidadesdigitais.wordpress.com/ ou http://hdbr.hypotheses.org/ ; Associação de Humanidades Digitais (Lusófona) - http://ahdig.org ; Grupo de Pesquisa História, Mapas e Computadores (HÍMACO) que realiza pesquisas históricas com ferramentas e metodologias de sistemas informacionais geográficos (SIGs) http://www2.unifesp.br/himaco/ ; Projeto Arquigrafia, que compartilha um importante acervo imagético da arquitetura brasileira - http://www.arquigrafia.org.br. Acesso em 11 jun. 2015.

8 Plataforma do grupo de trabalho Ciência Aberta - http://www.cienciaaberta.net/

9 Ciência Aberta na plataforma Wikiversity em português: https://pt.wikiversity.org/wiki/ Portal:Ciência_Aberta Acesso em 11 jun. 2015.
} 
Em uma segunda situação - Modelo B - o público está presente como produtor ou coletor de dados. Como descrito acima, a informatização e a convergência digital ampliaram o universo do codificável digitalmente. A presença de dispositivos digitais em objetos e processos também se beneficia da miniaturização e da queda dos custos de produção. Há, em todas as partes, sensores que produzem dados muito diversos (temperatura em um determinado ambiente, número de pessoas que cruzam certo local etc.); nossos dispositivos de comunicação geram e captam tantas outras informações (velocidade de deslocamento, coordenadas de GPS, volume do som ambiente etc.). De certa forma, como descrito por Latour (2004), o laboratório está em toda parte, e todos nós participamos, voluntária ou involuntariamente, de novos experimentos coletivos ${ }^{10}$. Neste modelo, conforme proposto por Hallavais, temos um gradiente de situações. Em alguns casos os cidadãos simplesmente fornecem dados (preenchimento de formulários, tabelas etc.) que alimentam bancos de dados ${ }^{11}$; ou disponibilizam informações pessoais produzidas pelo uso cotidiano de dispositivos digitais (seu deslocamento diário ou o grafo de suas relações em uma rede digital); mas há também situações nas

10 Pesquisas colaborativas sobre condições climáticas são um bom exemplo. No projeto Estação Meteorológica Modular os autores estão interessados tanto no fomento de uma rede de produção e coleta de dados como na sua possível aplicação na educação básica http://cta.if.ufrgs.br/projects/estacao-meteorologica-modular/wiki/Wiki\#Sobre-o-projeto . Outro exemplo interessante é a plataforma InfoAmazonia: uma combinação de investigação cidadã distribuída, jornalismo ambiental e investigativo com disponibilização de dados abertos - http://infoamazonia.org. Acesso em 11 jun. 2015.

11 Exemplos interessantes sobre problemas sociais e ambientais: mapeamento colaborativo sobre a falta de água na cidade na Região Metropolitana de São Paulo (https://www. facebook.com/faltouagua/); coleta de dados sobre incêndios em favelas na cidade de São Paulo e sua possível relação com outras dinâmicas urbanas (http://blog.fogonobarraco. laboratorio.us/sobre-o-projeto-como-ajudar/); plataforma colaborativa para o monitoramento de situações socioambientais no litoral norte de São Paulo - http://www.simapln. com.br/ . Acesso em 11 jun. 2015. 
quais os cidadãos atuam na filtragem, seleção e identificação de casos $^{12}$. A relação entre cientistas e o público neste modelo comporta diferentes divisões no trabalho no interior do processo de produção de conhecimentos. Entretanto, são os cientistas os responsáveis pela análise final, sistematização e formalização do conhecimento produzido.

Em uma terceira composição - Modelo C - é o público que analisa os dados produzidos ou disponibilizados por cientistas profissionais, instituições científicas ou órgãos governamentais. Hallavais insere neste quadro diversas iniciativas relacionadas às práticas de dados abertos (open data) onde os cidadãos podem fazer livre uso das informações disponibilizadas pelas instituições. Neste caso, podemos citar experiências de utilização, pelo público, de dados governamentais ou científicos ${ }^{13}$; iniciativas baseadas na abertura de dados governamentais, que permitem aos cidadãos elaborar novas análises sobre dados públicos ${ }^{14}$; e, também, práticas de

12 Projeto ForestWatchers conduzido pela Universidade Federal de São Paulo com diversos parceiros da sociedade civil (http://forestwatchers.net/pt-br/). Acesso em 11 jun. 2015. 13 O projeto Cuidando do Meu Bairro, coordenado por professores da Universidade de São Paulo, analisa dados governamentais do orçamento público e produz mapeamentos colaborativos e análises contextualizadas junto à organizações da sociedade civil - http:// cuidando.org.br/ Acesso em 11 jun. 2015.

14 Em 2011 foi aprovada no Brasil a Lei de Acesso à Informação (Lei 12527), introduzindo um importante conjunto de diretrizes para a disponibilização pública de dados governamentais - http://www.planalto.gov.br/ccivil_03/_ato20112014/2011/lei/l12527.htm . Veja também o portal do governo brasileiro que disponibiliza esses dados - http://dados.gov. $\mathrm{br} /$. Paralelamente, na sociedade civil, há diversas iniciativas que atuam tanto para efetivar uma maior abertura desses dados quanto no sentido de sua análise para produção de novas informações: http://databr.io/; http://www.infopatrimonio.org; http://escoladedados. org/.Acesso em 11 jun. 2015. 
jornalismo de dados ${ }^{15}$ ou investigativo ${ }^{16}$ poderiam ser enquadradas nesta tipologia.

Para que tais práticas sejam mais eficientes e robustas, é necessário que os dados abertos sigam determinadas especificações, o que não acontece em muitos casos. Trata-se, em suma, de respeitar protocolos que determinam as possibilidades de uso, modificação, interoperabilidade, difusão e reapropriação. Afinal, não basta disponibilizar informações, é necessário que elas estejam disponíveis para diversas finalidades e formas de uso.

Assim como a noção de ciência aberta, a definição de dados abertos é campo de inúmeras controvérsias. Como veremos na parte final do texto, a forma de abertura de informações em suporte digital tem evidentes consequências sobre o regime de produção de conhecimentos, sua economia (monetária ou simbólica) e a distribuição do poder relacionada ao uso da informação. Podemos tomar como referência inicial a definição proposta pela iniciativa OpenData ${ }^{17}$ : "[...]dados abertos significa que qualquer pessoa pode livremente acessar, usar, modificar e compartilhar para qualquer propósito (ressalvados, no máximo, os requisitos de preservação da origem e abertura)" ou ainda, "[...] dados abertos e conteúdos

15 Há um conjunto diverso de experiências de jornalismo de dados, praticado tanto por grandes jornais brasileiros (veja o caso do jornal O Estado de S. Paulo - http://blog.estadaodados.com/) como por iniciativas associativas e independentes de jornalistas (veja o caso do coletivo Hacks Hackers - http://hackshackers.com/ ou o projeto Jornalismo Digital - http://www.jornalismodigital.org/). Acesso em 11 jun. 2015.

16 Há algumas iniciativas interessantes de jornalismo investigativo no Brasil que combinam estratégias inovadoras de comunicação e visibilidade das narrativas, com processos investigativos rigorosos e posterior disponibilização dos dados pesquisados. Veja os casos de APública (Agência de Reportagem e Jornalismo Investigativo) - http://apublica.org/, e Repórter Brasil - http://reporterbrasil.org.br/ Acesso em 11 jun. 2015.

17 "[...] open means anyone can freely access, use, modify, and share for any purpose (subject, at most, to requirements that preserve provenance and openness)" ou ainda, "[...] open data and content can be freely used, modified, and shared by anyone for any purpose". Sítio da iniciativa Open Data está disponível em: http://opendefinition.org Acesso em 11 jun. 2015. 
podem ser livremente utilizados, modificados e compartilhados por qualquer pessoa para qualquer fim”. Dentro desta proposição, é necessário que um conjunto de requisitos mais específicos seja atendido, pois a condição para efetiva abertura depende de fatores socioculturais (práticas), jurídicos (normas e leis), econômicos (regime de propriedade e uso) e sociotécnicos (padrões, especificações, formatos para processamento em máquinas ${ }^{18}$.

Finalmente, no Modelo D, os cidadãos participam de todas as etapas do processo de produção, sistematização e difusão de novos conhecimentos. O público atua como produtor e coletor de dados, analisa os resultados e pode elaborar novas questões para a pesquisa. Hallavais insere neste quadro algumas experiências de indivíduos ou grupos que atuam como pesquisadores autônomos, como nos casos de investigações auto-orientadas ${ }^{19}$ ou nas iniciativas de colaboração distribuída (crowdsourcing) como a Wikipedia e Open Street Maps $^{20}$.

Seguindo a mesma tipologia, poderíamos incluir neste modelo outras iniciativas de ciência cidadã desenvolvidas por pesquisadores envolvidos em investigações participativas organizadas em conjunto com movimentos sociais, comunidades afetadas ou

18 Uma apresentação dos 11 tópicos que abrangem a descrição completa de dados abertos em português está disponível em: http://opendefinition.org/od/1.1/pt-br/ Acesso em 11 jun. 2015.

19 Exemplos deste caso, segundo Hallavais, podem ser observados nas diversas práticas de automonitoramento pessoal voltadas ao campo da saúde e do comportamento. $\mathrm{O}$ projeto Quantified Self-Self Knowledge Through Number - http://quantifiedself.com/ - dedica-se a investigar e disseminar diversas experiências de utilização de dispositivos digitais para o autoconhecimento. Muitas dessas práticas fazem uso de plataformas on-line para compartilhar os dados individuais e disponibilizá-los para novas investigações, especialmente na área da saúde. Há controvérsias sobre as implicações sociais e políticas dos possíveis usos dessas informações que merecem uma discussão detalhada, mas que escapam ao escopo deste artigo.

20 Wikipedia - http://www.wikipedia.org/; Open Street Maps - http://www.openstreetmap. org Acesso em 11 jun. 2015. 
grupos ativistas na produção de conhecimentos situados (HARAWAY, 1995) que irão, inclusive, produzir uma contra-expertise que disputará com outros atores institucionais a análise de alguns fenômenos. Todavia, diferentemente dos casos até aqui indicados, a utilização das tecnologias digitais, seja como instrumento de pesquisa ou como recurso que promove a integração entre cientistas e amadores, não aparece como principal vetor de caracterização dessas experiências, mas, sim, como parte integrante das metodologias em que o fundamental é a colaboração socialmente orientada ${ }^{21}$.

A pesquisa participativa não é novidade nas ciências humanas, e muito já foi produzido sobre as metodologias de pesquisa-ação, observação participante (entre outras denominações) no campo da sociologia, da antropologia, das ciências socioambientais, por exemplo. Há, todavia, práticas importantes que irão retomar essas correntes metodológicas para combiná-las à utilização de tecnologias digitais, criando outras possibilidades de investigação

21 Um interessante movimento que reúne diversas iniciativas orientadas pela democratização da produção científica pode ser encontrado na rede Movimento de Ciência Cidadã. Os objetivos dessa iniciativa são: "(1) Reunir os pesquisadores, os cientistas críticos e os cidadãos engajados motivados nas lutas sociais da agricultura, da alimentação, da habitação, da saúde e do ambiente. (2) Associar, em uma reflexão e uma ação transversal de democratização da ciência e da peritagem, e o empoderamento da sociedade civil, daqueles atores mais capacitados e ora isolados na organização compartimentada da ciência e da tecnologia. (3) Elaborar, propor, promover novas formas de fazer ciência em democracia, com a participação dos sujeitos (Convenções de Cidadãos, pesquisa participativa, Fóruns populares de educação científica, lojas de ciências, tecnologias sociais...) e submetê-las aos legisladores quando a ocasião se apresentar". Disponível em: http://www.movimentocienciacidada.org/ Acesso em 11 jun. 2015. 
e produção de conhecimentos ${ }^{22}$. No campo das ciências sociais ainda podemos citar algumas experiências de antropologia e sociologia visual em que os diversos atores e grupos partícipes atuam nas diferentes fases de elaboração do projeto de investigação e produção visual (fotográfica, audiovisual, cartográfica) ${ }^{23}$. Mas talvez, os casos em que a utilização das tecnologias digitais transbordam para além de um uso mais instrumental são aqueles em que observamos uma apropriação que intensifica suas especificidades tecnopolíticas ${ }^{24}$.

A despeito da ampliação, nas condições de participação cidadã na produção e no acesso ao conhecimento, há dimensões pouco exploradas nos modelos descritos acima: as diferentes condições de acesso à informação entre os cidadãos e cientistas; as possibilidades desiguais de apropriação, aplicação e ressignificação dos conhecimentos produzidos; os efeitos desiguais da circulação desses conhecimentos; ou mesmo os efeitos relativos às características

22 O Instituto Socioambiental - http://www.socioambiental.org/pt-br - tem uma trajetória de 20 anos de atuação em projetos de pesquisa e promoção dos direitos socioambientais, trabalhando conjuntamente às comunidades indígenas, quilombolas e outras comunidades tradicionais. Em muitos trabalhos a utilização de novas ferramentas para a produção de cartografias participativas, para a criação de redes alternativas de comunicação e documentação multimídia são recursos fundamentais. Outra experiência relevante em temas próximos, que gostaríamos de apontar, é o projeto Nova Cartografia Social da Amazônia - http://novacartografiasocial.com . Em ambas as experiências vale destacar o esforço de constituição de programas focados na produção de conhecimentos e formação contínua no encontro de diferentes saberes. Veja https://ensinosuperiorindigena.wordpress.com e http://novacartografiasocial.com/quadro-de-projetos/\#cienciasesaberes Acesso em 11 jun. 2015.

23 Um bom exemplo de pesquisa e documentação multimídia sobre Cidade Tiradentes, bairro da cidade de São Paulo - http://www.fabricadecultura.org.br/cidadetiradentes/ ; os trabalhos em fotografia e vídeo realizados pelo VISURB - Grupo de Pesquisas Visuais e Urbanas - http://visurb-unifesp.wix.com/visurb-unifesp Acesso em 11 jun. 2015.

24 O trabalho da Rede Mocambos, relacionada à temática quilombola, é um bom exemplo de uso experimental das tecnologias de comunicação digital - http://www.mocambos.org/ wiki/P\%C3\%A1gina_principal Acesso em 11 jun. 2015. 
das camadas (física e lógica; hardware e software) que realizam a mediação digital. Com relação a esta última, na medida em que a comunicação em redes digitais se torna cada vez mais reticular e ubíqua, ela tende a se tornar invisível ou natural. Aqui, tanto a posição ocupada no interior da estrutura da rede como a capacidade de controle sobre o funcionamento dos software e hardware utilizados torna-se altamente estratégica. Neste sentido, se por um lado, observamos o surgimento de novas condições de participação cidadã na produção científica, por outro é necessário explorar as dificuldades que surgem para que a colaboração entre cientistas e não-cientistas possa de fato criar relações e saberes orientados por princípios mais democráticos.

\section{ACESSO AO CONHECIMENTO E ATIVISMO INFORMACIONAL}

A dimensão dos objetivos e valores de uma ciência cidadã é indissociável da questão dos meios e processos necessários para sua realização. Na medida em que as características e efeitos das tecnologias digitais utilizadas no processo investigativo resultam de uma complexa dinâmica sociotécnica (PARRA, 2014b), as práticas de ciência aberta e cidadã em suas versões mais radicais adentram um campo propriamente tecnopolítico.

Um dos desafios frequentemente enfrentados é aquele relativo às condições de acesso e uso das informações. Ele está presente tanto no caso da colaboração direta entre cientistas, como nos casos de colaboração entre cientistas e não-cientistas. A quem pertencem os dados? Que usos podem ser feitos deles? Quais as possibilidades de interoperabilidade e acesso para outras pesquisas? Qual o seu regime de propriedade?

Nesta dimensão, as possibilidades de compartilhamento inauguradas pelas tecnologias digitais colidem com as tendências de mercantilização e privatização dos conhecimentos produzidos. Os novos enclosures (para usar a feliz expressão de James Boyle) sobre 
a produção do comum (informação, conhecimento e cultura) realizam-se tanto através da expansão do regime jurídico de propriedade intelectual como através da adoção tecnológica de software e hardware proprietários que limitam as possibilidades de uso, modificação e reapropriação das informações.

Para além do acesso às informações produzidas, o mesmo problema se aplica na utilização de software e hardware para a pesquisa. Espera-se que a investigação realizada através de tecnologias digitais seja, assim como toda pesquisa científica, aberta ao escrutínio de outros interessados. Neste sentido, como analisar os efeitos dos algoritmos, dos software ou hardware no percurso da coleta, processamento e análise dos dados, quando os mesmo estão fechados tanto por leis de propriedade intelectual como pela adoção de bloqueios tecnológicos?

Portanto, a dimensão pública e cidadã da ciência, realizada através das tecnologias digitais, adquire um sentido forte e atualizado. Uma controvérsia interessante ocorreu recentemente, quando pesquisadores da Universidade de Princeton em parceria com o Facebook realizaram um experimento de contágio emocional nas redes digitais ${ }^{25}$. A polêmica decorrente deste trabalho, publicado na prestigiada revista da PNAS, concentrou-se nas questões éticas relativas ao consentimento informado e privacidade dos participantes ${ }^{26}$. Todavia, uma dimensão não explorada neste evento diz respeito ao desconhecimento sobre o funcionamento do software do próprio Facebook, responsável pelos modos de interação entre os usuários e as informações publicadas. Ora, como garantir a dimensão pública da ciência quando desconhecemos o funcionamento de muitas

$25 \mathrm{O}$ artigo Experimental evidence of massive-scale emotional contagion through social networks, de autoria de Adam D. I. Kramer, Jamie E. Guillory e Jeffrey T. Hancock está disponível em: http://www.pnas.org/content/111/24/8788.full Acesso em 11 jun. 2015.

26 Diante da polêmica a revista publicou um editorial sobre as novas questões éticas implicadas no trabalho com o big data: http://www.pnas.org/content/111/29/10779.1.full Acesso em 11 jun. 2015. 
das tecnologias proprietárias utilizadas? Neste sentido, os cientistas interessados na ciência aberta ou cidadã ${ }^{27}$ tornam-se solidários dos ativistas do livre acesso à informação e conhecimento ${ }^{28}$ e dos tecnoativistas do software e hardware livres ${ }^{29}$.

Reconhecer o caráter não-semântico (abstrato-formal) da informação digital e a maneira como tal concepção participa de um modelo de produção científica promovido na convergência NBIC - nanotecnologia-biotecnologia-informática-ciências cognitivas é importante para contextualizarmos criticamente algumas pesquisas amparadas no big data. Frequentemente, confrontamo-nos com o risco da descontextualização do processo inicial de construção do dado digital. A própria definição do que é ou não escolhido como elemento indicial que irá gerar a informação digital é, por si só, um campo de disputa política. Tal reivindicação, por argumentos mais simples e diretos, é expressa na luta de movimentos sociais e grupos tecnoativistas que interrogam a utilização das tecnologias digitais para o controle social quando, baseadas

27 Na Universidade Federal do Rio Grande do Sul temos o Centro de Tecnologia Acadêmica - http://cta.if.ufrgs.br/ - que desenvolve software e hardware livres para aplicação científica; na Universidade de São Paulo podemos citar o Grupo de Pesquisa em Políticas Públicas para o Acesso à Informação - http://www.gpopai.usp.br/wiki/index.php/P\%C3\%A1gina_ principal ; na Universidade Federal de São Paulo citamos o Pimentalab - Laboratório de Tecnologia, Política e Conhecimento - http://blog.pimentalab.net Acesso em 11 jun. 2015. 28 A iniciativa Transparência Hacker talvez seja a rede com maior amplitude e que abriga uma grande diversidade de projetos relacionados à práticas de acesso à informação, transparência e apropriação crítica de dados no Brasil - http://thacker.com.br Acesso em 11 jun. 2015.

29 Reivindicações pelo livre acesso à informação e adoção de tecnologias livres estão presentes em diversos grupos brasileiros. Há uma forte comunidade de promoção do software livre no país - http://softwarelivre.org/- e um crescente movimento faça-você-mesmo (do-it-yourself) com inspiração na cultura hacker: Garoa Hacker Club - https://garoa.net.br/ wiki/P\%C3\%A1gina_principal ; e Metarreciclagem - http://rede.metareciclagem.org/ . O governo brasileiro também mantém alguns projetos específicos de apoio ao software livre como estratégia de desenvolvimento tecnológico e econômico: http://www. softwarelivre. gov.br/ e https://portal.softwarepublico.gov.br/social/ Acesso em 11 jun. 2015. 
na produção de perfis (profilling), definem ações gestionárias (políticas públicas) para cidadãos que se encaixam em um perfil de ameaça potencial. Neste sentido, problemas relativos à privacidade, proteção de dados pessoais e liberdade de expressão adquirem nova relevância política ${ }^{30}$.

Em uma outra direção, problemas relativos à economia política da informação também são enfrentados pelos cientistas. Como bem discutido por Amy Kapczynski (2010), a ciência aberta baseia-se, afinal, no promoção do commons intelectual ou em um mercado de permissões flexíveis amparado em uma concepção de propriedade intelectual? O trocadilho free from market ou free for market resume bem esta ambiguidade. Em algumas universidades brasileiras onde o modelo de privatização do conhecimento (patentes, marcas e direitos autorais) é a dinâmica dominante, praticar ciência aberta em uma direção não-mercantil torna-se um ação de resistência política que visa tornar público e de livre acesso o conhecimento científico produzido, na maior parte das vezes, com recursos públicos ${ }^{31}$.

A mediação digital introduz ainda um problema relativo à posse e acesso de dados sensíveis. Nestes casos, como regular a fronteira entre dados públicos e privados? Como garantir a privacidade? Como evitar que dados sensíveis, mesmo anonimizados, não sejam utilizados por governos ou empresas em modelizações visando à obtenção de vantagens no controle (político ou econômico) sobre os cidadãos? Uma vez que tanto o Estado como inúmeras corporações

30 No Brasil podemos indicar alguns grupos tecnoativistas que atuam em temáticas relativas à promoção da privacidade, segurança, liberdade de expressão: Actantes http://actantes.org.br ; Saravá - https://www.sarava.org/ . Acesso em 11 jun. 2015.

31 Um exemplo interessante foi a elaboração de uma proposta coletiva submetida ao Congresso da Universidade Federal São Paulo, onde foram discutidos temas norteadores da organização universitária. Veja a proposta "Deve o conhecimento ser livre? Sim!" Disponível em: http://pimentalab.milharal.org/2014/08/28/deve-o-conhecimento-ser-livre-sim/ Acesso em 11 jun. 2015. 
privadas são detentoras de grandes bancos de dados com informações sobre amplos aspectos da vida dos indivíduos, como evitar a emergência de um poder tirânico baseado no controle assimétrico dessas informações? Este é um problema difícil de ser enfrentado uma vez que as tecnologias digitais em redes cibernéticas produzem um novo volume de dados que, quando agregados, tornam-se muito valiosos para a ciência, para o Estado e para as corporações. Em suma, as possibilidades de novos saberes caminham lado a lado com as novas possibilidades de poder.

Após aprovação do Marco Civil da Internet em 2014 no Brasil, a demanda por uma nova regulamentação jurídica para a proteção de dados pessoais emerge como fronteira atual do debate público sobre a gestão dos dados informáticos em redes digitais. Em um seminário recente, o diretor responsável pela base de dados dos cidadãos brasileiros no Sistema Único de Saúde (SUS) afirmou: “(....) os dados pertencem ao cidadão"32. Mas o que exatamente significa este pertencer quando os dados são gerados, transmitidos, guardados e analisados em tantas mediações tecnológicas que desconhecemos quem e sob que condições é possível acessar tais informações? Portanto, é preciso interrogar qual o grau de autonomia possível para o cidadão comum em relação ao controle dos seus próprios dados, especialmente em relação a usos futuros ainda indeterminados.

Finalmente, talvez seja o momento de retomarmos a discussão de soberania tecnológica para além da concepção de soberania do estado-nação. Hacktivistas e tecnoativistas argumentam que a autonomia individual e coletiva depende da capacidade de usuários controlarem ao máximo as mediações tecnológicas implicadas em suas

32 Conforme reportagem publicada no sítio Convergência Digital: "Marco Civil: Saúde decide que o dado pertence ao cidadão". Disponível em: http://convergenciadigital.uol. com.br/cgi/cgilua.exe/sys/start.htm?amp\%253bpost\%255Fdata=\&infoid=37483\&sid=21 . Acesso em 28 jun. 2015 
vidas $^{33}$. Se tomarmos tal proposta em um sentido diverso da tecnoutopia liberal ou comunitarista, podemos inscrevê-la na direção de uma nova soberania (LATOUR, 2004) fundada por uma comunidade capaz de reconhecer, simultaneamente, a dimensão política da vida social e dos artefatos técnicos. Não é mais possível negligenciar as especificidades sociotécnicas e o horizonte político-cultural que conformam o ambiente tecnológico em que nossas vidas estão envoltas. Neste sentido, a produção de conhecimentos que esteja orientada pela promoção de modos de vida mais livres e solidários, coloca lado a lado cientistas, hacktivistas, bibliotecários, cidadãos e cypherpunks!

\section{REFERÊNCIAS}

HACHÉ, Alex (Ed.). Soberania tecnológica. Dossier Ritimo, 2014. Disponível em: http://www.plateforme-echange.org/IMG/pdf/dossier-st-cast-2014-06-30.pdf. Acesso em: 11 jun. 2015.

HALAVAIS, Alexander. Home made big data? Challenges and opportunities for participatory social research. First Monday, v. 18, n.10, 7 Oct. 2013.

HARAWAY, Donna. Saberes localizados: a questão da ciência para o feminismo e o privilégio da perspectiva parcial. Cadernos Pago, n.5, p.7-41, 1995.

KAPCZYNSKI, Amy. Access to knowledge: a conceptual genealogy. In: KRIKORIAN, Gaëlle; KAPCZYNSKI, Amy (Ed.). Access to knowledge in the age of intellectual property. [S.1.] Zone Books/MIT Press, 2010.

LAFUENTE, Antonio; ANDONI, Alonso. Amateur versus professionals politics, citizenship and science. International Journal of Technoethics (IJT), v.1, p. 2, 2010. Acesso em: 8 abr. 2012. doi:10.4018/jte.2010040105.

LAFUENTE, Antonio; ANDONI, Alonso. Ciencia expandida, naturaleza común y saber profano. Bernal: Univ. Nacional de Quilmes Editorial, 2011.

33 Há um excelente dossiê dedicado à discussão sobre soberania tecnológica editado por Alex Haché (2014). Além de examinar os diversos requisitos e características tecnológicos nas diversas camadas implicadas na comunicação em redes digitais, o dossiê apresenta experiências práticas de aplicação do conceito de soberania tecnológica. 
LAFUENTE, Antonio; ANDONI, Alonso; RODRIGUES, Joaquim. Todos sábios! Madrid: Ediciones Cátedra, 2013.

LATOUR, Bruno. Which protocol for the new collective experiments? In: SCHMIDGEN, H.; GEIMER, P; DIERIG, S. (Ed.). Kultur im experiment. Berlim: Kadmos Verlad, 2004. p.17-36.

PARRA, Henrique Z. M. Sujeito, território e propriedade: tecnologias digitais e reconfigurações sociais. Contemporânea - Revista de Sociologia da UFSCar, São Carlos, v.4, n. 1, p.183-209, jan./jun. 2014a. Disponível em: http://www.contemporanea. ufscar.br/index.php/contemporanea/article/download/203/107. Acesso em: 11 jun. 2015.

- Ciências humanas e mediação sociotécnica: questões sobre a tecnicidade do digital em redes cibernéticas. Liinc em Revista, v.10, n. 2, 2014b. Disponível em: http://revista.ibict.br/liinc/index.php/liinc/article/view/712/495. Acesso em: 11 jun. 2015.

- Controle social e prática hacker: tecnopolítica e ciberpolítica em redes digitais. Sociedade e Cultura, Faculdade de Ciências Sociais da Universidade Federal de Goiânia, v. 15, n. 1, p. 109-120, jan./jun. 2012. Disponível em: http:// www.revistas.ufg.br/index.php/fchf/article/download/20677/12328. Acesso em: 11 jun. 2015.

Política e medialidade nas redes digitais. ComCiência, UNICAMP, v. 110, p. 597, 2009. Disponível em: http://www.comciencia.br/comcien$\mathrm{cia} /$ ? section=8\&edicao=48\&id=597\&HYPERLINK. Acesso em: 11 jun. 2015.

SOCIENTIZE CONSORTIUM. Green Paper on Citizen Science. [S.1.] European Commission, 2013. Disponível em: http://ec.europa.eu/digital-agenda/en/news/ green-paper-citizen-science-europe-towards-society-empowered-citizens-and-enhanced-research-0. Acesso em: 1 mar. 2015. 



\section{7}

\section{Hardware aberto para ciência aberta no sul global: diplomacia geek?}

Denisa Kera

INTRODUÇÃO

O movimento da biologia Faça-você-mesmo (DIYbio) originou-se nos Estados Unidos, em 2009 aproximadamente, em torno das competições estudantis de biologia sintética promovidas pelo iGEM (Fundação Internacional de Máquinas Geneticamente Modificadas) (DURRETT; FIELD, 2011; KUZNETSOV et al., 2012), e de esforços paralelos de biologia aberta na Europa e na Ásia, com suas conexões com a bioarte e com práticas científicas críticas no final da década de 1990 (Bureaud; malina; Whiteley, 2014). Este movimento uniu-se, em anos recentes, a outros movimentos provenientes de cientistas profissionais em defesa de e-ciência, ciência aberta, acesso aberto e dados abertos (NEYLON; WU, 2009; MOLLOY, 2011; UHLIR; SCHRÖDER, 2007). O clamor para que se mude o modo de publicação e a abertura de dados, apoiando, ao mesmo tempo, a colaboração online e o crowdsourcing, está começando a fundir-se com tentativas de reduzir o custo da pesquisa experimental e de aumentar a reprodutibilidade, construindo-se equipamentos de laboratório customizáveis de baixo custo (PEARCE, 2014; LANDRAIN et al., 2013). 
Essa convergência entre os interesses dos hackerspaces e makerspaces de hardware aberto (Open Source Hardware - OSHW) com objetivos da ciência aberta (dados abertos, acesso aberto e colaboração on-line) criou oportunidades únicas de envolver cientistas cidadãos, além de cientistas de países em desenvolvimento em redes de pesquisa alternativas globais (KERA, 2012a; KERA, 2013). Neste trabalho, buscamos refletir sobre o papel crítico do hardware aberto na formação dessas redes e na cooperação em pesquisas únicas Sul-Sul e Sul-Norte. Analisaremos a questão como um tipo de diplomacia geek em ciência aberta.

A diplomacia geek é um tipo de envolvimento cidadão com a ciência, o qual constrói pontes entre diversos fossos de conhecimento e de infraestrutura para criar uma resposta mais inclusiva de pesquisa e desenvolvimento $(\mathrm{P} \& \mathrm{D})$ a questões internacionais desafiadoras, de natureza política, social e científica. É uma forma de diplomacia científica e cidadã (FLINK; SCHREITERER, 2010; BURNS, 2014; GILBOA, 2008; MAKHEMA, 2010), que enfatiza o papel importante da $\mathrm{P} \& \mathrm{D}$ baseada em tecnologias abertas na criação de condições para a paz e a cooperação. Ao mesmo tempo, reconhece a importância de conhecimentos e culturas, habilidades e fontes de experiência nativas, locais e vernaculares cosmopolitas. Nesse sentido, a diplomacia geek oferece oportunidades únicas para cooperação global em torno da ciência, mas também para $\mathrm{P} \& \mathrm{D}$, com uma agenda mais participativa, inclusiva, além de reflexiva e socialmente responsável.

Exemplos de diplomacia geek incluem projetos tais como a rede Hacketeria para biologia aberta ${ }^{1}$ ou a rede de monitoramento de radiação Safecast ${ }^{2}$ e a rede Open Technology Forever ${ }^{3}$. Essas redes mostram um esforço de inovação internacional de base em torno

\footnotetext{
1 Disponível em: http://hackteria.org/ Acesso em 7 jun. 2015.

2 Disponível em: http://blog.safecast.org/ Acesso em 7 jun. 2015.

3 Disponível em: https://opentechco.co/ Acesso em 7 jun. 2015.
} 
do hardware aberto, que mobilizou cidadãos a adotarem um papel ativo na resolução de problemas em suas comunidades, ao mesmo tempo em que repensam globalmente o papel da ciência e da tecnologia. O monitoramento Faça-você-mesmo de radiação pela Safecast criou uma rede global ativa de cidadãos preocupados com o monitoramento ambiental após Fukushima. Esta rede melhorou os padrões em sensoriamento por meio da cooperação com agentes produtivos (KERA; ROD; PETEROVA, 2013). A rede Hackteria especializa-se na construção de instrumentos de laboratório em hardware aberto usados em várias iniciativas artísticas, educacionais e de pesquisa em todo o mundo, principalmente na microbiologia e na nanotecnologia. A rede é muito ativa na Indonésia desde 2009. Lá, as ferramentas de hardware aberto aumentaram o letramento em ciência e expressão artística, mas também auxiliaram a comunidade de pesquisa local a desenvolver seus próprios objetivos de P\&D (KERA, 2012b; KERA, 2013).

Dado seu âmbito global e internacional, mas, ao mesmo tempo, sua sensibilidade aos contextos locais e culturais, essas redes apoiam objetivos democráticos e de resiliência. Podemos descrevê-las como uma diáspora de ciência aberta emergente, com referência à expressão diáspora científica proposta pelo Centro para Diplomacia Científica da Associação Americana para o Progresso da Ciência (American Association for the Advancement of Science - AAAS). Elas corporificam a emergente nova arquitetura de cooperação permitindo aos países "[....] inventar, criar, inovar e resolver problemas conjuntamente" (BURNS, 2014), na medida em que usam hardware aberto. A razão para enfatizar o papel do hardware aberto e de grupos relacionados de geeks, fazedores e hackers é que eles representam instituições informais e independentes de transferência de conhecimento e tecnologia, mais adaptáveis a contextos em desenvolvimento.

A diplomacia geek baseada em esforços de ciência aberta e de har$d w a r e$ aberto democratiza o processo de pesquisa e desenvolvimento 
ao torná-lo mais inclusivo: ela encoraja a participação de diversas partes interessadas e de cidadãos em todo mundo, que se inspiram mutuamente, compartilhando dados, protocolos ou esquemas de hardware e design. Pesquisa e desenvolvimento passam a ser menos a respeito da difusão e da transferência de tecnologia - o que perpetua diversas formas de divisão científica (scientific divide) - e mais a respeito do valor da cooperação e de nichos de interesse especiais. As redes emergentes de diáspora de ciência aberta cooperam com relação a tecnologias de código aberto para testar redes geopolíticas surpreendentes, mas também científicas, e para definir novas ideias sobre qual é o papel da ciência no Sul Global:

O quase monopólio dos governos no gerenciamento de assuntos internacionais certamente foi rompido. Redes de diáspora, tais como organizações não-governamentais, grupos da sociedade civil e corporações multinacionais tornam-se, cada vez mais, atores importantes e influentes nas relações internacionais. As diásporas científicas são vitais nessa nova arquitetura de cooperação que nos permitirá, todos juntos, inventar, criar, inovar e resolver problemas... Não existe uma única fórmula para desenvolver e fazer crescer uma rede de diáspora científica como plataforma de cooperação. Cada uma será o resultado sem igual da cultura, história, relações internacionais, do sistema político, do desenvolvimento econômico e da geografia de um país (BURNS, 2014)4.

4 "The near monopoly of governments in the management of international affairs has certainly been broken. Diaspora networks, like nongovernmental organizations, civil society groups, and multinational corporations, are increasingly important and influential actors in international relations. Science diaspora are vital to a new architecture of cooperation that will allow us to invent, create, innovate, and solve problems together[...]. There is no single formula for developing and growing a science diaspora network as a platform for cooperation. Each will be a unique outcome of a country's culture, history, international relations, political system, economic development, and geography". (BURNS, 2014) 
Estas abordagens DIY (Faça-você-mesmo) e maker (fazedoras) na construção de equipamentos de laboratório com ferramentas de hardware aberto democratizam a infraestrutura e envolvem mais pessoas na reflexão sobre o papel da ciência em suas comunidades e na definição desse papel. As ferramentas Faça-você-mesmo específicas, tais como microscópios, termocicladores PCR (reação em cadeia da polimerase), câmaras de fluxo laminar e centrífugas, apoiam o letramento científico. Elas também levam a um melhor gerenciamento de expectativas, fantasias, medos e riscos, ao desmistificar como fatos e dados científicos são mensurados e ao abrir essas práticas a atividades artísticas e de design. Ao construir equipamentos de laboratório, indivíduos e comunidades adquirem poder para definir seus próprios desafios e objetivos científicos, e para desenvolvimento em seus contextos locais, fora das diversas retóricas sobre linhas divisórias e transferência de tecnologia (BOUDOURIDES, 2002; HOLMGREN; SCHNITZER, 2004; PACKER; MENEGHINI, 2007). Esses indivíduos e comunidades podem também decidir quanto risco querem assumir, e que tipo de risco; isto reforça a resiliência, juntamente com a sustentabilidade e a simples agência.

\section{REDES DE DIÁSPORA DA CIÊNCIA ABERTA}

As redes de diáspora da ciência aberta e projetos, tais como Hackteria, Safecast ou Open Technology Forever, desafiam os estereótipos geopolíticos sobre diferenças Norte-Sul, em particular os diferentes discursos sobre algum tipo de divisão. Tais discursos são inspirados pela teoria do déficit na ciência e na comunicação, bem como em teorias de divisão digital etc. (BYERLEE; FISCHER, 2002; FORERO-PINEDA, 2006).

Essas redes e projetos se recusam a ver o Sul Global como um lugar de déficit e carência, que precisam apenas ser superados para se atingir o progresso. Os projetos e oficinas da Hackteria reúnem os 
participantes de Indonésia, Singapura, Índia, Suíça, Reino Unido, Alemanha e Eslovênia, de diversas formações, para compartilhar seu interesse comum em abordagens de hardware aberto para ciência. Estas abordagens englobam, por exemplo, a construção de microscópios, espectrômetros ou sensores de turbidez etc., usados tanto para empreendimentos científicos como para os artísticos. Os participantes trocam conhecimento e interesses em pé de igualdade, ajudando-se mutuamente; o trabalho em um projeto acontece concomitantemente a uma série de oficinas, performances e redes informais. A entidade legal - Hackteria - está registrada na Suíça como organização sem fins lucrativos, que pode acessar financiamentos locais, e atua, sobretudo, como uma meta-organização fractal, cujos membros não são apenas pessoas físicas, mas, frequentemente, representam ou pertencem a outras organizações. Essa estrutura horizontal e descentralizada, que apoia a polinização cruzada ao invés da transferência linear, também é aparente no caso das redes Safecast e Open Technology Forever. Essas últimas representam meta-instituições globais complexas, que não fazem diferença entre um membro pessoa física e outra organização, desde que todos estejam dispostos a compartilhar protocolos de ciência aberta e ferramentas de hardware aberto.

As redes congregam-se em torno do hardware de código aberto (Open Source Hardware - OSHW) que apoia essas estruturas organizacionais, por natureza híbridas e fractais. O hardware aberto apresenta um agrupamento de tecnologias, princípios de design e licenças, que conectam inovação a preocupações com infraestrutura e protocolos (abertos), questões de justiça social e sustentabilidade econômica. Isso permite que os geeks e fazedores ${ }^{5}$ trabalhem em todos esses níveis enquanto produzem protótipos (WEISS, 2008; GACEK; ARIEF, 2004; DAVIDSON, 2004). O hardware aberto inclui tentativas de democratizar a eletrônica, particularmente os

5 O termo usado em inglês é maker. 
micro controladores, mas também experimentos com fabricação digital (impressoras 3D), que prometem a mais pessoas, em todo o mundo, a possibilidade de construir o que quiserem. O objetivo principal continua sendo o de tornar essas ferramentas mais baratas abrindo seu design, mas também, com frequência, simplesmente encontrando novas formas de utilização de ferramentas já existentes. Isto significa abri-las para a aprendizagem, mas também para aperfeiçoamento e para apropriações individuais.

O hardware aberto também define um conjunto inteiro, novo, de lugares e instituições, onde pesquisa e desenvolvimento acontecem de forma holística e alternativa, como Maker Fairs; e centros nicho ou bibliotecas de ferramenta, como hackerspaces, makerspaces e FabLabs. A rede global, ou diáspora da ciência aberta, torna-se, nesse sentido, uma continuação de esforços já existentes e sua extensão a instituições intergovernamentais ou supranacionais.

Os esforços de hardware aberto integram outras tendências de desenho aberto relacionadas, que recentemente definiram um público emergente de fazedores ou mesmo de cidadãos Faça-você-mesmo (RATTO; BOLER, 2014; PAULOS, 2009), que conectam deliberações políticas e criação de protótipos. Cidadãos do mundo todo unem esforços para democratizar e construir ferramentas melhores para influenciar suas comunidades locais, mas também para desafiar divisões geopolíticas. Este tipo de diplomacia geek relacionada a protótipos apoia a $\mathrm{P} \& \mathrm{D}$ em lugares inesperados.

O valor de customização, abertura e cooperação nesses projetos é deontológico, mais do que simplesmente pragmático ou utilitário. Com o hardware aberto, podemos definir o que a ciência e a tecnologia podem ou devem significar, ao invés de buscar soluções mais eficientes e mais difundidas para diversas divisões que sustentam $a P \& D$ orientada por patentes e pelo lucro. $O$ valor dos protótipos de hardware aberto é que não são nem inventados nem adotados ou disseminados por atores claramente definidos; não são impostos, nem protegidos, nem regulados por quaisquer 
governos ou indústrias. São simplesmente formas de folclore tecnológico inclusivas e abertas ao contexto local, levando, ao mesmo tempo, a interações globais que são simultaneamente políticas e relacionadas ao design.

O hardware aberto apoia abordagens descentralizadas e participativas da inovação, que tornam a tecnologia acessível a diversas comunidades nicho. Os kits, que com frequência são usados como forma de distribuição, levam a mais desenvolvimento de hardware aberto, fornecendo componentes e instruções necessárias ao aprendizado de como construir o primeiro protótipo. Eles então inspiram vários grupos a criarem seus próprios clones e a desenvolverem-nos mais ainda. Esses kits definem essa nova relação entre especialistas e amadores, inovadores e produtores, tecnologias e contextos (nichos). Afirmamos que eles também podem constituir redes de pesquisa geopolíticas especiais, que ignoram os estereótipos dominantes Norte-Sul para possibilitar pesquisa e desenvolvimento em novos locais.

Pragmáticos e utópicos ao mesmo tempo, os instrumentos de hardware aberto estão se tornando, em todo o mundo, tanto um produto como um meio para comunidades autossuficientes e independentes, que buscam sua própria versão de progresso tecnológico. Exemplos de tais comunidades incluem projetos como o Open Source Ecology ${ }^{6}$ em Missouri, EUA; o Micro/Macornation ${ }^{7}$ de HONF em torno de Yogyakarta, na Indonésia, bem como os projetos emergentes no Nepal. Estes últimos incluem projetos como o coletivo Karkhana ${ }^{8}$ que trabalha com uma fazenda local, mas também com uma empresa de capital de risco voltada para o empreendedorismo social, Biruwa ${ }^{9}$.

6 Disponível em: http://opensourceecology.org/ Acesso em: 7 jun. 2015.

7 Disponível em: http://vimeo.com/45452898/ Acesso em: 7 jun. 2015.

8 Disponível em: http://www.karkhana.asia/ Acesso em: 7 jun. 2015.

9 Disponível em: http://www.biruwa.net/ Acesso em: 7 jun. 2015. 


\section{O MICROSCÓPIO DE HARDUARE ABERTO NA INDONÉSIA}

Um objeto que resume bem as possibilidades presentes nos esforços de hardware aberto para a ciência é o microscópio Faça-você-mesmo, de baixo custo na Indonésia. Ele foi testado em 2009 e desenvolvido para ser uma ferramenta profissional apoiando a cooperação, bem como diversos esforços artísticos e científicos, por vários anos. Baseia-se na lente invertida de um webcam convertido, cujo preço mais baixo é USD 2.00, e cujos sensores de imagem (CMOS - dispositivo de carga acoplada ou CCD - semicondutor de óxido metálico complementar) convertem a luz capturada pela lente em uma imagem digital. Enquanto a lente tipicamente captura uma perspectiva grande angular e a direciona para o sensor pequeno, podemos obter, invertendo o sensor, uma imagem de um microscópio ampliada 200 vezes. O mais importante é que esse microscópio pode ser conectado a um computador com um cabo USB. Isso permite a análise das imagens capturadas com diferentes software livres, tais como o CFU aberto ${ }^{10}$. O CFU aberto é um software que conta colônias de fungos/bactérias, pode analisar placas de agar e pode apoiar um protocolo comum de microbiologia. A contagem de unidades de formação de colônias (CFUs) pode, em seguida, ser compartilhada como dado aberto através de Wikimedia, Figshare ou outros repositórios de dados de imagem. Assim, pode transformar as práticas da microbiologia em uma pequena revolução de ciência aberta.

A parte mais importante de qualquer microscópio Faça-você-mesmo construído a partir de uma webcam reaproveitada é a base, que precisa ser móvel, mas deve ser suficientemente estável para capturar e manter a imagem na placa. Enquanto a lente e os sensores da webcam reaproveitada são de tecnologia fechada e patenteada, o design da base dos kits DIY tornou-se um projeto de hardware

10 Disponível em: http://opencfu.sourceforge.net/ Acesso em: 7 jun. 2015. 
aberto, conectando a Indonésia à Suíça no período entre 20092014. O desenvolvimento colaborativo de código aberto do kit de base $^{11}$ para o microscópio webcam captura as redes complexas em torno da biologia aberta. Ele constitui um caso original de transferência de conhecimento e de ciclo de pesquisa e desenvolvimento alternativo, conectando esforços de ciência aberta e cidadã entre Yogykarta e Lucerna, e outros lugares na Suíça onde trabalham os membros de Hackteria.

O protótipo original de 2009 foi desenvolvido durante uma visita de Marc Dusseiller da Hackteria.org, então uma rede recente criada por cientistas, artistas e designers em prol da biologia aberta. A visita coincidiu com a realização de Cellsbutton, um festival de arte na mídia, organizado em Yogykarta, Indonesia, por uma instituição local sem fins lucrativos, House of Natural Fibre. Marc Dusseiller ofereceu uma oficina sobre a construção de microscópios Faça-você-mesmo no laboratório de microbiologia da Faculdade de Agricultura da Universidade de Gadjah Mada. Lá ele observou tentativas de construir equipamentos de baixo custo para microbiologia, como a câmara de fluxo laminar construída pelo Professor Irfan D. Prijambada. Após alguma experimentação, o modelo final do microscópio recebeu uma webcam PS3eye, porque esta era capaz de operar com baixa intensidade de luz, um dos requisitos do projeto.

Estas webcams originais do Playstation transformadas em microscópios eram bastante precisas para as necessidades de alunos de microbiologia do laboratório de microbiologia da Gadjah Mada University (UGM). O componente crítico - a base - foi desenvolvido bem mais tarde, em 2012, após muitas tentativas frustrantes e improvisações com microscópios em projetos educacionais, artísticos e de pesquisa.

\footnotetext{
11 Disponível em: DIY microscopy resources: http://hackteria.org/?cat=15 Acesso em: 7 jun. 2015.
} 
Em 2012, um dos membros do Hackteria, Urs Gaudenz, que tinha familiaridade com os esforços na Indonésia e também com diversas oficinas na Europa, decidiu padronizar as bases para esses microscópios Faça-você-mesmo. Ele fez isso em cooperação com Fablab Luzern, na Suíça, onde trabalhava em tempo parcial. Lá, Gaudenz desenhou a primeira base de microscópio cortada a laser, e enviou o design, juntamente com dois de seus kits, para o laboratório de microbiologia da UGM na Indonésia, bem como para Lifepatch, uma organização afiliada, sem fins lucrativos, de cidadãos cientistas.

Lifepatch usou os microscópios em oficinas de ciência aberta com crianças carentes em Yogyakarta, e também em performances artísticas e atividades educacionais que demandavam uma base simplificada. Como ficava caro enviar os kits a partir da Suíça, um membro da Lifepatch copiou a base original cortada a laser do Fablab Luzern e transformou-a em uma base acrílica feita a mão ${ }^{12}$. Após esse protótipo inicial, que de forma paradoxal combina artesanato tradicional com fabricação digital, a Lifepatch conseguiu encontrar um cortador a laser e, finalmente, melhorar o design original da base.

Este diálogo de hardware aberto entre a Suíça e a Indonésia não apenas tornou possível uma infraestrutura científica (microscopia de hardware aberto), que pode apoiar projetos tanto de ciência livre como de ciência cidadã, mas também estabeleceu uma interação interessante entre o artesanato tradicional (fabricação de vidro) na Indonésia e um objeto de fabricação digital no estilo Fablab. A base especial de microscopia feita a mão copiou, de forma paradoxal, o design fabricado digitalmente de Fablab Luzern apenas para produzir um design melhor que, em seguida, foi cortado a laser em Lucerna. Na cópia feita a mão em Yogyakarta empregou-se material

12 DIY microscopy stage kit - Indonesian clone. Disponível em: http://hackteria.org/?p=2082 Acesso em 7 jun. 2015 
de sobras de acrílico para corte a laser, que estavam disponíveis no estúdio da Lifepatch ${ }^{13}$.

Essa base especial feita a mão para um webcam hackeado foi construída por Radix Nugroho do Otakatik Creative Workshop (Oficina Criativa de Otakatik), que reutiliza vidro e colabora com Lifepatch e outras organizações de ciência cidadã. Esse primeiro kit de base de microscopia de Lifepatch e Otatik foi clonado manualmente, mas as versões posteriores cortadas a laser melhoraram o design da base de Hackteria. No curto período de dois meses, os membros da Lifepatch desenharam seu próprio clone indonésio e criaram um kit de base para microscópio (SIAGIAN, 2015). Eles também exploraram a possibilidade de usar materiais locais reciclados a fim de torná-lo mais barato, mas também para aumentar seu valor como obra de arte.

A infraestrutura de laboratório de hardware aberto da Indonésia sempre participou de tais atividades artísticas e de design, orientadas para a comunidade. Isso prova que o modelo de hardware aberto de $\mathrm{P} \& \mathrm{D}$ não diz respeito apenas à eficiência e ao baixo custo, mas também à colaboração interdisciplinar e a nichos que geram apropriações e interações únicas entre tecnologias e materiais velhos e novos, entre o Norte e o Sul, ao mesmo tempo em que apoia as necessidades pragmáticas de infraestrutura e competências.

O diálogo entre artesanato tradicional e produção digital em massa mostra o potencial do hardware aberto para a ciência como uma prática capaz de questionar seu papel na sociedade. Os esforços de laboratório de baixo custo e de preço acessível caminham junto com a busca por uma ciência mais criativa e mais integrada na sociedade, no contexto de atividades de criação, de interesses educacionais e artísticos. O hardware aberto, de maneira simples torna

13 Documentação de todo o processo com fotos, disponível em: https://www.facebook.com/media/set/?set=a.549545511747116.131034.284578538243816\&type=1 e https://www.flickr.com/photos/92698778@N04/8447886916/in/photostream/ Acesso em 7 jun. 2015. 
possível uma ciência socialmente inclusiva, que envolve e inspira em vez de apenas resolver problemas.

O kit artesanal que clonou a base de microscopia original influenciou, em 2014, um projeto que tenta conectar o teatro indonésio Wayang Kulit (marionetes de sombra) com uma interface microfluídica (laboratório em um chip). Também tenta funcionar com zooplâncton, usando tanto equipamentos de laboratório de hardware aberto como materiais tradicionais (coco, mas também bambu, que são usados normalmente para instrumentos de música indonésia - gamelan). Os primeiros experimentos, que até certo ponto aconteceram por necessidade, evoluíram para interesses estéticos dos cientistas cidadãos em Yogyakarta e outros lugares, e inspiraram toda uma ramificação da pesquisa sobre design (AUSARENY et al., 2014).

Protótipos, kits e clones de hardware aberto, com frequência integram esses diálogos de hardware e improvisações entre vários países, disciplinas e instituições. Em 2012, os membros indonésios do Lifepatch clonaram não apenas o kit de microscopia, mas também o microcontrolador simplificado em um pen drive conhecido como GNUSbuino, que é usado, entre outras coisas, para controlar o diodo em um sensor de turbidez para recolher dados simples para análise da água. Este microcontrolador suíço foi apresentado em uma oficina em Yogyakarta em janeiro de 2012 e, em seguida, transformado por geeks indonésios em um BabyGnusbuino Tropical DIL versão v0.3 mais barato, que usa partes eletrônicas disponíveis em Yogyakarta ${ }^{14}$.

Tanto a base do microscópio como o microcontrolador foram usados mais tarde em uma oficina da Feira de Fazedores de Xangai (Shanghai Maker Fair) em outubro de 2013. Lá, atraíram a atenção

\footnotetext{
14 Documentação de Baby GNUSbuino Tropical, disponível em: https://www.facebook.com/ photo.php?fbid=10200667640320218\&set $=$ a. $10200400213394712.201694 .1437047270 \&$ type=1\&relevant_count=1. Acesso em 7 junho 2015.
} 
de Eric Pan, um dos diretores do Seeed Studio ${ }^{15}$ em Shenzhen, um mercado importante de hardware livre on-line, que apoia desenvolvedores de hardware em todo o mundo. O Seeed Studio convidou os membros do Lifepatch e do Hackteria a criarem uma nova linha de kits DIYbio para apoiar esforços de ciência aberta e de DIYbio através da produção em massa desses kits em Shenzen. A interação entre um protótipo artesanal e o kit Faça-você-mesmo produzido em massa gerou um número inesperado de redes de inovação entre a Suíça, a Indonésia e a China. O primeiro kit de microscopia Faça-você-mesmo indonésio, oferecido ao mundo geek global pelo Seeed Studio, provou como a divisão Norte-Sul é irrelevante quando se trata de pesquisa e desenvolvimento apoiada por hardware aberto.

\section{DIÁSPORAS DE CIÊNCIA ABERTA E RESILIÊNCIA}

O empoderamento científico, tecnológico, mas também político de indivíduos e comunidades pelo hardware aberto acontece, com frequência, por meio de diferentes kits Faça-você-mesmo tais como a base de microscopia ou o famoso caso de dispositivos para monitoramento de radiação desenvolvidos pelo Safecast. O ciclo se inicia com um protótipo de grupo desenvolvido na forma de um kit que envolve cidadãos em campanhas de crowd funding ou em oficinas nas quais as pessoas aprendem como usá-lo ou como desenvolvê-lo ainda mais. Ao mesmo tempo, o protótipo é profissionalizado através do envolvimento de empresas como a Safecast, que se ligou a outras empresas, produzindo contadores Geiger. Mais tarde, a Safecast ajudou a melhorar a qualidade dos padrões industriais de detectores de radiação (Medcom).

Os contadores Geiger DIY, durante todo esse ciclo de desenvolvimento de protótipo, teste e reiteração, permitiram aos cidadãos coletar e compartilhar dados independentes sobre radiação, e a tomar

15 Disponível em: http://www.seeedstudio.com/ Acesso em: 7 jun. 2015. 
parte ativamente em políticas relacionadas ao futuro da energia nuclear (KERA; ROD; PETEROVA, 2013). Os protótipos mais recentes - bGeigie nano - receberam mais de US\$100,000.00 em 2012, pela plataforma de crowd funding Kickstarter, de comunidades globais anônimas de apoiadores interessados em investir e incentivar a busca por dados precisos e independentes. Outro projeto - Bike 2.0 - amplia a ideia de monitoramento da atmosfera por cidadãos ao criar uma plataforma de sensores de radiação e qualidade do ar para bicicletas, inovando a função desse veículo de transporte diário e, como resultado, repensando o futuro.

Durante dois anos, a rede inicial ad hoc de monitoramento da radiação evoluiu para uma organização global sem fins lucrativos, que apoia mensurações e publicações abertas de diversos dados atmosféricos, mas também a cooperação de cidadãos-amadores com diversos órgãos reguladores responsáveis pelo meio ambiente. $\mathrm{O}$ hardware aberto, nesse caso, apoiou as interações entre as partes interessadas, possibilitando os esforços de mensuração independente de dados, através de ferramentas feitas sob medida, bem como a discussão sobre sua precisão e calibragem. Essas ações aproximaram geeks e órgãos reguladores, e definiram participantes das indústrias.

Uma estratégia parecida pode ser observada em projetos de sensoriamento ambiental em todo o mundo, tais como a plataforma Kanarci ${ }^{16}$, baseada na República Tcheca, ou os sensores e ferramentas de monitoramento oferecidos por mercados de hardware aberto, tais como Libelium ${ }^{17}$ ou Seeed Studio (KLOSOWSKI, 2015).

Enquanto projetos de hardware humanitários semelhantes (AKIBA, 2011) demonstram o potencial social e político do público amador emergente, inúmeros outros projetos de hardware aberto são menos específicos em termos de agenda. Protótipos e kits fornecidos

\footnotetext{
16 Disponível em: http://www.kanarci.cz/ Acesso em: 7 jun. 2015.

17 Disponível em: http://www.libelium.com/ Acesso em: 7 jun. 2015.
} 
por serviços como Adafruit ${ }^{18}$ e Sparkfun Electronics ${ }^{19}$ nos Estados Unidos, Seeed Studio na China, e diversos hackerspaces pelo mundo, frequentemente atendem a objetivos de diversão e educação. Indiretamente, no entanto, eles conectam a política com o design, criando as condições para que o público de amadores aceite novos desafios. As ferramentas e kits de hardware aberto auxiliam amadores a aprender como funcionam os sensores e componentes eletrônicos básicos, para customizar produtos existentes e, por fim, construir protótipos que lidam com várias questões - da saúde ao monitoramento ambiental - explorando e construindo uma infraestrutura independente.

Este é o caso do projeto Open Source Ecology (OSE) - uma rede de fazendeiros, engenheiros e apoiadores que estão construindo o Global Village Construction Set. Seu protótipo Global Village Construction Set (GVCS) utiliza hardware aberto para apoiar comunidades sustentáveis e autônomas em qualquer lugar do mundo: uma “plataforma modular 'Faça-você-mesmo', de baixo custo e alto desempenho, que permite a fabricação fácil das 50 máquinas industriais necessárias à construção de uma civilização pequena, sustentável e com confortos modernos"20. O protótipo GVCS é um objeto, mas é também um meio para repensar o futuro da agricultura e de comunidades sustentáveis. Ajuda amadores e fazendeiros em todo o mundo a discutir e deliberar sobre o futuro de suas comunidades locais, mas também da sociedade global.

O OSE está construindo as ferramentas e a comunidade; e, paralelamente, as está testando em seu Factor e Farm (FeF) na zona rural do Missouri, Estados Unidos. O site da FeF é um experimento que "tem por objetivo aproveitar tudo o que a civilização aprendeu até hoje para criar um esquema de trabalho para comunidades

\footnotetext{
18 Disponível em: http://www.adafruit.com/ Acesso em: 7 jun. 2015.

19 Disponível em: https://www.sparkfun.com/ Acesso em: 7 jun. 2015.

20 "a modular, DIY, low-cost, high-performance platform that allows for the easy fabrication of the 50 different Industrial Machines that it takes to build a small, sustainable civilisation with modern comforts". Disponível em: http://opensourceecology.org/ Acesso em: 7 jun. 2015.
} 
que funcionem"21. O projeto todo se dividiu em esforços paralelos que se tornaram uma rede internacional, ou diáspora científica. O projeto Open Technology Forever combina um aplicativo de mapeamento, baseado na Espanha, para compartilhamento de dados ambientais com uma fábrica de hardware aberto baseada nos Estados Unidos, a fim de incluir um sensor de pesticida patenteado de Singapura. Tem por objetivo integrá-los a um projeto de colmeias abertas, financiado por crowd sourcing, em resposta a mais uma crise global.

O hardware aberto auxilia o público global de conhecedores práticos a lidar com desafios locais e globais, e a testar futuros potenciais, em vez de apenas discutir questões ou delegar decisões. $\mathrm{O}$ hardware aberto é uma plataforma tecnológica para colaboração e criação de protótipos, que influencia tanto políticas como o design - a política e a tecnologia. Permite a participação do público e o engajamento global em diversas questões por meio do amadorismo coletivo que não se prende a qualquer regra de patentes ou a interesse geopolítico. A colaboração informal entre um grupo global de hackers, fazedores e especialistas, juntamente com cidadãos e amadores, acontece em oficinas, tanto on-line como off-line, e sua função principal parece ser a de envolver mais atores na base.

Os esforços de monitoramento da radiação demonstraram que, ensinando voluntários a conectar placas Arduíno a sensores e componentes eletrônicos e, mais tarde, simplificando tudo através de PCBs e kits sob medida, seria possível empoderar diversos grupos para obterem dados independentes, tomarem decisões e se engajarem com a política nesse nível material e de infraestrutura. Todo o processo de hardware aberto de design, distribuição, customização, aprendizagem e construção de protótipos encoraja cidadãos e amadores, participantes de projetos como Open Technology Forever, a

21 "aims to take everything that civilization has learned to date, to create a working blueprint for communities that work" Disponível em: http://opensourceecology.org/ Acesso em: 7 jun. 2015. 
participarem ativamente e a interagirem a cada passo do processo de pesquisa e desenvolvimento com especialistas, elaboradores de políticas e agentes empresariais.

\section{DIPLOMACIA GEEK}

O hardware aberto apresenta um desafio interessante à ideia de esfera pública, porque torna as pessoas capazes de usar e construir novas ferramentas, aplicativos e hardware, assim como de mudar as condições e limites sociais e técnicos enquanto discutem questões que são importantes para elas (monitoramento ambiental, sustentabilidade, energia mais barata etc.). Ação e reflexão, deliberação e transformação estão intimamente ligadas, e regulamentações normativas são formadas à medida que se constroem e testam as ferramentas. A esfera pública construída com base no hardware aberto não é apenas uma condição para a deliberação livre, mas algo literalmente construído com ferramentas de amadores. A habilidade do hardware de criar essas montagens por meio das quais as pessoas resolvem questões de interesse mútuo, de forma colaborativa, e insistem na abertura de outras tecnologias patenteadas enquanto trabalham nas regras de seu uso, está expressa com clareza na Declaração de Princípios do hardware aberto:

O hardware de código aberto é um hardware cujo design é tornado publicamente disponível de tal maneira que qualquer pessoa possa estudar, modificar, distribuir, fazer e vender o design ou o hardware baseado neste design. O código do hardware, o design a partir do qual é produzido encontra-se disponível no formato preferido para fazer modificações nele ${ }^{22}$.

22 "Open source hardware is hardware whose design is made publicly available so that anyone can study, modify, distribute, make, and sell the design or hardware based on that design. The hardware's source, the design from which it is made, is available in the preferred format for making modifications to it". Disponível em: http://www.oshwa.org/faq Acesso em: 7 jun. 2015. 
Esse clamor por tecnologias abertas como ferramentas de empoderamento teve origem no famoso slogan Acesso às Ferramentas do Whole Earth Catalog (WEC), publicado por Stewart Brand, entre 1968 e 1972. Assim se definia uma política radical, com um conjunto de produtos e ferramentas que possibilitam a autonomia, a autossuficiência, a ecologia e uma abordagem Faça-você-mesmo na resolução de diversos problemas globais e locais. Este slogan famoso da contracultura norte-americana inspirou não apenas o empreendedorismo tecnológico emergente do Vale do Silício, mas também os esforços desenvolvimentistas na Papua, na década de 70, quando um clone famoso do catálogo foi publicado sob o título de Liklik Buk, inspirando o movimento da permacultura que, atualmente, tem proporções globais. Com as atuais ferramentas de hardware aberto, estamos, de alguma forma, repetindo esse ciclo de repensar o empoderamento tecnológico e político com Stuart Brand. O que é específico aos atuais esforços é que eles envolvem mais diretamente a ciência, como, por exemplo, os esforços da DIYbio (Do-It-Yourself biology - biologia faça-você-mesmo) (KERA, 2012; KERA, 2014).

Esforços de ciência e tecnologia de base comunitária, tais como DIYbio, encarnam uma variedade de definições relativas à ciência aberta ou colaborativa (GACEK; ARIEF, 2004; LERNER; TIROLE, 2005) e, algumas vezes, dizem respeito a ferramentas, regras da comunidade, normas ou autorizações, ou, simplesmente, a participantes descritos como geeks, hackers e fazedores. Isso inclui qualquer cidadão-cientista, designers, engenheiros, ativistas, dispostos a engajar-se, compartilhar, aprender e ensinar em um ambiente aberto. A indisponibilidade de equipamentos de laboratório no Sul Global perpetua estereótipos relacionados à produção de conhecimento que percebemos como centrada no Norte. As décadas de desenvolvimento que se seguiram à Segunda Guerra Mundial, apoiando a ideia de transferência de tecnologia, não geraram nada mais do que políticas neoliberais; e criaram uma desigualdade ainda maior, e a dependência do Ocidente em pesquisa e conhecimento científicos 
(MOORE et al., 2011; KIHARA, 2010). Com o modelo de hardware aberto para ciência aberta, podemos, por fim, questionar o modelo do déficit de comunicação científica e o conceito irrefletido de transferência de tecnologia enraizado na visão colonial do Sul Global como recebedor de conhecimento científico que leva ao desenvolvimento (BYERLEE; FISCHER, 2002; FORERO-PINEDA, 2006).

Os debates sobre a ciência no Sul Global perpetuam uma espécie de violência epistêmica (SPIVAK, 1998), que define ciência e tecnologia como coisas sempre transferidas e aplicadas em países em desenvolvimento com a ajuda de diversos doadores, programas de responsabilidade corporativa e outros inovadores do Ocidente. Os esforços em torno da construção de equipamento de laboratório aberto em Yogyakarta apoiam e reconhecem a agência de atores no nível local, que podem questionar a retórica da transferência de tecnologia. A ciência aberta e com base na comunidade envolve uma variedade de atores em redes especiais de ciência aberta (HOLMGREN; SCHNITZER, 2004) e explora a possibilidade da ciência aberta em um contexto pós-colonial. Apesar de concordarmos com Spivak, para quem o subalterno talvez não possa pesquisar e inovar (falar), ainda assim vemos evidências de que ele ousa questionar o significado da pesquisa e da inovação nas crises econômicas e políticas atuais e no contexto pós-colonial.

Debates sobre a esfera pública em estudos de mídia (LUNT; LIVINGSTONE, 2013), ou sobre participação e deliberação pública (CANINI, 1994) em estudos sobre ciência, tecnologia e sociedade (CTS), são pontos de referência importantes na formulação da diplomacia geek emergente e das aspirações da ciência aberta pós-colonial. Eles contrastam duas visões bastante diferentes do papel político e da governança das tecnologias que podemos questionar no caso do hardware aberto. No campo da CTS, estamos debatendo como apoiar o público em deliberações sobre várias tecnologias que são percebidas como objeto de decisões de políticas.

Nos estudos de comunicação e mídia, as tecnologias são meios, em vez de objetos da deliberação pública. O público de amadores 
e de diplomatas geek tem elementos de ambos. Eles se relacionam às tecnologias como objetos e meios de participação e deliberação cidadã. A isto podemos acrescentar uma terceira função - hackear e modificar a tecnologia para apoiar as comunidades. Ela não é apenas objetos ou mídia, mas também algo desenhado pelos próprios cidadãos a fim de empoderá-los para definir o papel da tecnologia em sua sociedade.

A ontologia por trás dessa atitude aproxima-se de posições materialistas recentes que afirmam que o agente não humano deveria ser definido não como um fato puro ou uma realidade objetiva, mas em termos dos atores com quem negociamos interesses e relações e com quem ativamente co-criamos nosso futuro (HARMAN, 2009; HARMAN, 2002).

As intrincadas conexões entre sociedade e tecnologia baseadas nessas novas posições materialistas e realistas nos levam a definir a regulação e as políticas como design experimental. É preciso integrar as tecnologias, bem como deliberar a respeito delas, e negociar com elas - como novos atores com agência. Nesse sentido, o hardware aberto permite o empoderamento tecnológico, que é material, discursivo e social. Ele produz uma nova metafísica, mas também uma política de protótipos através da qual expressamos nossos valores e insights políticos, cooperando e construindo novas ferramentas. O público emergente de amadores e diplomatas geek percebe o ideal político como algo que precisamos co-criar e desenhar, em vez de algo que encarnamos como a verdadeira natureza de nossa alma ou da sociedade.

\section{CONCLUSÃO}

Encontramo-nos em um momento da história no qual estamos abrindo e democratizando não apenas o discurso público e os processos políticos, mas também protocolos técnicos, padrões e até a tecnologia. Isto favorece a ciência, bem como a pesquisa e o 
desenvolvimento. Esta abertura é discursiva e material ao mesmo tempo, porque estamos construindo infraestrutura de laboratório de hardware aberto enquanto discutimos o papel da ciência no Sul Global e o valor da ciência aberta como uma reforma no Norte. O público de amadores e diplomatas geek, que já está usando essas ferramentas para várias intervenções na microbiologia, na agricultura e no monitoramento ambiental, forma suas próprias redes globais e diásporas científicas. O desafio para o futuro é apoiar mais cidadãos na construção de ferramentas de hardware aberto como forma de autorregulação ou deliberação, ou mesmo de testar alguma tecnologia. Os exemplos bem conhecidos de hardware aberto, tais como placas Arduíno (uma plataforma de desenvolvimento de microcontroladores) ou o MakerBot Replicator (uma impressora 3D) originais permitem aos indivíduos e comunidades deliberar sobre, desenhar e negociar suas necessidades, bem como interagir com diversas pessoas interessadas em alguma questão. O hardware aberto é um sintoma de nossa mudança de atitude com relação às tecnologias, e envolve questionar e repensar as relações entre produtores e consumidores, entre cidadãos e reguladores, e a emergência de um novo público com conhecimento prático em tecnologia. O hardware aberto encoraja o envolvimento individual e coletivo com tecnologias que combinam compromissos políticos e ontológicos. Dessa maneira, está próximo a algumas concepções de agência da Teoria Ator-Rede (Actor Network Theory - ANT), da cosmopolítica, do realismo especulativo, do novo materialismo e de uma ontologia orientada para o objeto, que repensam a política em relação a objetos e processos fora da definição estreita de esfera social e agência humana.

\section{REFERÊNCIAS}

AKIBA. Kimono lantern and humanitarian open source hardware. 2011. Disponível em: http://www.freaklabs.org/index.php/Blog/Misc/Kimono-Lantern-and-Humanitarian-Open-Source-Hardware.html. Acesso em: 07 jun. 2015 
AUSARENY, Justyna; KERA Denisa; DRUGA, Stefania; RESHEF, Yair. Open Source Hardware (OSHW) Supporting Interaction between Traditional Crafts and Emergent Science. In: SIGGRAPH Asia 2014 Designing Tools For Crafting Interactive Artifacts on - SIGGRAPH ASIA, 14, New York. New York, USA: ACM Press, 2014. doi:10.1145/2668947.2668955. Disponível em: http://dl.acm.org/citation. cfm?id=2668947.2668955. Kera. Acesso em: 07 jun. 2015

BOUDOURIDES, Moses A. Science, technology and governance. In: EASST. CONFERENCE RESPONSIBILITY UNDER UNCERTAINTY, 2002. John De La Mothe (Ed.), 1-15. Science, Technology and the International Political Economy Series. Continuum. Disponível em: http://www.math.upatras.gr/ mboudour/. Acesso em: 07 jun. 2015

BUREAUD, Annick; MALINA, Roger F.; WHITELEY, Louise (Ed.). Meta-Life: biotechnologies, synthetic biology, ALife and the arts. Cambridge, MA, USA: Leonardo/ISAST; MIT Press, 2014.

BURNS, William. The potential of science diasporas | science \& diplomacy. Science Diplomacy Blog, 2014. Disponível em: http://www.sciencediplomacy.org/perspective/2013/potential-science-diasporas. Acesso em: dez.2014.

BYERLEE, Derek; FISCHER, Ken. 2002. Accessing modern science: policy and institutional options for agricultural biotechnology in developing countries. World Development, v. 30, n.6, p. 931-948, 2002.

CANINI, Giovanni. Public participation in decision-making in science and technology. Communicatio, v.20, n.1, p.15-25, Jan.1994. doi:10.1080/02500169408537870. Disponível em: http://dx.doi.org/10.1080/02500169408537870. Acesso em: 07 jun. 2015

DAVIDSON, Scott. Open-Source Hardware. IEEE Design and Test of Computers, v. 21, n.5, p. 456, 2004.

DURRETT, Russell; FIELD, F. A. R. Hackerspaces, diybio and citizen science: the rise of tinkering and prototype culture. Forging, p.9-12, 2011.

FLINK, Tim; SCHREITERER, Ulrich. Science diplomacy at the intersection of S\&T policies and foreign affairs: toward a typology of national approaches. Science and Public Policy, v. 37, n.9, p. 665-677, 2010. Disponível em: http://www.academia. 
edu/4031307/Flink_T._Schreiterer_U._2010_Science_diplomacy_at_the_intersection_of_S_and_T_policies_and_foreign_affairs_toward_a_typology_of_national_approaches._In_Science_and_Public_Policy_37_9_pp._665-677. Acesso em: 07 jun. 2015

FORERO-PINEDA, Clemente. The impact of stronger intellectual property rights on science and technology in developing countries. Research Policy, v.35, n.6, p. 808-882, 2006.

GACEK, Cristina; ARIEF, Budi. The many meanings of open source. IEEE Software, 2004.

GILBOA, E. Searching for a theory of public diplomacy. The Annals of the American Academy of Political and Social Science, 2008. doi:10.1177/0002716207312142.

HARMAN, Graham. Prince of networks: Bruno Latour and metaphysics. Victoria, v. 1, 2009. Anamnesis. re.press. doi:10.1104/pp.105.075838.brca2. Disponível em: http://books.google.com/books?id=7zxkaiX1gxEC\&pgis=1. Acesso em: 07 jun. 2015

HARMAN, Graham. Tool-being: Heidegger and the metaphysics of objects. Library, v. 45, 2002. Edited by Open Court Publishing. doi:10.1353/tech.2004.0014. Disponível em: http://books.google.co.uk/books?id=XvkzX9JnlAwC. Acesso em: 07 jun. 2015

HOLMGREN, Milena; SCHNITZER, Stefan A. Science on the rise in developing countries. PLoS Biology, 2004.

KERA, Denisa. Hackerspaces and DIYbio in Asia: connecting science and community with open data, kits and protocols. Journal of Peer Production, p.1-8, June 2012. Disponível em: http://peerproduction.net/issues/issue-2/peer-reviewed-papers/diybio-in-asia/?format=pdf. Acesso em: 07 jun. 2015

KERA, Denisa. Innovation regimes based on collaborative and global tinkering: synthetic biology and nanotechnology in the hackerspaces. Technology in Society, 2013. Disponível em: http://www.sciencedirect.com/science/article/pii/ S0160791X13000638. Acesso em: 07 jun. 2015

KERA, Denisa. NanoŠmano Lab in Ljubljana: disruptive prototypes and experimental governance of nanotechnologies in the hackerspaces. Journal of Science 
Communication, v. 11, n.4, 2012a. Disponível em: http://jcom.sissa.it/archive/11/04/Jcom1104(2012)C01/Jcom1104(2012)C03/Jcom1104(2012)C03.pdf. Acesso em: 07 jun. 2015

KERA, Denisa; ROD, Jan; PETEROVA, Radka. Post-Apocalyptic citizenship and humanitarian hardware. Nuclear Disaster at Fukushima Daiichi : Social, Political and Environmental Issues, New York: Routledge, p.97-116, 2013.

KIHARA, Hidetoshi. Neoliberal bias of science \& technology communication. Kagaku Tetsugaku, 2010.

KLOSOWSKI, Thorin. Monitor your air quality with a cheap sensor and an arduino. 2015. Disponível em: http://lifehacker.com/5903710/monitor-your-air-quality-with-a-cheap-sensor-and-an-arduino. Acesso em: 30 jan. 2015.

KUZNETSOV, Stacey; TAYLOR, Alex S.; REGAN, Tim; VILLAR, Nicolas;PAULOS, Eric. At the seams: DIYbio and Opportunities for HCI." In: DESIGNING INTERACTIVE SYSTEMS CONFERENCE ON - DIS.,12, 2012, New York. Proceedings... New York, USA: ACM Press, 2012. doi:10.1145/2317956.2317997. Disponível em: http://dl.acm.org/citation.cfm?id=2317956.2317997. Acesso em: 07 jun. 2015 LANDRAIN, Thomas; MEYER, Morgan; MARTIN PEREZ, Ariel; SUSSAN, Remi. Do-it-yourself biology: challenges and promises for an open science and technology movement. Systems and Synthetic Biology, v. 7, n. 3, p. 115-126, Aug. 2013. doi:10.1007/s11693-013-9116-4. Disponível em: http://link.springer. com/10.1007/s11693-013-9116-4. Acesso em: 07 jun. 2015

LERNER, Josh; TIROLE, Jean. The Economics of Technology Sharing: Open Source and Beyond. Journal of Economic Perspectives, 2005.

LUNT, P.; LIVINGSTONE, S. Media studies fascination with the concept of the public sphere: critical reflections and emerging debates. Media, Culture \& Society, v. 35, n.1, p. 87-96, 17 Jan. 2013. doi:10.1177/0163443712464562. Disponível em: http://mcs.sagepub.com/content/35/1/87.extract. Acesso em: 07 jun. 2015 MAKHEMA, Joseph. Globalization and the diplomacy of science. Journal of Research Administration, v. 41, n.2, p. 83-88, 2010. Disponível em: http://search. ebscohost.com/login.aspx?direct=true\&db=eric\&AN=EJ886802\&site=eds-live. Acesso em: 07 jun. 2015 
MOLLOY, Jennifer C. The open knowledge foundation: open data means better science. PLoS Biology, v. 9, n.12, 2011.

MOORE, Kelly; KLEINMAN, Daniel Lee; HESS, David Hess; FRICKEL, Scott. Science and neoliberal globalization: a political sociological approach. Theory and Society, v.40, n.5, p. 505-532, 2011.

NEYLON, Cameron; WU, Shirley. Open science: tools, approaches, and implications. Pacific Symposium on Biocomputing, 2009.

PACKER, Abel L.; MENEGHINI, Rogério. Learning to communicate science in developing countries. Interciencia, 2007.

PAULOS, Eric. The rise of the expert amateur: DIY culture and citizen science. In: ANNUAL ACM SYMPOSIUM ON USER INTERFACE SOFTWARE AND TECHNOLOGY, 22., 2009. Proceedings...ACM New York, NY, USA: ACM, 2009. p.181-182. Disponível em: http://dl.acm.org/citation.cfm?id=1622211\&dl=ACM\&coll=DL\&CFID $=528136295 \&$ CFTOKEN=46247205. Acesso em: 07 jun. 2015

PEARCE, Joshua M. Open-Source Lab. Open-Source Lab., Elsevier, 2014. doi:10.1016/B978-0-12-410462-4.00005-6. Disponível em: http://www.sciencedirect.com/science/article/pii/B9780124104624000056. Acesso em: 07 jun. 2015 RATTO, Matt; BOLER, Megan (Ed.). DIY citizenship: critical making and social media. Cambridge, MA, USA: MIT Press, 2014.

SIAGIAN, Andreas. Juxtapose through media - DIY microscope webcam for hemocytometer collaborative research | Andreas Siagian on WordPress.com. 2015. Disponível em: https://andreassiagian.wordpress.com/2010/03/11/juxtapose-through-media-diy-microscope-webcam-for-hemocytometer-collaborative-research/. Acesso em: 30 jan. 2015.

SPIVAK, Gayatri Chakravorty. Can the subaltern speak? Marxism and the Interpretation of Culture, p. 271-313, 1998.

UHLIR, Paul F.; SCHRÖDER, Peter. Open Data for Global Science.” Data Science Journal, 2007. doi:10.2481/dsj.6.OD36.

WEISS, Aaron. Open Source Hardware. NetWorker, 2008. doi:10.1145/1435535.1435541. 


\section{8 \\ Ciência aberta: dos hipertextos aos hiperobjetos}

Rafael Peretti Pezzi

\section{INTRODUÇÃO}

Participantes do movimento de ciência aberta argumentam que, para que a ciência funcione adequadamente e resulte nos devidos benefícios para toda a população humana, é essencial o livre acesso aos detalhes operacionais da prática científica, tais como caderno científico aberto (open notebook science), dados abertos, divulgação dos códigos fontes de programas de computador científicos (open code manifesto) e acesso universal às publicações científicas e aos dados correspondentes (open access, Panton Principles). A tese defendida aqui afirma a existência de elementos adicionais da prática científica que podem ser compartilhados a fim de se atingirem os benefícios presumidos. Estes elementos correspondem ao funcionamento, ao uso e à construção de aparatos científicos, e às ferramentas utilizadas para sua concepção e materialização, ou seja, a documentação de desenvolvimento e uso dos equipamentos científicos e suas aplicações. A disponibilização desta documentação visa fomentar, e em alguns casos até mesmo viabilizar, a reprodução de experimentos científicos, aprimorando os mecanismos de disseminação do conhecimento e suas aplicações. Um dos mecanismos desta disseminação será a utilização e o estudo desses equipamentos no ensino técnico e universitário. 
A fim de embasar a sugestão apresentada neste capítulo, traçaremos paralelos entre a infraestrutura livre, que levou ao advento da World Wide Web para a criação e comunicação de conteúdo multimídia, e a criação e comunicação de conteúdo que resulte na concepção de elementos materiais - em específico, de instrumentos científicos. Esta analogia é conveniente, pois a WWW surgiu como um conjunto de padrões e ferramentas colocadas em domínio público por um grande laboratório científico ${ }^{1}$, a Organização Europeia para a Pesquisa Nuclear, conhecida como CERN (antigo acrônimo para Conseil Européen pour la Recherche Nucléaire), viabilizando a construção, a publicação e o acesso a hipertextos para fins de otimização da comunicação científica. Isto se mostrou de grande importância, não apenas para a ciência isolada, mas para a sociedade como um todo, levando-nos a uma nova era informacional.

A informática, além de ampliar o acesso a dados, textos e gráficos, permitiu o compartilhamento de códigos para a realização de análises numéricas e simulações científicas. Seguindo esta tendência, podemos pensar no próximo passo da informática como uma infraestrutura que facilite a concepção, o compartilhamento e a fabricação de objetos materiais, tais como aparatos científicos. Com isso, chegaremos à concepção de uma infraestrutura aberta para a construção de hiperobjetos científicos. Tal infraestrutura engloba ferramentas livres para desenho, estudo e fabricação digitais, como CAD (Computer Aided Design), CAMs (Computer Aided Manufacturing) e máquinas CNC (Controles Numéricos Computadorizados).

Adiante são abordados aspectos conceituais que fundamentam a WWW, tomando o hipertexto como base para a construção do conceito de hiperobjeto. Em seguida são aprofundados os aspectos técnicos e legais que viabilizam hipertextos científicos e mostram

1 O software que impulsiona a WWW foi posto em domínio público pelo CERN em 30 de abril de 1993. Ver http://home.web.cern.ch/about/updates/2013/04/twenty-years-free-open-web. Acesso em: 2 de abril de 2014. 
como estes podem ser estendidos para hiperobjetos. Por fim, são propostos elementos de uma infraestrutura ideal para criação, compartilhamento, modificação e materialização de hiperobjetos científicos e suas aplicações.

\section{NÃO RIVALIDADE DO CONHECIMENTO}

A não rivalidade é uma das propriedades básicas do conhecimento e de suas representações, efetivamente explorada com sucesso em muitos hipertextos da WWW.

O termo vem da economia: é rival aquele bem ou recurso cujo uso por alguém impede (ou compete com) o uso por outra pessoa. Os bens materiais são sempre rivais: o meu uso de uma cadeira, uma maçã ou um exemplar de um livro impede (ou compete com) o uso desses mesmos objetos por outra pessoa.

Um bem ou recurso não rival, por sua vez, é aquele que admite usos simultâneos que não competem entre si. [....] como as ideias, os programas de computador, as obras artísticas, científicas e culturais - são, em geral, não rivais. (SIMON, 2008, p. 16)

Esta não rivalidade permite que hiperlinks presentes em hipertextos e seus conteúdos possam ser utilizados simultaneamente por um grande número de pessoas. Ao contrário dos bens e objetos materiais, o conhecimento ou os objetos digitais não requerem uso exclusivo, e sua disponibilidade não é diminuída com o uso. Na prática, seu uso é não rival.

Quando estamos lidando com objetos físicos, tais como instrumentos científicos, seus usos são evidentemente rivais. Duas pessoas não podem utilizar o mesmo instrumento científico para realizar simultaneamente dois experimentos. Entretanto, o conhecimento e as representações digitais relacionados a qualquer objeto físico, como o instrumento científico, são não rivais e podem ser 
utilizados para a construção de dois equipamentos similares. A tese apresentada aqui sugere qualificar e sistematizar a organização e a publicação de informações digitais relacionadas aos objetos científicos, a fim de se obter pleno aproveitamento dos seus aspectos não rivais. Este potencial pode ser efetivamente aproveitado não apenas para fins de reprodução e estudo dos instrumentos, mas também para seu desenvolvimento e adaptação. A realização deste potencial está se tornando evidente pelos avanços e redução de custos dos equipamentos de fabricação personalizada, tais como impressoras 3D e máquinas de usinagem de código aberto (PEARCE, 2012). As mesmas características não rivais também são usufruídas por software livre científico, geralmente baseado em compiladores e linguagens de programação livres, permitindo o livre compartilhamento dos códigos e seus usos e reusos.

\section{ECOLOGIA COGNITIVA: DA ORALIDADE AOS HIPEROBJETOS}

Ao longo da história, observa-se o advento de novas formas de comunicação: a oralidade, a escrita, a imprensa, a informática. O surgimento de cada uma delas altera profundamente a cultura humana por também alterar as formas de saber e conhecer. No que tange à ciência, os reflexos da escrita até a criação da imprensa já podem ser bem identificados; entretanto, as implicações da informática ainda estão sendo assimiladas (LEVY, 1993; NIELSEN, 2012).

A informática, por meio do maior sistema de hipertexto da atualidade, a World Wide Web, e de outros programas de computador, viabilizou um meio de suporte e transmissão de representações do conhecimento que desfruta das propriedades mais próximas àquelas da própria cognição humana, do nosso potencial intelectual: o pensamento, as ideias, a linguagem e a comunicação são fluidas, transformam-se, adaptam-se e se propagam com ou sem 
modificações, com naturalidade. Pierre Lévy apresenta o hipertexto como representante da conectividade entre as representações no contexto da era informacional. Além disto, Lévy caracteriza os potenciais das ferramentas de comunicação pelo conceito de ecologia cognitiva:

O meio ecológico no qual as representações se propagam é composto por dois grandes conjuntos: as mentes humanas e as redes técnicas de armazenamento, de transformação e de transmissão das representações. A aparição de tecnologias intelectuais como a escrita ou a informática transforma o meio no qual se propagam as representações. (LEVY, 1993, p. 84)

É claro que o sucesso da propagação das representações do conhecimento é diretamente dependente de padrões de representação inteligíveis para as partes envolvidas, a exemplo de um idioma: a existência de um idioma comum é o padrão fundamental para a eficiente propagação direta de conhecimento entre indivíduos, por palavras escritas ou faladas. Quando a troca de informação é mediada por instrumentos tais como computadores, padrões digitais que especificam sinais elétricos e codificações binárias devem ser precisamente definidos e implementados, para que as informações sejam trocadas entre máquinas. Além disso, estando a implementação técnica associada a práticas de licenciamento permissivo, estabelecem-se os fundamentos de uma ecologia cognitiva que prima pela disseminação e pelo uso do conhecimento, suas representações, suas aplicações e sua evolução (vide seção Questões técnicas e legais deste capítulo). Ou seja, o verdadeiro potencial da ecologia cognitiva da WWW é revelado quando os aspectos técnicos e legais são orquestrados de maneira a permitir novas formas de geração e acesso de informação como, por exemplo, a Wikipédia. Buscaremos então algo semelhante, que possa ser utilizado como referencial para a construção de objetos cujas informações e potencial de 
materialização e uso estão organizados e acessíveis de maneira análoga à dos hipertextos - aqui chamados de hiperobjetos.

\section{HIPERTEXTOS}

Hipertexto é o termo que remete a um texto ao qual se agregam outros conjuntos de informação na forma de blocos de textos, palavras, imagens ou sons, cujo acesso se dá através de referências específicas que, no meio digital, são denominadas hiperlinks ${ }^{2}$, ou simplesmente links. Esses links ocorrem na forma de identificadores destacados no corpo de texto, ícones gráficos ou imagens e têm a função de interconectar os diversos conjuntos de informação, oferecendo acesso sob demanda às informações que estendem ou complementam o texto principal. (WIKIPÉDIA, a enciclopédia livre).

Os hiperlinks têm como função "[....] oferece(r) acesso sob demanda às informações[...]". Ou seja, espera-se que o caminho de um hiperlink ofereça acesso às informações desejadas. Caso a informação não esteja disponível ou seja ininteligível, o link pode ser considerado quebrado, sendo então de pouco ou nenhum valor. Se o conteúdo destino estiver codificado de maneira não padronizada, ele não será legível para o usuário. Por outro lado, se estiver disponível sob termos de licenças permissivas - tais como algumas licenças Creative Commons, como é o caso da Wikipédia - o valor do conteúdo é ainda maior para quem o acessa, dadas as possibilidades de reuso.

No que tange à pesquisa científica, a World Wide Web teve sua origem na busca por um meio de agilizar a forma na qual informação era compartilhada entre cientistas, ou seja, para dinamizar as

2 Disponível em: https://pt.wikipedia.org/wiki/Hiperliga\%C3\%A7\%C3\%A3o. Acesso em 21 jun.2015. 
colaborações científicas. Em 1993 o CERN colocou os programas da WWW em domínio público ${ }^{3}$ para maximizar a sua disseminação, já que Tim Barners-Lee, líder do projeto, concebeu-o para suprir a demanda de troca de informação entre cientistas, universidades e instituições ao redor do mundo ${ }^{4}$.

Aplicando o conceito de ecologia cognitiva ao caso dos hipertextos, não apenas o idioma é necessário para a eficiente propagação das representações: também são fundamentais os padrões adicionais da WWW que devem estar implementados com precisão em editores de hipertextos, servidores web, navegadores e protocolos de comunicação de rede, para que seja possível a navegação pelos hiperlinks, garantindo o "(....) acesso sob demanda às informações que estendem ou complementam o texto". O grande mérito do CERN foi ter criado e integrado elementos básicos necessários para que tal navegação fosse possível e, reconhecendo o seu valor, tê-los lançado publicamente, permitindo a sua adoção universal, tal como acontece com qualquer idioma. Hoje vivemos em uma sociedade altamente conectada, onde o hipertexto é uma representação familiar graças à popularidade da World Wide Web.

3 Disponível em: http://home.web.cern.ch/about/updates/2013/04/twenty-years-free-open-web .Acesso em 2 abril 2014.

4 Neste contexto é fácil perceber que links quebrados em hipertextos são impedimentos ao avanço de uma pesquisa ou de um estudo. Em um artigo científico atual, estes hiperlinks apontam para materiais suplementares, assim como referências bibliográficas - outros artigos científicos - todos fundamentais para a avaliação, validação e reprodução dos objetos de pesquisa do artigo científico. Percebemos então que referências inacessíveis, apontadas por hiperlinks em hipertextos científicos, são indicativas de hipertextos quebrados. Em muitos casos, o hipertexto científico só será válido (sem hiperlinks quebrados) para quem dispõe de assinatura das revistas científicas citadas ou dispõe de recursos para aquisição das referências individuais. A aquisição das referências individuais pode facilmente chegar de centenas a milhares de dólares para cobrir todas as referências de um único artigo científico. Assim, o movimento do acesso aberto pode ser entendido como uma reação natural de uma sociedade que reconhece as vantagens do hipertexto frente ao texto convencional, e considera não apenas frustrante, mas danosa, a existência sistemática de links quebrados nos hipertextos científicos. 


\section{HIPEROBJETOS}

Percebendo que o hipertexto transcendeu o texto nas suas formas de representação de conhecimento, podemos utilizar o conceito para compreender a transformação de objetos em hiperobjetos:

Hiperobjeto é o termo que remete a um objeto ao qual se agregam ações e/ou conjuntos de informação na forma de blocos de códigos, textos, palavras, imagens, sons, funções e ações, cujo acesso se dá através de referências específicas que, no meio digital, são denominadas hiperlinks, ou simplesmente links. Esses links ocorrem na forma de identificadores destacados no objeto ou em suas representações na forma de textos (tags), ícones gráficos ou imagens, e têm a função de interconectar os diversos conjuntos de informações, oferecendo acesso, sob demanda, às informações que estendem ou complementam o hiperobjeto. (Adaptação de Hipertexto em Wikipédia, a enciclopédia livre).

Com efeito, um objeto pode ser transformado em hiperobjeto pela disponibilização de hiperlinks que dinamizam o acesso ao que se conhece ou é relevante saber sobre o objeto em cada contexto. Por exemplo, um eletrodoméstico pode ser considerado um hiperobjeto quando informações tais como um manual de usuário, rede de assistência técnica, lojas de peças e acessórios podem ser facilmente acessados, seja por hiperlinks presentes no objeto físico como códigos de barra, $Q R$ Codes - ou através de representações digitais interativas como realidade aumentada.

No caso científico e educacional, o interesse reside em hiperobjetos cujos links apontam para informações como modelos teóricos, digitais ou matemáticos do objeto, instruções de uso e manutenção, aplicações, códigos e programas de computador e firmware (programas embarcados no próprio objeto). Também 
podem ser inseridos hiperlinks que dão acesso a funções ou ações do objeto, a representações digitais que facilitam a sua materialização, a simulações físicas, mecânicas ou suas transformações. Os hiperobjetos podem conter diferentes níveis de detalhamento, de acordo com o seu objetivo e contexto. As aplicações científicas e educacionais dos hiperobjetos são modelos ideais para estes, em que a omissão e o obscurecimento de informações não são desejados.

\section{HIPERINSTRUMENTOS NA PRÁTICA}

As realizações de hiperinstrumentos, tal como propostas neste texto, requerem a consolidação de aspectos técnicos, legais, e boas práticas que lhes permitam desfrutar das possibilidades não rivais análogas às dos hipertextos. Os modelos de desenvolvimento de software livre e de conteúdo livre, tais como, respectivamente, o Kernel GNU/Linux e a Wikipédia, são os pontos de partida para a construção de hiperobjetos, para os quais os aspectos legais e técnicos ampliam mais ainda as possibilidades de uso, mas agora considerando, também, novas características materiais.

\section{Questões técnICAS E LEGAIS}

Para garantir sustentabilidade e ampla adoção da ecologia cognitiva dos hiperobjetos, elementos técnicos e legais devem ser satisfeitos. Espera-se, desta ecologia cognitiva, o livre acesso aos conteúdos apontados pelos hiperlinks, e que estes conteúdos, por sua vez, desfrutem das propriedades não rivais do conhecimento, a fim de que possam ser usados, estudados, modificados e distribuídos. Com isto, os hiperobjetos poderão ser moldados e transformados com todo o potencial das ferramentas digitais e das mentes humanas. 
Formatos de dados, programas de computador e máquinas de fabricação digital

A ação de navegar pelos hiperobjetos e a ação de transformá-los, mesmo que digitalmente, seja pela criação de novos hiperlinks, seja pela alteração daqueles existentes, requerem que dois aspectos sejam integrados: i) a implementação de padrões abertos para dados em arquivos de computador e protocolos de comunicação; e ii) o uso de ferramentas livres, programas de computador e máquinas de fabricação digital que permitam o acesso e a modificação do conteúdo dos hiperlinks através da interpretação dos arquivos de computador e dos protocolos de comunicação e sua execução/materialização. A respeito da primeira categoria, "Um formato aberto é uma especificação publicada para armazenar dados digitais, mantida geralmente por uma organização de padrões não proprietária, e livre de limitações legais no uso." (WIKIPÉDIA) ${ }^{5}$

Alguns formatos abertos já são bem definidos para textos, materiais multimídia, linguagens de programação, armazenamento de dados e bancos de dados, permitindo o compartilhamento e o uso de boa parte do conteúdo de interesse científico. Entretanto, ainda existe uma grande lacuna nos formatos de dados pertinentes para hiperobjetos que não foram definidos como padrões abertos ou que carecem de validação para aplicações técnicas e científicas de precisão. Entre estes, cabe ressaltar a falta de, ao menos, um formato aberto para descrição de objetos tridimensionais e suas propriedades para fins de estudo, desenho, construção e simulação de instrumentos científicos ${ }^{6}$. A materialização dos objetos em

5 Disponível em: https://pt.wikipedia.org/wiki/Formato_aberto .Acesso em 26 de outubro de 2014.

6 Existem padrões abertos para objetos 3D como o AMF (Additive Manufacturing File Format) e o X3D, porém suas aplicações para CAD de precisão científica e implementações em programas CAD livres para uso em hiperobjetos ainda está aberta. Disponível em: https:// en.wikipedia.org/wiki/X3D e https://en.wikipedia.org/wiki/Additive_Manufacturing_File_ Format. Acesso em 14 out. 2014. 
representação digital será tratada a seguir, neste capítulo, na seção sobre Infraestrutura para hiperobjetos.

No que tange aos programas de computador, o seu uso corresponde à parte operacional da metodologia científica realizada por meio de computadores. O uso e a evolução destes programas são fundamentais para o avanço da ciência. O acesso ao código fonte dos programas é, inclusive, considerado, pelos adeptos da ciência aberta, uma premissa para o processo de validação de publicações científicas que deles fazem uso ${ }^{7}$.

No mesmo sentido, o CERN, em nota técnica de Tecnologia da Informação elaborada por força tarefa para licenciamento de software, recomenda que:

- sempre que possível, o software de propriedade do CERN, no todo ou em parte, deve ser feito disponível como software livre;

- todo software livre licenciado pelo CERN deve utilizar licenças aprovadas pela Open Source Initiative $(\mathrm{OSI})^{8}$.

Seguindo estes princípios, o CERN e o Fermilab - outro laboratório de física de altas energias - contribuem para o desenvolvimento e a manutenção de um sistema operacional e programas de suporte à pesquisa científica, chamado Scientific Linux ${ }^{9}$. Iniciativas semelhantes podem ser encontradas na Nasa (sigla em inglês de National Aeronautics and Space Administration - Administração Nacional da Aeronáutica e do Espaço) ${ }^{10}$.

7 Disponível em: http://sciencecodemanifesto.org/ Acesso em 26 de outubro de 2014.

8 Final Report of the Open Source Software Licence Task Force CERN; CERN-IT-Note-2012-029;Jan, 2012.

9 Disponível em: https://www.scientificlinux.org/. Acesso em 21 jun. 2015

10 Disponível em: http://ti.arc.nasa.gov/opensource/ Acesso em 21 jun. 2015. A licença dos programas abertos da NASA não pode ser considerada uma licença de software livre pois esta não permite que se faça a integração destes programas com códigos/programas de terceiros. 
Por outro lado, também existem meios científicos nos quais tarefas corriqueiras dos cientistas, tais como operações aritméticas, cálculos numéricos, criação de gráficos e edição de texto são realizadas em grande parte por meio de programas proprietários, enquanto existe uma diversidade de programas, livres e de qualidade, disponíveis para os mesmos propósitos. O uso de programas proprietários cria barreiras para que a prática científica se dissemine pela sociedade - por exemplo, limitando o escopo das atividades universitárias de ensino e extensão. Como consequência, o uso de software proprietário no meio acadêmico reduz a possibilidade de oferecimento ou relevância de atividades de ensino e extensão que envolvem o treinamento no uso do computador. Assim, a disseminação do conhecimento acadêmico e sua aplicação fora dos grupos de pesquisa, seja em escolas ou comunidades populares, seja em ambiente industrial/tecnológico, fica limitada àqueles que têm acesso aos programas utilizados ${ }^{11}$.

\section{Licenciamento de hiperobjetos}

Para que se desfrute dos aspectos não rivais dos hiperobjetos de acordo com as habilidades intelectuais humanas associadas às possibilidades das tecnologias digitais é necessário que, além do acesso ao conteúdo destino de cada hiperlink e à disponibilização das ferramentas necessárias para acessá-lo, tenhamos autorização para seu uso, estudo, modificação e distribuição. Para isto, o conteúdo deve estar disponível de acordo com a definição de

\footnotetext{
11 Cabe apontar que, infelizmente, muitas vezes o acesso aos programas proprietários se dá por cópias clandestinas, preocupantemente propagando um vício velado no uso indevido de software proprietários através da pirataria.
} 
conhecimento aberto $^{12}$, a definição de software livre ${ }^{13}$, e a definição de hardware aberto ${ }^{14}$, para cada tipo de categoria de informação a ser utilizada.

Atualmente, os aspectos legais são pontos fundamentais da prática científica e educacional. A diversidade de leis e jurisdições resulta em grande dificuldade para cientistas e educadores. Estas misturam elementos de leis de propriedade intelectual que caem em duas categorias: i) direito autoral e ii) propriedade industrial; e merecem esclarecimento.

O primeiro aspecto compreende as obras intelectuais, artísticas, literárias, programas de computador. Elas podem ser categorizadas em licenças de software e licenças de conteúdo. Nas últimas décadas, especialistas e organizações têm elucidado formas de licenciamento para as diferentes categorias de licenças, formando um arcabouço legal para a criação de hiperobjetos ${ }^{15}$, e tornando inteligível o ecossistema de licenciamento que permite também a remixagem, a combinação de objetos. A tabela 1 apresenta um cronograma temporal das primeiras licenças de software, conteúdo e hardware abertos e suas autorias.

12 Disponível em: http://opendefinition.org/od/1.1/pt/ Acesso em: 14 de Outubro de 2014.

13 Disponível em: https://www.gnu.org/philosophy/free-sw.html Acesso em: 14 de Outubro de 2014.

14 Disponível em: http://www.oshwa.org/definition/portuguese/ Acesso em: 14 de Outubro de 2014.

15 A Fundação Software Livre (FSF - Free Software Foundation) mantém uma página com comentários a respeito de diversas licenças de software e outros tipos de conteúdo em https://www.gnu.org/licenses/license-list.html . Acesso em: 14 de Outubro de 2014. 
Tabela 1 - Cronograma temporal das licenças de software livre, conteúdos livres e hardware abertos e suas autorias.

\begin{tabular}{|c|c|c|c|}
\hline Ano & Alvo da Licença & Nome da Licença & Origem / Autor \\
\hline 1989 & Software livre & $\begin{array}{c}\text { General Public Licence } \\
\text { (GPL) }\end{array}$ & $\begin{array}{c}\text { Free Software Foundation } \\
\text { Richard Stallman }\end{array}$ \\
\hline 2002 & $\begin{array}{c}\text { Conteúdo em } \\
\text { geral }\end{array}$ & $\begin{array}{c}\text { Creative Commons } \\
\text { Creative Commons / } \\
\text { Lawrence Lessig }\end{array}$ \\
\hline 2007 & Hardware aberto & $\begin{array}{c}\text { TAPR Open Hardware } \\
\text { Licence }\end{array}$ & $\begin{array}{c}\text { Tucson Amateur } \\
\text { Packet Radio / John R. } \\
\text { Ackermann }\end{array}$ \\
\hline
\end{tabular}

Fonte: Elaboração própria.

As licenças de software e conteúdo já fazem parte de ecossistemas cognitivos que integram os aspectos legais e técnicos os quais permitem a sua sustentação, como os exemplos citados da Wikipédia e os sistemas operacionais GNU/Linux. Projetos de hardware abertos e livres começaram sendo licenciados com os mesmos tipos de licença que software e conteúdo, como o Arduino. Entretanto, como a fabricação de equipamentos está regida pelo regime da propriedade industrial, as licenças de software livre e conteúdo, como as Creative Commons, não são inteiramente adequadas para estes. Desta maneira, o hardware aberto merece licenças específicas.

\section{Licenças de hardware aberto}

São recentes as discussões sobre equipamentos (hardware) que oferecem a seus usuários a liberdade de uso, estudo, modificação e distribuição - aquelas definidas para o software livre. A conversa a respeito do hardware aberto se iniciou entre hobistas (ACKERMANN, 2009) e resultou na publicação da Licença de Hardware Aberto TAPR 
em $2007^{16}$. Atualmente o principal mercado de hardware aberto é o de amadores e adeptos do faça você mesmo (DIY - do it yourself). A ciência e a educação constituem iniciativas que podem ser imediatamente beneficiadas com a adoção destes princípios, pois eles estão alinhados com os seus propósitos de avanço e disseminação do conhecimento. Grande impulso foi dado a este movimento com o lançamento da Licença de Hardware Aberto do CERN.

\section{Hardware aberto do CERN}

Em março de 2011, o CERN lançou a versão 1.0 da Licença de Hardware Aberto do CERN (a última versão, 1.2, publicada em setembro de 2013). No lançamento inicial, a nota pública do CERN informa o seguinte:

No espírito de disseminação de conhecimento e tecnologia, a Licença de Hardware Aberto do CERN foi criada para governar o uso, cópia, modificação e distribuição de documentação de desenhos de hardware e a manufatura e distribuição de produtos. A documentação de desenho de hardware inclui diagramas esquemáticos, desenhos, circuitos ou leiaute de placas de circuito, desenhos mecânicos, fluxogramas e textos descritivos, assim como outros materiais explicativos ${ }^{17}$.

Atualmente, a Licença de Hardware Aberto do CERN tem sido utilizada para a publicação de diversos instrumentos científicos, educacionais e industriais. Uma boa amostra destes equipamentos e de suas aplicações pode ser encontrada no repositório de hardware

16 TARP OHL - Tucson Amateur Packet Radio Open Hardware Licence - Disponível em: http://www.tapr.org/OHL Acesso em 24 Out. 2014.

17 Disponível em: http://press.web.cern.ch/press-releases/2011/07/cern-launches-open-hardware-initiative Acesso em: 24 Out. 2014. 
aberto $^{18}$ e nos projetos do Public Laboratory for Open Technology and Science (PLOTS) ${ }^{19}$.

\section{BOAS PRÁTICAS}

Além das questões técnicas e legais já apontadas, o sucesso da disseminação dos hiperobjetos depende de elementos práticos que facilitem ou até mesmo permitam a sua utilização: a qualidade da sua documentação. Podemos fazer um paralelo entre a navegabilidade de um website e o seu leiaute, sua organização. O conteúdo pode estar lá, e seu licenciamento pode estar adequado; porém a forma de apresentação do conteúdo e de seus hiperlinks afeta a experiência de alguém que utiliza um sítio na internet. A necessidade de programas especiais para acesso aos elementos que não utilizam os padrões definidos também é impeditivo para o uso adequado do conteúdo. Esta é a razão para a existência de organizações que definem padrões, como o W3C (World Wide Web Consortium), responsável por manter o padrão de linguagem de marcação de hipertexto (HTML - Hypertext Markup Language).

Analogamente, a navegabilidade por um hiperobjeto é afetada pela disposição de hiperlinks, do conteúdo para o qual estes apontam, de como os conteúdos evoluem no tempo, e da facilidade para participação desta evolução. Esta é uma questão de organização e documentação de hiperobjetos - enfim, boas práticas.

Bons exemplos destas boas práticas, que servem de referência, são os projetos de software, conteúdo e hardware abertos, que utilizam metodologias às quais o conceito de hiperobjeto pode ser imediatamente aplicado, e nos quais até se inspira. Estes projetos comumente utilizam:

\footnotetext{
18 Disponível em: http://www.ohwr.org - Open Hardware Repository .Acesso em: 24 Out. 2014.

19 Disponível em: http://publiclab.org/ Acesso em: 31 Março 2015.
} 
- ferramentas abertas de desenvolvimento;

- controle de versão;

- repositórios de acesso público;

- wikis de documentação;

- fóruns e listas de e-mails para usuários e desenvolvedores;

- sistema de gerenciamento de defeitos (bugs).

O desenvolvimento do kernel GNU/Linux ${ }^{20}$, a Wikipédia ${ }^{21}$ e a impressora auto-replicante RepRap ${ }^{22}$ são casos exemplares. A familiarização com as ferramentas destas iniciativas para uso e reciclagem de códigos, dados e instrumentos científicos, é de importância crescente para a prática científica. $O$ treinamento científico nas metodologias colaborativas é algo a ser incentivado para as novas gerações de cientistas, engenheiros, técnicos e professores ${ }^{23}$. Para isto, participantes do Centro de Tecnologia Acadêmica da UFRGS criaram e mantêm um modelo padrão para a documentação de projetos, que inclui seções específicas para documentação de desenvolvimento, de uso, além de aplicações educacionais ${ }^{24}$.

\section{INFRAESTRUTURA PARA HIPEROBJETOS}

Novas ecologias cognitivas surgem quando os elementos de suporte ao armazenamento, transmissão e processamento de conhecimento e suas representações são adotados por uma massa crítica capaz de utilizá-los e disso beneficiar-se. A infraestrutura da ecologia cognitiva, além de existir, deve estar acessível e ser adaptável

\footnotetext{
20 Disponível em: https://www.kernel.org/ Acesso em: 24 Out. 2014.

21 Disponível em: https://www.wikipedia.org Acesso em: 24 Out. 2014.

22 Disponível em: http://reprap.org/ Acesso em: 24 Out. 2014.

23 Destaque para controle de versão com o git, textos wiki como o MediaWiki, ou similares.

24 Disponível em: http://cta.if.ufrgs.br/projects/suporte-cta/wiki/Modelo_de_Documentação_Padrão Acesso em: 20 Fev. 2015.
} 
para que possa ser difundida, sustentável e de benefício a toda a humanidade.

Já abordamos o tema da infraestrutura disponibilizada pelo CERN para a criação da WWW: meios que permitem a criação de hipertextos, sua publicação e sua navegação. Em uma abordagem simplificada, podemos considerar que a infraestrutura técnica que viabilizou a ecologia cognitiva do software livre foi um editor de texto livre e um compilador de programas de computador também livre, tornando possível o desenvolvimento e a disseminação de códigos de computador que evoluíram para formar o sistema operacional GNU/Linux e muitos de seus programas.

Programas livres são fundamentais para a criação de hiperobjetos livres. Entretanto, por serem intangíveis ou não rivais, não são suficientes para fundamentar a ecologia cognitiva dos hiperobjetos, que incluem a sua materialização através de instrumentos de fabricação personalizada. A um protótipo mínimo da infraestrutura para a criação e navegação de hiperobjetos chamaremos de Bancada de Código Aberto, ou OpenSourceWorkbench.

\section{Bancada de Código Aberto}

A Bancada de Código Aberto apresentada aqui consiste de um grupo de instrumentos mínimos, de baixo custo, capazes de criar hiperobjetos científicos e educacionais. Essas ferramentas de hardware aberto e software livre viabilizam fluxos de trabalho desde a concepção conceitual do projeto até a materialização de instrumentos pelas máquinas de fabricação digital ${ }^{25}$. A própria bancada é composta de hiperobjetos.

\footnotetext{
25 Existe uma iniciativa complementar à Bancada de Código Aberto chamada Replab, iniciado no Open Source Ecology. A bancada de código aberto não compete com o RepLab, pois este visa à concepção de instrumentos mais pesados do que aqueles propostos para a Bancada de Código Aberto. Ambas compartilham valores similares e se complementam. Disponível em: http://opensourceecology.org/wiki/RepLab. Acesso em: 24 Out. 2014.
} 
A bancada de código aberto também visa contribuir para a qualificação educacional, podendo ser utilizada de duas maneiras. A mais direta consiste na sua aplicação para a reprodução de instrumentos científicos e educacionais disponíveis em repositórios on-line. Um pacote de arquivos adequados para serem enviados às máquinas de fabricação digital da bancada é obtido da internet, e utilizado para a fabricação das peças do instrumento de interesse, que é então montado e utilizado. A segunda maneira de utilização das máquinas consiste no próprio estudo da máquina e da sua evolução. Professores e estudantes de engenharias, ciências e outras áreas técnicas podem conhecer os elementos básicos das máquinas, as partes mecânicas e sua programação. Em ambos os casos, além de cultivar a curiosidade e o interesse de estudantes de todas as idades, o potencial criativo despertado pela familiarização com a fabricação digital desmistifica o desenvolvimento tecnológico e empodera os indivíduos, que passam de um papel passivo (consumidores de produtos prontos) para o papel de agentes ativos, desenvolvedores da tecnologia.

\section{Fabricação digital}

Fabricação digital ou fabricação personalizada consiste na materialização de objetos a partir de desenhos e representações digitais utilizando-se métodos aditivos ou subtrativos de materiais controlados numericamente por computador $(\mathrm{CNC})$, a fim de se obter um objeto físico com as características desejadas. Pode-se citar os seguintes métodos de fabricação digital:

- Fabricação aditiva (impressão 3D)

- Impressão de termoplásticos (polímeros)

- Impressão de metais

- Impressão a partir de pó (cerâmicas e metais)

- Fabricação subtrativa

- Fresadoras e tornos CNC 
- Usinagem por descarga elétrica (Electrical Discharge Machining - EDM)

- Cortadoras a laser e a plasma

- Centros de usinagem

Figura 1 - Mapa da Bancada de Código Aberto em março de 2015. Verde: disponível como tecnologia aberta; amarelo: projeto aberto em desenvolvimento; vermelho: ferramenta aberta inexistente, ou que carece de elementos importantes para difusão de seu uso (falta de interface amigável ou documentação).

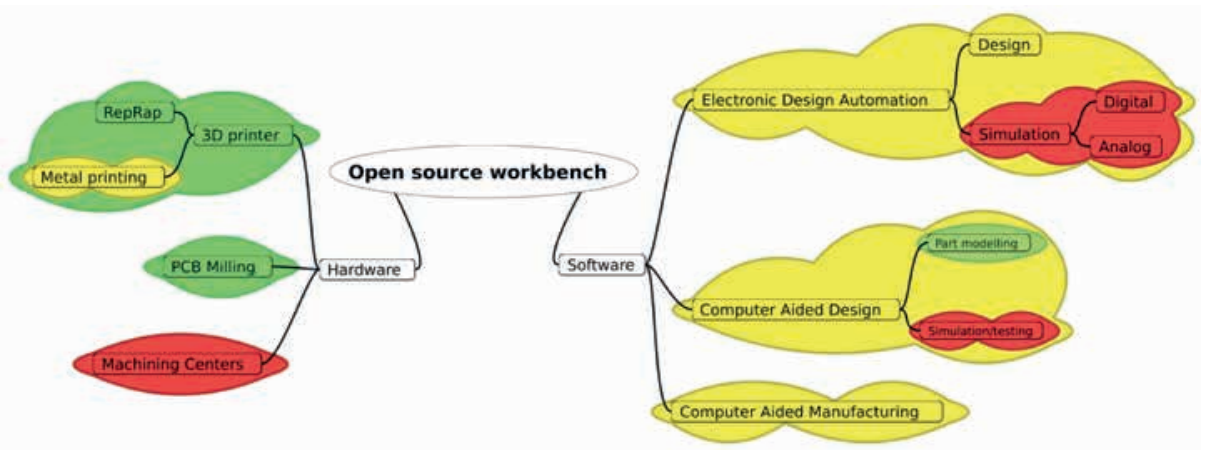

A fabricação digital se tornou popular com o lançamento do projeto RepRap, iniciado em 2004 por Adrian Bowyer, na Inglaterra (JONES et al., 2011) A RepRap iniciou uma linhagem de impressoras 3D de código aberto (CANO, 2011) que se mostraram capazes de reduzir em até 8 vezes o custo de instrumentação científica (PEARCE, 2012), não só demonstrando um novo potencial para a criação de experimentos científicos, mas também ampliando o acesso aos equipamentos de laboratório e facilitando a sua adaptação e manutenção. Os trabalhos de Jones e Pearce (JONES et al., 2011, PEARCE, 2012) demonstram o potencial da fabricação digital para a ecologia cognitiva dos hiperobjetos e suas aplicações para ciência e educação abertas. Entretanto, dadas as limitações das máquinas abertas e de baixo custo disponíveis na atualidade, podemos afirmar que a fabricação 
digital de código aberto ainda está na sua infância, mas, dado o entusiasmo de acadêmicos e não acadêmicos, em franco desenvolvimento.

Um dos gargalos da fabricação digital está nas limitações das ferramentas livres disponíveis para o desenho auxiliado por computador $(\mathrm{CAD})$ e para a fabricação de hardware, esta praticamente limitada a objetos plásticos. Outra limitação está associada às propriedades físico-químicas e mecânicas das peças de plástico polimérico, pois, para que sejam passíveis de utilização em ambientes mais adversos - por temperatura, pressão ou desgaste - também é necessária a elaboração de instrumentos especializados, utilizando-se outros materiais como metais, minerais e cerâmicas especiais.

Tão importantes quanto equipamentos de fabricação digital de baixo custo são as ferramentas em software livre para desenho, visualização, simulação eletrônica, mecânica e geométrica (montagem) das partes e instrumentos a serem construídos com estes aparelhos ${ }^{26}$, como apontado pelas regiões amarelas e vermelhas da figura 1 .

Um dos elementos mais recentes adicionados ao rol de máquinas de fabricação digital de baixo custo consiste em uma fresadora para placas de circuito impresso (PCI).

\section{Fresadora PCl João-de-barro (Furnarius rufus Milling Machine)}

O Centro de Tecnologia Acadêmica do Instituto de Física da UFRGS está atuando no desenvolvimento de elementos da Bancada de Código Aberto. Sua primeira contribuição consiste na concepção de uma máquina aberta para a prototipagem de placas de circuito impresso, a Fresadora PCI João-de-barro, concebida pelo engenheiro

\footnotetext{
26 Na verdade, muitas funcionalidades avançadas podem estar implementadas em programas do tipo software livre; entretanto a qualidade deste software está muito aquém dos equivalentes proprietários, pois carecem de integração, apresentam interfaces de usuário não intuitivas, alta taxa de bugs; e são de difícil aprendizado.
} 
Germano Postal. Seu primeiro protótipo funcional foi lançado em setembro de 2014 sob os termos da Licença de Hardware Aberto do CERN v $1.2^{27}$ (ver figura 2). Esta iniciativa busca reduzir o custo e a barreira para a prototipagem de placas de circuito impresso para fins científicos e educacionais através de um instrumento que seja fácil de fabricar e adaptar. O nome do projeto é homenagem ao pássaro João-de-barro (Furnarius rufus), que constrói seu ninho com barro, de maneira muito semelhante à das modernas máquinas de fabricação digitais aditivas, como as impressoras 3D.

Figura 2 - A Fresadora PCI João-de-barro: pronta para usinar (esquerda) e resultado de usinagem para a construção de shield gravador de microcontrolador AVR ATtiny para Arduino (direita).
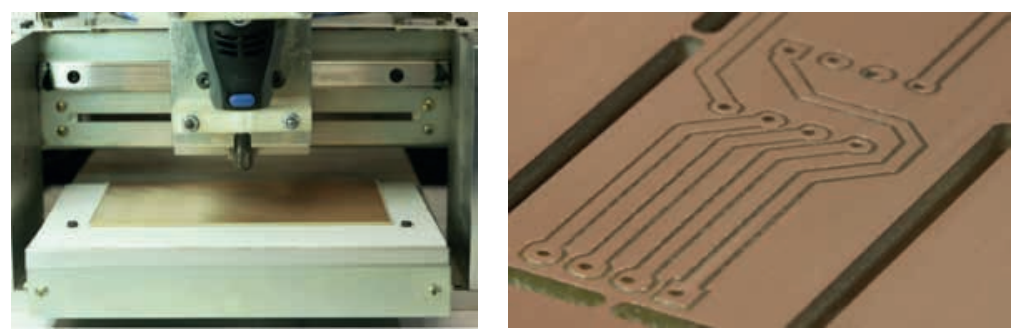

O projeto da Fresadora PCI João-de-barro tem os seguintes objetivos:

- baixo custo ( US\$1000) para as peças;

- alta precisão: capaz de prototipar placas de circuitos convencionais (through-hole) e circuitos SMD;

- facilidade de montagem: a maioria das partes pode ser montada com furadeira de bancada, corte e dobra de chapas de metal, disponíveis como serviços nos maiores centros urbanos.

27 Disponível em: http://ohwr.org/cernohl . Acesso em: 24 set. 2014. 


\section{Documentação do projeto}

A fim de garantir ampla disseminação em uma comunidade de usuários e desenvolvedores, o projeto da Fresadora PCI João-de-barro está sendo documentado em detalhes que incluem informações sobre cada peça da máquina, em formatos para impressão (pdf) e CAD $(\mathrm{dxf})^{28}$. O repositório também contém descrições de como cada peça do primeiro protótipo foi construída. A documentação do projeto pode ser encontrada no site do Centro de Tecnologia Acadêmica ${ }^{29}$; e sua versão em inglês, para a comunidade internacional, no repositório de hardware Aberto do $\mathrm{CERN}^{30}$. No momento da elaboração deste texto, o primeiro protótipo da Fresadora PCI João-de-barro havia sido concluído; e o repositório já contém os diagramas de cada parte mecânica da máquina, além de um guia passo-a-passo para a sua utilização, empregando-se exclusivamente software livre.

\section{Software livre}

A comunidade científica e educacional já faz uso de diversas ferramentas livres para elaboração de textos, imagens e programas de computador, porém carece de programas CAD livres para a elaboração e o compartilhamento de objetos e projetos 3D. Uma infraestrutura digital intangível eficiente se faz necessária para que os empreendimentos científicos e educacionais possam atingir seus objetivos com mais facilidade, através da colaboração para a criação de instrumentos que possam ser compartilhados por todos.

\footnotetext{
28 Pela ausência de um software livre adequado, a fresadora foi projetada em CAD proprietário de baixo custo.

29 Disponível em: http://cta.if.ufrgs.br/projects/fresadora-pci-joao-de-barro/wiki Acesso em: 24 set. de 2014 .

30 Disponível em: http://www.ohwr.org/projects/fr_pcb_mm/wiki Acesso em: 26 set. 2014.
} 
Abaixo são listados alguns programas CAD de interesse científico, que podem ser divididos em três categorias:

- AEC - Architecture, Engineering and Construction

- Programas para auxílio de desenho de objetos com duas ou três dimensões, interessantes para arquitetura, engenharia e construção. FreeCAD, LibreCAD, OpenSCAD, BRLCAD são alguns exemplos.

- EDA - Electronic Design Automation

- Programas para auxílio de desenho de esquemáticos e placas de circuitos eletrônicos. gEDA, KiCAD são alguns exemplos livres.

- CAM - Computer Aided Manufacturing

- Programas que codificam a representação digital de uma peça concebida a partir de um CAD para o controle de máquinas de manufatura aditiva ou de usinagem. Printrun ${ }^{31} \mathrm{e}$ FlatCAM $^{32}$ são casos de CAMs para impressão 3D e usinagem de placas de circuito impresso, respectivamente.

$C A D$ - Desenho auxiliado pelo computador para AEC e EDA

Existe uma variedade de ferramentas para desenho auxiliado pelo computador (CAD), que estão disponíveis como software livre. O objetivo deste trabalho não é o de realizar uma comparação entre diferentes ferramentas ${ }^{33}$ : quer-se apenas afirmar que os programas livres para CAD da atualidade carecem de funcionalidades avançadas, comumente encontradas em equivalentes proprietários. Em

\footnotetext{
31 Disponível em: http://www.pronterface.com/ Acesso em: 28 Out. 2014.

32 Disponível em: http://flatcam.org/ Acesso em: 28 Out. 2014.

33 Existe uma iniciativa aberta na Wikiversidade para a avaliação colaborativa das ferramentas CAD livres existentes e levantamento das funcionalidades essenciais a fim de promover seu desenvolvimento. Disponível em português e inglês em: https://pt.wikiversity. org/wiki/Pesquisa:Ferramentas_livres:Desenvolvimento_de_CAD_Livre Acesso em: 1 set. 2014.
} 
função do hiato existente entre o nível de usabilidade e as funcionalidades das opções livres e das ferramentas proprietárias de $\mathrm{CAD}$, é prática corrente o uso das proprietárias para o desenho de instrumentos científicos, inclusive aqueles considerados hardware aberto $^{34}$. Desta maneira, a colaboração aberta e o compartilhamento de desenhos de instrumentos científicos ficam bastante limitados, uma vez que o custo de ferramentas CAD pode alcançar facilmente dezenas de milhares de dólares por licença. Universidades e centros de pesquisas investem anualmente milhões na aquisição de licenças de software, recursos que poderiam ser muito melhor direcionados para o desenvolvimento de alternativas livres tornadas disponíveis para todos.

\section{Desenho de Circuitos Eletrônicos (EDA)}

Existe uma variedade de software livre para o Desenho de Circuitos Eletrônicos (EDA - Electronic Design Automation, em inglês). Uma das opções é o Fritzing, um excelente ponto de partida para iniciantes, pois apresenta uma visão de protoboard - no qual as representações dos componentes são idênticas aos próprios, facilitando a familiarização com eletrônica - além das visualizações mais usuais, como esquemático de circuitos, onde os componentes são representados por símbolos, e placa de circuito para construção de trilhas de conexões entre componentes. Entretanto, o Fritzing é bastante limitado para aplicações avançadas. O programa CAD para EDA, ideal para a ecologia cognitiva dos hiperobjetos, deve ter as funcionalidades avançadas, ao mesmo tempo que é fácil de instalar e adequado para iniciantes realizarem seu aprendizado de eletrônica pelo desenho de circuitos simples e sua simulação.

34 Como os desenhos de instrumentação eletrônica do repositório de hardware aberto mantido pelo CERN em http://www.ohwr.org . Acesso em: 28 Out. 2014. 
A ferramenta CAD mais promissora para EDA avançado da atualidade é o KiCAD. Ele está sendo desenvolvido por uma comunidade de colaboradores, inclusive pesquisadores e desenvolvedores ligados ao CERN, que perceberam a importância de programas livres para a colaboração em desenhos de instrumentos científicos ${ }^{35}$.

Uma das funcionalidades importantes ainda inexistentes em CAD e EDA refere-se à possibilidade de conduzir simulações do circuito de forma integrada com a interface do usuário. A simulação permite estimar o comportamento do circuito antes da sua fabricação/prototipagem, reduzindo o tempo de desenvolvimento e o desperdício de materiais.

\section{Potencial da Bancada de Código Aberto}

A ciência e a educação compartilham muitos de seus fundamentos. Ambos os esforços objetivam o aperfeiçoamento e a disseminação do saber humano a fim de beneficiar a sociedade. A fronteira entre ciência e educação é bastante tênue. Programas de pós-graduação, de iniciação científica, que envolvem alunos de graduação ou ensino técnico, ou até mesmo iniciativas de ciência cidadã na escola, são exemplos nos quais as duas áreas estão diretamente interligadas.

A adoção de práticas, métodos e ferramentas científicas no contexto educacional é de benefício claro, pois evidencia as aplicações do que é visto em aula e seus desdobramentos. Ferramentas para a criação, navegação e adaptação de hiperinstrumentos científicos podem ser imediatamente aplicadas no contexto educacional. Enriquecem o conceito de Recursos Educacionais Abertos adotado pela Organização das Nações Unidas para a Educação, a Ciência e

35 Disponível em: https://giving.web.cern.ch/civicrm/contribute/transact?reset=1\&id=6. Acesso em: 28 Out. 2014. 
a Cultura (Unesco) ${ }^{36}$ em 2002. Recursos Educacionais Abertos são “[...] os materiais de ensino, aprendizagem e investigação em quaisquer suportes, digitais ou outros, que se situem no domínio público ou que tenham sido divulgados sob licença aberta que permite acesso, uso, adaptação e redistribuição ${ }^{37 "}$.

Acesso à ampla infraestrutura científica não rival também reduz as barreiras para o empreendedorismo, que pode ser inspirado em modelos de negócios baseados em software livre: consultoria, suporte, treinamento, desenvolvimento personalizado, assim como modelos de negócio emergentes para hardware aberto ${ }^{38}$ (RAASCH, 2009, MERKEL, 2012) tornando natural a integração entre ciência, educação e empreendedorismo.

\section{HIPERINSTRUMENTOS CIENTíFICOS E EDUCACIONAIS}

Um hiperinstrumento científico ou educacional é um instrumento cujas representações digitais contêm detalhes que facilitem, a qualquer pessoa interessada, aprofundar seus conhecimentos nos diversos aspectos do instrumento, de modo a garantir o seu uso, estudo, reprodução, adaptação e disseminação. Por princípio, informações não são deliberadamente omitidas dos objetos científicos, de forma que os hiperlinks em hiperobjetos podem apontar para teorias, artigos, resultados e suas bases de dados, manuais, casos de uso, repositórios de peças e fornecedores, formas de fabricação, guias de manutenção, wikis, grupos de usuários, ferramentas de

\footnotetext{
36 A Unesco adotou em 2002 o conceito de Recursos Educacionais Abertos. Disponível em: http://www.unesco.org/new/en/communication-and-information/access-to-knowledge/open-educational-resources/. Acesso em: 25 out. 2014.

37 Disponível em: http://www.unesco.org/new/fileadmin/MULTIMEDIA/HQ/CI/ WPFD2009/Portuguese_Declaration.html. Acesso em: 25 out. 2014.

38 Disponível em: http://www.openp2pdesign.org/2011/open-design/business-models-for-open-hardware/ Acesso em: 26 out. 2014.
} 
fabricação. A tabela 2 apresenta uma comparação da utilização de hiperlinks em hipertextos e para hiperobjetos científicos.

Tabela 2: Usos típicos de hiperlinks em hipertextos e hiperobjetos científicos.

\begin{tabular}{|c|c|c|}
\hline & Hipertextos científicos & Hiperobjetos científicos \\
\hline 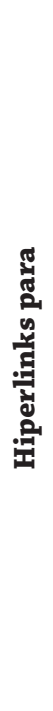 & $\begin{array}{l}\text { - Blocos de textos: } \\
\text { - Referências bibliográficas } \\
\text { - Materiais suplementares } \\
\text { - Imagens (gráficos, diagramas, } \\
\text { fotos e vídeos) } \\
\text { - Programas e códigos científicos } \\
\text { - Bancos de dados }\end{array}$ & $\begin{array}{l}\text { - } \text { - } \text { - } \text { - Mosenesentações digitais } \\
\quad(2 \mathrm{D}) \\
\text { - Modelos, teorias e manuais } \\
\text { - Programas, firmwares } \\
\text { - Repositórios de peças e } \\
\text { fornecedores } \\
\text { - Instruções de fabricação e } \\
\text { montagem } \\
\text { - Ferramentas de fabricação } \\
\text { - Guias de uso, manutenção } \\
\text { e ensino } \\
\text { - Grupos de usuários: } \\
\text { - Wikis } \\
\text { - Aplicacões }\end{array}$ \\
\hline
\end{tabular}

Fonte: Elaboração própria

Os hiperlinks de um hiperobjeto podem ser disponibilizados de diversas maneiras, entre elas:

- textos explicitamente presentes no objeto físico. Exemplo: URL de página web;

- códigos identificados por software de reconhecimento de imagem;

- mapa de links html (imagemap) sobre uma ou mais imagens do objeto;

- listas de hiperlinks em páginas html. 


\section{Exemplos de hiperinstrumentos científicos e educacionais}

Podem ser considerados hiperinstrumentos científicos aqueles que integram o virtual e o não virtual de maneira a facilitar o seu uso, estudo, modificação e distribuição. Existem diversos exemplos de instrumentos de interesse científico e/ou educacional que podem ser considerados hiperobjetos. Aqui serão referidos dois exemplos que contêm elementos de interesse em diversas disciplinas ou campos transdisciplinares: a impressora 3D RepRap da Universidade de Bath e as Estações Meteorológicas Modulares do Centro de Tecnologia Acadêmica IF/UFRGS.

\section{Impressora 3D RepRap}

A impressora 3D RepRap é um projeto originado em uma escola de engenharia mecânica inglesa da Universidade de Bath (JONES et al., 2011), cujas repercussões vão além da engenharia, atingindo diversos aspectos da ciência e da educação, bem como da economia.

A RepRap é vista como um hiperinstrumento quando percebemos que suas hiperligações permitem seu uso, sua fabricação e sua modificação. A RepRap e suas derivações podem ser utilizadas para a criação de objetos educacionais para crianças, para estudo de geometria, mecânica e programação, assim como para ciência dos materiais. É uma máquina que permite seu aprofundamento em diferentes disciplinas, de acordo com o contexto e interesse de cada um.

\section{Estações Meteorológicas Modulares de Código Aberto}

O projeto das Estações Meteorológicas Modulares do Centro de Tecnologia Acadêmica da Universidade Federal do Rio Grande do $\mathrm{Sul}^{39}$ busca integrar uma rede de monitoramento climático e

39 Centro de Tecnologia Acadêmica. Disponível em: http://cta.if.ufrgs.br . Acesso em: 28 out. 2014. 
ambiental mantida e operada por cidadãos. Porém o objetivo não é apenas o acúmulo de dados coletados por cidadãos ${ }^{40}$, mas também promover a educação científica e tecnológica para que a própria construção dos instrumentos, sua programação, manutenção, desenvolvimento e calibração possam ser feitos por cientistas cidadãos.

O projeto desenvolve ações para integrar o cidadão às atividades de iniciação científica e iniciação tecnológica baseadas em tecnologias livres (SILVA, 2014), incluindo-o no processo de medição de grandezas científicas, de compartilhamento de dados e de discussões sobre suas repercussões. Convida cada cidadão a navegar no hiperinstrumento científico e a entender melhor o ambiente em que vive.

Busca-se, com este projeto, a consolidação de um programa de ensino em ciência e em tecnologia baseada em uma ecologia cognitiva, cujas ferramentas são, na medida do atualmente possível, livres para serem usadas, estudadas, modificadas e distribuídas. Neste contexto são oferecidos cursos de introdução à meteorologia, à eletrônica analógica e digital, e programação de microcontroladores, fabricação digital de placas de circuitos eletrônico e peças $3 \mathrm{D}$, além de aquisição, visualização e interpretação de dados.

\section{CONSIDERAÇÕES FINAIS}

Este capítulo apresentou o conceito de hiperobjeto e a proposta de concepção de instrumentação científica nele baseada. Este conceito visa à criação de uma ecologia cognitiva, que promova a disseminação dos conhecimentos relacionados aos instrumentos

40 Existem diversas iniciativas cidadãs de monitoramento climático e ambiental tais como http://www.smartcitizen.me/ e http://www.wunderground.com/. Acessos em: 28 de out.2014. A iniciativa do Centro de Tecnologia Acadêmica busca também a educação nos aspectos científicos e tecnológicos dos cidadãos envolvidos na aquisição de dados. 
científicos e suas aplicações, fornecendo elementos para a expansão da infraestrutura de criação, construção, disseminação, aplicação e materialização destes objetos. O conceito de hiperobjeto se torna um modelo ideal para aplicação científica e educacional, pois nestas áreas não há razão para omissão ou obscurecimento de informações a respeito de hiperobjetos.

Por fim, é sugerido que uma pequena fração dos investimentos em pesquisa e infraestrutura seja direcionada para suporte e desenvolvimento da infraestrutura dos hiperobjetos, a fim de dinamizar o compartilhamento de informações de projetos e a fabricação de instrumentos científicos, ampliando seu acesso e reduzindo esforços redundantes, assim como custos. Esta infraestrutura também é de grande valor para uma educação alinhada com os princípios da ciência e dos Recursos Educacionais Abertos.

\section{REFERÊNCIAS}

ACKERMANN, John R. Toward open source hardware, 34 U. Dayton L. Rev., v. 183, 2009.

CANO, Juan Luis Chulilla. The cambrian explosion of popular 3D printing, International Journal of Artificial Intelligence and Interactive Multimedia, v. 1, n. 4. p. 30-32, 2011.

JONES, R.; HAUFE, P.; SELLS, E., IRAVANI, P., OLLIVER, V., PALMER, C., ; BOWYER, A. RepRap - The Replicating Rapid Prototyper, Robotica. Cambridge: Cambridge University Press, 2011. v.29, p.177-191.

LÉVY, Pierre. As tecnologias da inteligência: o futuro do pensamento na era da informática. Rio de Janeiro: Editora 34, 1993.

MERKEL, Andreas; HOPF, Hendrik; MÜLLER, Egon. Accelerating the innovation process with the help of open source prototyping hardware. Annals of Faculty Engineering Hunedoara - International Journal Of Engineering, v.10, n.1, 2012.

NIELSEN, Michael. Reinventing discovery: the new era of networked science. Princeton: Princeton University Press, 2012. 
PEARCE, Joshua M. Building research equipment with free, open-source hardware. Science, v. 337, n.6100, p. 1303-1304, 2012.

RAASCH, Christina; HERSTATT, Cornelius; BALKA, Kerstin Balka. On the open design of tangible goods. R\&D Management, 2009. doi:10.1111/j.1467-9310.2009.00567.x.

SILVA, Renan Bohrer et al. Estações meteorológicas de código aberto: um projeto de pesquisa e desenvolvimento tecnológico. Aceito para publicação na Revista Brasileira de Ensino de Física, 2014.

SIMON, Imre; SAID VIEIRA, Miguel. O rossio não-rival” In: PRETTO, Nelson De Luca; SILVEIRA, Sérgio Amadeu da (orgs.). Além das redes de colaboração: internet, diversidade cultural e tecnologias do poder.Salvador: EDUFBA, 2008. Disponível em: http://dx.doi.org/10.7476/9788523208899 Acesso em: 20 jun. 2015. 


\section{9}

\section{Dados abertos e ciência aberta}

Jorge Machado

\section{INTRODUÇÃO}

Compartilhar eletronicamente dados de pesquisa não é algo tão novo como parece. Há mais de 40 anos, cientistas da computação já compartilhavam arquivos, de forma anônima, através de FTP ${ }^{1}$, que era o protocolo padrão de rede usado para transferir arquivos de um computador hospedeiro para outro, em uma rede. Há 23 anos, surgia o arXiv.org, que hoje reúne quase 1 milhão de trabalhos, principalmente das áreas de física, matemática, ciência da computação, estatística. A expressão acesso aberto foi lançada com a Declaração de Budapeste da Iniciativa do Acesso Aberto, documento de 2002, de grande importância política. Em 2007, a definição de dados abertos em oito princípios veio dar mais força ao processo de abertura de dados e à ampliação dos usos e reusos da informação, com impactos também na ciência.

Informação e conhecimento são insumos básicos no processo de trabalho científico e intelectual. Por tal razão, o pesquisador precisa ter franco acesso ao conhecimento científico em sua área. Ganhos de qualidade e produtividade são maiores se uma grande quantidade de informação puder ser selecionada ou

1 FTP - File Transfer Protocol (Protocolo de Transferência de Arquivos). 
filtrada, analisada, processada e recombinada. As tecnologias de informação e comunicação tornaram esse processo cada vez mais poderoso.

O debate hoje sobre o acesso aberto ao conhecimento científico se cruza com dados abertos. Atualmente se difundem protocolos, formatos, plataformas que permitem maior interoperabilidade, processamento, cruzamento e reusos da informação. O acesso aberto tradicional, como foi debatido nos últimos 10 ou 15 anos, ficou ultrapassado, sendo insuficiente para dar conta dos avanços do uso e reuso de uma base de dados aberta.

O objetivo deste capítulo é mostrar a evolução do acesso à informação científica até os dados abertos, mostrando alguns dos desafios a serem enfrentados para sua expansão.

Este texto está dividido em cinco partes. A primeira é uma breve introdução ao tema. Na segunda, abordamos a evolução do processo de abertura de dados em meios eletrônicos. Na terceira parte, discorremos sobre o acesso aberto ao conhecimento e sua relação com documentos internacionais que visam garantir o acesso à informação, e a relação de ambos com o desenvolvimento humano. $\mathrm{Na}$ quarta parte tratamos das diferentes formas de conhecimento aberto, apresentando alguns de seus conceitos e sua relação com os dados abertos. E, na quinta, discutimos os princípios dos dados abertos e sua aplicação à ciência. Por fim, apresentamos, de forma crítica, as principais conclusões.

\section{EVOLUÇÃO DOS DADOS CIENTÍFICOS ON-LINE}

A considerar por seus embriões, o desenvolvimento do acesso aberto a conteúdos digitais pela rede confunde-se com a própria história da Internet, que foi criada com o objetivo de compartilhar recursos envolvendo processamento de informação, armazenamento e banda de tráfego entre os centros de pesquisas envolvidos. 
A primeira iniciativa de criar um banco de dados de bibliografia eletrônica de acesso aberto foi do Educational Resources Information Center (ERIC - http://www.eric.ed.gov), em 1966. No mesmo ano, foi criado o Medline, um banco de dados on-line de livre acesso gerido pela National Library of Medicine e o National Institutes of Health (ambos dos EUA) com citações bibliográficas de periódicos da área de biomédica, que mais tarde passaria a ser chamado PubMed (http://pubmed.gov), apresentando hoje mais de 14 milhões de artigos completos ${ }^{2}$. Em 1971, foi criado, por Michel Hart, o Projeto Gutenberg (http://www.gutenberg.org/)com o objetivo de encorajar a produção e a distribuição de e-books (HART, 2004). O objetivo era disponibilizar publicamente livros que pudessem ser lidos ou impressos a partir do maior número de computadores e programas. Em 1974, o Stanford Linear Accelerator Center (SLAC) (http://www.slac.stanford.edu) e o Deutsches Elektronen Synchrotron (http://www.desy.de) começaram a catalogar literatura eletrônica na área de física.

Mas foi na década de 1990, com a expansão mundial da Internet, que começaram a proliferar os bancos de dados de artigos científicos de livre acesso. Em 1991, surgiu o repositório de textos de física, matemática e ciência da computação ArXiv (http: //arxiv.org). Em 1992, foi criado o banco de dados de pesquisa genética Genbank (http://www.ncbi.nlm.nih.gov/Genbank). Em 1996, sob os auspícios da Universidade de Virgínia, surgiu a Networked Digital Library of Theses and Dissertations (NDLTD) (http://www.ndltd.org), que passou a ser o maior banco de teses e dissertações do mundo. Em março de 1997, a Bireme - Centro Latino-Americano e do Caribe de Informação em Ciências da Saúde - com apoio da Fundação de Amparo à Pesquisa do Estado de São Paulo (Fapesp), criou a base de periódicos SciELO (Scientific Electronic Library On-line) (http://www.scielo.org). Nos anos

2 Ver http://en.wikipedia.org/wiki/PubMed. Acesso em 11 jun. 2015. 
seguintes surgiram o BioMed Central (http://www.biomedcentral.com) e o PloS (Public Library of Science), (https://www.plos. org/), que logo se tornariam referências nas áreas de biologia e medicina, juntamente com o PubMed.

Os repositórios científicos também desempenharam um papel fundamental no acesso aberto, permitindo a disponibilização de artigos, papers e documentação de pesquisa produzidos nas universidades e nos centros de investigação. Alguns dos pioneiros foram o California Digital Library, da Universidade da California (http://repositories.cdlib.org), o Papyrus, da Universidade de Montreal (https://papyrus.bib.umontreal.ca) e o E-Prints Soton, da Universidade de Southampton (http://eprints.soton. ac.uk). Cabe citar o projeto SHERPA - Securing a Hybrid Environment for Research Preservation and Access (http://www. sherpa.ac.uk), resultado de um consórcio de 20 bibliotecas universitárias britânicas, cujo objetivo foi estabelecer repositórios nas instituições participantes.

\section{O ACESSO ABERTO AO CONHECIMENTO E SUA RELAÇÃO COM O DESENVOLVIMENTO}

Do ponto de vista político, a publicação da Declaração de Budapeste (fevereiro de 2002) e da Declaração de Berlim (um aprimoramento do primeiro documento, lançada em 22 de outubro de 2003) estabeleceu, em nível mundial, as bases ao movimento acesso aberto.

Mencione-se também o Directory of Open Access Journals. Surgido a partir da First Nordic Conference on Scholarly Communication, realizada em 2002, e mantido pela Universidade de Lund, da Suécia, tem como objetivo "incrementar a visibilidade e a facilidade de uso das publicações acadêmicas e científicas através da promoção de sua difusão e impacto" (DOAJ, 2014a). Esse diretório oferece livre acesso a 10 mil periódicos de todas as áreas 
do conhecimento, os quais incluem cerca de 1,7 milhões de artigos (DOAJ, 2014b).

Na América Latina, há a RedAlyC - Rede de Revistas Científicas da América Latina, Caribe, Espanha e Portugal, que reúne 916 publicações eletrônicas e 352 mil artigos completos (RedAlyC, 2014); e o SciELO, já citado, que reúne cerca de 1187 periódicos e cerca de 507 mil artigos (Scielo, 2014). Este último não estabeleceu compromisso com o movimento acesso aberto, mas sua expansão chamou a atenção dos editores de periódicos do Brasil para a as vantagens da publicação na Internet.

Em 2010, um grupo de cientistas e ativistas lançou os chamados Panton Principles for Open Data in Science. Indo muito além da Declaração de Berlim, seus princípios se focam no licenciamento de conteúdos que garantam claramente o compartilhamento, a distribuição, o reuso e a produção de obras derivadas de acordo com ethos "geral de compartilhamento e reutilização" da informação, pela comunidade científica (PANTON PRINCIPLES, 2010).

Em uma perspectiva mais ampla, um marco fundamental para as políticas de acesso à informação está no documento produzido pela Cúpula Mundial da Sociedade da Informação, promovida pelas Nações Unidas, em 2003, e realizada com a participação de 173 países. A chamada Declaração de Princípios, cujo subtítulo é Construir a Sociedade da Informação: um desafio global para o novo milênio, assim se inicia:

Nós, representantes dos povos do mundo, reunidos em Genebra, 10-12 dezembro 2003, pela primeira fase da Cúpula Mundial sobre a Sociedade da Informação, declaramos nosso desejo e compromisso de construir um desenvolvimento inclusivo e centrado nas pessoas e orientado à Sociedade da Informação, onde todos possam criar, acessar, utilizar e compartilhar informação e conhecimento, permitindo que indivíduos, comunidades e povos alcancem todo seu potencial na promoção do desenvolvimento sustentável e melhoria de sua qualidade de vida, como 
premissa os propósitos e princípios da Carta das Nações Unidas e respeitando plenamente e defendendo a Declaração Universal dos Direitos Humanos. (WSIS, 2014, art 1).

O texto da Declaração vincula o acesso a informação e conhecimento, bem como seu compartilhamento, ao desenvolvimento dos povos e em consonância com a Carta de Direitos Humanos das Nações Unidas.

O segundo artigo da Declaração de Princípios vincula o acesso à informação e ao conhecimento com os Objetivos do Milênio ${ }^{3}$ das Nações Unidas ${ }^{4}$.

Nosso desafio é aproveitar o potencial das tecnologias de informação e comunicação para promover os objetivos de desenvolvimento da Declaração do Milênio, nomeadamente a erradicação da pobreza extrema e da fome; realização do ensino primário universal; promoção da igualdade de gênero e o empoderamento das mulheres; redução da mortalidade infantil; melhoria da saúde materna; combater o HIV/ AIDS, a malária e outras doenças; garantir a sustentabilidade ambiental; e o estabelecimento de parcerias globais para o desenvolvimento para alcançar um mundo mais justo, próspero e mais pacífico. Também reiteramos nosso compromisso com o desenvolvimento sustentável e as metas de desenvolvimento acordadas, conforme consta na Declaração de Joanesburgo e o Plano de Implementação e do Consenso de Monterrey, e outros resultados das cúpulas das Nações Unidas. (WSIS, 2014, art 2).

\footnotetext{
3 Ver http://www.objetivosdomilenio.org.br/ Acesso em 11 jun. 2015.

4 O documento reconhece também que "a educação, o conhecimento, a informação e a comunicação são o centro do progresso humano", e que o rápido progresso das tecnologias abre "novas oportunidades de atingir níveis mais elevados de desenvolvimento", quando levado à superação de "obstáculos tradicionais, especialmente as de tempo e distância, tornando possível, pela primeira vez na história, utilizar o potencial dessas tecnologias para o benefício de milhões de pessoas em todos os cantos do mundo". (WSIS, 2014: art 8).
} 
Acesso ao conhecimento e à informação são fundamentais para o desenvolvimento humano, social e econômico. Isso já é amplamente reconhecido através de documentos como a Declaração dos Direitos Humanos (UDHR, 2014), Cúpula Mundial da Sociedade da Informação (WSIS, 2014), Pacto Internacional de Direitos Civis e Políticos (PIDCP, 2014), Convenção Americana sobre Direitos Humanos (CADH, 2014) e as declarações de Brisbane (UNESCO, 2010) e Maputo (UNesco, 2008), além da já citada Cúpula Mundial da Sociedade da Informação (WSIS, 2014).

Sem dúvida, a abertura dos dados científicos representa enormes benefícios para a humanidade. No plano político, há forte consenso no sentido de que o direito de acesso à informação seja considerado um direito humano fundamental. A essa concepção se soma o aumento das iniciativas open na ciência, que tem levado ao surgimento de novos paradigmas para produção e distribuição do conhecimento.

Benkler, em The Wealth of Networks (2006), afirma que surge uma nova "economia da informação em rede", baseada na lógica da Internet. Distribuída, descentralizada e auto-organizada, seu desenvolvimento tem, como base, práticas colaborativas. O autor cita como exemplo os projetos de computação distribuída, as plataformas colaborativas de inovação biológica, repositórios de acesso livre, materiais didáticos abertos, além do modelo de colaboração e desenvolvimento do software livre. Benkler destaca a importância da informação no desenvolvimento, refletida nos componentes que formam o índice de desenvolvimento humano (IDH): expectativa de vida, alfabetização e escolaridade, e renda per capita, conforme o quadro 1 (BENKLER, 2006, p. 322-3). 
Quadro 1: Importância da Informação para os componentes do IDH

\begin{tabular}{|c|l|}
\hline Componente do IDH & \multicolumn{1}{c|}{$\begin{array}{c}\text { Importância da informação e do } \\
\text { conhecimento }\end{array}$} \\
\hline Expectativa de vida & $\begin{array}{l}\text { Inovações agrícolas; } \\
\text { técnicas de cultivo; } \\
\text { pesquisa de medicamentos, acesso a produtos; } \\
\text { cuidados com a saúde (acesso à pesquisa, publi- } \\
\text { cação e disseminação de informação). }\end{array}$ \\
\hline $\begin{array}{c}\text { Alfabetização e } \\
\text { escolaridade }\end{array}$ & $\begin{array}{l}\text { Facilidade de acesso a textos, bibliotecas, com- } \\
\text { putadores e sistemas de comunicação; } \\
\text { acesso a materiais educacionais para professores } \\
\text { e centros acadêmicos. }\end{array}$ \\
\hline Renda per capita & $\begin{array}{l}\text { Depende de acesso à inovação/desenvolvimento } \\
\text { de tecnologias avançadas - principalmente para } \\
\text { países em desenvolvimento, que precisam se } \\
\text { adaptar a novas plataformas tecnológicas. }\end{array}$ \\
\hline
\end{tabular}

Fonte: Adaptado de BENKLER, 2006, p. 322-323.

As novas práticas de colaboração e compartilhamento da informação têm um papel relevante para a difusão de informação, cultura e conhecimento, fundamentais para o desenvolvimento humano. Na sociedade da informação, a abertura de conhecimento humano acumulado passa a ser uma realidade possível, assumindo assim um papel prioritário em qualquer política que tenha como objetivo promover a melhoria nas condições de vida dos cidadãos e a redução das grandes desigualdades globais. Neste ponto, convergem os movimentos de defesa do acesso aberto, do acesso à informação pública, das tecnologias e protocolos abertos, da educação aberta e outros open, como se verá a seguir. 


\section{OPEN DATA E OUTROS OPEN}

A palavra open tem sido cada vez mais utilizada para se referir a alternativas aos modelos proprietários - com restrições para cópia, distribuição e reusos da informação. Assim surgem as expressões open science ${ }^{5}$, open access, open research ${ }^{6}$, open education, open contents, open source, open notebook, open licences, open courses etc.

Há também o conceito de Ciência 2.0. Inspirado na web 2.0, ele sugere uma nova abordagem para o uso da informação na ciência baseada no compartilhamento e na colaboração através da rede, o que inclui o uso de ferramentas como wikis, blogs, vídeo para compartilhar achados, dados brutos e novas teorias, conforme o quadro 2 (WIKIPEDIA, 2014a).

Quadro 2: Diferenças entre a ciência tradicional e a "Ciência 2.0"

\begin{tabular}{|l|l|}
\hline \multicolumn{1}{|c|}{ Modelo atual } & Modelo emergente (Ciência 2.0) \\
\hline $\begin{array}{l}\text { Pesquisa feita de forma privada, } \\
\text { depois submetida a periódicos; } \\
\text { revisada por pares (guardiões) dos } \\
\text { periódicos; publicação. }\end{array}$ & $\begin{array}{l}\text { Compartilhamento de dados em } \\
\text { todos os estágios da pesquisa; } \\
\text { cientistas colaboram e achados são } \\
\text { disseminados on-line. }\end{array}$ \\
\hline $\begin{array}{l}\text { Literatura científica sob barreiras de } \\
\text { pagamento. }\end{array}$ & $\begin{array}{l}\text { Descobertas científicas on-line e sem } \\
\text { custos. }\end{array}$ \\
\hline
\end{tabular}

5 O projeto denominado Open Science (http://www.openscience.org/blog/), coordenado pelo professor de química da Universidade de Notre Dame Dan Gezelter desde 2006, é um dos pioneiros no uso do conceito. Gezelter define o significado de open science a partir do cumprimento de quatro objetivos: i) transparência na metodologia, na observação e na coleta de dados; ii) acesso público e possibilidade de reuso dos dados científicos; iii) acesso público e transparência na comunicação científica; e o iv) uso de ferramentas da web para facilitar a colaboração científica.(GEZELTER, 2009).

6 O elemento central de pesquisa aberta é tornar os componentes metodológicos livremente acessíveis através da web, assim como os dados e resultados obtidos ou derivados. Isso permite uma colaboração distribuída em grande escala, da qual qualquer um pode participar em qualquer nível do projeto (WIKIPEDIA, 2014b). 


\begin{tabular}{|l|l|}
\hline \multicolumn{1}{|c|}{ Modelo atual } & Modelo emergente (Ciência 2.0) \\
\hline $\begin{array}{l}\text { Reputação estabelecida pelo renome } \\
\text { do periódico ou fator de impacto. }\end{array}$ & $\begin{array}{l}\text { Reputação estabelecida pelas ci- } \\
\text { tações, page views ou downloads. }\end{array}$ \\
\hline Dados são privados até a publicação. & $\begin{array}{l}\text { Dados são compartilhados antes da } \\
\text { publicação. }\end{array}$ \\
\hline $\begin{array}{l}\text { Papers têm os direitos autorais pro- } \\
\text { tegidos de forma genérica. }\end{array}$ & $\begin{array}{l}\text { Diferentes licenças são possíveis: } \\
\text { copyright, Creative Commons 3.0, } \\
\text { domínio público, etc. }\end{array}$ \\
\hline $\begin{array}{l}\text { Editores ganham pela cobrança ao } \\
\text { acesso. }\end{array}$ & $\begin{array}{l}\text { Editores usam novos modelos de } \\
\text { negócio. }\end{array}$ \\
\hline $\begin{array}{l}\text { Resumo do artigo é disponível após } \\
\text { a publicação. }\end{array}$ & $\begin{array}{l}\text { Compartilhamento de dados, } \\
\text { métodos e achados via blogs, redes } \\
\text { sociais, wikis, internet. }\end{array}$ \\
\hline
\end{tabular}

Fonte: Adaptado da WIKIPEDIA, 2014a

Para estabelecer um conceito de aberto, a Open Knowledge Foundation desenvolveu uma definição bem abrangente, que passou a ser uma referência importante para os movimentos que advogam pela abertura do conhecimento. Composta por 11 itens, essa definição abrange aspectos técnicos, legais e procedimentais no uso e distribuição da informação (OKF, 2014), conforme o quadro 3.

Quadro 3: Itens para ser considerados Open, segundo a OKF

\begin{tabular}{|l|l|}
\hline 1. Acesso & $\begin{array}{l}\text { A obra deve ser disponibilizada na íntegra, por um } \\
\text { preço que não exceda o custo razoável de repro- } \\
\text { dução; preferencialmente gratuita na Internet. A } \\
\text { obra também deve estar disponível em uma forma } \\
\text { utilizável e modificável. }\end{array}$ \\
\hline
\end{tabular}




\begin{tabular}{|c|c|}
\hline 2. Redistribuição & $\begin{array}{l}\text { A licença não deve restringir a possibilidade de ven- } \\
\text { da ou distribuição da obra em si ou como parte de } \\
\text { um pacote com obras de fontes diversas. A licença } \\
\text { não deve exigir pagamento de direitos ou outra taxa } \\
\text { para venda ou distribuição. }\end{array}$ \\
\hline 3. Reutilização & $\begin{array}{l}\text { A licença deve permitir modificações e obras } \\
\text { derivadas; deve permitir que estas sejam distribuí- } \\
\text { das sob as mesmas condições da obra original. }\end{array}$ \\
\hline $\begin{array}{l}\text { 4. Ausências de re- } \\
\text { strições tecnológicas }\end{array}$ & $\begin{array}{l}\text { Não deve haver restrições tecnológicas. A dis- } \\
\text { ponibilização da obra deve estar em formato cuja } \\
\text { especificação seja disponível pública e gratuita- } \\
\text { mente, e cujo uso não esteja sujeito a restrições } \\
\text { monetárias ou outras. }\end{array}$ \\
\hline 5. Atribuição & $\begin{array}{l}\text { Como condição para a redistribuição e a reutilização, } \\
\text { a licença pode exigir atribuição da autoria - desde } \\
\text { que de forma não onerosa - aos autores da obra. }\end{array}$ \\
\hline 6. Integridade & $\begin{array}{l}\text { É aceitável que, como condição para a distribuição da } \\
\text { obra, se exija, no caso de sua modificação, nome ou } \\
\text { número de versão diferente daquele da obra original. }\end{array}$ \\
\hline $\begin{array}{l}\text { 7. Não discriminação } \\
\text { de pessoas ou grupos }\end{array}$ & $\begin{array}{l}\text { A licença não discriminará indivíduos ou grupos de } \\
\text { indivíduos. }\end{array}$ \\
\hline $\begin{array}{l}\text { 8. Não discriminação } \\
\text { de domínios de } \\
\text { atividade }\end{array}$ & $\begin{array}{l}\text { A licença não pode restringir o uso da obra a uma } \\
\text { área de atividade específica. }\end{array}$ \\
\hline $\begin{array}{l}\text { 9. Distribuição da } \\
\text { Licença }\end{array}$ & $\begin{array}{l}\text { Os direitos da obra devem ser aplicados na re- } \\
\text { distribuição da mesma, sem necessidade de uma } \\
\text { licença adicional. }\end{array}$ \\
\hline $\begin{array}{l}\text { 10. A Licença não } \\
\text { deve ser específica de } \\
\text { um pacote }\end{array}$ & $\begin{array}{l}\text { Os direitos à obra não devem depender de sua in- } \\
\text { serção em um determinado pacote. Cada obra deve } \\
\text { ter os mesmos direitos que o conjunto do pacote. }\end{array}$ \\
\hline $\begin{array}{l}\text { 11. A Licença não } \\
\text { deve restringir a } \\
\text { distribuição de outras } \\
\text { obras }\end{array}$ & $\begin{array}{l}\text { A licença não deve restringir outras obras que sejam } \\
\text { distribuídas conjuntamente com a obra licenciada. } \\
\text { Por exemplo, a licença não deve impor que todas as } \\
\text { obras distribuídas pelo mesmo meio sejam abertas. }\end{array}$ \\
\hline
\end{tabular}

Fonte: Resumido pelo autor a partir da definição de Open da Open Knowledge Foundation (OKF, 2014). 
O conceito de aberto da Open Knowledge abrange os principais obstáculos ao acesso ao conhecimento. No entanto, ele permite a possibilidade de pagamento como condição para o acesso, o que o faz escapar à clássica definição da Open Access Initiave (OAI), para a qual o acesso aberto é o acesso "digital, online, free of charge, and free of most copyright and licensing restrictions" (SUBER, 2013). Embora a definição da OAI seja demasiada genérica e simplista para servir como referência prática, ela é muito clara no que se refere à gratuidade do acesso como condição para ser considerado aberto.

\section{DADOS ABERTOS NA CIÊNCIA}

Dados abertos são definidos por um conjunto de princípios estabelecidos em um encontro realizado em dezembro de $2007^{7}$ em Sebastopol, na Califórnia, que reuniu um grupo de pesquisadores, de representantes de organizações da sociedade civil e de ativistas norte-americanos. Entre eles estavam Lawrence Lessig, Tim O’Reilly, Ethan Zuckermann, Joseph Hall, Aaron Schwartz, Carl Mamamud e os criadores de organizações Sunlight Foundation, My Society e GovTrack - pioneiras no uso dos dados abertos na promoção da transparência. O foco do encontro foi a abertura de informações governamentais. No entanto, nos anos que se seguiram, o conceito passou a ter seu uso ampliado, passando a incluir dados científicos ou mesmo de organizações privadas. Seus princípios afirmam que qualquer dado, para ser aberto, deve ser utilizado por qualquer um para qualquer propósito. Tal definição visa orientar o processo de abertura de dados de modo que possa ser considerado aberto. São eles:

7 Open Government Data (OGD): http://www.opengovdata.org/home/8principles 
Quadro 4: Os 8 Princípios dos Dados Abertos

\begin{tabular}{|c|c|}
\hline \multicolumn{2}{|c|}{ Os 8 Princípios dos dados abertos } \\
\hline Completo & $\begin{array}{l}\text { Todos os dados públicos devem ser disponibilizados. } \\
\text { Dados públicos são aqueles que não estão sujeitos a } \\
\text { restrições de privacidade, segurança ou privilégios } \\
\text { de acesso. }\end{array}$ \\
\hline Primários & $\begin{array}{l}\text { Os dados devem ser coletados na fonte, com o maior } \\
\text { nível de detalhamento possível, e não de forma } \\
\text { agregada ou modificada. }\end{array}$ \\
\hline Oportunidade & $\begin{array}{l}\text { Sua disponibilidade deve ser feita tão rapidamente } \\
\text { quanto necessário para preservar o valor dos dados. }\end{array}$ \\
\hline Acessibilidade & $\begin{array}{l}\text { Os dados devem estar disponíveis para a mais ampla } \\
\text { gama de usuários e as mais diversas finalidades. }\end{array}$ \\
\hline $\begin{array}{l}\text { Processável por } \\
\text { máquinas }\end{array}$ & $\begin{array}{l}\text { Os dados devem ser razoavelmente estruturados, de } \\
\text { modo a permitir o processamento automatizado. }\end{array}$ \\
\hline Não-discriminatório & $\begin{array}{l}\text { Os dados devem estar disponíveis para qualquer } \\
\text { pessoa, sem necessidade de registro. }\end{array}$ \\
\hline Não-proprietário & $\begin{array}{l}\text { Os dados devem estar disponíveis em um formato } \\
\text { sobre o qual nenhuma entidade tem o controle } \\
\text { exclusivo. }\end{array}$ \\
\hline Licença livre & $\begin{array}{l}\text { Os dados não estão sujeitos a quaisquer direitos de } \\
\text { autor, patentes, marcas comerciais ou regulamento } \\
\text { secreto. Podem ser permitidas uma razoável privaci- } \\
\text { dade e restrições de privilégio e segurança. }\end{array}$ \\
\hline
\end{tabular}

Fonte: OPEN Data Government Working Group, 2007

\section{DISCUSSÃO: APLICAÇÃO DOS DADOS ABERTOS NA CIENNCIA}

A aplicação de tais princípios na ciência implica a superação de um grande número de barreiras técnicas, legais e culturais. Conforme dito anteriormente, tais princípios foram pensados no contexto da abertura de dados governamentais. No entanto, são a priori aplicáveis 
em qualquer contexto onde há informação digital. A ampliação de seu escopo tem se dado devido à adesão de organizações públicas e privadas aos dados abertos, inclusive em nível internacional e multilateral no âmbito da Open Government Partnership (OGP) ${ }^{8}$ e no G8$^{9}$, com a publicação do G8 Open Data Charter. Nesta parte, analisamos cada um dos quesitos para um dado ser aberto à luz de seus desafios para aplicação no campo da ciência. O objetivo não é dar conta dos pormenores e das particularidades em cada área, mas levantar alguns aspectos relevantes em uma aplicação mais geral dos princípios.

Princípio 1 - Completo. Todos os dados públicos devem ser disponibilizados. Dados públicos são aqueles que não estão sujeitos a restrições de privacidade, segurança ou privilégios de acesso.

O primeiro princípio dos dados abertos é que todos sejam disponibilizados. Isso quer dizer que a disponibilização deve ser feita de um conjunto completo de dados (dataset). A disponibilização de bases de dados completos permite que uma pesquisa possa ser refeita, que se possa verificar se os resultados são compatíveis com os dados utilizados e, mais que tudo isso, pode permitir que sejam encontrados erros ou mesmo que se chegue a novos achados.

O modelo tradicional de ciência é muito competitivo. A disponibilidade pública dos dados tira boa parte das vantagens competitivas de um autor ou grupo de autores. A única variável que pode atenuar essa ameaça ao autor é o retardo proposital na disponibilidade das informações. Isso não impede verificações de erros e novas descobertas a posteriori com base nos mesmos dados, mas garante que os autores obtenham o primeiro crédito pelo uso dos dados.

\footnotetext{
8 Os dados abertos estão presentes em muitos planos de ação dos 65 países que aderiram à OGP. Ver: http://www.opengovpartnership.org/countries. Acesso em 11 jun. 2015.

9 Ver G8 Open Data Charter, disponível em https://www.gov.uk/government/publications/ open-data-charter/g8-open-data-charter-and-technical-annex e G8 Open Data Charter and Technical Annex. Disponível em https://www.gov.uk/government/publications/open-data-charter/g8-open-data-charter-and-technical-annex. Acesso em 11 jun. 2015.
} 
Mas muitos autores resistem a abrir seus dados, mesmo com a pesquisa encerrada e publicada. Um estudo feito na área de economia por Andreoli-Verbacha et al. (2013) a partir de uma amostra randômica de 488 trabalhos de acadêmicos publicados em sítios, demonstrou que, em $89 \%$ dos casos, não havia qualquer informação sobre estarem disponíveis na web os dados coletados. Em 8,8\% dos casos, era disponibilizada parte dos dados; somente em $2 \%$ todos os dados estavam disponíveis (ANDREOLI-VERBACHA et al., 2013).

Não há muitos estudos conclusivos, e cada área do conhecimento tem sua realidade particular. No entanto, de modo geral, falta ainda muito estímulo à disponibilização dos dados completos - em especial enquanto a pesquisa não foi publicada. Se não existir uma política ou benefício para o autor, dificilmente este fará voluntariamente essa disponibilização.

Princípio 2 - Primários. Os dados devem ser coletados na fonte, com o maior nivel de detalhamento possível, e não de forma agregada ou modificada.

Documentos em formatos abertos possibilitam uma série de usos da informação, que incluem cruzamento, processamento automatizado, tratamento de dados e a realização de estudos e análises mais detalhados das bases disponibilizadas. Por suas características, dados em formatos abertos oferecem uma grande vantagem para a reutilização, enquanto dados agregados restringem as possibilidades de uso da base. E, pior ainda, podem prejudicar a verificação, mascarar resultados.

Um exemplo disso é o de dados socioeconômicos agregados de cidades que escondem as desigualdades de bairros e zonas de um mesmo município. A agregação de dados geográficos impõe ao pesquisador limitações que poderiam ser evitadas.

Nesse sentido, agregar dados é semelhante a esconder dados. É compreensível que, em pequena escala, agregar dados seja uma 
forma de anonimizar, por exemplo, uma base censitária, de modo a impedir que um cidadão venha a ser identificado por suas características. Salvo algumas exceções, a oferta de dados primários pode ser feita sem problemas, em benefício do reuso da informação.

Em resumo: dados podem ser publicados e oferecidos de forma não primária, mas desde que se ofereça a informação completa para outros usuários, preservando os dados para a possibilidade de usos posteriores.

Princípio 3 - Oportunidade. Sua disponibilidade deve ser feita tão rapidamente quanto necessário para preservar o valor dos dados.

A possibilidade transformadora de usar os dados para finalidades úteis se reduz com o passar do tempo. O ideal para maximizar a utilidade é a atualização de informações em tempo real. Para cumprir esse quesito com eficiência, é necessária a utilização de plataformas e ferramentas que disponibilizem a informação na web. Obviamente, é preciso publicizá-las também para que possam ser encontradas. Atualmente existem muitas ferramentas disponíveis; as mais simples e acessíveis são os serviços de webhosting compartilhado $^{10}$ (como github, bitbucket, gitlab etc.), repositórios, wikis e pads ${ }^{11}$.

O uso de tais ferramentas na ciência varia muito nas diferentes áreas, mas ainda é muito pequeno, considerando-se o potencial

\footnotetext{
10 Webhosting compartilhados são repositórios de código - não somente de software, mas podendo ser usados para qualquer informação passível de codificação. Esse compartilhamento permite um controle distribuído de revisões e um gerenciamento de código, registrando as alterações, bugs e versões. Pode incluir documentação referente ao código, lista de e-mails, wiki, entre outras ferramentas. É amplamente usado em projeto de código aberto que tem múltiplos colaboradores. Para uma comparação entre os principais repositórios de códigos, ver Wikipedia (2015).

11 Pads são blocos de notas on-line multiusuários, que permitem registro das alterações e que incluem ferramentas de chat, importação e exportação de documentos, registros de versões consolidadas, entre outras funcionalidades.
} 
benefício em termos de qualidade, eficiência no uso de recursos e impacto na inovação.

Princípio 4 - Acessibilidade. Os dados devem estar disponíveis para a mais ampla gama de usuários e as mais diversas finalidades.

Acessibilidade se refere à facilidade para se obter a informação. A necessidade de solicitação formal para acessar os dados constitui um obstáculo ao acesso automatizado. A acessibilidade é maior ao se oferecer a possibilidade de download de todas as informações armazenadas em um banco de dados em uma única vez (o chamado bulk access) ou, ainda, ao possibilitar solicitações remotas específicas através de uma API ${ }^{12}$.

A facilidade de encontrar uma informação e baixá-la é o ponto-chave para atender a esse quesito. Aparentemente fácil de ser atendido, o cumprimento efetivo desse princípio vai além da publicação simples dos dados na web. Ao publicar, de modo a facilitar a localização e o uso da informação, há necessidade de uma ação pró-ativa do pesquisador. Isso pode incluir informações adicionais aos dados, como informações sobre os procedimentos que podem facilitar a localização e o uso da informação desejada em uma base.

Por falta de acesso à pesquisa de outros cientistas, muitos trabalham de forma isolada, gastando tempo em atividades desnecessárias, ou que poderiam ser otimizadas através do compartilhamento de experimentos e resultados. Muitos dados úteis estão espalhados, indisponíveis ao acesso público, protegidos ou em bases não integradas, gerando assim grande ineficiência e desperdício de recursos públicos.

\footnotetext{
12 Application Programming Interface, em português Interface de Programação de Aplicações. Trata-se de um conjunto de padrões e rotinas estabelecidas que permite a terceiros usarem seus serviços através da web. A grande vantagem da API para o uso de dados abertos é a de tornar desnecessário o download de bases de dados, permitindo acessar a base atualizada em tempo real.
} 
Princípio 5 - Processável por máquinas. Os dados devem ser razoavelmente estruturados, de modo a permitir o processamento automatizado.

Os dados precisam ser corretamente codificados para que possam ser amplamente utilizados. Uma imagem PDF não substitui o documento original que o gerou. Deve haver documentação sobre o formato e a codificação dos dados, assim como os significados de cada um dos itens para que os usuários possam conhecer o sentido e o contexto dos dados.

$\mathrm{Na}$ academia, ainda é muito comum o argumento de que um documento PDF preserva a integridade dos dados. Nada mais falso. Um documento convertido em imagem dificulta o processamento automatizado da informação, fazendo com que gráficos, tabelas e diagramas sejam muitas vezes perdidos no processamento da informação.

Por outro lado, os editores científicos comerciais optam pelo PDF para dificultar a cópia e o reuso da informação.

Uma política de acesso a dados científicos deve incluir uma recomendação com relação aos formatos de arquivos, de modo que estes não venham a constituir uma barreira ao reuso.

Princípio 6 - Não-discriminatório. Os dados devem estar disponíveis para qualquer pessoa, sem necessidade de registro.

Não deve haver necessidade de registro ou de qualquer termo de adesão. Também não deve haver restrição do acesso a apenas alguns aplicativos específicos. Nesse sentido, deve ser permitido o acesso anônimo aos dados. Isso inclui a utilização de próxies anônimos.

O modelo jardins murados das plataformas proprietárias e pagas dos grandes editores científicos está definitivamente excluído deste princípio.

Ainda que passível de discussão, o cumprimento deste item satisfaz a demanda principal do movimento open access. A discriminação do acesso aos resultados científicos constitui hoje o negócio 
mais lucrativo. Para se ter uma ideia disto, basta citar uma das maiores editoras científicas, a Elsevier, cujo faturamento segue crescendo ano a ano, alcançando em 2013 o valor de 11,5 bilhões de dólares. A corporação atua com uma margem de lucro de $39 \%$ (ELSEVIER, 2013), valor excepcionalmente alto comparado com outras atividades econômicas. Esse negócio lucrativo das informações científicas se deve ao ambiente monopólico e, portanto, não competitivo, que se constitui em torno dela.

Princípio 7 - Não-proprietário. Os dados devem estar disponíveis em um formato sobre o qual nenhuma entidade tem o controle exclusivo.

Este princípio é especialmente importante em áreas onde empresas conseguiram estabelecer um padrão de software - e frequentemente, como consequência, de formato de arquivo - como padrão de mercado. Quando uma empresa produz o programa que é necessário para que um arquivo onde dados armazenados podem ser lidos, o acesso do usuário a tais informações passa a ser dependente do programa. O uso de formato proprietário cria a possibilidade de o programa estar disponível ao público somente mediante a cobrança de um determinado valor. $\mathrm{Na}$ pior das hipóteses, ele pode estar até mesmo indisponível. Formatos proprietários incluem em geral restrições desnecessárias sobre quem pode usar os dados, como pode usá-los e com quem podem ser compartilhados. Tais restrições existem apenas por razão de reserva de mercado.

Para evitar restrições, é sempre recomendável o uso de formatos livres/não proprietários. A eliminação de eventuais custos ou outras barreiras associadas a isso possibilita tornar disponíveis os dados a um grupo maior de usuários.

Esse é um problema não específico da ciência. Ele está relacionado à tendência de estabelecimento de padrões de uso (muitas vezes associados à praticidade ou ao conforto do usuário) que predominam em um ambiente onde faltam políticas governamentais 
de acesso à informação pública e ao conhecimento científico - considerado o investimento público em sua produção ${ }^{13}$.

Princípio 8 - Licença livre. Os dados não estão sujeitos a quaisquer direitos de autor, patentes, marcas comerciais ou regulamento secreto. Podem ser permitidas uma razoável privacidade e restrições de privilégio e segurança.

A redação desse princípio leva a interpretações equivocadas. $\mathrm{Na}$ prática, dados precisam estar protegidos com algum tipo de licença para que não sejam apropriados por outra parte que venha restringir a cadeia de inovação com base nessa informação. Isso ocorre quando uma nova camada de proteção surge após a transformação de um conteúdo que estava sob domínio público. Uma alternativa a esse fato é o uso de modelos de licenças que garantam aos usuários as liberdades e os princípios dos dados abertos. Para isso, existem as chamadas licenças livres.

$\mathrm{Na}$ academia, a adoção de licenças continua sendo algo bastante alternativo, em que pesem bons exemplos, como o do PLoS (Public Library of Science) e o SciELO, que usam Creative Commons (CC by $4.0^{14}$ e CC by NC-SA $3.0^{15}$, respectivamente). Mas o padrão de publicação continua sendo baseado no tradicional copyright, quer seja em periódicos, quer pelas editoras de livros.

Até outubro de 2014, os 10 maiores repositórios da web listados, listados no Webmetrics (2014) - Arxiv.org, Social Science Research Network, Europe PubMed Central, Research Papers in

\footnotetext{
13 Boultona et al. (Boultona et al., 2011) lembram que há dados científicos privados que são de interesse público. Neste caso, há que se fazer uma discussão profunda sobre a necessidade de equilíbrio entre os interesses privado e público quando a informação se relacionar a assuntos cujo acesso mais amplo é fundamental, como o combate a enfermidades, redução da fome ou geração de energias limpas.

14 Disponível em: https://creativecommons.org/licenses/by/4.0/ . Acesso em 21 jun. 2015

15 Disponível em: https://creativecommons.org/licenses/by-nc-sa/3.0/ . Acesso em 21 jun. 2015
} 
Economics, HAL Institut National de Recherche en Informatique et en Automatique Archive Ouverte, University of California eScholarship Repository, Smithsonian/NASA Astrophysics Data System, NASA Technical Reports Server, Agecon Search Research in Agricultural and Applied Economics e HAL Sciences de l'Homme et de la Société - ou não possuíam política de licenciamento dos conteúdos ou esta não era adequada ao ambiente digital, por suas características de possibilitar o compartilhamento e reuso da informação.

\section{INCENTIVOS A POLÍTICAS DE DADOS ABERTOS NA CIÊNCIA}

Para que o potencial dos dados abertos se realize nas ciências, há necessidade de políticas, por parte de agências governamentais, que incentivem o cumprimento de seus princípios. Nesse sentido, há bons exemplos que, embora não se orientem exatamente para tais princípios, apontam para avanços nessa direção. É o caso do Conselho de Pesquisa do Reino Unido (RCUK) que, ao propor a política de acesso aos resultados de pesquisa, afirma o compromisso com a transparência e incentivo aos dados abertos, ao buscar garantir que o resultado da pesquisa esteja disponível em acesso aberto para toda a sociedade, estabelecendo vínculos com o desenvolvimento social e econômico, e a responsabilidade com o financiamento público (RCUK, 2013, p. 1).

A Organização para Cooperação e o Desenvolvimento Econômico (OCDE) também segue no mesmo sentido, ao publicar o documento OECD Principles and Guidelines for Access to Research Data from Public Funding. O documento defende a promoção de "uma cultura de abertura e compartilhamento de dados de pesquisa", estímulo ao intercâmbio de boas práticas e aumento da conscientização sobre os custos e benefícios, de possíveis restrições e limitações de acesso e compartilhamento de dados de pesquisa com financiamento público (OCDE, 2006, p. 11). 
Em 2011, o Research Information Network (RIN) e o National Endowment for Science, Technology and the Arts (NESTA) do Reino Unido publicaram o relatório Open to All? Case studies of openness in research. As conclusões sintetizam muito bem as vantagens de uma abertura e compartilhamento mais incisivos e sistemáticos de dados científicos. Em resumo, o estudo apresenta as seguintes conclusões: o compartilhamento de dados (i) evita a duplicação de coleta de dados, aumentando a eficiência da pesquisa e promovendo a adoção de padrões abertos; (ii) promove o rigor acadêmico e melhorias para a qualidade da pesquisa, ao tornar a informação sobre métodos de trabalho, protocolos e dados mais prontamente disponíveis para revisão por pares e escrutínio;( iii) melhora a visibilidade e as possibilidades de engajamento, com oportunidades para compromissos mais amplos em toda a comunidade de pesquisa, incluindo novas possibilidades para a ciência do cidadão e o engajamento do público nos processos e resultados de pesquisas; (iv) permite novas perguntas de pesquisa e novas abordagens através da reutilização de dados e materiais de outros pesquisadores, apoiando o desenvolvimento do uso intensivo de dados científicos através da capacidade de agregar e reanalisar dados a partir de uma vasta gama de fontes; (v) melhora a colaboração e a construção de comunidade, possibilitando novas oportunidades de cooperação através das fronteiras institucionais, nacionais e disciplinares para o compartilhamento de conhecimentos e experiências; e (vi) possibilita o aumento do impacto econômico e social da pesquisa, da inovação nos negócios e nos serviços públicos, bem como um maior retorno do investimento público em pesquisa ao permitir que indivíduos e organizações fora da comunidade científica possam ser envolvidos.

Em seu conjunto, esses documentos apontam para a necessidade de mudanças profundas, mesmo que graduais, na forma como se produzem, publicam, compartilham e são usados dados científicos. No entanto, demandam também a superação das contradições 
entre o ambiente digital e o ecossistema jurídico baseado no tradicional copyright, além da necessidade de superação das resistências culturais ainda existentes em amplos setores da ciência.

\section{CONCLUSÕES}

Neste capítulo apresentamos a evolução da informação aberta até os dias atuais, quando surgem os chamados dados abertos, que passam a ser importante expressão da possibilidade de compartilhar a informação de modo mais amplo e otimizado. Em paralelo, viu-se o reconhecimento do direito de acesso à informação e da importância desta para o desenvolvimento humano em uma perspectiva global.

A abertura dos dados científicos dentro dos princípios dos dados abertos traz, sem dúvida, enormes vantagens, não apenas para os acadêmicos, mas para toda a sociedade de modo geral. A cadeia da informação se enriqueceria com uma maior difusão e ampliação das possibilidades de usos e reusos da informação.

Mas há grandes dificuldades a serem superadas para a expansão dos dados abertos no âmbito científico. Uma delas é a necessidade de que um público mais amplo - inclusive gestores acadêmicos - conheça seus princípios e possa aplicá-los; de que dados sejam publicados de forma adequada e inteligível, de modo a alcançar comunidades mais amplas - para além dos experts - aproximando-se dos ideais da ciência cidadã. É necessário um arcabouço legal que sustente e incentive sua disponibilização - como uma lei que garanta o acesso à informação pública e o acesso a dados obtidos com financiamento público. Também são necessárias políticas científicas que apoiem sua disponibilização de forma ativa e sob licenças livres. E há que vencer as resistências culturais, pois abertura de dados e informação tende a reduzir as assimetrias entre os usuários de tais dados, reduzir privilégios entre os que têm acesso e concentram mais informação e conhecimento. Ademais, a abertura 
de dados pode ter o efeito colateral de gerar uma distribuição de recursos e de processos de tomada de decisão menos verticais e eventualmente mais participativos. Em poucas palavras, tende a incluir novos atores no processo de produção e uso do conhecimento, com impactos sociais e econômicos de difícil mensuração.

Nesse processo, os organismos de fomento, instituições universitárias, editores e autores têm um papel estratégico no desenvolvimento de políticas institucionais adequadas. Há necessidade do estabelecimento de políticas para definir parâmetros de qualidade, normas e padrões de publicação, além da criação de indicadores para mensurar o sucesso de tais medidas - de modo a garantir sua efetividade, uma vez que documentos internacionais citados neste texto servem mais para a declaração de princípios e o estabelecimento de metas futuras. É necessária também a existência de políticas claras que contemplem aspectos jurídicos, legais e procedimentais, de modo a garantir que cientistas se sintam seguros ao disponibilizar seus dados.

Aumentar o estoque de informação disponível de forma livre e aberta, e estimular o seu fluxo global pode ajudar significativamente na promoção do desenvolvimento humano, da inovação e da justiça social, constituindo-se também como meta muito importante para a superação das barreiras do conhecimento na relação Norte-Sul do planeta.

\section{REFERÊNCIAS}

ANDREOLI-VERSBACHA, Patrick; MUELLER-LANGERA, Frank. Open access to data: An ideal professed but not practised. Feb. 2013. Disponível em: https://ideas.repec.org/p/rsw/rswwps/rswwps215.html .Acesso em: 26 set. 2014.

BENKLER, Yoshai. The wealth of networks. How social production transforms markets and freedom. New Haven: Yale University Press, 2006. Disponível em: http://www. benkler.org/Benkler_Wealth_Of_Networks.pdf. Acesso em: 30 out. 2014. 
BERLIN Declaration on Open Access to Knowledge in the Sciences and Humanities. Disponível em: http://openaccess.mpg.de/2365/en . Acesso em: 26 set. 2014. BOULTONA, Geoffrey; RAWLINSB, Michael; VALLANCEC, Patrick; WALPORTD, Mark. Science as a public enterprise: the case for open data. Disponível em : http:// www.thelancet.com/journals/lancet/article/PIIS0140-6736\%2811\%2960647-8/ fulltext. Acesso em: 10 out. 2014.

CADH. Convenção Americana sobre Direitos Humanos [San José, Costa Rica, 22 de novembro de 1969]. [S.1.] [s.n.] 2014. Disponível em: http://www.cidh.org/Basicos/Portugues/c.Convencao_Americana.htm English version. Disponível em: http://www.oas.org/dil/treaties_B-32_American_Convention_on_Human_Rights.htm. Acesso em: 10 out. 2014.

DOAJ - Directory of Open Access Journals Aim and scope. [S.1.] [s.n.] [2014a]. Disponível em: http://doaj.org/about\#aimscope . Acesso em: 26 set. 2014.

DOAJ. Directory of Open Access Journals. [S.1.] [s.n.] 2014b. Disponível em: http:// doaj.org/. Acesso em: 26 set. 2014.

ELSEVIER. Annual Reports and Financial Statements 2013. [S.1.] 2013. Disponível em: http://www.reedelsevier.com/investorcentre/reports\%202007/Documents/2013/reed_elsevier_ar_2013.pdf. Acesso em: 30 out. 2014.

GEZELTER, Dan. What, exactly, is open science? [S.1.] [s.n.] 2009. Disponível em: http://www.openscience.org/blog/?p=269. Acesso em: 30 out. 2014.

GOV.UK. G8 Open data charter. United Kingdom, 2013a. Disponível em: https://www.gov.uk/government/uploads/system/uploads/attachment_data/ file/207772/Open_Data_Charter.pdf. Acesso em: 30 out. 2014.

GOV.UK. G8 Open data charter and technical annex. United Kingdom, 213b. Disponível em: Acesso em: 30 out.2014.

https://www.gov.uk/government/publications/open-data-charter/g8-open-data-charter-and-technical-annex. Acesso em: 30 out.2014.

HART, Michael. Project Gutenberg mission statement. [S.1.][s.n.] 2014. Disponível em: http://www.gutenberg.org/wiki/Gutenberg:Project_Gutenberg_Mission_ Statement_by_Michael_Hart.Acesso em: 30 out. 2014. 
MURRAY-RUST, Peter; NEYLON, Cameron; POLLOCK, Rufus; WILBANKS, John. Panton Principles - principles for open data in science. [S.1.][s.n.] 19 Feb. 2010. Disponível em: http://pantonprinciples.org/. Acesso em: 30 out. 2014.

NESTA/RIN. Open to All? Case studies of openness in research, report. [S.1.] 2010. Disponível em: http://www.rin.ac.uk/system/files/attachments/NESTA-RIN_ Open_Science_V01_0.pdf.Acesso em: 30 out. 2014.

OECD - Organisation for Economic Co-operation and Development. Promoting Access to Public Research Data for Scientific, Economic and Social Development. [S.1.] [s.n.] 2010. Disponível em: http://www.oecd.org/sHYPERLINK "http://www. oecd.org/science/scienceandtechnologypolicy/38500813.pdf"cience/scienceandtechnologypolicy/38500813.pdf . Acesso em: 30 out. 2014.

OKF. Open definition. Disponível em: http://opendefinition.org/od/. Acesso em: 30 out. 2014.

OPEN DATA GOVERNMENT WORKING GROUP. Principles of open data (RFC). [S.1.] 2007. Disponível em https://public.resource.org/8_principles.html. Acesso em: 28 out. 2014.

PANTON Principles. Fevereiro de 2010. www.pantonprinciples.org . Acesso em: 30 out. 2014.

PIDCP (Pacto Internacional de Direitos Civis e Políticos). 16 de Dezembro de 1966 .Disponível em: http://www.gddc.pt/direitos-humanos/textos-internacionais-dh/tidhuniversais/cidh-dudh-direitos-civis.html English version http://www. ohchr.org/en/professionalinterest/pages/ccpr.aspx. Acesso em: 30 out. 2014.

RCUK. RCUK Policy on Access to Research Outputs. [S.1.] 24 May 2013. Disponível em: http://www.rcuk.ac.uk/RCUK-prod/assets/documents/documents/ RCUKOpenAccessPolicy.pdf . Acesso em: 30 out. 2014.

REDALYC. Mission. [S.1.][s.n.] 2005. Disponível em http://www.redalyc.org/. Acesso em: 30 out. 2014.

SCIELO. Scientific Electronic Library Online. São Paulo, 2014. Disponível em: http://www.scielo.org/php/index.php. Acesso em: 30 out.2014.

SUBER, Peter. Open Access Overview. [S.1.]s.n.] 2013. Disponível em: http://www. earlham.edu/ peters/fos/overview.htm. Acesso em: 30 out. 2014. 
UDHR - Universal Declaration of Human Rights. 10 December 1948 http://www. un.org/en/documents/udhr/Acesso em: 30 out. 2014.

UNESCO. Brisbane declaration: freedom of information - the right to know. [S.1.] 2010. Disponível em: http://www.unesco.org/new/en/unesco/events/prizes-and-celebrations/celebrations/international-days/world-press-freedom-day/previous-celebrations/2010/brisbane-declaration/. Acesso em: 30 out. 2014.

UNESCO. Maputo declaration. Fostering freedom of expression, access to information and empowerment of people. Maputo, 2008. Disponível em: http:// www.unesco.org/new/en/unesco/events/prizes-and-celebrations/celebrations/ international-HYPERLINK "http://www.unesco.org/new/en/unesco/events/ prizes-and-celebrations/celebrations/international-days/world-press-freedom-day/previous-celebrations/worldpressfreedomday2009001/maputo-declaration/"days/world-press-freedom-day/previous-celebrations/worldpressfreedomday2009001/maputo-declaration/. Acesso em: 30 out. 2014.

WEBMETRICS. Ranking web of repositores. [S.1.][s.n.] 2014. Disponível em: http:// repositories.webometrics.info/.Acesso em: 30 out. 2014.

WIKIPEDIA. Comparison of source code software hosting facilities. [S.1.][s.n.] 2015. Disponível em: http://HYPERLINK "http://en.wikipedia.org/wiki/Comparison_ of_source_code_software_hosting_facilities"en.wikipedia.org/wiki/Comparison_ of_source_code_software_hosting_facilities. Acesso em: 2 mar. 2015.

WIKIPEDIA. Science 2.0. [S.1.][s.n.] 2014a. Disponível em: http://en.wikipedia. org/wiki/Science_2.0. Acesso em: 30 out. 2014.

WIKIPEDIA. 2014b. Open reseach. [S.1.][s.n.] 2014. Disponível em: http://en.wikipedia.org/wiki/Open_research. Acesso em: 30 out. 2014.

WSIS - DECLARACIÓN DE PRINCIPIOS. Construir la sociedad de la información: un desafío global para el nuevo milenio. Disponíveis em: http://www.itu.int/wsis/ docs/geneva/official/dop-es.html . English version World Summit of the Information Society : http://www.itu.int/wsis/docs/geneva/official/dop.html. Acesso em: 30 out. 2014. 



\section{0}

\section{Educação superior a distância, universidade aberta e ciência cidadã: o desafio das diferenças ${ }^{\prime}$}

Ludmila dos S. Guimarães

Um devir não é uma correspondência de relações. Mas tampouco é ele uma semelhança, uma imitação e, em última instância, uma identificação.

Devir não é progredir nem regredir segundo uma série...

O devir não produz outra coisa senão ele próprio ${ }^{2}$.

Gilles Deleuze

\section{INTRODUÇÃO}

No âmbito da discussão sobre as relações entre universidade, trabalho e tecnologia, a educação superior a distância se insere no capitalismo contemporâneo como novo dispositivo de formação e trabalho imaterial.

A educação superior a distância como possibilidade de autonomia e formação continuada coincide também com a vida, na medida em que o trabalho cognitivo, trabalho vivo, precisa gerar acesso

1 Discussão e resultados de Pesquisa oriunda da tese de doutorado intitulada Autoformação e Autovalorização na Educação a Distância na Universidade Pública Brasileira (GUIMARÃES, 2013).

2 Deleuze (1997, p.18). 
a alguma forma de renda e, para tanto, o sujeito (discente) que dela se vale precisa estar conectado às redes de cérebros. A participação nessas redes demanda subsidiar o próprio acesso nas conexões das metrópoles e inserir-se em seus espaços de produção. Ou seja, para criar sua renda, o discente-trabalhador precisa investir em conectividade - garantindo assim sua permanência na conexão-metrópole - e em formação. Será uma forma conjugada de pagar a própria renda, mantendo os custos de sua formação e a conectividade nos espaços de produção.

A atual condição e disciplina da organização da produção representa-se na conectividade e no excedente das relações sociais contido nas conexões, a mais-valia possibilitada e retirada do trabalho vivo e colaborativo. Ou seja, é compreender como o capitalismo contemporâneo atua na formação das subjetividades e acomoda suas demandas no interior das práticas de saber, tanto no nível micropolítico quanto no macropolítico, fazendo coincidirem, em um mesmo jogo produtivo, o desejo e as produções sociais.

Nesse sentido, é pertinente examinar o atual modelo praticado na educação superior a distância (EAD) na Universidade Pública Brasileira e sua relação com os processos de autoformação e autovalorização no capitalismo contemporâneo.

Percebe-se que a atual política de educação a distância, apesar dos avanços, ao desconhecer e desconsiderar as motivações e expectativas de formação dos alunos, reproduz um modelo educacional hierarquizado, disciplinarizado e parametrizado, que dificulta o exercício de uma autonomia voltada para as mudanças nas relações poder-saber-trabalho.

O horizonte de formulação política da educação a distância, ao desconsiderar a autonomia como elemento da dimensão política-produtiva da vida dos alunos, revela que o acesso ao ensino superior ocorre em torno de um duplo e paradoxal processo de inclusão e fragmentação da vida no saber/conhecimento e no trabalho: autoformação e autovalorização. 
Trata-se de uma inflexão geral, um paradoxo, que desqualifica a possibilidade de diferenciação, de novas configurações educacionais, e que reafirma a primazia disciplinar de um modelo de relação entre o saber e o poder, esvaziado de análise e descontextualizado frente à dupla função que as expectativas e motivações exercem na produção das subjetividades do alunado de educação a distância.

A tentativa de elucidar como as dinâmicas micro e macropolíticas interferem na formação das subjetividades na EAD, e como a Universidade Pública tem respondido ou tem se posicionado frente aos desafios da formação superior a distância e sua relação com o trabalho, pode indicar os contornos e confrontos que a autonomia enfrenta nas dinâmicas do sistema educacional brasileiro.

\section{UNIVERSIDADE ABERTA: POLÍTICA PÚBLICA E ARQUITETURA DE PODER}

A partir das três dimensões — poder, saber e autonomia — tentaremos conduzir nossa análise e observação sobre o conjunto de práticas universitárias na educação a distância. No âmbito das relações de poder é preciso descrever, analisar e acompanhar o tipo de assimilação de subjetividade que decorre das estruturas de produção econômica e política aplicadas no campo virtual — isto é, nos ambientes virtuais como espaço de acontecimentos - e também fora deles.

Como diz Foucault (1997, p. 71), "É preciso procurar saber como as relações de sujeição podem fabricar sujeitos". Isto porque os efeitos da estrutura de poder sobre as subjetividades incidem sob a forma de uma arquitetura, um funcionamento do sistema de aprendizagem, os quais permitem revelar a própria identidade morfológica do sistema de poder. A ideia de sistema de poder como relações de poder conjuga-se neste sentido com a noção de sistema político moderno e seus desdobramentos, tal como referido por Deleuze e Guattari no texto 1933 - Micropolítica e Segmentaridade: 
O sistema político moderno é um todo global, unificado e unificante, mas porque implica um conjunto de subsistemas justapostos, imbricados, ordenados, de modo que a análise das decisões revela toda espécie de compartimentações e de processos parciais que não se prolongam uns nos outros sem defasagens ou deslocamentos. A tecnocracia procede por divisão do trabalho segmentário (inclusive na divisão internacional do trabalho). (Deleuze; GUATTARI, 1996, p. 89)

Portanto, a problemática da educação a distância pode ser tratada ao mesmo tempo como um subsistema de caráter político (já que se trata de um panorama social e de possibilidades de intervenção) e ético, na medida em que implica em um trabalho do indivíduo sobre si mesmo na perspectiva de produção de formas de vida para além dos mecanismos de poder.

Também se pode questionar a educação a distância, tanto nas formas determinadas de transmissão do saber e de seus espaços de produção como virtualidade, quanto nas relações de poder, nas regras coercitivas, nas hierarquias, nas divisões de tarefas, as quais têm deixado de fora a subjetividade, os modos e os estilos de vida, os interesses e as motivações dos seus reais beneficiários, alunos e usuários.

Um dos problemas do político na educação a distância revela-se na forma de sua arquitetura informacional, que é a sua forma de governo e a sua própria identidade. E, ainda, nas normas, regras, burocracias, contenção e direcionamento de fluxos em um sistema global e segmentado, isto é, resumindo, a territorialização dos espaços e das relações.

Pode-se pensar também, de forma similar em todo o aparato sistêmico e na arquitetura de governo interna à instituição escolar (de saber) e nos espaços que a ela se vinculam (na educação a distância) como focos de resistência e de criação, tal como "[....] máquinas de guerra que invistam na invenção de um modo de vida não fascista, que trace linhas de fuga e possibilite a emergência de vacúolos de liberdade". (DELEUZE; GUATARRI, 1996, p. 113) 
De forma ampla, as questões identificadas na atual arquitetura da educação a distância podem ser configuradas em dois universos complementares: a) a análise do universo micropolítico com a emergência das questões disciplinares, de empregabilidade, flexibilidade, plataforma de aprendizagem virtual e motivações particulares para ingresso ao ensino superior; e b) a análise do universo macropolítico com a emergência das questões institucionais da universidade na mira das políticas educacionais de acesso ao ensino superior. Nesses dois universos, a forma de governo aplicada ao ensino a distância, bem como a conformação e a orientação à produção de uma certa identidade, apresentam-se direcionadas e aderentes ao sistema econômico e político do capitalismo contemporâneo, bem como estão/são corroboradas nas formulações da política educacional brasileira ${ }^{3}$ dos últimos dez anos, quando se dá a emergência da educação a distância.

Alguns indicativos relevantes despontam preliminarmente da abordagem das relações poder-saber, dentre os quais destacamos a prevalência do fenômeno disciplinar (como autoorganização) e sua

3 Plano Nacional de Educação 2001-2010. Ver avaliação do PNE 2001-2010: desafios e perspectivas realizada pelo INEP, compõe-se de três volumes, os quais encontram-se disponíveis nos endereços eletrônicos: volume 1. Disponível em: http://fne.mec.gov.br/ images/pdf/volume1.pdf; Acesso em: 20 jun. 2015. Volume 2: Disponível em: http://fne. mec.gov.br/images/pdf/volume2.pdf Acesso em: 20 jun. 2015. Volume 3: Disponível em: http://fne.mec.gov.br/images/pdf/volume3.pdf. Acesso em: 20 jun. 2015. Publicado em 2009, apresenta resultados do processo avaliativo do PlanoNacional de Educação (PNE) 2001-2008, sob a coordenação e supervisão da Secretaria Executiva Adjunta (SEA), por designação do Ministro de Estado da Educação, com o expressivo apoio do INEP. Registra-se ainda a participação dos órgãos gestores do MEC e a colaboração de pesquisadores(as) da área de educação, reunidos pela Universidade Federal de Goiás (UFG). A construção, os ajustes e a atualização dos indicadores educacionais para monitoramento das metas, bem como o desempenho desses indicadores, ao longo do período de avaliação, foram feitos pela equipe da Coordenação Geral de Informações e indicadores educacionais da DTDIE/ INEP, sob a coordenação de Carlos Eduardo Moreno Sampaio e com o apoio efetivo de Vanessa Nespoli. 
relação com a flexibilidade (como competência de manejo sobre o tempo, e vetor de busca e exercício da autonomia).

Por outro lado, questionamos a artificialização produzida pelo sistema que, ao permitir a inclusão do aluno/usuário, insere-o nos moldes e formas que não perturbam a produção. Ou seja, o sistema flexibiliza e oportuniza o estudo, mas de maneira que esta inclusão se dê por investimento do próprio sujeito e retorne a ele (o sistema) em forma de mais competência, inteligência e conhecimento. Então, a prática de autovalorização passa a constituir um mote de geração de valor, produzido e apropriado pelo sistema, cuja justificativa permite ao sujeito aportar os conhecimentos adquiridos em troca de sua permanência nele, como trabalhador do conhecimento.

Por outro lado, as ideias de autoformação e autovalorização corroboram que essa mesma realidade comporta o paradoxo, ou a verdade incômoda, de que a capacidade social de produzir o novo está disseminada por toda parte, e que essa capacidade não é ou não está completamente subsumida no capital, independendo de sua valorização. Isto porque a invenção, a criatividade não é exclusividade dos que se encontram no sistema produtivo, nem de gênios; não é monopólio da ciência ou da indústria; é, antes, um efeito da subjetividade, uma potência psíquica e política que tem um valor em si mesma, capaz de se autovalorizar e de constituir novas possibilidades de vida - uma biopotência da multidão.

Para melhor visualizar o problema, é importante compreender as variáveis e as intensidades que operam no tempo e no espaço da educação a distância; tempo e espaço contraídos, rápidos ou mesmo instantâneos, fugazes e perenes, flexíveis e inflexíveis, dinâmicos ou estáticos. É neste tempo e espaço que as relações de forças, entendimentos, vontades e seus negativos ocorrem entre as pessoas e as tecnologias. Aqui é preciso destacar duas questões: a) a função fundamental que a tecnologia desempenha na relação com a vida e com a linguagem como dispositivo de poder; b) 
a governamentalidade exercida por meio da tecnologia e a relação desta com a autonomia e a produção de novos estilos de vida.

Para tanto, é preciso interrogar qual é a racionalidade com que se depara a educação a distância, ou como são racionalizadas as relações de poder em um sistema do qual participam docentes, discentes, técnicos-administrativos, agentes de governo, teorias e processos de gestão, dentre outros. Ou, ainda, entender como essa racionalidade opera e orienta o conjunto das condutas das pessoas no espaço virtual e institucional, como enquadra as relações e identifica os indivíduos.

Trata-se de ações totalizantes e individuais exercidas e mediadas por dispositivos tecnológicos de informação e comunicação, que têm como objetivo possibilitar o acesso dos excluídos ao ensino superior público e possibilitar a expansão do sistema de forma mais rápida. Este é o leitmotiv governamental para a implantação das ações totais no sistema educacional com vistas à igualdade $e$ inclusão social da população. Em torno dele constitui-se e justifica-se toda uma lógica que orienta as condutas individuais e as relações políticas, no interior do sistema educacional e fora dele.

Indicações e mecanismos dessa governamentalidade podem ser observados nas dinâmicas dos currículos, nas formas de acompanhamento pelas tecnologias, na avaliação dos alunos, na relação precarizada da universidade com os docentes e tutores, no conjunto de práticas articuladas e estruturadas - porém desinstitucionalizadas - e mesmo na sua exclusão das pautas dos órgãos de classe, em contraposição à demanda de educação a distância vigente no Plano Nacional de Educacão 2010-2020.

Retomaremos a seguir a noção de saber político tratada por Foucault, e seus desdobramentos na educação superior a distância, sobretudo em relação às ideias de segurança, território e população, justamente porque ela nos permitirá situar a noção de biopolítica, e seus vínculos intrínsecos com as estratégias poder-saber. 


\section{BIOPOLÍTICA E PODER-SABER NA EDUCAÇÃO A DISTÂNCIA}

No Resumo dos Cursos do Collège de France, Foucault (1997, p. 81) nos chama atenção para o fato de que, na antiguidade clássica, “[....] o exercício do poder político (nas sociedades gregas e romanas) não implicava nem o direito, nem a possibilidade de um governo entendido como atividade de direção dos indivíduos ao longo de suas vidas, colocando-os sob a autoridade de um guia responsável por aquilo que fazem e lhes acontece". Que pistas tal afirmativa pode nos fornecer para compreendermos o que de fato ocorre nas relações e engrenagens no campo da educação a distância?

Inicialmente podemos pensar na sua vinculação às políticas governamentais, no âmbito macropolítico, e as determinações e prescrições sob a forma de regulamentos, normativas institucionais e todo um conjunto de instrumentos de regulação e supervisão que são historicamente aplicados e mantidos para o tratamento e controle da educação pública. E em seguida, no âmbito micropolítico, seus impactos ou efeitos na produção de uma subjetividade voltada para a ordem e a disciplina, ou seja, mecanismos de sujeição e controle da subjetividade.

Esses mecanismos de poder operam de formas mais ou menos sutis no interior dos discursos científico e educacional, constituindo-se em regras a obedecer, com que se conformar. Desta forma, basta lembrar o destaque que disciplina tinha na produção das subjetividades no século XVIII, formar indivíduos de caráter dócil, ajustados ao sistema de vigilância e controle social. A continuidade ou a manutenção desses princípios ou valores é possível no século XXI? Sob quais pretexto e forma são enunciados?

A questão da disciplina aqui é fundamental porque faz emergir e discute as ideias de governar e de se governar. Ou, dito de outra forma: faz questionar tanto o propósito do conjunto de regras ou princípios de conduta - são destinadas à condução da própria vida ou se deixam conduzir — quanto a sua função política de regulação 
das relações sociais, econômicas e, portanto, restritivas da autonomia. É necessário disciplina para manter o funcionamento da estrutura do sistema e proporcionar a segurança e a estabilidade necessárias à sua produtividade e controle político. Sem um aparelho fixo e suas engrenagens funcionando de modo mecânico, disciplinar, não é possível manter as ressonâncias necessárias ao exercício do poder.

A análise das disciplinas ou micropoderes, segundo Foucault (escola, exército, fábrica, hospital etc), atesta estes focos de instabilidade onde se afrontam reagrupamentos e acumulações, mas também escapadas e fugas, e onde se produzem inversões:

Tais relações vão fundo na espessura da sociedade, elas não se localizam nas relações do Estado com os cidadãos ou na fronteira das classes, e não se contentam em reproduzir [...] a forma geral da lei ou do governo. [...] Elas definem inúmeros riscos de conflito, de lutas e de inversão ao menos transitória das relações de força. (FoucAuLt, 1977, p. 29)

As disciplinas, as hierarquias possuem um caráter organizador, de governo; exercem-se de forma singular - algumas vezes de forma dura, e outras, de forma flexível, centralizadas e descentralizadas.

Portanto, a questão política suscita sempre indagações sobre os propósitos de governar e a governamentalidade ${ }^{4}$ política que se estabelece ao seu redor. O problema da governamentalidade revela o exercício do poder, suas formas, vícios e virtudes, porque aponta o que se pode ou não infringir e o porquê disso. E é justamente nesta circularidade que se constitui e se fundamenta um saber político

4 Tal como entendida por Foucault (1995, p. 110), como um domínio de relações estratégicas entre indivíduos ou grupos - relações que têm como questão central a conduta do outro ou dos outros, e que podem recorrer a técnicas e procedimentos diversos, dependendo dos casos, dos quadros institucionais em que ela se desenvolve, dos grupos sociais ou das épocas. 
para sustentação e legitimação do exercício de poder sobre os outros, os vivos.

Os mecanismos da governamentalidade transformam os indivíduos em microorganizações e operam por meio deles. É o que se pode observar no processo educacional e suas microformações, os quais produzem os ajustes de posturas, atitudes e percepções, antecipando o comportamento adequado que a sociedade deseja dos indivíduos.

A governamentalidade é exercida pela difusão dos métodos e procedimentos de disciplina ajustados para normalizar, estabelecendo uma multiplicidade de relações de poder que se entrecruzam; está ligada por dispositivos complexos e circulares a forma de poder, e não simplesmente justificada por princípios e técnicas científicas.

Os modos de poder, tipos de controle e vigilância que se exercem sobre os indivíduos no interior do sistema permitem tanto o conhecimento sobre eles quanto a revelação de sua identidade e a intervenção sobre ela.

Analisando-se a educação a distância, não é difícil, por exemplo, identificar os mecanismos que operam no processo de comunicação entre docentes e discentes nas plataformas de aprendizagem, onde, de um lado, encontram-se registrados os acontecimentos discursivos, e de outro, a pulverização das entidades hierarquizadas que respondem como e pelo sistema. Eis que a instituição educacional se encarrega de regular a reciprocidade das relações, monitorando/ equilibrando/moderando os acessos e a comunicação por meio dos níveis hierárquicos, mantendo sob controle os seus desdobramentos. Desta forma, o sistema inclui e exclui a circulação dos enunciados em conformidade com a produção de identidades que deseja fabricar. Ao controlar a comunicação e, portanto, a circulação e os fluxos de ideias, o poder político se exerce segundo uma estrutura e um conjunto de regras. Este "novo" dispositivo de vigilância e controle pelo sistema torna claro que o desenvolvimento do saber não ocorre independente do poder, e que o aparato tecnológico 
confirma a sua submissão à logica do poder. Portanto, não se pode pensar o progresso do saber sem pensar os mecanismos de poder.

Sem dúvida, a questão dos mecanismos de poder remete ao problema do governo, de forma circular, uma vez que se trata de governar as coisas. Mas, o que isto quer dizer, ou em quê implica? - Que essas coisas de que o governo deve se encarregar constituiem-se dos homens, de suas relações, dos recursos, das riquezas, da segurança, do território e de tudo o que diz respeito a eles, seus costumes, hábitos, maneiras de fazer ou de pensar, ou seja, o governo da vida dos homens, o governo dos vivos.

O governo dos vivos é também o governo da vida dos indivíduos de forma conveniente e direcionada a uma finalidade, e por meio de um conhecimento das coisas adequadas e úteis à vida de todos, da população. Eis que a necessidade e a justificativa da racionalidade como discurso político encontra na história e no governo dos vivos o seu espaço. Nasce a biopolítica.

\section{O DESAFIO DAS DIFERENÇAS: A CONSTITUIÇÃO DAS SUBJETIVIDADES X GOVERNAMENTALIDADE}

É exatamente sobre o indivíduo, suas maneiras de pensar e de se comportar, na dimensão subjetiva da ação e sua articulação com o real, que o poder exerce vigilância, disciplina e controle de forma obscura, ou seja, por meio dos valores e ideias que dissemina para produzir um comportamento ajustado ao sistema. O sistema é que produz, comanda e faz cumprir as regras, e não as pessoas; é fato cotidiano ouvir que o sistema de controle (automatizado, é claro), ao estilo de um big brother ${ }^{5}$, não permite fazer isto ou aquilo, não

5 Empréstimo do sentido empregado por Deleuze e Guattari(1996, p. 80) em 1933 - Micropolítica e Segmentaridade: "A segmentaridade torna-se dura, na medida em que todos os centros ressoam, todos os buracos negros caem num ponto de acumulação - como um ponto de cruzamento em algum lugar atrás dos olhos. [...] Um olho central computador que varre todos os raios". 
está programado para tais funcionalidades, está em manutenção e fora do ar; que os dados foram perdidos na migração, na atualização etc.

O funcionamento e a eficácia do sistema dependem da instância da subjetividade como uma dimensão fundamental da política contemporânea (tal como apontado por Foucault depois dos anos 1960), devidamente conformada aos seus objetivos.

À conta dessa naturalização dos sistemas de poder sobre a conduta humana, na qual o sujeito não exerce sua ação transformadora (antes é passivo), metamorfaseado por suas ações, Foucault considera um perigo tratar a identidade e a subjetividade como componentes profundos e naturais, que não são determinados por fatores políticos e pessoais. Um conjunto de valores da cultura do sistema, com a regulação das ações, do espaço e do tempo se impõe sobre as atividades e pensamentos cotidianos, que são continuamente introjetados e reforçados com múltiplas ressonâncias.

Gerir a subjetividade interessa ao sistema tanto quanto a gestão dos resultados globais, pois trata-se da eficácia de um governo total e profundo sobre os outros, em um terreno desterritorializado e sem superfície, que é o da educação a distância. Cada indivíduo constitui-se em um segmento homogeneizado em relação a si e aos outros, e, como uma unidade de medida, apresenta equivalência em relação aos outros indivíduos (unidades). A dinâmica e/ou a organização de gestão no terreno desterritorializado opera a partir de descolamentos de um centro de normativas que dá a consistência e a materialidade de um espaço político homogêneo.

Por outro lado, este governo se exerce por meio de disciplina-gestão governamental, e se apoia em uma instrumentalização econômica e tecnológica para assegurar o controle do sistema e seus diversos componentes. Ou seja, para se sustentar, esse governo necessita de pequenas táticas locais e individuais que garantam a execução da grande estratégia, pois, sem as pequenas relações de poder, ele não se efetiva. É preciso que haja uma inflação de poder na 
vida cotidiana para que o governo dos outros se realize. Por exemplo, no sistema educacional, as hierarquias, as avaliações, os prazos definidos, as defesas de trabalhos, os currículos, as disciplinas, o ambiente virtual de aprendizagem, o campus. Enfim, muitos segmentos e relações para que o poder circule.

O exame da questão da governamentalidade, como discurso político ou como racionalidade política, estratificação e institucionalização, é relevante justamente porque incide diretamente na autonomia, nas práticas de si. É por meio dos dispositivos de controle que a governamentalidade legitima, com o apoio do discurso político-científico; e, como estratégia de poder-saber, põe-se em primeiro plano a problemática do sujeito, e, portanto, de sua autonomia.

O exercício da governamentalidade como governo dos outros implica na exclusão do governo de si (na autonomia), uma vez que o cuidado de si resulta em oposição, rebeldia, lutas múltiplas e resistência ao poder.

Do ponto de vista das relações poder-saber, a governamentalidade se mostra mais complexa, pois coloca a questão da forma e da arquitetura de como as sociedades transmitem o saber, a maneira como constituem a sua identidade, seu sistema de valores, suas recusas e exclusões.

A mecânica do poder operada no sistema educacional impõe-se em gestos, repressões, disciplina, atitudes, discursos, na própria forma da aprendizagem e seus processos de ritualização, de inclusão e exclusão do saber, os quais são naturalizados e incorporados como normalidade. E desta forma se estabelece sobre os indivíduos o controle contínuo que conduz a um saber e que por sua vez produz hábitos de vida que se engendram e se perpetuam em um circuito de satisfação de necessidades e exigências.

Do ponto de vista da educação superior, o pensamento individual e o conhecimento de si devem ser estimulados, mais que a produção teórica dos acadêmicos, pois a resistência e contestação dos estudantes às relações do poder-saber, a ação política e a trajetória 
rumo a um devir-aluno é que podem produzir as transformações do poder.

Mas, no plano político, o quê e como podem os professores oferecer para esse devir-aluno? - Este é justamente o ponto que toca na autonomia enquanto busca por novas possibilidades de construção do conhecimento e estilos de vida - tal como aponta Foucault - na direção de uma ética e das técnicas de si, ou governo de si, como o mais importante propósito do saber.

O devir-aluno implica escolhas em meio a múltiplos estímulos e o viver a própria vida de forma autocrítica. $\mathrm{O}$ apoio à autonomia, à liberdade dos estudantes remete os professores ao questionamento responsável e constante das relações de poder em torno do ofício do professor e do saber, a quê se destina, ao exame crítico permanente da lógica do sistema em que se insere e atua, da eficácia dos instrumentos que propõe, e das contribuições válidas e criativas à sociedade.

\section{EDUCAÇÃO E UNIVERSIDADE: IMPASSES PARA UMA CIÊNCIA ABERTA}

A identificação de elementos constitutivos do fenômeno de subjetivação é relevante e preliminar ao estabelecimento futuro de uma cartografia das subjetividades, bem como ao subsidiar da mudança de práticas educativas no campo da educação superior a distância e presencial.

A atual formulação política da educação a distância, ao desconsiderar a autonomia como elemento da dimensão política-produtiva da vida dos alunos, revela a fragmentação da vida no saber/conhecimento e no trabalho, e dificulta a emergência de dinâmicas de construção científica abertas, colaborativas e cooperativas. Neste sentido, algumas observações importantes acerca da atual orientação da política educacional empreendida pelo Estado merecem destaque. Elas se assentam em impasses e desafios que os entretecimentos 
da realidade provocam, para os quais não há um modelo ou uma forma única que permita superá-las.

Nesta discussão não se trata de sobrepor um novo modelo que incidiria em uma outra arquitetura de poder advinda de cima para baixo - mas de apontar justamente que outros valores devem conduzir o estabelecimento de novas dinâmicas, as quais consideramos que devem sempre ser abertas.

Retomando as nossas observações sobre os impasses e dificuldades provocados pela política educacional e suas diretivas institucionais sobre o sistema universitário, apontamos os seguintes: a) a concepção de sistema universidade aberta para a educação a distância prioriza e pratica um ensino de massa, hierarquizado, disciplinarizado e precarizado, que não estimula a pesquisa, a invenção e a criatividade, em decorrência dos excessos de parametrização aplicados independentemente das realidades; b) como estratégia para proporcionar a inclusão da população, a efetividade das contribuições da educação a distância para a expansão e interiorização da universidade Pública encontram-se limitadas pela centralização e dependência da União, bem como pelas relações entre os entes federativos - ou seja, autonomia limitada frente às questões jurídicas e legais; c) as métricas aplicadas à expansão universitária desconhecem os limites de capacidade da gestão universitária, despejando sobre elas responsabilidades e competências que não the são devidas (por exemplo, aos mecanismos de prestação de contas, que ignoram a sua finalidade e reduzem a universidade a empresa pública de prestação de serviços; d) o acirramento dos controles superdimensionados aplicados à escala universitária promove uma paralisia das atividades fins - como, por exemplo, compra de equipamentos, materiais para o ensino, a pesquisa e a extensão; e) as abordagens avaliativas aplicadas apresentam um mix de caráter desenvolvimentista da qualidade (por exemplo, o mecanismo de autoavaliação com foco na melhoria da qualidade da instituição), bem como indica uma política de avaliação orientada às 
quantidades e ao mercado, na qual se destaca a preocupação com a eficiência do sistema (custo/benefício e argumentos de natureza fiscal, orçamentária do Estado), como se pode constatar nas avaliações da SEED/MEC do PNE 2008; f) o regulacionismo exacerbado praticado por meio dos vários sistemas informatizados, pelos quais a universidade é controlada, impedem uma gestão integrada dos recursos, operando um excesso que mobiliza o tempo das pessoas para o atendimento e dificulta a busca de soluções e alternativas - a universidade é posta para trabalhar para efetivar os controles e não para gerir os recursos da melhor forma e conforme a sua realidade; g) a institucionalização precária da educação a distância reflete a dicotomia enfrentada pela universidade entre expansão e qualidade da educação, revelada tanto na precariedade da infraestrutura da instituição, quanto nos polos (como mostram os enunciados e as avaliações da Capes), quanto nos argumentos conservadores e dos órgãos de classe com pouca ou nenhuma base científica para não se lançar na empreitada; e, ainda, os desafios de responder à demanda por matrículas, isto é, a expansão das matrículas, com redução de custo/aluno, usando como justificativa a utilização das novas tecnologias (conforme critério aplicado pelo Banco Mundial $^{6}$, 1998); h) as dicotomias entre verticalidade e horizontalidade evidentes nos sistemas - ora centralizados, ora descentralizados - das agências do MEC, os quais não se comunicam, gerando antagonismos evidentes (por exemplo, hipercorreção nas avaliações institucionais, das quais as universidades são objeto; i) a dicotomia entre um devir de universidade flexível, móvel, e a rigidez dos atuais currículos e projetos pedagógicos — eminentemente disciplinares e voltados à padronização da realidade, em uma construção identitária das subjetividades — os quais impedem o exame

6 Ver ARAÚJO, Raimundo Luiz Silva. Financiamento da educação básica no governo Lula: elementos de ruptura e de continuidade com as políticas do governo de FHC. 2007. 182 f. Dissertação (Mestrado em Educação) - Universidade de Brasília, Brasília, 2007. 
da realidade do ponto de vista das diferenças; $j$ ) a questão da sustentabilidade financeira da educação a distância frente às possibilidades orçamentárias, dependência atual dos recursos de fomento da Capes e a possibilidade efetiva de captação de recursos por meio de parcerias público-privadas; k) a uniformidade cultural empregada para reforçar a redução custo/aluno; 1) a internacionalização da educação e sua relação com o processo de transnacionalização da educação superior; m) o tratamento de sistema orientado à meta com inputs, outptus e feedback segundo regras e critérios universais de organização; n) o desconhecimento do sistema quanto ao alunado, o comportamento destes, os motivos de evasão, permanência e persistência no sistema por um lado, e, por outro, o desconhecimento, por parte do alunado, dos objetivos do programa, da organização institucional, dos serviços de atendimentos.

Essas observações indicam de que forma os mecanismos de biopoder, na forma de governamentalidade, são exercidos sobre a universidade - ou seja, as relações de poder-saber. A análise da dimensão macropolítica da educação a distância permite situar o quanto a dimensão micropolítica das subjetividades é desconsiderada, ou mesmo insuficiente do ponto de vista do sistema como conjunto de práticas; e como a política pública é comprometida mais com expansão quantitativa e métrica do que com a busca de equidade e qualidade das ações educacionais. A esse respeito objeta-se que esta é uma tarefa da universidade, que precisa promovê-la com a comunidade universitária; mas ao mesmo tempo impedem-na, com seus excessos de parâmetros, demandas de controle e variações orçamentárias, dificultando o exercício de uma programação autônoma para alcançar o propósito estabelecido visado.

As atuais dificuldades de renovação do sistema educacional rumo à qualidade, à flexibilidade e à mobilidade requeridas para a vida contemporânea nos fazem relembrar um pouco o atraso em saúde e educação vividos nos decênios de 1960 e 70: um mercado gigante, fragmentado, pouco produtivo, com grande déficit de gestão 
profissional, baixo nível de conhecimento tecnológico e baixa capitalização. O que nos lembram esses argumentos? - Rapidamente podemos identificá-los ao sistema econômico mundial daquele período (leia-se OCDE, Banco Mundial, OMC, dentre os principais) para justificar uma área atrativa e de grande potencial para um capital em busca de novas áreas de valorização e investimentos.

Podemos pensar, contrariamente a essa lógica, que a educação a distância pode contribuir para se repensar a autoformação e a autovalorização, ou seja, em vez de se constituir em mecanismo de captura da intelectualidade de massa, seja orientada por outros valores, por uma ética da subjetividade voltada para a autonomia e a liberdade, a fim de constituir uma linha de fuga às atuais prisões da existência e do exercício da biopotência.

De forma concreta, o docente pode: conduzir o aluno à reflexão sobre as ações que sofre; ajudá-lo a identificar os seus desejos e crenças; potencializar uma discussão mais política e criativa sobre a educação a distância; investigar os agenciamentos, as dinâmicas de interação, a interatividade da cotidianidade dos alunos, os seus modos e planos de vida; organizar a potência coletiva por meio de novos dispositivos (por exemplo, organizar uma militância na Internet); colocar em movimento uma nova ética agenciada por produções cujo valor é coletivo (e que sejam produções colaborativas, pois que todo ato é coletivo); produzir deslocamentos para uma perspectiva biopotente da educação a distância em oposição à macropolítica; praticar uma educação menor, mais dinâmica, e que contemple as expectativas dos alunos.

Neste sentido, a dimensão macropolítica da educação aponta para a realidade instituída, aquela dos Planos Nacionais, das Leis, dos grandes programas e sistemas, dos parâmetros e dos referenciais; uma megamáquina de aprendizagem e controle, de produção de indivíduos sem singularidade. Em oposição às decisões e estratégias da macropolítica, o exercício de uma micropolítica de singularização, de exercício das diferenças, das pluralidades, das 
multiplicidades, empreendimento de revolta e resistência; aprendizagem para além dos controles, das avaliações finalísticas e preocupação com resultados.

Não se trata evidentemente de reconciliar os imperativos macro e micropolíticos. Como ato político que é, a educação precisa desterritorializar a produção desses discursos no cotidiano das pessoas, desconstruí-los, opor-lhes resistência. Esta educação como apontamento de uma ética da subjetividade no nível micropolítico se estabelece na política do cotidiano, nas relações diretas entre os indivíduos; e produzem efeitos sobre o nível macropolítico.

Tal educação é fragmentada, segmentada e não se coaduna com qualquer falsa pretensão de totalidade, de unidade; ela é produção de multiplicidades, na qual toda ação e todo fracasso são coletivos, máquina de resistência ao controle.

As multiplicidades são a própria realidade, e não supõem nenhuma unidade, não entram em nenhuma totalidade e tampouco remetem a um sujeito. As subjetivações, as totalizações, as unificações são, ao contrário, processos que se produzem e aparecem nas multiplicidades Deleuze e Guattari $(1995$, p. 7)

As questões que emergiram nas dimensões micropolíticas e macropolíticas permitiram visualizar o conjunto de lutas e enfrentamentos que se efetuam nas relações poder-saber. Tais relações de poder-saber, como foram apontadas por Foucault, impedem que se efetue um saber que é potência de si.

É fundamental observar que transformações substanciais só podem ocorrer a partir de lutas na busca da autonomia, na produção de diferenças em oposição ao atual regime de construção identitária.

O exercício maior é pensar a educação como movimento, acontecimento, conjunto de acontecimentos, dinâmicas e fluxos e, portanto, retratá-la em diferentes dimensões. 
No contexto da subjetividade, é notório que as diferenças só podem emergir da multiplicidade de singularidades em movimento, nas velocidades e intensidades em interação; e que as expectativas, motivações e vontades devem ocupar um lugar central na produção das subjetividades para liberá-las em direção ao comum. Singularidades numa multiplicidade, que atentam para a diversidade como elemento positivo na produção de conhecimento, de saber, marcadas pelas diferenças entre si. A esse respeito, diz Nietzsche:

Devemos afinal, como homens de conhecimento, ser gratos a tais resolutas inversões das perspectivas e valorações costumeiras, como que o espírito, de modo aparentemente sacrílego e inútil, enfureceu-se consigo mesmo por tanto tempo: ver assim diferente, querer ver assim diferente, é uma grande disciplina e preparação do intelecto para a sua futura 'objetividade' - a qual não é entendida como 'observação desinteressada' (um absurdo sem sentido), mas como a faculdade de ter seu pró e seu contra sob controle e deles poder dispor: de modo a saber utilizar em prol do conhecimento a diversidade de perspectivas e interpretações afetivas ... Mas, eliminar a vontade inteiramente, suspender os afetos todos sem exceção, supondo que o conseguíssemos: como? - não seria castrar o intelecto? (NIETZSCHE, 1998, p.108-109)

Faz-se necessário reafirmar a dependência recíproca entre o comum e a diferença como processos que coexistem, fundamentalmente para que o saber e o conhecimento se produzam. Enfim, diante da imensidão de fluxos que colocam desafios em profusão para o saber, não é conveniente lançar mão de respostas fáceis, prontas e rápidas.

Para buscar alternativas ao atual estágio das relações poder-saber no campo educacional é necessário admitir a crise da universidade, o esgotamento dos modelos centrais e identitários, propagar esse esgotamento, resistir ao desejo de massificação e, sobretudo, 
não deixar recuar o imperativo da autonomia e da construção coletiva do saber e do conhecimento.

Coube-nos ressaltar que a autonomia como liberdade humana vem primeiro, é constitutiva da luta, do estar no mundo e da ação humana, e não se subordina tão somente à educação e à lei. A educação, neste sentido, só pode oferecer elementos e condições para a autoreflexão; não pode dirigir os resultados da ação humana e nem mesmo designar possibilidades de julgamento. Isto porque o julgamento só pode se instalar quando cessa o pensamento, já que a ação é, por si mesma, incondicional ao pensamento e ao próprio julgamento.

\section{CONCLUSÃO}

A autonomia ou liberdade humana é a liberdade de agir/ação no mundo, confrontada com ele e, portanto, contingencial e contingenciada, inscrita no plano da imanência da experiência radical da subjetividade.

Compreendemos, tal como Deleuze (1992, p. 127), que, sendo o Eu um hábito, uma contemplação, e que todo hábito é criador, o eu é o resultado da contemplação de habitar o mundo, de estar no mundo, o qual funda-se sobre o plano da imanência radical: as convenções, os costumes, as normas. O Eu converte-se, constitui-se em um processo de ações oriundas da liberdade humana, do começo arbitrário da existência humana, das convenções no mundo. A constituição do Eu, da subjetividade, liga-se ao território, habitando-o e sendo habitado por ele, movendo-se em um plano que se afirma sobre ele - o plano da imanência, o da própria autonomia.

Da mesma forma, é do conjunto das ações sob o solo movente das convenções e costumes, bem como da capacidade de contemplá-los, que o processo de subjetivação permitirá a afirmação da condição da pluralidade humana. Ou seja, conjunção entre a 
autonomia e o mundo, onde a liberdade humana é a motivação constitutiva para agir.

A experiência de si ( $\mathrm{Eu})$ enquanto decorrência da contingência de habitar/ser habitado no mundo/território só pode se dar no campo empírico.

Os processos de subjetivação, como fenômenos de ordem empírica, apresentam/ trazem ao homem desafios e responsabilidades para sua liberdade e exercício efetivo. Um dos desafios do exercício da autonomia humana é o seu limite frente aos outros habitantes do mundo/território, já que a própria liberdade põe, como condição de sua existência, a igualdade e a diferença, ao mesmo tempo.

A autonomia só existe entre homens livres, sendo ela mesma o plano imanente para o pensamento e a ação humana. O pensamento se estende, movimenta no território e dele necessita para ter consistência; da mesma forma a ação humana só se funda habitando um território onde possa se exprimir.

Não há dicotomia entre o Eu e o mundo/território, se existem autonomia e diferença. A liberdade humana/autonomia afirma-se como possibilidade radical das experiências subjetivas no mundo.

Conhecer e habitar o território constituem uma mesma experiência, que só se faz na luta pela autonomia. Os processos de subjetivação, portanto, não são transcendentais, ou externos ou desvinculados do mundo, mas, contrariamente, são imanentes ao existir no mundo.

Tal qual o pensamento carece de um território para habitar, e ser habitado e experimentado, o cuidado de si só pode ocorrer em consequência de habitar um território com os outros: hábito político.

A educação como hábito político, advinda de subjetividades em movimento, é que pode ensejar uma educação viva e a constituição do comum no território.

A direção rumo a um território comum pode emergir de ondas propagadas de um devir-diferença como novas experiências na educação, na ciência e na tecnologia. 


\section{REFERÊNCIAS}

ALBAGLI, Sarita; MACIEL, Maria Lucia (Org.). Informação, conhecimento e poder: mudança tecnológica e inovação social. Rio de Janeiro: Garamond, 2011.

COCCO, Giuseppe; ALBAGLI, Sarita (Org.). Revolução 2.0 e a crise do capitalismo global. Rio de Janeiro: Garamond, 2012.

COCCO, Giuseppe; GALVÃO, Alexander Patez; SILVA, Gerardo. Capitalismo cognitivo: trabalhos, redes e inovação. Rio de Janeiro: DP\&A, 2003.

COLETIVO EDU-FACTORY: todo poder a autoformação! Revista Lugar Comum, Rio de Janeiro, n. 28, p. 134-135, maio/ago. 2009.

DELEUZE, Gilles. Diferença e repetição. São Paulo: Editora 34, 2006.

DELEUZE, Gilles; GUATTARI, Félix. Mil platôs: capitalismo e esquizofrenia. Rio de Janeiro: Editora 34, 1995, v.1.

. Mil Platôs: capitalismo e esquizofrenia. São Paulo: Editora 34, 1996. v. 3.

. Mil platôs: capitalismo e esquizofrenia. São Paulo: Editora 34, 1997. v.4

. O que é filosofia? São Paulo: Editora 34, 1992.

FOUCAULT, Michel. A arqueologia do saber. 2. ed. Rio de Janeiro: Forense-Universitária, 1986.

. Ditos e escritos: estratégia, poder-saber. 3. ed. Rio de Janeiro: Forense Universitária, 2012. v. 4.

. A hermenêutica do sujeito: curso dado no Collège de France (1981-1982).

3. ed. São Paulo: Editora WMF Martins Fontes, 2010. (Obras de Michel Foucault) . Microfísica do poder. 11. ed. Rio de Janeiro: Graal, 1979.

. Nascimento da biopolítica. São Paulo: Martins Fontes, 2008.

. Resumo dos Cursos do Collège de France (1970-1982). Rio de Janeiro: Zahar, 1997.

. Segurança, território, população. São Paulo: Martins Fontes, 2008.

GUIMARÃES, Ludmila dos Santos. Autoformação e autovalorização na educação a distância na Universidade Pública Brasileira. 2013. 232f. Tese (Doutorado em Ciência da Informação) - Instituto Brasileiro de Informação em Ciência e tecnologia, Universidade Federal do Rio de Janeiro, Rio de Janeiro, 2013. 
LAZZARATO, Maurizio; NEGRI, Antonio. Trabalho imaterial: formas de vida e produção de subjetividade. Rio de Janeiro: DP\&A, 2001.

. As revoluções do capitalismo. Rio de Janeiro: Record, 2007.

MARAZZI, Christian. O lugar das meias: a virada linguística da economia e seus efeitos sobre a política. Rio de Janeiro: Civilização Brasileira, 2009. (Coleção A política no império).

NEGRI, Antonio. Cinco lições sobre o Império. Rio de Janeiro: DP\&A, 2003. (Coleção Política das multidões)

. O poder constituinte: ensaio sobre as alternativas da modernidade. Rio de Janeiro: DP\&A, 2002.

NIETZSCHE, Friedrich. Genealogia da moral. Rio de Janeiro: Companhia das Letras, 1998.

PASQUINELLI, Matteo. Capitalismo maquínico e mais-valia de rede: notas sobre a economia política da máquina de Turing. Revista Lugar Comum, Rio de Janeiro, n.39, p.13-36, jan./abr. 2013.

PELBART, Peter Pál. Vida capital: ensaios de biopolítica. São Paulo: Iluminuras, 2011.

VERCELLONE, Carlo. A crise e os contornos de um socialismo totalitário do capital. IHU online, n. 301, 26 nov. 2011.

. É na reversão das relações de saber e poder que se encontra o principal fator da passagem do capitalismo industrial ao capitalismo cognitivo. IHU online, n. 216, 23 abr. 2007.

. Um panorama sobre a divisão cognitiva do trabalho. IHU online, n. 161, 24 out. 2005.

VIRNO, Paolo. Gramática da multidão: para uma análise das formas de vida contemporânea. Trad. Leonardo Retamoso Palma. Santa Maria, RS: [s. n.], 2003. 


\section{1}

\section{Por que open notebook science? Uma aproximação às ideias de Jean-Claude Bradley'}

Anne Clinio

\section{OPEN NOTEBOOK SCIENCE: O QUE É E O QUE NÃO É}

Historicamente, o caderno de laboratório (laboratory notebook) ou caderno de pesquisa tem sido o principal instrumento de registro das atividades realizadas por um cientista, constituindo-se em documentação de protocolos e resultados de pesquisa, assim como em ferramenta organizacional. São cadernos de papel, com folhas sequenciais, datados e utilizados por um cientista para registrar a execução de atividades, de acordo com as preferências individuais e orientações institucionais, podem ser individuais ou coletivos, ter um formato livre de registro ou, ainda, modelo estruturado, podem apenas registrar o que foi realizado ou agregar observações pessoais e insights.

Ao adotar o formato digital, o caderno de laboratório se tornou um caderno de laboratório eletrônico (Eletronic Laboratory Notebook - ELN), transferindo os dados levantados do suporte material do papel para softwares que oferecem facilidades, como ferramentas de busca, possibilidade de transferência de dados, criação de cópias de segurança (backups), incorporação direta de dados oriundos

\footnotetext{
1 Trabalho desenvolvido com o apoio da Faperj e da Capes.
} 
de instrumentos científicos, além de apoiar algum nível de colaboração entre cientistas.

Para além do argumento de facilitar a execução de atividades realizadas cotidianamente pelos cientistas, Jean-Claude Bradley, professor de química e pesquisador da Universidade de Drexel, nos Estados Unidos, criou, em setembro de 2006, o conceito de ciência de caderno aberto (Open Notebook Science - ONS). Ou seja, uma forma de fazer ciência baseada na abertura dos cadernos de laboratório. Seu objetivo era promover um debate claro sobre colaboração aberta na ciência (BRADLEY; LANG; KOCH; NEYLON, 2011, p. 427) .

Segundo o autor, este conceito se refere a "um modo de fazer ciência em que - da melhor maneira possível - você torna a sua pesquisa aberta ao público em tempo real" (BRADLEY, 2010)². A prática não inclui apenas dados, informações e resultados favoráveis de uma pesquisa científica: divulga também status parciais, debilidades e desafios, quando eles ainda não foram resolvidos pelos cientistas. Compartilhar "os bastidores" da ciência, seus estágios intermediários, dúvidas e dificuldades, é parte da estratégia de Bradley para promover uma "ciência rápida, ciência melhor" ("fast science, best science") e atrair colaboradores e recursos para resolver questões científicas que o desafiavam.

Ao nomear esta nova prática como open notebook science, Bradley queria distingui-la da expressão Open Source Science, que ele mesmo havia utilizado anteriormente, mas que se tornara ambígua pelos vários significados e perspectivas creditados a ela - por exemplo, a sua utilização em discussões sobre pré-prints de artigos científicos. Embora concordasse que algumas concepções do termo Open Source Science "eram bastante consistentes com nosso uso no

2 " a way of doing science in which - as best as you can - you make all your research freely available to the public and in real time" (BRADLEY, 2010). 


\title{
UsefulChem ${ }^{3 "}$ e reconhecesse o Open Source Software como uma inspiração, Bradley queria esclarecer sua proposta:
}

\begin{abstract}
No Open Source Software, o código é disponibilizado para que qualquer pessoa possa modificá-lo e adaptá-lo. O que estamos tentando fazer com UsefulChem é oferecer uma entidade análoga para a pesquisa química, que são os dados brutos dos experimentos e a interpretação do pesquisador, em um formato que qualquer pessoa pode facilmente re-analisar, re-interpretar e re-utilizar. Um bom exemplo é a reutilização de observações e resultados de experimentos fracassados de maneira não planejada pelo pesquisador original. Isso só não acontece regularmente em ciência porque as experiências fracassadas quase nunca são incluídas nas publicações (BRADLEY, 2006a). ${ }^{4}$
\end{abstract}

\section{E define open notebook science do seguinte modo:}

Para aclarar a confusão, eu vou utilizar a expressão"open notebook science", que ainda não sofreu uma mutação memética. Com ela, eu me refiro à existência de uma URL linkada a um caderno de laboratório (como esse) que está disponível abertamente e é indexado por ferramentas de busca habituais. Ele não precisa obrigatoriamente parecer com um caderno de laboratório de papel, mas é essencial que as informações necessárias

\footnotetext{
3 UsefulChem é o nome de um projeto criado em 2005 por Jean-Claude Bradley com o objetivo de sintetizar compostos antimaláricos, desenvolvidos a partir da perspectiva de uma ciência de caderno aberto. Uma wiki e um blog homônimos disponibilizam, respectivamente, seu caderno de laboratório e suas reflexões.

4 "In Open Source Software, the code is made available to anyone to modify and repurpose. What we have been trying to do with UsefulChem is to provide the analogous entity for chemical research, which is raw experimental data along with the researcher's interpretation in a format that anyone can easily re-analyze, re-interpret and re-purpose. A good example ofre-purposing is using some results and observations from a failed experiment in a way that was never intended by the original researcher. This just doesn't happen regularly in science because failed experiments are almost never included in publications." (BRADLEY, 2006a)
} 
para que o pesquisador chegue as suas conclusões esteja igualmente disponíveis para o resto do mundo. Basicamente, nenhuma informação privilegiada. (BRADLEY, 2006a)

Posts publicados por Jean-Claude Bradley mostram que ele tomou o seu lema de "nenhuma informação privilegiada" ("no inside information") no nível máximo. Ele não apenas compartilhava não apenas os dados e informações gerados por suas pesquisas, expondo o dinamismo, as complexidades e as reviravoltas da atividade científica, mas também disponibilizava informação que influenciava as condições de realização de seu trabalho. Alguns exemplos: publicação de avaliações comparativas de serviços de informação em química; disponibilização de ferramentas computacionais criadas por ele; recomendação de artigos publicados por outros pesquisadores; agradecimento público pela ajuda recebida de colaboradores; e, ainda, elaboração, de modo aberto, de propostas de financiamento para suas pesquisas.

A alegação de que o caderno aberto pode acelerar e melhorar a qualidade da ciência ("fast science, better science") é um argumento recorrente entre adeptos, como Matthew Todd, Anthony Salvagno e Steve Koch, e "evangelistas" da ciência aberta como Cameron Neylon, Peter Murray-Rust, entre outros. Matthew Todd, por exemplo, professor da Universidade de Sydney, que trabalhava em estreita parceria com Bradley em um projeto de open drug discovery afirma que "[...] Egoisticamente, do ponto de vista de um cientista é uma enorme vantagem que pessoas corrijam seus erros antes que você os comenta" (TODD, 2014). O fato de que outras pessoas possam corrigir seus erros antes que você perca tempo em linhas de pesquisa improdutivas favorece que o pesquisador passe a trabalhar de forma aberta. (TODD, 2014).

Mas como o fato de manter um caderno aberto atrairia colaboradores e recursos para resolver questões científicas? Como professor, Bradley vislumbrou que seus alunos podiam contribuir para a 
abertura de conhecimento científico através de mensurações realizadas durante as aulas. Assim, criou em parceria com Cameron Neylon e Rajarshi Guha em setembro de 2008, o Open Notebook Science Challenge (ONSC) - um projeto de pesquisa crowdsourcing, que articulava ensino e pesquisa, com o objetivo de coletar medições de solubilidade não-aquosa de compostos orgânicos.

Como iniciativa de natureza aberta, qualquer pessoa poderia participar. A única exigência era a de que os experimentos deviam ser registrados, como um caderno aberto - o que significava o acesso público e imediato aos cadernos de laboratório, onde estavam registrados os detalhes do trabalho laboratorial, aos dados brutos que subsidiam o cálculo das medições e conclusões. Os participantes eram avaliados mensalmente por Jean-Claude Bradley, Andrew Lang, Bill Hooker, Cameron Neylon, Rajarshi Guha, Steve Koch e Anthony Williams, que acessavam e comentavam os cadernos de laboratório abertos, retroalimentando os estudantes com pareceres relevantes. O principal critério de avaliação não era a quantidade de experimentos realizados, mas "quem havia melhor registrado como eram realizados seus experimentos". (ONSC, 2010, p.2)”.

Basicamente, nós queremos reconhecer estudantes que prometem ser bons cientistas. Isso inclui a manutenção de um caderno de laboratório (com links para dados brutos) de maneira que outras pessoas entendam facilmente o que foi feito e o que foi observado. A seção log do caderno deve ser preenchida em tempo hábil. Geralmente, até $24 \mathrm{~h}$ após a realização do experimento. Ninguém mantém, desde o princípio, um caderno de laboratório de maneira perfeita e é por isso que os organizadores irão comentar, em negrito e itálico, diretamente em suas páginas. Um critério importante de avaliação é a rapidez e o zelo do estudante para responder os comentários. A criatividade na concepção da técnica de medição da solubilidade em termos de eficiência, a velocidade e a reprodutibilidade também desempenham um papel importante na avaliação. A sua participação na comunidade científica através de redes Web 2.0 é 
certamente um algo a mais. E, evidentemente, o número de medições contará (ONS CHALLENGE, 2008) 5 .

Esta perspectiva atraiu a atenção de outros professores, iniciando novas colaborações. Brent Friesen, professor de química da Universidade Dominicana, transformou o ONSC em uma tarefa para seus alunos do segundo ano. E Steve Koch, pesquisador de física da Universidade do Novo México, adotou a prática em seu laboratório, incentivando estudantes a fazerem o mesmo (BRADLEY; LANG; KOCH; NEYLON, 2011, p. 436).

Logo, alunos também se interessaram por essa perspectiva e a adotaram. Marshall Moritz era ainda um estudante do primeiro ano na Universidade de Syracuse quando descobriu ONSC na internet. Ele escreveu diretamente para Bradley, tornou-se um participante do desafio e chegou a receber um prêmio em julho de $2009^{6}$ pela qualidade de suas contribuições. Anthony Salvagno foi apresentado à prática do caderno aberto através de seu professor Steve Koch, e desenvolveu uma série de textos introdutórios sobre o tema. Ele também fundou a Open Notebook Science Network ${ }^{7}$, plataforma on-line que facilita a criação e a manutenção de cadernos abertos com software Wordpress.

5 "Basically we are looking to reward students who show promise of becoming good scientists. This includes maintaining a laboratory notebook (including links to raw data) in a manner that makes it easy for others to understand exactly what you did and what you observed. The log portion of the notebook must be recorded in a timely fashion, usually within 24 hours of performing the experiment. Nobody maintains a notebook perfectly from the start and that is why the organizers will be providing feedback in bold and italics directly on your notebook pages. How quickly and thoroughly you address that feedback is an important criterion. Creativity in the design of the solubility measurement technique in terms of efficiency, speed and reproducibility will also play a strong role in the evaluation. Participation in the scientific community via Web2.0 networks would certainly be a plus. And, of course, the number of measurements will count." (ONS CHALLENGE, 2008)

6 Disponível em: http://onschallenge.wikispaces.com/students. Acesso em: 05 fev. 2015

7 Disponível em: http://onsnetwork.org. Acesso em: 05 fev. 2015 
Como cientista, manter o caderno aberto permitiu a Bradley identificar e ser identificado, conectar-se e trabalhar, em vários níveis, com programadores, matemáticos, jornalistas, além de profissionais das áreas de química sintética, química computacional, bioquímica, além de companhias químicas, etc. A vantagem de trabalhar de forma aberta é poder conhecer pessoas e colaborar com elas, para Bradley esta colaboração assumiu diversas formas.

Ele reconheceu como contribuições valiosas algumas interações que podem parecer irrelevantes, mas, que, na verdade, beneficiaram seu trabalho. Por exemplo, a sugestão de David Bradley de utilizar a ortografia do inglês britânico para o verbo "sintetizar", na seção de comentários de um de seus primeiros posts, ajudou Jean-Claude Bradley a expandir uma pesquisa bibliométrica que definiu a malária como seu tema de pesquisa para os anos seguintes. Ou ainda, um comentário de Matthew Todd, no blog UsefulChem Molecules, que inaugurou uma parceria entre eles (BRADLEY, LANG; KOCH; NEYLON, 2011, p . 428).

Bradley também colaborou com profissionais que lidavam com os desafios da representação, manipulação e comunicação de informação em química na perspectiva da ciência aberta. Ele caracterizou este tipo de interação como uma "metacolaboração" porque não envolvia objetivos específicos de um projeto, mas, sim, formas de representar e manipular informação química e métodos para torná-la legível por máquina (BRADLEY; LANG; KOCH; NEYLON, 2011, p. 432). Nesse campo, trabalhou com Egon Willighagen, Peter Murray-Rust, Anthony Williams e Andrew Lang de diversas formas: acompanhando os blogs uns dos outros, compartilhando experiências e conhecimentos ou cooperando no desenvolvimento de soluções.

Sob a ótica dos objetivos de suas pesquisas científicas, Bradley reconheceu como colaborações, por exemplo, a possibilidade de trabalhar com bibliotecas virtuais e modelagem molecular em 3D (3D docking information) oferecidos pelo projeto Find a Drug. Ele 
também destacou que o primeiro "open science loop" para a descoberta de medicamentos - "no qual a elaboração de hipóteses, docking, síntese e os resultados da análise foram elaborados abertamente e em tempo real"8 - foi realizado, em maio de 2007, com o apoio de Daniel Zaharevitz, Chefe do Information Technology Branch of the Developmental Therapeutics Program do National Cancer Institute (NCI). Zaharevitz descobriu o projeto UsefulChem através de uma rede de open scientists e ofereceu testes de atividade antitumoral (BRADLEY; LANG; KOCH; NEYLON, 2011, p. 430).

Encontrar colaborações imprevisíveis, através da "abertura" do conhecimento científico e da serendipidade on-line, também é considerado vantagem por Matthew Todd. Atualmente, Todd coordena o Open Source Malária ${ }^{9}$, um projeto de pesquisa aberta (open research) que também mantém seus cadernos abertos. No entanto, ele diferencia a manutenção de um caderno aberto e de um blog: "Você pode descrever o que tem feito diariamente em seu laboratório, sem fazer ciência aberta [...] ter um caderno aberto é crucial, onde você é honesto sobre o sucesso e as falhas e o que você tem realizado, incluindo os dados brutos, na íntegra. É isso o que eu quero dizer com ciência aberta, mas vem se tornando um termo muito dilatado." (TODD, 2014) $)^{10}$.

Em agosto de 2005, Bradley (2005b) já distinguia três tipos de publicações on-line no campo científico. O primeiro é o dos blogs de "atualidades em ciência" que "basicamente informa as novidades na ciência assim que elas são divulgadas em comunicados de imprensa ou publicadas em revistas importantes". Um segundo tipo

\footnotetext{
8 "where hypothesis formation, docking, synthesis, and assay results were performed openly in real time" (BRADLEY; LANG; KOCH; NEYLON, 2011, p. 430).

9 Disponível em: http://opensourcemalaria.org/Acesso em: 07/02/2015

10 "You can describe what you have done daily in your laboratory without making open science" [...] "Having an open notebook is crucial, where you are honest about success and failures and what you have done, including all the raw data. That's what I mean by open science, but it is becoming a very dilated term." (TODD, 2014)
} 
é constituído pelos "blogs pessoais sobre ciência" que "abordam a rotina diária do trabalho em um laboratório" e que são "geralmente anônimos”. E, por último, mas não menos importante, os blogs que apresentam resultados de experimentos e revisões de literatura científica - algo que ele vinha experimentando com seus alunos, e seria chamado de open notebook science um ano depois.

Isto é o que eu gostaria de ver muito mais, os detalhes dos experimentos, os links para a literatura, basicamente o trabalho acadêmico. Por definição esses blogs não devem ser muito populares porque o nível de detaIhe para explicar um conceito o torna acessível para quem é familiarizado com o campo (um bom exemplo da cauda longa) - podem ser novos resultados de experimentos ou revisões detalhadas da literatura. É isto que estou tentando alcançar com os alunos que trabalham em meu laboratório ou assistem a minhas aulas de química orgânica. É muito mais difícil manter o padrão do rigor científico com alunos de graduação, mas eu acho que estamos chegando lá (BRADLEY, 2005b). ${ }^{11}$

\section{Os Pseudo Open Notebook Science}

Na prática, a maioria dos cientistas que mantém cadernos abertos adota parcialmente a proposta de Bradley de "no inside information", convertendo os cadernos em parcialmente abertos ou pseudoabertos (PONS) (BRADLEY, 2009; BACON, 2008). São exemplos

\footnotetext{
11 This is what I would like to see a lot more of. Experimental details. Links to literature. Basically scholarship. By definition these blogs should not be widely popular because the detail required to explain the concepts makes them accessible to those familiar with the field (a nice example of the long tail). These can be new experimental results or detailed reviews of the literature. This is what I am trying to achieve with the students working in my lab or taking my organic chemistry class. It is much more difficult to maintain the standard of scientific rigor with undergraduates but I think we are getting there. (BRADLEY, 2005b)
} 
desta discrepância a omissão ou o adiamento da publicação de dados e de informações.

Um estudo exploratório realizado por Grubb e Easterbrook (2011) indicou "falta de consenso sobre o significado de "aberto" em um universo de 20 cientistas identificados como promotores da ciência aberta e do conhecimento aberto. As discordâncias abrangem diversos aspectos da prática científica aberta, inclusive o compartilhamento de dados e de resultados - que caracteriza a proposta do caderno aberto. Os respondentes concordaram que dados e resultados de pesquisa assim como publicações, devem estar acessíveis gratuitamente a qualquer pessoa, mas divergiram em relação ao momento de divulgação. Alguns afirmaram “o mais rápido possível", enquanto a grande maioria afirmou preferir tornar dados e resultados acessíveis "só depois da publicação" (GRUBB; EASTERBROOK, 2011, p.7). É curioso dois participantes afirmaram que os dados devem ser compartilhados apenas quando solicitados.

Os autores concluem que há três atitudes em relação ao compartilhamento de dados e resultados: a) aquelas que compartilham dados e resultados imediatamente; b) aquelas que compartilham dados e resultados em algum momento; c) aquelas que acreditam no compartilhamento de dados e resultados, mas não o realizam, por preocupações relativas a questões de patenteamento e plágio.

Atento a estas barreiras, Bradley desenvolveu, ainda em 2009, uma série de logos, inspirados na modularidade das licenças Creative Commons, para identificar diferentes graus de abertura dos cadernos de pesquisa. 
Tabela 1: Logos e graus de abertura do Open Notebook Science

\begin{tabular}{|c|c|}
\hline Grau de abertura & Descrição \\
\hline All Content - Immediate (ACI) & $\begin{array}{l}\text { Todo conteúdo, imediatamente - O } \\
\text { caderno de laboratório e os respectivos } \\
\text { dados brutos associados à investiga- } \\
\text { ção estão disponíveis, na íntegra, em } \\
\text { tempo real ou o mais rápido possível. } \\
\text { Outros podem assumir que se algo não } \\
\text { está publicado no caderno, o pesquisa- } \\
\text { dor não o realizou. }\end{array}$ \\
\hline All Content - Delayed (ACD) & $\begin{array}{l}\text { Todo conteúdo, com atraso - O } \\
\text { caderno de laboratório e os respectivos } \\
\text { dados brutos associados à investigação } \\
\text { estão disponíveis, na íntegra, mas com } \\
\text { algum atraso - talvez por questão de } \\
\text { patenteamento ou de publicação. }\end{array}$ \\
\hline Selected Content - Immediate (SCI) & $\begin{array}{l}\text { Conteúdo selecionado, imediata- } \\
\text { mente - Apenas uma parte do caderno } \\
\text { de laboratório e os respectivos dados } \\
\text { brutos associados à investigação estão } \\
\text { disponíveis em tempo real ou o mais } \\
\text { rápido possível. Se algo não está publi- } \\
\text { cado no caderno de laboratório, outros } \\
\text { não devem supor que não foi realizado } \\
\text { pelo pesquisador. }\end{array}$ \\
\hline Selected Content - Delayed (SCD) & $\begin{array}{l}\text { Conteúdo selecionado, com atraso } \\
\text { - Apenas uma parte do caderno de } \\
\text { laboratório e os respectivos dados } \\
\text { brutos associados à investigação estão } \\
\text { disponíveis, com algum atraso. Se algo } \\
\text { não está publicado no caderno de labo- } \\
\text { ratório, outros não devem supor que } \\
\text { não foi realizado pelo pesquisador. }\end{array}$ \\
\hline
\end{tabular}

Fonte: BRADLEY, 2009 
Para esclarecer o que esse modo de fazer ciência significa na prática, o Open Source Malaria formulou seis "leis" que regulam tais atividades.

"Este é um tipo de código de conduta, diferente dos Panton Principles que são importantes para a questão dos dados [abertos]. Refere-se a maneira que você deve agir se quiser fazer parte do projeto. Você não é obrigado a seguir, mas se o não o faz, não pode associar-se ao projeto.” (TODD, 2014)12. As seis leis são: “1) Todos os dados são abertos e todas as ideias são compartilhadas. 2) Qualquer pessoa pode participar, em qualquer nível, do projeto. 3) Não haverá patentes. 4) Sugestões são a melhor forma de crítica. 5) A discussão pública é muito mais valiosa do que um e-mail privado. 6) O projeto é maior e não é propriedade de nenhum laboratório. O objetivo é encontrar uma boa droga para a malária, por qualquer meio, tão rápido seja possível” (TODD, 2011) $)^{13}$.

\section{AS ORIGENS DA OPEN NOTEBOOK SCIENCE}

O caderno aberto, tal qual proposto por Bradley, é uma das muitas inovações no campo científico cujas origens se localizam na confluência das novas formas de colaboração em ambientes digitais e das influências da cultura livre. A prática é considerada uma das vertentes da ciência aberta, um movimento que reúne ativistas e cientistas de diversos campos do conhecimento, engloba diferentes

\footnotetext{
12 "This is a kind of conduct law, it is not the Panton Principles that are important for data, for example. This is about how you should operate if you want to be a part of the project. You don't have to do this, but if you don't, you can't be associated with the project" (TODD, 2014). 13 "1) All data are open and all ideas are shared. 2) Anyone can take part at any level of the project. 3) There will be no patents. 4) Suggestions are the best form of criticism. 5) Public discussion is much more valuable than private email. 6) The project is bigger than, and is not owned by, any given lab. The aim is to find a good drug for malaria, by whatever means, as quickly as possible" (TODD, 2011)
} 
significados e tipos de iniciativas ${ }^{14}$, adota distintas perspectivas e pressupostos. Compartilha a premissa de que os modos atuais de produção e comunicação da atividade científica são inadequados e que criam, especialmente no âmbito da ciência institucionalizada, obstáculos legais e econômicos para o acesso à informação e ao conhecimento. Neste contexto, vislumbra-se na internet uma "oportunidade tecnológica" para retomar ou promover, dependendo da perspectiva, uma "verdadeira ciência". Essa visão já havia sido manifestada pelo pioneiro movimento pelo acesso aberto às revistas científicas em sua Declaração de Budapeste (2002).

Uma antiga tradição e uma nova tecnologia convergiram para tornar possível um avanço histórico. A antiga tradição é a disposição de cientistas e acadêmicos em publicar o fruto de suas pesquisas sem remuneração, em nome da transparência e democratização do conhecimento. A nova tecnologia é a internet. $O$ avanço histórico que eles possibilitam é

14 Além do open notebook science, a ciência aberta reúne iniciativas como: 1) Open Access - refere-se ao acesso à literatura científica de modo que qualquer pessoa possa pesquisar, consultar, fazer download, imprimir, copiar e distribuir o texto integral de artigos publicados em revistas científicas (via dourada) ou depositados em outras fontes de informação científica como repositórios institucionais (via verde). 2) Open Data - expressão popularmente vinculada à questão da transparência e interoperabilidade de dados governamentais, mas com conteúdo mais amplo. No campo científico, demanda a publicização do conjunto de dados primários de uma pesquisa, pois se considera que a omissão impede a reprodutibilidade e o amplo escrutínio. Tampouco permite a sua reutilização em pesquisas derivadas, ocultando inconsistências, baixa qualidade, plágio ou fraude. 3) Open Hardware (Hardware aberto)- Refere-se à divulgação, sem restrição, de informações para construção de ferramentas científicas pela adoção de padrões que garantem sua reprodução em larga escala. 4) Citizen Science (ciência cidadã) - alude à participação, em diversos graus, de não especialistas em pesquisa científica, com a motivação de ampliar a participação pública. Não se restringe à coleta de dados ou ao compartilhamento do tempo ocioso de seus computadores pessoais, mas envolve, também, a análise de dados e desenvolvimento de tecnologias. 4) Educação Aberta - Tendência que busca repensar os processos de aprendizagem e que tem, como um de seus expoentes, as discussões sobre o licenciamento aberto de materiais de ensino e pesquisa (recursos educacionais abertos) 
a distribuição da literatura acadêmica arbitrada por toda a extensão do globo e o acesso totalmente irrestrito e gratuito por parte de qualquer cientista, acadêmico, professor, estudante ou outro interessado. Desfazer as barreiras que impedem o acesso a esta literatura irá acelerar a pesquisa, fortalecer a educação e difundir o conhecimento de maneira geral, tirando dela seu máximo proveito e assentando as bases para a união da humanidade em uma ampla e inédita conversação intelectual comum em sua marcha pelo conhecimento. (BOAl, 2002)

Jean-Claude Bradley (2013a) compartilha a visão de que a internet é uma "oportunidade tecnológica", mas frisa que a possibilidade de transformar a relação com a informação e com o conhecimento, favorecida pela tecnologia, pode ser facilmente descartada. O autor lembra que, já em 2003, a popularização dos meios de produção e disseminação de podcasts propiciava a disponibilização on-line de material didático por professores, mas a maioria dos educadores preferia uma posição intermediária, em que compartilhava apenas uma parte de seus materiais, na esperança de conseguir comercializar outras, consideradas mais relevantes ou diferenciadas.

$\mathrm{Na}$ contracorrente, Bradley explora a oportunidade tecnológica e a perspectiva do conhecimento aberto, compartilhando materiais educativos (podcasts de aulas, slides, textos etc), dicas de uso de ferramentas e reflexões sobre sua experiência no ambiente universitário, através do blog Drexel CoAS E-Learning, iniciado em fevereiro de 2005, no qual assina como coordenador de E-Learning no College of Arts and Sciences, da Universidade de Drexel.

Nesse blog, Bradley publica uma série de posts, através dos quais podemos perceber que a origem do conceito está diretamente ligada à sua atuação como professor universitário, à sua experiência e experimentos em e-learning, e aos debates sobre as limitações do processo de revisão por pares, e às potencialidades da Internet para a comunicação científica. Outra fonte de informação é o blog UsefulChem ${ }^{15}$.

15 Disponível em: http://usefulchem.blogspot.com. Acesso em: 01 fev. 2015 


\section{A IDEIA DE SER ÚTIL}

Logo nos primeiros posts do blog UsefulChem, Bradley revela uma das suas motivações para a elaboração do conceito é o desejo de contribuir, como cientista, de forma "útil" para a sociedade. Este interesse está presente no título escolhido para o seu blog "Useful Chemistry" (Química Útil, em português) e em comentários positivos sobre a iniciativa de Elias Corey, da Universidade de Harvard University e ganhador do Prêmio Nobel de 1990, de se dedicar à produção de Tamiflu (oseltamivir), um antiviral utilizado para o tratamento da gripe aviária, em um processo que não previa seu patenteamento. Sobre isto, Bradley comentou: "Este é um bom exemplo em que químicos focam sua atenção em soluções químicas para problemas reais e imediatos - este é o espírito do que o projeto UsefulChem deve se esforçar para alcançar e manter" (BRADLEY, $2006 b)^{16}$.

A partir da motivação de ser útil, Bradley realiza um estudo bibliométrico no Google Scholar and Scirus para "identificar problemas e objetivos específicos em química, tal qual afirmam os pesquisadores em seus artigos"17 (BRADLEY, 2005c) e decide pesquisar o desenvolvimento de drogas contra a malária. Em entrevista a Richard Pointer, ele afirma:

Ao refletir sobre o significado de ser um cientista, eu percebi que o trabalho que realizava não tinha o tipo de impacto que eu gostaria que tivesse, que não beneficiava a humanidade como eu esperava. Cheguei à conclusão de que isto era, em parte, uma consequência do sigilo. No entanto, eu não poderia tornar-me aberto porque trabalhava em um

\footnotetext{
16 "This is a good example of chemists focusing their attention on chemical solutions to real immediate problems, which is the spirit of what the UsefulChem project should strive to achieve and maintain" (BRADLEY, 2006b).

17 "identify specific problems and objectives in chemistry, as stated by researchers in their articles" (BRADLEY, 2005c)
} 
projeto em colaboração com pessoas que não sentiam da mesma maneira. A minha decisão de fazer ciência aberta significava cortar laços com os meus colaboradores anteriores. Feito isto, em 2005, comecei o projeto UsefulChem (BRADLEY, 2010) ${ }^{18}$.

\section{SOBRE A QUALIDADE: O QUE É UMA INFORMAÇÃO SATISFATÓRIA?}

Bradley percebia que o caderno aberto poderia enriquecer a comunicação da ciência porque ofereceria informação suficiente para que um par (peer), razoavelmente competente, pudesse repetir os experimentos relatados. Ele reconhecia casos positivos, em que os autores especificam sua metodologia de coleta e análise de dados a fim de garantir a reprodutibilidade, mas observava que a maioria das revistas científicas oferecia poucos detalhes sobre a execução dos experimentos. As informações estariam altamente condensadas, mesmo em versões on-line, onde não há restrição de espaço (BRADLEY, 2007).

Diante da constante comprovação de que existem lacunas de informação relevante nos artigos publicados em revistas científicas, ele questionava: "Qual é o parâmetro atual para considerar uma "informação satisfatória” na comunicação em química orgânica? (BRADLEY, 2012a)"19. E ainda: "Se você trabalha em química orgânica e quer repetir um experimento, você não sabe como realizaram o que afirmam ter realizado porque falta informação. Mas, se você tiver

\footnotetext{
18 In thinking about what has meaning for me as a scientist, I realized that the work I was doing wasn't having the kind of impact that I would like it to have, and it was not benefitting mankind in the way I would have hoped. I concluded that this was partly a consequence of secrecy. However, I couldn't be open with the project I was then working on, because I was collaborating with someone who didn't feel the same way as me. My decision to do open science meant cutting ties with my previous collaborators. Having done that in 2005 , I started the project UsefulChem (BRADLEY, 2010).

19 "What is the current standard for considering a 'satisfactory information" in Organic Chemistry communication?" (BRADLEY, 2012a).
} 
acesso ao caderno de laboratório, você pode verificar se é você ou o autor que está cometendo um erro. (BRADLEY, 2008c)"20

Um exemplo constantemente utilizado pelo autor (BRADLEY, 2012b, 2013b) para demonstrar os prejuízos de não se ter "informação satisfatória" e as vantagens de se manter um caderno de pesquisa aberto é um caso ocorrido em sala de aula com a síntese da dibenzalacetona, popular em laboratórios de química orgânica. Bradley propôs a realização deste experimento e vários alunos utilizaram acetato de etila para a recristalização - o que não fazia sentido para ele, porque tal substância não é miscível em água. Para entender a opção dos estudantes pelo acetato de etila, Bradley rastreou as principais fontes de informação em química orgânica e descobriu que essa substância vem sendo utilizada inadequadamente nesta reação desde a publicação de um artigo em 1903.

Por isso, como professor da disciplina "Recuperação da Informação em Química”, Bradley incentivava seus alunos a desconfiar de todas as fontes de informação, inclusive as de maior prestígio. Ele destacava que a revisão por pares não deve ser considerada uma prova irrefutável de informações e legitimidade, e pretendia modificar a atitude de seus alunos, de meros usuários a curadores de informação. Em outras palavras, transformá-los em pessoas capazes de coletar, selecionar e avaliar as informações relevantes em química orgânica.

Bradley propôs a seus alunos outro exercício. Eles deviam coletar informações sobre um único experimento em cinco fontes diferentes. Os estudantes deviam certificar a confiabilidade do conteúdo, avaliando os protocolos e requisitos de cada procedimento

20 "If you are organic chemical and want to repeat an experience, you cannot figure out how they did what they say they did so, because they lack information. But if you have access to the lab notebook, you can see if it's you or him that is making a mistake" (BRADLEY, 2008c) 
para entender divergências entre as fontes de informação. "Este exercício deve fazê-los aprender que não se deve confiar implicitamente em uma fonte. [...] Não há "fontes confiáveis" (BRADLEY, $2010 b)^{21}$.

\section{SOBRE QUANTIDADE: O DESPERDÍCIO DE INFORMAÇÃO CIENTíFICA RELEVANTE}

Além do critério qualitativo, Bradley também analisou aspectos quantitativos do modo dominante de produção e comunicação da ciência. Ele estimou que $87 \%$ do seu trabalho seriam de acesso restrito ao pequeno grupo de pesquisadores de seu laboratório, caso não adotasse a perspectiva dos cadernos abertos (BRADLEY, 2013b). A questão é que a maioria dos experimentos realizados em seu laboratório não atingia um determinado resultado "esperado" e, por isso, era equivocadamente rotulada como "fracassada". Ainda que seja inapropriado chamar de fracassado um experimento cuja hipótese não foi confirmada, ele sabia que este tipo de resultado diminuía significativamente as chances de ser publicado por uma revista científica. A diferença entre o volume de conhecimento científico produzido pelos cientistas e o que eles disponibilizam para a sociedade através da comunicação formal era considerada por Bradley um desperdício de recursos.

Há também uma enorme quantidade de informação útil sobre reações ou tentativas de reações que nunca é compartilhada. Independentemente da obtenção ou não de uma reação "bem sucedida", se sua execução é cuidadosamente registrada, ela pode fornecer informações valiosas. Existem algumas ferramentas e padrões excelentes que permitem, de maneira fácil, realizar uma marcação semântica de reações e de

21 "This training should make them learn that no sources should be trusted implicitly". There aren't "trusted sources" (BRADLEY, 2010b) 
propriedades químicas, de modo que um experimento pode ser disponibilizado para descoberta assim que é iniciado. (BRADLEY, 2013)22

Ele acreditava que a decisão das revistas científicas pela publicação, ou não, de um conteúdo científico não o torna irrelevante ou diminui sua validade para atividades de ensino e pesquisa. Pelo contrário, sua experiência como professor e pesquisador indicava que essas duas instâncias podem convergir e se fortalecer mutuamente quando adotam a perspectiva do conhecimento aberto. Em sua visão, a ciência não é feita apenas de experiências "de sucesso", que atingem os "resultados esperados", mas também daquilo que dá "errado".

\section{OS LIMITES DA REVISÃO PELOS PARES}

Em posts publicados entre fevereiro e março de 2006, portanto, anteriores à publicação do conceito em setembro de 2006, Bradley concluiu que a internet e as ferramentas de busca on-line representavam uma mudança estrutural no acesso à informação que, por sua vez, modificaria a função da revisão por pares na perspectiva dos cientistas.

Ele afirmou que, até o começo da década de 1990, encontrar informação relevante era um trabalho árduo, que demandava o deslocamento físico de estudantes e pesquisadores até bibliotecas, para localizar, analisar, selecionar e, por fim, fotocopiar artigos de interesse para suas pesquisas. A revisão por pares funcionava, então, como um serviço de curadoria que evitava o desperdício de tempo

22 There is also a tremendous amount of useful information in reactions or reaction attempts that is never shared. Regardless of whether or not a reaction is 'successful', if its execution is carefully recorded it can provide valuable information. Some excellent tools and standards exist that allow for easy semantic tagging of chemical reactions and properties so that an experiment can be available for discovery as soon as it is started. (BRADLEY, 2013) 
em fontes de informação cujo retorno não era claro e garantido (BRADLEY, 2006c).

Com a internet e suas ferramentas de busca, localizar literatura científica relevante e obter uma cópia dos artigos de interesse, através de download, deixou de ser uma tarefa exaustiva. Esta mudança modificaria a função da revisão por pares, pois o tempo despendido para acessar fontes seria otimizado pelas novas possibilidades tecnológicas. Assim, os cientistas passariam a determinar o valor de um trabalho científico a partir de novos critérios que, segundo Bradley, seriam a sua rápida disponibilização on-line e a qualidade das descrições dos experimentos realizados.

Então, na verdade, o modo eu utilizava a revisão por pares, como cientista, era como critério para decidir quanto tempo eu deveria gastar buscando uma determinada referência. [...] O interessante aqui é que eu não estou realmente interessado em saber se o artigo é revisado por pares ou não. Estou mais interessado em saber se eles apresentam as condições experimentais para o composto que eu tento produzir. E eu posso avaliar se a descrição do experimento é realmente válida, ou quão provável é que ele seja bom, apenas com base na forma que é descrito. [...] Então, esta é uma situação interessante porque eu não uso mais a revisão por pares como costumava utilizar, para proteger o meu tempo. Agora é algo completamente diferente que determina o valor de um artigo: é em que medida eu posso obtê-lo on-line imediatamente. E se eu não posso, eu geralmente não me importo. De novo, apenas se eu estiver muito desesperado, eu vou tentar buscá-lo. Mas, honestamente, atualmente há tanta repetição na literatura científica que geralmente você encontra o que está procurando de maneira direta e on-line. Ou pelo menos sabe que aquilo ainda não foi feito, o que é outra maneira de olhá-lo. (BRADLEY, 2006d) ${ }^{176}$

Bradley apontava que a revisão por pares, do ponto de vista do editor de uma revista científica, é como "uma maneira 
custo-benefício para manter a qualidade e foco da revista" ${ }^{24}$, mas destacava que esse sistema de avaliação se restringe e atende apenas aos objetivos particulares de três atores: 1) o autor, interessado em publicizar sua "descoberta"; 2) o editor, que dá seu crivo ao trabalho e analisa sua aderência à linha editorial da revista, com o objetivo de torná-la referência em uma área de conhecimento; 3) os avaliadores, que analisam as informações, mas não são obrigados a reproduzir as experiências que subsidiam suas observações e conclusões (BRADLEY, 2012a).

Neste âmbito, “a revisão por pares não pretende validar medições individuais - sua função é garantir que os autores formulem conclusões adequadas com base em seus conjuntos de dados processados e no estado da arte do conhecimento naquele campo" (BRADLEY et al., 2009, p. 2) ${ }^{25}$. Portanto, se os avaliadores não repetem experimentos, eles não podem checar a possibilidade de fraude. "Isto só pode ser determinado ao longo do tempo, depois que outros pesquisadores tenham a oportunidade de tentar utilizar

23 "So, peer review, actually, the way I used it as a scientist was to make a decision as to how much time I should spend trying to hunt down a particular reference. [...] What's interesting here is I'm not really that interested in whether the article is peer reviewed or not. I'm more interested in, do they have the experimental conditions for the compound that I'm trying to make, and I can judge whether their description of the experimental is actually valid, or how likely is it to be good, just based on the way in which they describe it. [...] So it's kind of an interesting situation, because, I'm not using peer review in the way that I used to use it, to protect my time. So now it's something completely different that determines the value of an article. It's whether or not I can get it online immediately, and if I can't I usually don't bother. Again, unless I'm very desperate, and then I'll try to hunt it down. But honestly there's so much repetition now in the scientific literature that you can usually find what you're looking for online directly, or at least know that it hasn't been done, that's the other way to look at it." (BRADLEY, 2006d).

24 "is as a cost-effective way to maintain the quality and focus of journal" (BRADLEY, 2006c).

25 "Peer review is not intended to validate individual measurements - its function is to ensure that the authors made appropriate conclusions based on their processed datasets and the state of knowledge in the field" (BRADLEY et al., 2009, p. 2). 
as técnicas relatadas." (BRADLEY, 2006c). ${ }^{26}$ Bradley considera que "quando informação de apoio não é imediatamente disponibilizada, a revisão por pares pode não funcionar da maneira que muitos assumem que ela opera" (BRADLEY, 2006c) ${ }^{27}$.

Com tais critérios, eu acredito que (quando elaborados com cuidado) os posts de um blog sobre uma pesquisa científica são potencialmente mais fáceis de autenticar que um artigo em uma revista impressa, porque cada afirmação pode ser amparada por um link que pode ser visto imediatamente. Cada conclusão pode ser sustentada pelos dados on-line. Será interessante ver o quão perto dessa proposta podemos chegar com os dois estudantes que estão trabalhando no meu laboratório e bloggando neste verão (BRADLEY, 2005a). ${ }^{28}$

Além disso, Bradley reconhecia que uma série de escândalos, como a publicação de fraudes e de documentos gerados por computador a partir do uso randômico de jargões, somados à facilidade de criar uma "revista científica" on-line com avaliação anônima, tornavam a expressão "revisão por pares" um indicador de qualidade questionável (BRADLEY, 2006c). Ele indaga:

A ideia de que a revisão por pares é útil para "autenticar" a pesquisa sempre me pareceu um pouco estranha. Afinal, o público-alvo da maioria dos artigos científicos é constituído (por definição) por pares do autor. O que

\footnotetext{
26 "This only can be determined over time, after other researchers have had a chance to try to use reported techniques" (BRADLEY, 2006c)

27 "When supporting information is not immediately available, peer review may not work the way many assume it does". (BRADLEY, 2006c)

28 With these criteria, I think that (if done with care) blog posts of scientific research are potentially easier to authenticate than a paper in a printed journal because every statement can be supported by a hyperlink that can be immediately verified. Every conclusion can be supported by online data. It will be interesting to see how close we can get to this with the two students working in my lab and blogging about it this summer (BRADLEY, 2005a).
} 
torna os colaboradores selecionados por um editor mais capazes de validar um artigo do que o seu público-alvo? (BRADLEY, 2006C) ${ }^{29}$

A partir deste cenário de incertezas e anonimato, Bradley pretendia ensinar seus alunos a distinguir o que considerava uma "referência aparentemente autorizada" e "certificada" (BRADLEY, 2005a) desenvolvendo neles "a habilidade de atribuir a probabilidade da autenticidade em um documento fora de seu contexto" (BRADLEY, 2005a) ${ }^{30}$. "Eu não estou dizendo que a revisão por pares não tem nenhum valor. [...] Mas, como esses avaliadores certificam os manuscritos que recebem para publicação nas revistas? Essas são habilidades que eu quero que meus alunos aprendam" (BRADLEY, 2005a) ${ }^{31}$. Ele comenta: "Na química, isso significa que toda declaração postulada como um fato tem uma referência. Toda conclusão está ligada a dados experimentais. Opiniões e especulações não precisam de uma referência - o autor é a referência" (BRADLEY, $2005 a)^{32}$.

\section{A IMPORTÂNCIA DA MISCELÂNEA}

Embora seu principal argumento seja o de que artigos publicados em revistas com revisão por pares são uma versão reduzida da

29 The idea that peer review is useful to "authenticate" research has always seemed a bit strange to me. After all, the targeted audience for most scientific articles consists of (by definition) peers of the author. What makes the reviewers selected by an editor any more capable of validating an article than the targeted audience? (BRADLEY, 2006c)

30 "the ability to assign a probability of authencity to a document found out of context" (BRADLEY, 2005a)

31 "I am not saying that peer review is of no value. [...] But how do those reviewers authenticate the manuscripts they receive for publication in those journals? Those are skills I want my student to learn" (BRADLEY, 2005a).

32 "In chemistry, that means that every statement expressed as a fact has a reference. Every conclusion is linked to experimental data. Opinions and speculations don't need a reference - the author is the reference" (BRADLEY, 2005a) 
atividade científica, cuja riqueza está provavelmente detalhada nos cadernos encerrados atrás das portas fechadas de um laboratório, Bradley (2008b) considerava o caderno aberto como instrumento complementar que não pretende tomar o lugar do formato atual, mas enriquecê-lo. "Há bastante espaço para ambos os tipos de comunicação” (BRADLEY, 2006c) ${ }^{33}$. E complementa:

Se você trabalha há algum tempo em um laboratório, um dia você percebe que quase tudo o que você faz não será publicado porque os experimentos falham ou porque alcançam um estado sub-ótimo e precisam ser repetidos [...] E se você não for capaz de encaixar a reação em uma história mais ampla, você, de fato, não poderá publicá-la. Logo, nós não estamos nos privando de publicar artigos tradicionais, nós estamos basicamente colocando nosso laboratório em uma wiki de modo que as pessoas possam se beneficiar do que fazemos diariamente" ${ }^{\prime \prime 34}$ (BRADLEY , 2006f).

Na citação acima, Bradley identifica outra importante característica do modo dominante da comunicação científica que ele pretendia transformar: a necessidade de construir uma narrativa, de "uma história maior que você pode empacotar", para tornar o conhecimento público o conhecimento científico, através de um artigo revisado por pares.

O paradigma da pesquisa em química demanda elaboração de experimentos a partir de teorias estabelecidas, ou potencialmente novas para o campo, sua execução e registro dos procedimentos utilizados e dos resultados obtidos em cadernos de laboratório. Porém,

\footnotetext{
33 "There is a plenty of room for both types of communication" (BRADLEY, 2006c).

34 "If you work in a lab for a couple of years, one day you realize that almost everything that you do does not get published, because the experiments have either failed or there suboptimal someway and they have to be repeated [...] if it does not fit into a bigger history that you can wrap up, you really can't publish it. So we are not avoiding publishing normal articles, we are just basically putting our lab on a wiki directly so people can benefit of what we do in day-day basis." (BRADLEY, 2006f)
} 
apenas quando determinados resultados são obtidos, inicia-se um processo cujo objetivo é comunicar mais amplamente o conhecimento científico. Nesta etapa, uma versão resumida e editada do que foi realizado no laboratório é elaborada, reunindo uma narrativa coerente e uma quantidade limitada de informação e de dados brutos (supporting data). Esta versão corresponde ao formato de artigo científico, que apresenta um relato coeso da atividade científica, em que todas as peças parecem estar no lugar certo, o tempo todo.

Pela sua experiência, Bradley sabia que a ciência, pelo contrário, é um processo desordenado, com retrocessos e avanços, hipóteses que não se confirmam, e muitas repetições. Neste sentido, ele almejava mais transparência na ciência, não apenas para prevenir fraudes, mas também para promover oportunidades de ensino e aprendizagem.

Não há documento produzido por um ser humano que não seja formatado por outro motivo que não o de uma divulgação imparcial. Frequentemente, o que não é mencionado é tão importante quanto aquilo que é. Experimentos que não produzem os resultados desejados geralmente não são relatados. E isso é ainda mais verdadeiro no caso de experimentos mal executados ou sub-ótimos. Qualquer estudante de química pode relatar o enorme valor em discutir experiências fracassadas com pessoas que são tão ou mais bem informadas. No entanto, este debate se limita geralmente aos colegas do laboratório. Ao registrar as experiências em curso em um blog, eu posso ajuda-lo simplesmente por saber o que você está tentando realizar mesmo, que você ainda não tenha conseguido (BRADLEY , 2006e) $)^{35}$.

35 There is not a document produced by a human being that is not shaped by a motive other than impartial disclosure. Often what is not mentioned is just as important as what is. Experiments that don't yield desired results are usually not reported. And that is even more true for experiments that are somehow botched or suboptimal in some way. Any chemistry grad student can tell you that there is tremendous value in discussing failed experiments with others who are equally or more knowledgeable. However, this discussion is usually limited to lab co-workers. By recording ongoing experiments in blogs, I can help you just by knowing what you are trying to do, even if you have not yet succeeded. (BRADLEY, 2006e) 
Além da transparência e do acesso, através de plataformas indexadas por ferramentas de busca, ele pretendia promover "replicação". Em suas palavras, "Não há nenhum gatekeeper a ser convencido neste sistema. Nenhum software para fazer download. Nenhum servidor a ser configurado. Praticamente nenhuma curva de aprendizagem. Qualquer um que faz a ciência é livre para replicar em seu campo de interesse. Ciência plenamente democrática." (BRADLEY, $2006 e)^{36}$

Ele identificou que "devemos separar o problema de comunicar de forma eficiente a informação científica do problema de convencer uma comissão sobre o impacto da de uma bolsa de estudos para um membro da faculdade" (BRADLEY, 2006c) ${ }^{37}$. Uma vez a revisão por pares é "uma espécie de padrão de ouro na promoção acadêmica e domínio ao contabilizar publicações" (BRADLEY, 2006c) ${ }^{38}$, o processo de comunicação da ciência demanda a elaboração de narrativas, a figura de autores e um formato de publicação que opera como um ativo que constrói e valoriza carreiras. Assim, o sistema de crédito da ciência formata a maneira pela qual os cientistas comunicam o seu trabalho.

"E ao fazer ciência aberta, a primeira preocupação é a comunicação da informação"39. Por isso, Bradley sugere uma grande mudan-

\footnotetext{
36 "There is no gatekeeper to convince in this system. No software to download. No server to set up. Almost no learning curve. Anyone doing science is free to replicate in their field of interest. Fully democratic science." (BRADLEY, 2006e)

37 "we have to separate the problem of efficiently communicating scientific information from the problem of convincing a committee of the impact of a faculty member's scholarship" (BRADLEY, 2006c).

38 "kind of gold standard in academic promotion and tenure when counting publications" (BRADLEY, 2006c)

39 "And when doing open science, the first concern is the communication of the information... (BRADLEY; 2006d)
} 
ça: "Primeiro libere, em seguida, discuta e, finalmente, convença, quando necessário." ${ }^{40}$ (BRADLEY; 2006d)

\section{ALGUNS COMENTÁRIOS}

Este trabalho apresenta resultados parciais de uma pesquisa documental não exaustiva, que pretende sistematizar as ideias de Jean-Claude Bradley, autor do conceito de open notebook science. Pelo exposto, acredita-se que sua proposta de caderno aberto não deva ser reduzida a uma inovação incremental da tradicional ferramenta de registro da atividade científica e tampouco confundida com os blogs científicos, que divulgam a ciência para público mais amplo, muitas vezes operando uma espécie de tradução da linguagem hermética de pesquisadores para outra, acessível a não especialistas. Ela se insere em um debate amplo e consistente sobre a ciência, motivado pelas aspirações pessoais de Jean-Claude Bradley de transformar a atividade científica e favorecer processos de aprendizagem.

O caderno aberto é uma inovação que pretende transformar a produção e a comunicação da ciência, oriunda da percepção de Jean-Claude Bradley de que a atividade científica, ainda nos dias de hoje, se baseia excessivamente na confiança. Um de seus objetivos é, portanto, promover transparência nos processos de validação do conhecimento científico, substituindo a confiança (trust) por provas (proof).

Uma grande falha no atual sistema de publicação científica é que ainda há demasiada confiança. Espera-se que os leitores confiem nos editores para selecionar pares anônimos e adequados para avaliar as submissões. Os avaliadores confiam nos autores principais que relatam de maneira

40 "First diclose, then discuss and finally convince, when necessary." (BRADLEY; 2006d) 
resumida os resultados de pesquisa. Os autores principais confiam em seus colaboradores, estudantes e pós-doutores na produção de informação precisa para os artigos. Se tornamos públicos o caderno de laboratório e os dados brutos associados a uma pesquisa, podemos reduzir significativamente a quantidade de confiança necessária para manter este castelo de cartas em pé. (BRADLEY, 2007) $)^{41}$

Ao afirmar que "a ciência envolve desconfiança" ("Science is about mistrust"), Bradley lembrava que "um aspecto chave da revolução científica há alguns séculos foi a passagem da confiança em uma autoridade para a desconfiança de tudo e de todos" (BRADLEY, $2007)^{42}$. Seu ceticismo não se foca tanto na fabricação de dados, ainda que ele admitisse ocorrências, mas na "cascata de fontes confiáveis" (trusted source cascade) que se origina dos erros e atalhos que os cientistas realizam para publicar artigos científicos sob pressão. Ele assinala que “[...] uma vez que estes erros são impressos é muito difícil fazer com as pessoas os corrijam, se chegarem a ser descobertos (BRADLEY, 2007)".

Por isso, Bradley pretendia transformar o hábito, comum aos cientistas e estudantes de utilizar uma determinada informação, baseando-se apenas no fato de que foram publicadas em revistas cientificas, com revisão por pares, sem saber os detalhes, a origem e o histórico dos dados (data provenance) que subsidiam suas conclusões. Ele desejava estimular rigor científico e destacava que

41 A major flaw in the current scientific publication system is that there is still too much trust. Readers are expected to trust editors to choose appropriate anonymous peers to review submissions. Reviewers trust primary authors when reporting the summarizing of their research results. Primary authors trust their collaborators, students and postdocs to give them accurate information when writing papers. If we make the laboratory notebook and all associated raw data public we can significantly reduce the amount of trust required to keep this house of cards standing. (BRADLEY, 2007)

42 "a key aspect of the scientific revolution a few centuries ago was moving from trust in an authority to mistrust of everything and everybody" (BRADLEY, 2007). 
"enquanto os cientistas não fornecerem a íntegra dos detalhes de seus experimentos, detalhes registrados em seus cadernos de laboratório, este tipo de incerteza vai continuar assolando a ciência" (BRADLEY, 2010b). Ideias como "não há fonte confiável" ("no trusted source") ou "nenhuma informação privilegiada" ("no inside information") são recorrentes em seus posts.

Bradley aspirava abrir a "caixa preta" da ciência porque, uma vez que os dados e informações gerados ou associados às pesquisas são disponibilizados abertamente, eles permitem o estudo, o escrutínio, a validação ou a refutação por uma audiência mais ampla que o tradicional processo de revisão por pares. Ainda que outros fatores, tais como assimetrias de informação, ausência de materiais, instrumentos e infraestruturas, dificultem o acesso, o uso e a reutilização do conhecimento científico, eles são registrados nos cadernos abertos.

Vale destacar que a ênfase de Bradley na necessidade dos cientistas de manter registros detalhados dos experimentos conduzidos em seus laboratórios não deve ser confundida com uma valoração excessiva do conhecimento escrito. Ao contrário, em diversos posts, ele indica que sua vontade de comunicar a informação em química "da melhor maneira possível" não estava restrita a um tipo específico de mídia. Ele experimentou diferentes ferramentas e serviços on-line. Além de podcasts, utilizou a plataforma Flickr para compartilhar imagens de experimentos; Second Life, para criar visualização de moléculas em 3D; Youtube, para publicar seus experimentos e apresentações. Bradley também publicou um trabalho ${ }^{43}$ no Journal of Visualized Experiments (JOVE), uma revista científica

43 BRADLEY, J.; MIRZA, Baig Mirza, K.; OSBOME, T.;WILLIAMS, A.; OWENS, K. Optimization of the ugi reaction using parallel synthesis and automated liquid handling. J. Vis. Exp. n.21, e942, 2008. doi:10.3791/942. Disponível em: http://www.jove.com/video/942/optimization-ugi-reaction-using-parallel-synthesis-automated-liquid. Acesso em: 28 jan.2015 
com revisão por pares que publica artigos sobre técnicas experimentais em formato audiovisual.

De fato, podemos economizar uma quantidade enorme de palavras ao relatar experimentos com um vídeo curto ou uma imagem. É incrível como mesmo em procedimentos aparentemente simples, como uma destilação, todos do nosso grupo tinham diferentes pressupostos sobre uma "configuração padrão" diferente. Nesses casos, fotos foram inestimáveis para complementar tudo aquilo que não havia sido registrado no log. Vídeos são ainda melhores porque permitem averiguar a dinâmica de uma reação (BRADLEY, 2006g) ${ }^{44}$.

Por último, vale lembrar que este conceito é extremamente novo, elaborado originalmente no campo da química orgânica, em uma universidade nos Estados Unidos, por um cientista profissional, com trajetória particular no campo do ensino e da pesquisa, e vínculo com debates sobre o conhecimento aberto. Este contexto influencia seu primeiro desenho, mas a prática pode assumir novos formatos, porque está em construção por seus adeptos. A pesquisa documental não localizou, até o momento, algum registro que indique pretensão de tornar o caderno aberto um padrão para todo o campo da química, tampouco um modelo para outras disciplinas. No entanto, cientistas de outras áreas do conhecimento, especialmente da biologia e da física, vêm experimentando esta proposta e podem desenvolver novos formatos a partir de sua filosofia geral.

44 It really is true that we can save an awful lot of words with a quick video or image when reporting experiments. Even for ostensibly simple procedures like distillation it is amazing how everyone in our group had different assumptions about a "standard setup". In these cases the pics were invaluable to fill in for everything not said in the log. Videos are usually even more useful because the dynamics of a reaction can be ascertained. (BRADLEY, 2006g) 


\section{REFERÊNCIAS}

BACON, Dave. Pseudo Open Notebook Science?. The Quantum Pontiff (blog) Publicado em: 26 jun. 2008. Disponível em: <http://scienceblogs.com/pontiff/2008/06/26/pseudo-open-notebook-science>. Acesso em: 12 dez. 2013.

BRADLEY, Jean Claude. Bird Flu chemistry progress. UsefulChem (blog). Publicado em: 7 maio 2006 (b). Disponível em: <http://usefulchem.blogspot.com. br/2006/05/bird-flu-chemistry-progress.html>. Acesso em: 05 fev. 2015

BRADLEY, Jean-Claude. Blogger as lab notebook. Drexel CoAS E-Learning (Blog). Publicado em: 9 fev. 2006 (e). Disponível em: http://drexel-coas-elearning.blogspot.com.es/2006/02/blogger-as-lab-notebook.html. Acesso em: 18 mar. 2015.

BRADLEY, Jean Claude. Cheminformatics in Open Notebook Science Advanced Informatics in Chemistry Education. Palestra proferida na Universidade de Indiana em 29 jul. 2008 (c). Disponível em: <https://www.youtube.com/watch?v=EVHVyQY-_fM>. Acesso em: 30 maio 2014.

BRADLEY, Jean-Claude. Communicating Science through Video. Drexel CoAS E-Learning (Blog). Publicado em: 20 nov. 2006(g). Disponível em:

http://drexel-coas-elearning.blogspot.com.es/2006/11/communicating-sciencethrough-video.html. Acesso em: 18 mar.2015.

BRADLEY, Jean-Claude. Dangerous Data: lessons from my Cheminfo Retrieval Class. UsefulChem (Blog). Publicado em: 2 jan. 2010(b). Disponível em:

http://usefulchem.blogspot.com.es/2010/01/dangerous-data-lessons-from-my-cheminfo.html. Acesso em: 18 mar. 2015.

BRADLEY, Jean-Claude. Data on display. Nature News. Publicado em: 15 set. 2008 (a). Disponível em: <http://www.nature.com/news/2008/080915/full/455273a. html>. Acesso em: 20 jan. 2014.

BRADLEY, Jean-Claude. Interview to Beth Ritter-Guth and students. Publicada em set. 2006(f). Disponível em: http://showme.physics.drexel.edu/share/jcbedit. mp3. Acesso em: 18 mar. 2015.

BRADLEY, Jean-Claude. Interview with Jean-Claude Bradley. The Impact of Open Notebook Science by Richard Poynder. Information Today. Publicado em: set. 
2010. Disponível em: 〈http://www.infotoday.com/it/sep10/Poynder.shtml\#top〉 Acesso em: 24 jan. 2014.

BRADLEY, Jean Claude. Open Education. Palestra proferida em "Tuesday Tech Talks" em: 12 fev. 2013 (b). Disponível em: <https://www.youtube.com/watch?v=BN8UjULNG9A >. Acesso em: 1 jun. 2014.

BRADLEY, Jean-Claude. Open Notebook Science. Publicado em: 26 set. 2006 (a). Disponível em: http://drexel-coas-elearning.blogspot.com.br/2006/09/open-notebook-science.html. Acesso em: 24 jan. 2014.

BRADLEY, Jean Claude. Open Notebook Science: implications for the future of libraries. Palestra proferida na University of British Columbia Library School em 2 abr. 2008 (b). Disponível em: <https://www.youtube.com/watch?v=5g8ef3BF274> Acesso em: 28 maio 2014.

BRADLEY, Jean-Claude . Open Notebook Science Claims and Logos. Blog UsefulChem. Publicado em: 24 fev. 2009. Disponível em: <http://usefulchem.blogspot. com.br/2009/02/open-notebook-science-claims-and-logos.html>. Acesso em: 17 nov. 2013.

BRADLEY, Jean-Claude. Opening up and sharing. Site Chemistry World. Publicado em: 18 abr. 2013 (a). Disponível em: http://www.rsc.org/chemistryworld/2013/04/ open-science-chemistry-sharing-information. Acesso em: 20 fev. 2014.

BRADLEY, Jean-Claude. Peer review and supported documents. Drexel CoAS E-Learning (Blog). Publicado em: 24 jul. 2005 (a). Disponível em: http://drexel-coas-elearning.blogspot.com.es/2005/07/peer-review-and-supported-documents.html. Acesso em: 18 mar. 2015.

BRADLEY, Jean-Claude. Peer review in Google Age. Drexel CoAS E-Learning (Blog). Publicado em: 13 fev. 2006 (c). Disponível em: http://drexel-coas-elearning.blogspot.com.es/2006/02/peer-review-in-google-age.html. Acesso em: 18 mar. 2015.

BRADLEY, Jean-Claude. Peer review in the Google Age. Drexel CoAS E-Learning Transcripts. Publicado em: 4 mar. 2006 (d). Disponível em: http://drexel-coas-elearning-transcripts.blogspot.com.es/2006/03/peer-review-in-google-age-bradley. html Acesso em: 18 mar. 2015. 
BRADLEY, Jean-Claude. Sample search phrases. UsefulChem (Blog). Publicado em: http://usefulchem.blogspot.com.es/2005/07/sample-search-phrases.html 29 jul. 2005 (c). Disponível em: Acesso em: 18 mar. 2015.

BRADLEY, Jean-Claude. Science is about mistrust. UsefulChem (Blog). Publicado em: 4 out. 2007. Disponível em:

http://usefulchem.blogspot.com.es/2007/10/science-is-about-mistrust.html. Acesso em: 18 mar. 2015.

BRADLEY, Jean-Claude. Science blogs. Drexel CoAS E-Learning (Blog). Publicado em: 5 ago. 2005 (b). Disponível em:

http://drexel-coas-elearning.blogspot.com.es/2005/08/science-blogs.html. Acesso em: 18 mar. 2015.

BRADLEY, Jean-Claude. Shining a light on chemical properties with Open Notebook Science and open strategies. Palestra proferida no ACS Symposium em 20 ago. 2012(a). Disponível em: 〈https://www.youtube.com/watch?v=7mK6SY-jXqk>. Acesso em: 05 fev. 2015

BRADLEY, Jean Claude. A recrystallization App based on Open Services. Palestra proferida no Drexel Chemistry Mini-Symposium em 27 set. 2012.(b). Disponível em: 〈https://www.youtube.com/watch?v=vMndyT-DSXM>. Acesso em: 1 jun. 2014.

BRADLEY, Jean-Claude. Web 2.0 in Science: success or failure?. UsefulChem (blog). Publicado em: 7 out. 2008 (d). Disponível em: <http://usefulchem.blogspot.com. br/2008/10/web-20-in-science-success-or-failure.html>. Acesso em: 13 abr. 2014. BRADLEY et al. Open Notebook Science Challenge Solubilities of Organic Compounds in Organic Solvents. Versão de 12 dez. 2009. Disponível em: <http://precedings. nature.com/documents/4243/version/2/files/npre20104243-2.pdf〉 Acesso em: 10 fev. 2014.

BRADLEY, Jean-Claude; LANG, Andrew S. I. D.; KOCH, Steve; NEYLON, Cameron. Colaboration using Open Notebook Science in Academia. In: COLLABORATIVE Computational Technologies for Biomedical Research. New York: John Wiley \& Sons, 2011. Disponível em: <http://media.wiley.com/product_data/excerpt/36/04706380/0470638036-1.pdf> Acesso em: 15 nov. 2013. 
BUDAPESTE OPEN ACCESS INITIATIVE - BOAI. Declaração de Budapeste (2002). Disponível em: <http://www.budapestopenaccessinitiative.org/translations/portuguese-translation $>$. Acesso em: 10 jan. 2014.

DAVID, Paul A. From keeping 'Nature's Secrets' to the institutionalization of 'Open Science'. Economic and Social History, n. 23, July 2001. Disponível em: http://www.economics.ox.ac.uk/oxford-economic-and-social-history-working-papers/from-keeping-natures-secrets-to-the-institutionalization-of-open-science>. Acesso em: 12 dez. 2013.

GRUBB, Alicia M.; EASTERBROOK, Steve M. On the lack of consensus over the meaning of openness: an empirical study. PLoS ONE, v.6, n.8, 2001. doi:10.1371/ journal.pone.0023420.

ONS CHALLENGE. Submeta Awards 08. ONS Challenge (wiki). Publicado em: 4 nov. 2008. Disponível em: http://onschallenge.wikispaces.com/submetaawards08. Acesso em: 18 mar. 2015.

ONS CHALLENGE. Solubilities of Organic Compounds in Organic Solvents. Feb. 11, 2010, p. 2. Disponível em: https://www.academia.edu/893810/Open_Notebook_Science_Challenge_Solubilities_of_Organic_Compounds_in_Organic_Solvents. Acesso em: 18 mar. 2015.

TODD, Matthew. Open Source Drug Discovery for Malaria. The Synaptic Leap Open Source Biomedical Research (blog). Publicado em: 25 jul. 2011. Disponível em: <http://www.thesynapticleap.org/node/343〉. Acesso em: 3 mar. 2014.

TODD, Matthew . Open Science Orienteering (presentation). Session Wikiresearch and open Science notebooks. In: OPEN SCIENCE, OPEN ISSUES INTERNATIONAL SEMINAR. Rio de Janeiro, 18 - 22 ago. 2014. Disponível em: https:// www.youtube.com/watch?v=rQtA1gXRZjk. Acesso em: 18 mar. 2015. 


\title{
12
}

\section{Direções para uma academia contemporânea e aberta}

\author{
Alexandre Hannud Abdo
}

\section{INTRODUÇÃO'}

Como pesquisador interessado em valer-me das possibilidades atuais para trabalhar de forma mais harmoniosa com os princípios efetivos da própria academia (a crítica, a verificabilidade, a incrementalidade, a recombinação, a replicabilidade) e da sociedade (o diálogo, a participação, o uso racional dos recursos) enfrento, frequentemente, desamparos ou obstáculos para o bom aproveitamento do meu trabalho. Muitas vezes essas dificuldades vêm da própria falta de técnica e de hábito de pesquisar com tais possibilidades em mente. Mas também há muito o que as instituições acadêmicas podem fazer por quem está já lutando contra a inércia cultural de profissionais.

Universidades, institutos e agências de pesquisa, particularmente brasileiros, vivem há pelo menos uma década em estado de contradição. Por um lado, é inadiável um movimento por maior compartilhamento e colaboração do conhecimento mantido e produzido, assim como dos recursos disponíveis, aplicando-se na academia as inovações propocionadas pela tecnologia e cultura da colaboração e compartilhamento, que já transformaram e dinamizaram a sociedade e

\footnotetext{
1 Este texto está também disponível em "http://pt.wikiversity.org/w/index.php?title=Utilizador:Solstag/Capítulo_para_Ciência_Aberta,_Questões_Abertas\&oldid=77167". Acesso em 4 Dez. 2014.
} 
a economia (BENKLER, 2006). Até nos aspectos administrativos há necessidade urgente de projetar luz sobre as contas e contratos dessas instituições. Por outro lado, uma atitude corporativa, de muros e de "donos do conhecimento" incide na contramão dessas inovações. Desconectada da contemporaneidade e mantida pelo hábito e para a sustentação, justificada, do modo de vida de uma parcela da academia, essa atitude manifesta-se em diversos aspectos da vida acadêmica, aparecendo também, por vezes, entrincheirada em círculos viciosos de privilégios e interesses anacrônicos. Estes precisam ser superados para que, aos poucos, a academia possa dar espaço a novas experimentações nos modos de produção acadêmica.

Infraestrutura, treinamento e política científica - esta em termos de financiamento, reconhecimento, diretrizes e incentivos são aspectos da prática acadêmica em que apoio institucional pode fazer diferença com a adoção de inovações operacionais. Cruzando-os com os eixos de práticas da ciência aberta, do acesso aberto à ciência cidadã, podemos montar um esquema do que precisa ser feito para posicionar uma instituição como mobilizadora de um pesquisar mais efetivo e promotor de desenvolvimento.

Este texto não pretende justificar o posicionamento por uma ciência aberta, que acreditamos já extensamente justificado por tantos outros (NIELSEN, 2011; CARDOSO; JACOBETTY; DUARTE, 2012). Assim, partimos do princípio de que o acesso universal e imediato aos produtos do processo científico, viabilizando a participação colaborativa nesse processo e estimulando uma competição que recompense a capacidade de inovação e não o acesso aos meios, é ponto pacífico no detalhamento das ações descritas.

\section{INFRAESTRUTURA}

\section{REPOSITÓRIOS}

O trabalho de pesquisa tem inúmeros produtos que, numa perspectiva de ciência aberta, desejamos compartilhar. Teses, artigos, 
livros, recursos educacionais, objetos multimídia, dados, protocolos, designs (documentação de instrumentos), software e materiais fazem parte desse universo. Repositórios institucionais são importantíssimos para o pesquisador, reduzindo-lhe o trabalho de preservar e compartilhar tais produtos do seu esforço para que outros possam estudá-los e trabalhar sobre eles. Para maximizar seu impacto de abertura, esses repositórios devem ser interoperantes com outras instituições, replicáveis e agregáveis em centros de referência. Devem, também, ser eles mesmos desenvolvidos abertamente, e identificar em seus conteúdos as licenças e demais permissões associadas.

Esses repositórios não precisam ser próprios de cada instituição; podem resultar de consórcios delas ou de financiamentos diretos para repositórios compartilhados por diversas organizações.

No Brasil, um número significativo de instituições dispõe de repositórios para teses e artigos, contudo pouquíssimas apresentam ou participam de repositórios para as demais categorias de produção científica. Notavelmente, durante um período a partir de 2003, houve desenvolvimento e disponibilização de um repositório de software dentro da Fundação de Amparo à Pesquisa do Estado de São Paulo (Fapesp), como parte do projeto da Incubadora Virtual (SIMON, 2004), que acabou encerrada por dificuldades econômicas após o término do seu projeto guarda-chuva, o Tidia (Tecnologia da Informação para o Desenvolvimento da Internet Avançada). Vale também mencionar que há no país, ainda que sejam restritos, alguns repositórios dedicados à sistematização de dados de redes de colaboração temáticas, como o SinBiota².

$\mathrm{Na}$ prática, pesquisadores brasileiros que, por interesse próprio ou exigência da sua área utilizam algum repositório, recorrem àqueles que são públicos, de base acadêmica ou não, mantidos sem a participação de insituições nacionais. É o caso de repositórios de

2 Disponível em: http://sinbiota.biota.org.br/about/. Acesso em 4 dez. 2014. 
dados (Dataverse ${ }^{3}$, GenBank$^{4}$, Figshare ${ }^{5}$, PaleoBioDB $^{6}$ ), software (Sourceforge $^{7}$, Gitorious ${ }^{8}$, Github $^{9}$ ), de objetos multimídia (Wikimedia Commons ${ }^{10}$, Flickr ${ }^{11}$, YouTube ${ }^{12}$ ), de artigos (arXivis), de designs (CERN Open Hardware Repository ${ }^{14}$, Instructables ${ }^{15}$ ), de materiais (iGem Registry of Standard Biological Parts ${ }^{16}$, DNASU Plasmid Repository ${ }^{17}$, Addgene ${ }^{18}$, repositórios agregados no Specimen Central ${ }^{19}$, EuroBioBank ${ }^{20}$, Cooperative Human Tissue Network ${ }^{21}$ ) etc.

Porém é preciso cuidado, pois esses repositórios, em princípio, não têm vínculo ou responsabilidade para com o pesquisador ou sua instituição. Assim, salvo nos casos em que são geridos por iniciativas de sólida base acadêmica, tais repositórios não suprem a carência de repositórios institucionais e não são confiáveis para a preservação dos seus conteúdos, pois seus modelos de negócio, políticas de acesso e até mesmo existência estão sujeitos a mudanças sem compromisso público.

3 Disponível em: http://thedata.org/ . Acesso em 4 dez. 2014.

4 Disponível em: http://www.ncbi.nlm.nih.gov/genbank. Acesso em 4 dez. 2014.

5 Disponível em: http://figshare.com/. Acesso em 4 dez. 2014.

6 Disponível em: http://paleobiodb.org/ . Acesso em 4 dez. 2014.

7 Disponível em: http://sourceforge.net/ . Acesso em 4 dez. 2014.

8 Disponível em: https://gitorious.org/ . Acesso em 4 dez. 2014.

9 Disponível em: http://github.com/. Acesso em 4 dez. 2014.

10 Disponível em: http://commons.wikimedia.org/ . Acesso em 4 dez. 2014.

11 Disponível em: https://www.flickr.com/ . Acesso em 4 dez. 2014.

12 Disponível em: http://youtube.com/. Acesso em 4 dez. 2014.

13 Disponível em: http://arxiv.org/ . Acesso em 4 dez. 2014.

14 Disponível em: http://www.ohwr.org/ . Acesso em 4 dez. 2014.

15 Disponível em: http://www.instructables.com/ . Acesso em 4 dez. 2014.

16 Disponível em: http://igem.org/Main_Page . Acesso em 4 dez. 2014.

17 Disponível em: https://dnasu.org/DNASU/. Acesso em 4 dez. 2014.

18 Disponível em: https://www.addgene.org/ . Acesso em 4 dez. 2014.

19 Disponível em: http://www.specimencentral.com/ . Acesso em 4 dez. 2014.

20 Disponível em: http://www.eurobiobank.org/ . Acesso em 4 dez. 2014.

21 Disponível em: http://www.chtn.nci.nih.gov/. Acesso em 4 dez. 2014. 


\section{Plataformas de COMUNICAÇÃO CIENTÍFICA}

Além de repositórios, a comunidade acadêmica precisa de plataformas para a gestão dos seus processos de comunicação. Aí se incluem a revisão por pares e a publicação de periódicos, a organização de congressos e a publicação de anais, como também canais para colaboração e exposição a, ou prospecção de, colaboradores de dentro e de fora da academia. Além disso, podemos contemplar o registro de cadernos de pesquisa, destacadamente a prática de cadernos de pesquisa abertos.

No Brasil enquadram-se nessa categoria, dentre outras, o SciE$\mathrm{LO}^{22}$, a Plataforma Lattes ${ }^{23}$, a rede $\mathrm{Stoa}^{24}$ e a encerrada Incubadora Virtual da Fapesp.

O SciELO, cuja finalidade é a publicação de periódicos em acesso aberto, tem demonstrado interesse em disponibilizar ferramentas mais dinâmicas, que apoiem a execução do processo editorial, como o software Open Journal Systems ${ }^{25}$; e, recentemente, há sinais indicando abrir suas bases através de interfaces programáticas, que permitiriam acesso aos dados por aplicativos de terceiros (APIs), abrindo caminho para usos inovadores.

Já a Plataforma Lattes, do Conselho Nacional de Desenvolvimento Científico e Tecnológico (CNPq), um banco nacional de currículos acadêmicos, que tem por fim facilitar a avaliação e o contato com colaboradores, opera exclusivamente de forma estática, não interoperando com outros instrumentos nem tornando seus dados descarregáveis, mesmo quando a Lei de Acesso à Informação o exigiria, dificultando muito qualquer uso inovador para avaliação ou colaboração científica.

22 Disponível em: http://scielo.org/ . Acesso em 4 dez. 2014.

24 Disponível em: http://stoa.usp.br/ . Acesso em 4 dez. 2014. 
Um caso interessante é a criação da rede Stoa na USP, em 2007, que provê ambientes virtuais de aprendizagem baseados no software Moodle - mais um espaço wiki, para produção colaborativa de páginas web, baseado no software MediaWiki - e a criação de blogs e a organização de comunidades e eventos baseada no software Noosfero.

Anterior a essa iniciativa, durante um período a partir de 2004, houve já o desenvolvimento e a disponibilização de uma plataforma para portais de colaboração, baseado no software Plone, dentro do projeto da Incubadora Virtual (SIMON, 2004) da Fapesp, já mencionada neste texto.

Outros ambientes de comunicação e colaboração são hospedados por organizações estrangeiras, mas utilizados no Brasil. O exemplo mais importante desses é a Wikipédia ${ }^{26}$, utilizada diariamente tanto por parte dos acadêmicos, desenvolvendo seu trabalho e estudos, como pela população lusófona, para aprendizado e cultura geral, e sendo construída por contribuições voluntárias da parte desses grupos.

Um projeto irmão da Wikipédia também é adotado por pesquisadores brasileiros, a Wikiversidade ${ }^{27}$. Ele hospeda páginas wiki para grupos e projetos de pesquisa profissionais, ou aprendizes e amadores, que ali podem criar espaços para apresentar seu trabalho, organizar colaborações e manter registros de estudo ou pesquisa, como cadernos de pesquisa abertos, podendo, com isso, receber contribuições ou apenas garantir a transparência do trabalho.

É notável que o uso e a participação nessas wikis pela academia brasileira carece de reconhecimento ou apoio institucional. Apesar disso, há casos interessantes de acadêmicos utilizando-as individualmente, tanto em sala de aula como em projetos de pesquisa, para

26 Disponível em: http://pt.wikipedia.org/ . Acesso em 4 dez. 2014.

27 Disponível em: http://pt.wikiversity.org/ . Acesso em 4 dez. 2014. 
promover formas colaborativas de aprendizagem e investigação. Destaca-se aí o programa Wikipédia na Universidade ${ }^{28}$.

Ainda internacionalmente, temos outras wikis, como a OpenWetWare ${ }^{29}$, ambientes para criação e recombinação de material didático como o Connexions ${ }^{30}$; mídias sociais voltadas para acadêmicos, como academia.edu ${ }^{31}$, e também o uso, orientado para fins de pesquisa, de outras mídias sociais e plataformas inespecíficas, como Wordpress, Twitter e RedMatrix.

\section{LABORATÓRIOS DE FABRICAÇÃO}

Se considerarmos a possibilidade de colaboração sobre design compartilhado de instrumentos científicos, um requisito para o aproveitamento total dessas oportunidades é a disponibilização, nas instituições de ensino e pesquisa, de equipamentos para fabricação desses instrumentos. Se possível, eles próprios abertos e utilizando software livres. Aí se encontram impressoras 3D, cortadoras laser, tornos, fresadores e afins, controlados via Controle Numérico Computadorizado (CNCs).

Instituições, como o Centro de Tecnologia Acadêmica da UFR$G S^{32}$, já estão buscando construir e padronizar um conjunto básico de fabricadoras abertas, que permitam produzir a maior parte dos instrumentos científicos a partir da documentação de seus designs, além de inovar, aprimorando designs existentes e concebendo novos instrumentos.

\footnotetext{
28 Disponível em: https://pt.wikipedia.org/wiki/Wikipédia:Wikipédia_na_Universidade/ Cursos. Acesso em 4 dez. 2014.

29 Disponível em: http://openwetware.org/wiki/Main_Page. Acesso em 4 dez. 2014.

30 Disponível em: http://cnx.org/ . Acesso em 4 dez. 2014.

31 Disponível em: http://academia.edu/ . Acesso em 4 dez. 2014.

32 Disponível em: http://cta.if.ufrgs.br/ . Acesso em 4 dez. 2014.
} 


\section{COMPUTAÇÃO LIVRE}

Ao colaborar para o uso e desenvolvimento de software de aplicação científica e utilizá-los, os integrantes de uma instituição acadêmica beneficiar-se-iam de realizar seu aprendizado e seu trabalho em ambientes computacionais livres, de código aberto. Cabe, assim, às instituições disponibilizar computadores com sistemas operacionais livres e linguagens de programação livres, além de utilizar e desenvolver esses software.

Para esses fins, algumas instituições têm implantado Centros de Competência em Software Livre, como a USP, nos campi do Butantã ${ }^{33}$ e São Carlos $^{34}$, e o IFRN ${ }^{35}$,no campus Caicó.

\section{EQUIPAMENTOS MULTIUSUÁRIO}

A prática da construção de equipamentos multiusuário viabiliza não apenas o uso racional dos recursos, permitindo acesso mais amplo e justo, como também estimula a colaboração entre os pesquisadores utilizando esses equipamentos. Entram nesse processo desde a disponibilização de recursos computacionais (caso da $\mathrm{Nu}$ vem $\mathrm{USP}^{36}$ ) até instalações laboratoriais, a exemplo do Laboratório Nacional de Nanotecnologia ${ }^{37}$; e equipamentos científicos de grande porte, como o Laboratório Nacional de Luz Síncrotron ${ }^{38}$.

\footnotetext{
33 Disponível em: http://ccsl.ime.usp.br/ . Acesso em 4 dez. 2014.

34 Disponível em: http://ccsl.icmc.usp.br/ . Acesso em 4 dez. 2014.

35 Disponível em: http://ccsl.ifrn.edu.br/ . Acesso em 4 dez. 2014.

36 Disponível em: http://www.cce.usp.br/?q=node/52. Acesso em 4 dez. 2014.

37 Disponível em: http://Innano.cnpem.br/ . Acesso em 4 dez. 2014.

38 Disponível em: http://Inls.cnpem.br/ . Acesso em 4 dez. 2014.
} 


\section{TREINAMENTO}

\section{EQUIPES DE APOIO}

A fim de orientar e auxiliar pesquisadores e grupos de pesquisa na adoção de diversas práticas de ciência aberta, considere-se a organização de equipes de apoio técnico, formadas ou apoiadas por bibliotecários e pesquisadores com experiência relevante. A essas equipes cabe uma série de ações.

No que diz respeito a publicações, cabe produzirem e encaminharem indicações personalizadas sobre os periódicos de acesso aberto mais indicados para a área de cada pesquisador da instituição. Com referência aos dados, cabe ajudar os pesquisadores a (1) preservar e compartilhar seus dados, agregando os metadados e anotações adequadas; (2) a escolher os meios e o repositório onde compartilhá-los. No que diz respeito a designs, materiais e outros objetos da pesquisa, cabe guiar os pesquisadores na busca dos formatos, licenças e procedimentos apropriados para preservá-los e compartilhá-los, identificando os melhores repositórios ou, se estiverem indisponíveis, instituições ou soluções para tal.

Em todos os casos, é preciso que esses profissionais tenham o entendimento básico sobre as licenças para público geral e formatos de armazenamento aplicáveis a cada tipo de objeto; que compreendam a importância das licenças livres e formatos abertos para a preservação e compartilhamento, e que saibam buscar orientação para si próprios, quando surgirem questões de maior complexidade.

Além de apoio à preservação e compartilhamento, essas equipes podem, também, ajudar os grupos de pesquisa a comunicar-se efetivamente online, seja em contatos que levem a colaborações, seja na organização das informações e processos do grupo, até na produção de cadernos de pesquisa abertos.

Junto às comunidades de ciência aberta já existentes, essas equipes podem formar espaços permanentes de referência para aprendizado e aprimoramento de práticas. 


\section{Cursos e oficinas}

Adotar práticas abertas na pesquisa requer um aprendizado de conceitos e de procedimentos que ainda estão sendo incorporados à cultura geral acadêmica. Tendo isso em vista, as instituições podem, junto de seus integrantes mais informados e das comunidades de ciência aberta já existentes, organizar oficinas e produzir materiais sobre novas práticas de compartilhamento e colaboração no trabalho acadêmico. Além disso, podem, em outras atividades de treinamento cujos temas toquem as inovações da ciência aberta, incluir considerações pertinentes a tais inovações. Por exemplo, oficinas para capacitar pesquisadores em escrita e publicação de artigos devem levantar a importância do acesso aberto, e indicar os recursos para publicar nos periódicos que o praticam, com as devidas orientações.

Outro ponto é que as práticas acadêmicas abertas frequentemente envolvem o uso da computação. Considerando que a qualidade geral da compreensão e da prática da computação ainda é muito precária na maior parte da academia, mesmo onde ela é cotidiana e fundamental na produção de conhecimento, é duplamente benéfico promover cursos para elucidar pesquisadores sobre o funcionamento e o uso prático dos computadores. A iniciativa Software Carpentry ${ }^{39}$, também atuante no Brasil, tem um trabalho exemplar nesse sentido.

\section{MATERIAL DE APRENDIZADO}

É importante que se produzam manuais e guias para aprendizado, de apoio ou autodidático, e que as instituições possam conferir a eles maior qualidade, produção profissional e reconhecimento. Vídeos, textos e recursos multimídia de alto padrão, disponibilizados com

39 Disponível em: http://software-carpentry.org/ . Acesso em 4 dez. 2014. 
licenças livres e formatos abertos, melhoram a capacidade de aprendizado local e ainda podem ser adotados e adaptados em outros contextos, promovendo o reconhecimento da instituição criadora.

\section{POLÍTICA CIENTÍFICA}

Com relação a políticas institucionais, é possível sugerir ações em vários níveis que beneficiariam e qualificariam a produção científica ao incentivar e viabilizar maior abertura.

\section{Publicação}

Pode-se financiar os custos de publicação em periódicos de acesso aberto, como já o fazem algumas instituições. E, paralelamente, investir na qualidade e no reconhecimento de periódicos de acesso aberto organizados pelas próprias instituições, por associações científicas e por outros grupos sem fins lucrativos. Esses atores são particularmente importantes para que se admita não cobrar a publicação quando o pesquisador não tiver recursos, como faz a Public Library of Science ${ }^{40}$, e com isso pressionar atores que tenham fins lucrativos a adotar políticas semelhantes, como a do PeerJ ${ }^{41}$.

Deve-se prever que os resultados de pesquisas realizadas na instituição ou com seu apoio sejam publicados em acesso aberto.

E, ainda, reconhecer e premiar pesquisadores que optam por publicar em acesso aberto.

E reforçar o consenso da Iniciativa de Budapeste pelo Acesso Aberto $^{42}$, particularmente a necessidade de se utilizarem licenças livres e formatos abertos. Isso implica evitar licenças com restrições incompatíveis, como as que limitam finalidade comercial.

\footnotetext{
40 Disponível em: http://plos.org/ . Acesso em 4 dez. 2014.

41 Disponível em: https://peerj.com/. Acesso em 4 dez. 2014.

42 Disponível em: http://www.budapestopenaccessinitiative.org/translations/portuguese-translation. Acesso em 4 dez. 2014.
} 


\section{DADOS}

Instituições devem prever que dados produzidos em pesquisas nelas realizadas ou com seu apoio sejam depositados em repositórios públicos de acesso aberto, ou, no mínimo, disponibilizados para preservação institucional.

Periódicos devem prever que dados inéditos utilizados em artigos sejam publicados junto a este, disponibilizados em repositório confiável de acesso aberto. Quanto a dados de pesquisas anteriores, é preciso que seja devidamente referenciada a forma de um outro pesquisador obtê-los.

Precisa-se estimular periódicos especializados a publicar a produção de dados, documentando essa produção, indexando-a, tornando-a citável, e a ela dar reconhecimento.

Deve-se reconhecer e premiar pesquisadores que optam por publicar seus dados abertamente.

$\mathrm{E}$, ainda, é preciso reforçar a adesão às orientações de formatos e licenças constantes nos Panton Principles for Open Data in Science ${ }^{43}$, assim como as referentes à citação de dados na Joint Declaration of Data Citation Principles ${ }^{44}$.

\section{INSTRUMENTOS}

Deve-se prever, como requisito funcional e de financiamentos, disponibilizando recursos para tal, que pesquisadores documentem tanto seus designs de instrumentos científicos como seus aprimoramentos, tornando-os disponíveis em repositórios abertos; e que publiquem os software desenvolvidos para pesquisa com o código disponível sob uma licença livre, como as GNU-GPL ${ }^{45}$ ou $\mathrm{MIT}^{46}$.

\footnotetext{
43 Disponível em: http://pantonprinciples.org/ Acesso em 4 dez. 2014.

44 Disponível em: https://www.force11.org/datacitation. Acesso em 4 dez. 2014.

45 Disponível em: http://www.gnu.org/copyleft/gpl.html . Acesso em 4 dez. 2014.

46 Disponível em: https://pt.wikipedia.org/wiki/Licença_MIT. Acesso em 4 dez. 2014.
} 
Da mesma forma, que se privilegie o uso de instrumentos disponíveis nesses repositórios a alternativas não compartilhadas.

Grupos de pesquisa que se utilizam dos mesmos instrumentos ou semelhantes devem ser incentivados a colaborar na sua produção e aprimoramento.

Deve haver, também, investimento para a produção de designs abertos de instrumentos, em substituição a alternativas não compartilhadas. Pode-se realizar um levantamento de instrumentos que trariam maior impacto se abertos, e formar forças tarefas para produzi-los.

É fundamental reconhecer e premiar pesquisadores que optam por publicar seus designs abertamente.

E, ainda, reforçar a adesão a licenças livres, como a CERN Open Hardware License ${ }^{47}$, adotada pelo repositório de design de equipamentos do CERN.

\section{MATERIAIS}

Deve-se prever, como requisito funcional e de financiamentos, que os protocolos e documentação de materiais obtidos no trabalho de pesquisa, e os póprios materiais quando cabível, sejam compartilhados em repositórios abertos, disponibilizando recursos para isso.

Também é preciso reconhecer e premiar pesquisadores que optam por compartilhar seus materiais abertamente.

E, ainda, reforçar a adesão a bancos e procedimentos bem estruturados de cada instituição ou área.

\section{PROCESSO DE PESQUISA}

Reconhecer e premiar pesquisadores que optam por conduzir suas pesquisas abertamente, compartilhando seus cadernos de pesquisa para colaboração, usualmente em wikis ou blogs acadêmicos.

47 Disponível em: http://www.ohwr.org/projects/cernohl/wiki . Acesso em 4 dez. 2014. 
Divulgar essas pesquisas para motivar a colaboração de pesquisadores em outras áreas ou grupos e instituições.

Financiar esforços concentrados de pesquisa aberta e massivamente colaborativa em áreas onde essa transparência e colaboração podem ser críticas para o avanço do conhecimento.

Promover a investigação e o aprimoramento de ambientes virtuais que favoreçam a colaboração científica.

\section{INOVAÇÃO}

Dentro das políticas de inovação deve existir a possibilidade de o pesquisador optar por um paradigma de inovação aberta, livre de patentes ou, se necessário, registrar a patente para reconhecimento ou defesa, publicando-se a inovação com licenças que lhe permitam o uso livre de royalties, mas exigindo o compromisso de o usuário reciprocar essa liberdade, caso distribua modificações dela. Um instrumento que atinge esse objetivo é a CERN Open Hardware License, já mencionada neste texto.

É importante notar que, no discurso de inovação hoje vigente, a busca por mapear e tornar mais visíveis as contribuições inovadoras se confunde com uma visão da exploração monopolística de patentes como destino principal dessas inovações. Essa é uma perspectiva ideológica e desconectada do que a própria ciência econômica tem a dizer sobre o assunto, em particular na perspectiva dos países em desenvolvimento. É urgente experimentarmos novas formas de abordagem à inovação que se distanciem do reforço a monopólios.

\section{Educação}

As instituições devem reconhecer e incentivar contribuições em espaços de conhecimento onde predomina uma lógica de abertura e espírito público, como a Wikipédia, Wikilivros e Wikiversidade, além dos blogs de ciência. 
Deve ser presumido que todo material de aprendizado, produzido ou financiado por instituições públicas, seja depositado em repositórios abertos nas condições de Recursos Educacionais Abertos.

É fundamental reconhecer e premiar pesquisadores que optam por compartilhar seus recursos educacionais abertamente. Como exemplo, no Brasil, a Universidade Federal do Paraná (UFPR) concede na pontuação docente um acréscimo de $25 \%$ ao valor de publicações quando forem Recursos Educacionais Abertos ${ }^{48}$.

No tempo de aula presencial, devem ser estimuladas dinâmicas de ensino baseadas em metodologias de aprendizagem ativa, como peer-learning e Scale-up ${ }^{49}$, reorientando o papel das aulas expositivas para vídeos e outros recursos assíncronos (HENRIQUES; PRADO; VIEIRA, 2014).

As editoras universitárias devem ser provocadas a renovar seus modelos econômico e intelectual, trabalhando para produzir recursos educacionais abertos, focando na publicação digital, investindo em ambientes que permitam a adaptação desses recursos e reorientando a impressão para uma atividade sob demanda dos clientes ou requisito do produto.

E, ainda, reforçar a Declaração de Cidade do Cabo para Educação Aberta $^{50}$, em particular no que diz respeito a licenças livres e formatos abertos para recursos educacionais.

\footnotetext{
48 UFPR é pioneira na valorização de Recursos Educacionais Abertos (REA). Curitiba: Assessoria de Comunicação Social da UFPR, 2014. Notícia. Disponivel em: http://www.ufpr.br/ portalufpr/blog/noticias/ufpr-e-pioneira-na-valorizacao-de-recursos-educacionais-abertos-rea/. Acesso em: 3 dez. 2014.

49 Disponível em: http://scaleup.ncsu.edu/ . Acesso em: 3 dez. 2014.

50 Disponível em: http://www.capetowndeclaration.org/translations/portuguese-translation. Acesso em 4 dez. 2014.
} 


\section{CIÊnCIA CIDADÃ}

A academia deve reconhecer espaços de produção de conhecimento não profissionais ou não vinculados às suas instituições tradicionais, sejam esses virtuais (comunidades em torno de wikis, grupos de discussão, repositórios colaborativos, mídias sociais e outros ambientes) ou físicos - como hackerspaces, makerspaces, pontos de cultura e organizações similares. Ademais, deve haver registro e avaliação do intercâmbio entre universidades e esses espaços comunitários de produção de conhecimento, para compreender a importância desse intercâmbio no desenvolvimento social e na inovação, e sugerir, com isso, melhorias de orientação à universidade. Espaços cidadãos mais estruturados devem ser entendidos como pontos de produção de conhecimento e admitidos para receber financiamento à pesquisa como institutos de pesquisa.

Ações de extensão, mais do que compartilhamento de conhecimento, devem expandir o local da universidade, estendendo-a a todas as pessoas e todo o território, numa perspectiva máxima de engajar a totalidade da população na produção acadêmica e sua aplicação.

É preciso promover ainda a investigação e o aprimoramento de instrumentos que permitam à população contribuir com computadores e outros recursos, ou executando coletas e atividades cognitivas, para projetos acadêmicos de forma distribuída. Por exemplo: os instrumentos BOINC ${ }^{51}$ e PyBossa ${ }^{52}$, além da sua adoção por grupos de pesquisa.

Ademais da contribuição com tarefas ou recursos, deve-se reconhecer e incentivar, na produção acadêmica, a participação dos cidadãos como colaboradores plenos e colaboradores profissionais em iguais condições, seja essa participação cidadã originada de

\footnotetext{
51 Disponível em: http://boinc.berkeley.edu/ . Acesso em 4 dez. 2014.

52 Disponível em: http://pybossa.com/. Acesso em 4 dez. 2014.
} 
iniciativas de grupos nas instituições acadêmicas ou estimulada pelos próprios cidadãos, atuando em espaços não profissionais.

\section{AVALIAÇÃO E RECONHECIMENTO}

Como destacado nos casos específicos, instituições podem dar reconhecimento e incentivos a seus integrantes ou beneficiários que optem por práticas abertas. Mas, mais do que isso, muitas práticas abertas podem, de forma imediata ou numa transição acordada, ser incorporadas nas exigências dos trabalhos acadêmicos. E isso pode ser feito em níveis de granularidade: do orientador, do grupo de pesquisa, do departamento, do instituto ou área, da universidade ou agência.

A proposta de uma academia aberta ainda exige e permite que se aprimorem os próprios sistemas de avaliação. Ao tornar possível indexar e referenciar o que antes eram entranhas do processo de produção, abre caminho para expressões de reconhecimento mais significativas que simples citações. Essas novas formas nem mesmo precisam enquadrar-se no esquema autor de artigo, nem precisam restringir-se a um processo de revisão linear. Há aí necessidade e oportunidade de investimento institucional em formas mais informativas de avaliar o trabalho de pesquisa, entendendo-se que uma pesquisa com práticas abertas facilita essa avaliação aprimorada, e privilegiando-a também por isso.

A avaliação de pesquisadores, dada essa riqueza de informação, também se beneficiará quanto mais se basear em transparência e explicitação das suas razões, sem comitês opacos decidindo a distribuição dos méritos e recursos acadêmicos, ou apelação à numerologia para esquivar-se de desenvolver processos apropriados e assumir responsabilidades.

Especificamente sobre práticas abertas, pode-se promover o estudo, teórico e experimental, das suas vantagens e dificuldades ante modelos correntes de produção, orientando, com isso, 
políticas mais eficazes para estimular a abertura e colher seus benefícios. Nesse espírito de experimentação, como também num sentido de vanguarda, é cabível e esperável que instituições criem linhas de financiamento especiais com previsão de abertura completa do trabalho acadêmico.

\section{RUMO À DESMISTIFICAÇÃO DO CONHECIMENTO}

De mãos dadas com a abertura de suas práticas, cabe ainda às instituições acadêmicas contribuir para a desmistificação do processo científico. Entenda-se que está em curso uma desmistificação geral das instituições, públicas e privadas. Exigências de transparência e participação nunca foram tão intensas e com adesão tão numerosa. E, junto a isso, corre um processo de substituição de funções sociais, em que a Wikipédia, o YouTube e também os Cursos Massivos Online são representantes da reinvenção da organização e transmissão do conhecimento e da cultura, a partir de relações mais transparentes e participativas.

No Brasil, vale lembrar o contexto dessas ocorrências: uma comunidade acadêmica, saída de um período de ditadura e ainda lutando com a herança cultural e institucional desse período, levada, então, a uma expansão mal preparada e sendo exposta ao poder que o diálogo foi adquirindo na transição para uma sociedade democrática, poder que foi multiplicado na sociedade interconectada. Assim, a primeira reação dessa comunidade pode ter sido proteger-se desse diálogo, através da ferramenta de que dispunha: a manutenção da mistificação herdada da ditadura, com o isolamento e pouco diálogo sobre seus processos e instituições. Tornou-se, assim, pouco capaz de inteligência no coletivo, sofrendo de paralisia criativa diante das novas possibilidades para difusão e produção de conhecimento, salvo raras imposições esclarecidas. Essa irracionalidade, essa postura 
mística das instituições e da comunidade acadêmica, têm atrasado avanços e, à medida que esses atrasos são superados sem sua participação, cede-se a credibilidade e o papel social da academia para outros atores. Contam-se, ainda, consequências econômicas, políticas e administrativas desse fenômeno, mas não cabe discuti-las aqui.

Cabe, sim, propormos que se tomem medidas para mudar essa postura das instituições e da comunidade acadêmica, expondo-se e fazendo conhecer para si mesmas e para a sociedade as dinâmicas e os objetos das pesquisas, da sua organização e da distribuição de recursos, sua natureza social e as redes de colaboração entre pares que fundamentam sua confiabilidade, e também suas fragilidades e os erros cometidos. Isso vai desde uma reformulação de materiais didáticos escolares, para desmontar o mito do cientista individual e estimular uma aproximação com a prática da pesquisa, ao estímulo nas graduações à reflexão conjunta sobre a ciência; vai da adoção crítica de práticas abertas na pesquisa, como as discutidas neste texto, até, por fim, ao uso intensivo de informações e registros de pesquisa, do nível individual ao institucional, para refundar a ciência da ciência, tornando o repensar dos processos um fato cotidiano e integral - o que só será possível sob um paradigma de práticas abertas.

Hoje, não há mais necessidade de traçar limites para a participação da sociedade na produção de conhecimento. Em breve, é possível que tais limites nem sequer sejam aceitos, pelo prejuízo que causam. Seguindo os avanços do acesso a tecnologias e da disponibilidade de informação, a cada dia cabe mais ao indivíduo pesquisador, profissional ou cidadão, optar pelo grau de participação que deseja, do que às instituições acadêmicas e pesquisadores profissionais da área modulá-lo. Desses últimos, a responsabilidade passa a ser arquitetar a produção de conhecimento para que acomode o máximo de contribuições. 


\section{REFERÊNCIAS}

BENKLER, Yochai. The wealth of networks. Yale: Yale University Press, 2006.

CARDOSO,Gustavo; JACOBETTY, Pedro; DUARTE, Alexandra. Para uma ciência aberta. Lisboa: Editora Mundos Sociais, 2012.

HENRIQUES, Vera B.; PRADO, Carmen P. C.; VIEIRA, André P. Editorial convidado: Aprendizagem ativa. Revista Brasileira de Ensino de Física, v. 36, n. 4, p. 4001, 2014. Disponível em: 〈http://www.sbfisica.org.br/rbef/pdf/364001.pdf〉. Acesso em: 4 dez. 2014.

NIELSEN, Michael. Reinventing discovery: the new era of networked science. Princeton: Princeton University Press, 2011.

SIMON, Imre. A incubadora virtual da FAPESP. Apresentação. São Paulo: FAPESP, 2004. Disponível em: http://www.ime.usp.br/ is/aula/incubadora-2004/incubadora-2004.pdf .Acesso em: 3 dez. 2014. 


\section{Sobre os autores}

\section{ADOLFO ESTALELLA}

Instituto de Historia, Consejo Superior de Investigaciones Científicas (CSIC), Espanha. Universidade de Manchester, Reino Unido.

E-mail: adolfoestalella@gmail.com

\section{ALESSANDRO DELFANTI}

Institute of Communication, Culture, Information and Technology, University of Toronto Mississauga, Canadá.

E-mail: a.delfanti@insiberia.net

ALEXANDRE HANNUD ABDO

Open Knowledge Brasil, Brasil. E-mail: abdo@member.fsf.org ANCELA OKUNE

iHub, Quênia. Co-coordenadora da Open and Collaborative Science in Development Network (OCDSNet).

E-mail: angela@ihub.co.ke

\section{ANNE CLINIO}

Doutoranda do Programa de Pós-graduação e Ciência da Informação, PPGCI - Ibict/UFRJ, Brasil.

E-mail: anneclinio@gmail.com 


\section{ANTONIO LAFUENTE}

Centro de Ciencias Humanas y Sociales, Consejo Superior de Investigaciones Científicas (CSIC), Espanha. MediaLab Prado de Madrid.

E-mail: alaf999@gmail.com

CAMERON NEYLON

Pesquisador independente, anteriomente da Public Library of Science (PLoS), Reino Unido.

E-mail: cn@cameronneylon.net DENISA KERA

National University of Singapore.

E-mail: denisa@nus.edu.sg HENRIQUE Z. M. PARRA

Departamento de Ciências Sociais, Universidade Federal de São Paulo (Unifesp), Brasil. Coordenador do Pimentalab - Laboratório de Tecnologia, Política e Conhecimento.

E-mail: polart@riseup.net

JORGE MACHADO

Escola de Artes, Ciências e Humanidades da Universidade de São Paulo, Brasil. Coordenador do Co-Laboratório de Desenvolvimento e Participação (COLAB).

E-mail: machado@usp.br

\section{LESLIE CHAN}

Centre for Critical Development Studies, University of Toronto Scarborough, Canada. Coordenador da Open and Collaborative Science in Development Network (OCDSNet).

E-mail: chan@utsc.utoronto.ca

LUDMILA DOS S. GUIMARÃES

Universidade Federal do Estado do Rio de Janeiro (Unirio), Brasil. Coordenadora Adjunta de Educação a Distância UAB/CAPES da Unirio.

E-mail: lguimaraes2007@gmail.com 
MARIA LUCIA MACIEL

Universidade Federal do Rio de Janeiro (UFRJ), Brasil. Coordenadora do Laboratório Interdisciplinar sobre Informação e Conhecimento (Liinc), IBICT/UFRJ.

E-mail: lucamaciel@gmail.com

NANJIRA SAMBULI

iHub, Research Manager, Quênia.

E-mail: nanjira@ihub.co.ke

NICO PITRELLI

Laboratorio Interdisciplinare per le Scienze Naturali ed Umanistiche, Scuola Internazionale Superiore di Studi Avanzati (SISSA), Itália.

E-mail: pitrelli@sissa.it

RAFAEL PERETTI PEZZI

Instituto de Física, Universidade Federal do Rio Grande do Sul (UFRGS), Brasil. Coordenador do Centro de Tecnologia Acadêmica da UFRGS.

E-mail: rafael.pezzi@ufrgs.br

SARITA ALBACLI

Instituto Brasileiro de Informação em Ciência e Tecnologia (IBICT), Brasil. Coordenadora do Liinc, IBICT/UFRJ.

E-mail: sarita.albagli@gmail.com 


ESTA OBRA FOI COMPOSTA PELA FONT CHAPARRAL PRO E IMPRESSA NA GRÁFICA DO TRIO STUDIO EM 2015 
Este livro reúne contribuições de pesquisadores de diferentes áreas, do Brasil e do exterior, com significativa atuação e reflexão no campo da ciência aberta e colaborativa. A ciência aberta faz parte das novas dinâmicas de produção e circulação do conhecimento, da informação e da cultura, bem como o papel que essas dinâmicas desempenham nos processos contemporâneos de participação e mudança social. Esta publicação dirige-se, assim, não apenas ao universo acadêmico, mas também para todos que se preocupam com a democratização do conhecimento e da informação.

Apoio

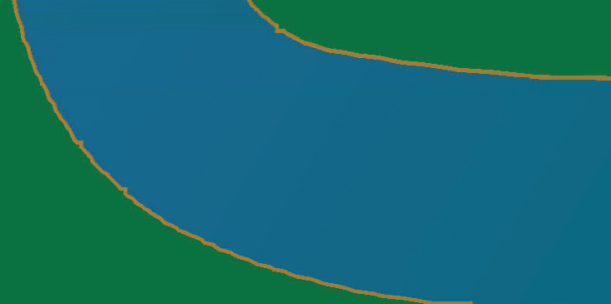

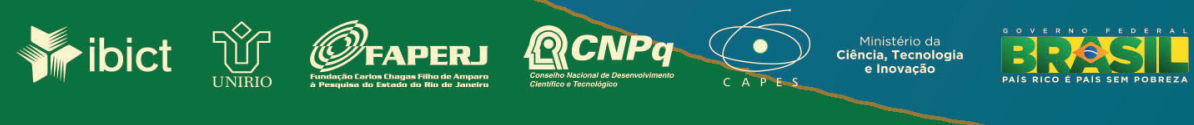

